\title{
Implementing the South African Free Basic Alternative Energy Policy
}

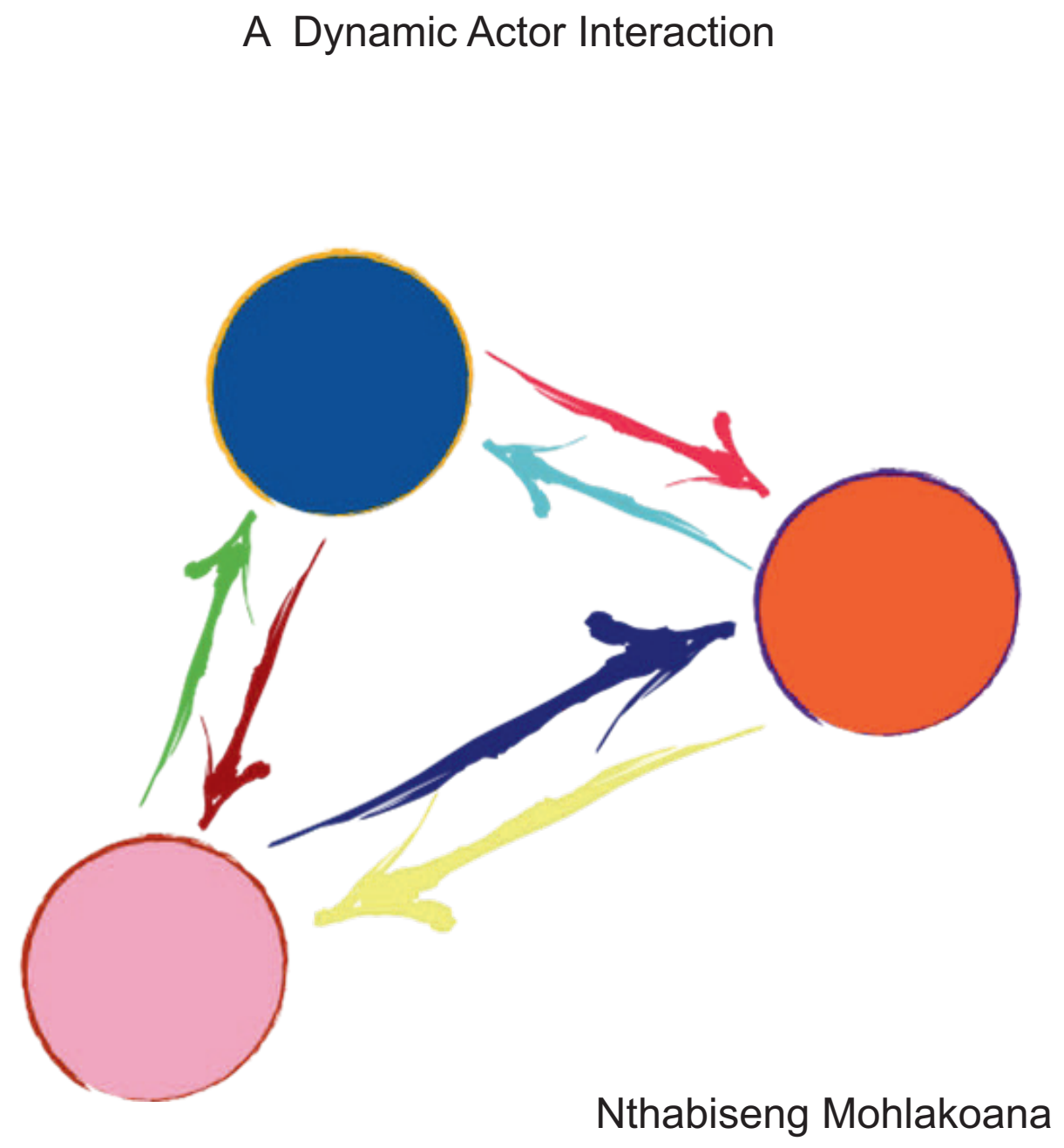





\title{
IMPLEMENTING THE SOUTH AFRICAN FREE BASIC ALTERNATIVE ENERGY POLICY
}

\section{A DYNAMIC ACTOR INTERACTION}

\author{
DISSERTATION \\ to obtain \\ the degree of doctor at the University of Twente, \\ on the authority of the rector magnificus, \\ Prof.dr. H. Brinksma, \\ on account of the decision of the graduation committee, \\ to be publicly defended \\ on Thursday 11th of December 2014 at 16.45 hours.
}

by

Nthabiseng Mohlakoana

Born on the 25th of August, 1975

in Johannesburg, South Africa 
This thesis has been approved by

Promoter: prof. dr. H. Th. A. Bressers

Assistant Promoter: dr. Joy S. Clancy 


\section{Members of the Committee:}

Chair:

Secretary:

Promotor:

Co-Promotor:
Prof.dr.ir. A.J. Mouthaan

Prof.dr. A.J. Mouthaan

Prof. dr. J.Th.A. Bressers

Dr. Joy S. Clancy

Prof.dr.ir. Th. Van der Meer

Dr. T. Filatova

Prof.dr. A.J. Dietz

Prof.dr. J van Lankveld
University of Twente

University of Twente

University of Twente

University of Twente

Member:

Member:

Member:

Member:

University of Twente

University of Twente

Leiden University

Open Universiteit

The work described in this thesis was performed at the Department of Governance and Technology for Sustainability, Institute for Innovation and Governance Studies, Faculty of Management and Governance, University of Twente, PO Box 217, 7500 AE, Enschede, The Netherlands.

Most of this research was funded by the scholarship granted by The Oppenheimer Memorial Trust, South Africa. 
Colophon

Interior layout by: Maya van den Berg

Dutch Summary by: Ewert Aukes

Cover image: Clipart Panda

Printed by: Gildeprint - Enschede.

(C) 2014 Nthabiseng Mohlakoana, University of Twente, CSTM.

No part of this publication may be reproduced, stored in a retrieval system, or transmitted, in any form or by any means, electronic, mechanical, photocopying, recording or otherwise, without prior written permission of the author.

ISBN 978-90-365-3797-1

\section{UNIVERSITY OF TWENTE.}

School of Management and Governance

Department of Governance and Technology for Sustainability (CSTM)

Enschede, The Netherlands

Email (for correspondence): nmkaxulu@gmail.com 


\section{DEDICATION}

This thesis is dedicated to everyone that is affected by the implementation of the Free Basic Alternative Energy policy. The women and men that work tirelessly to deliver alternative energy sources to impoverished households that are living and experiencing energy poverty. The individuals that are living in households without modern energy services because of their low-income status due to various circumstances, most of which are a direct result of the South African history. It is my hope that this thesis makes a contribution to the efforts of providing access to better energy services and to alleviating energy poverty in the low-income rural and urban areas of South Africa. 


\section{Contents}

LIST OF FIGURES XVI

LIST OF TABLES XVII

LIST OF ABBREVIATIONS $\quad$ XX

PREFACE AND ACKNOWLEDGMENTS XXII

CHAPTER 1: INTRODUCTION 1

$\begin{array}{ll}\text { 1.1. Background } & 1\end{array}$

1.2. Statement of the problem and study objectives 2

1.2.1. Study objectives $\quad 5$

$\begin{array}{ll}\text { 1.3. Research questions: } & 6\end{array}$

$\begin{array}{ll}\text { 1.4. Methodology } & 7\end{array}$

1.4.1. Case selection $\quad 7$

1.4.2. Data gathering $\quad 10$

Case areas $\quad 12$

National and provincial government $\quad 17$

1.4.3. Selection criteria for key informants $\quad 17$

1.4.4. Data analysis 18

1.5. Use of Contextual Interaction Theory in the research design 19

1.6. Structure of thesis $\quad 21$

CHAPTER 2: INTRODUCTION TO THE FBAE POLICY AND THE SOUTH AFRICAN ENERGY CONTEXT 23 
2.2. Policy changes and their impacts

2.3. A focus on the South African energy policy development starting in $1994 \quad 26$

2.3.1. The Reconstruction and Development Programme 27

2.3.2. The White Paper on Energy Policy 29

2.4. Beyond the White Paper on Energy Policy - facing the energy poverty dilemma

2.4.1. Energy policy: a focus on the poor $\quad 37$

$\begin{array}{ll}\text { Energy poverty in South Africa } & 37\end{array}$

2.5. The introduction of households' basic services subsidies $\quad 40$

Free Basic Water $\quad 41$

2.5.1. Electricity Basic Support Services Tariff (EBSST) 42

2.5.2. Free Basic Alternative Energy (FBAE) policy 45

$\begin{array}{ll}\text { 2.6. Conclusions } & 49\end{array}$

CHAPTER 3: USING THE CONTEXTUAL INTERACTION THEORY AS A THEORETICAL FRAMEWORK

3.1. Introduction $\quad 51$

3.2. Policy implementation $\quad 51$

3.2.1. A summary of the three generations of implementation policy research $\quad 52$

3.3. The Contextual Interaction Theory $\quad 57$

3.3.1. A brief history of the Contextual interaction Theory (CIT) 57

3.3.2. The flow chart two actor model and its applications 60

3.3.3. The multiple contexts model and its applications 61

3.3.4. Capturing the interaction of actor characteristics 64

3.4. Using the CIT framework for this study 67

3.4.1. Using CIT in a developing country context 68

3.4.2. Definition of concepts $\quad 71$

3.4.3. Adding and highlighting the third actor $\quad 71$ 
3.4.4. Using the CIT framework to analyse the mutual influence of actor characteristics on policy implementation

CHAPTER 4: HOW MULTI-LEVEL GOVERNANCE INFLUENCES THE IMPLEMENTATION OF THE FREE BASIC ALTERNATIVE ENERGY POLICY 
5.5. Port St. Johns' municipality's indigent households' register and FBAE policy implementation

5.6. The process of FBAE policy implementation by different actors in Port St. Johns

5.6.1. Implementing actors' role in the Free Basic Alternative Energy policy implementation

5.6.2. The target actors' role in the Free Basic Alternative Energy policy implementation

Noqhekwana village

Mthumbane township

5.6.3. The linking actors' role in the Free Basic Alternative Energy policy implementation process

Noqhekwana village linking actor

Mthumbane township linking actor

5.7. Comparing the key actor characteristics of the implementing, target and linking actors

5.7.1. Summary of comparison of Port St. Johns' key actor characteristics

5.7.2. Summary of mutual relations of actor characteristics

\section{CHAPTER 6: INGQUZA HILL CASE: WEIGHING THE OPTIONS 139}

\subsection{Introduction}

6.3. Methodology specific to this case 
6.5. Ingquza Hill municipality's indigent households' register and FBAE policy implementation

6.6. The process of FBAE policy implementation by different actors in Ingquza Hill $\mathbf{1 4 6}$ 6.6.1. The implementing actors' role in Free Basic Alternative Energy policy implementation

6.6.2. Target actors' role in Free Basic Alternative Energy policy implementation 152

6.6.3. Linking actors' role in Free Basic Alternative Energy policy implementation 155

6.7. Comparing the key actor characteristics of the implementing, target and linking actors

6.7.1. Summary of comparison of Ingquza Hill's key actor characteristics

6.7.2. Summary of mutual relations of actor characteristics

6.8. Conclusion

165

\section{CHAPTER 7: KING SABATA DALINDYEBO CASE: AN UNBALANCED ACT

7.1. Introduction

7.2. Area description

7.2.1. KwaMpuku informal settlement

7.3. Methodology specific to this case

Implementing actors

Target actors

Linking actors

7.5. KSD municipality's indigent households' register and FBAE policy implementation

7.6. The process of FBAE policy implementation by different actors in King Sabata Dalindyebo

7.6.1. Implementing actors' role in the Free Basic Alternative Energy policy implementation 
7.6.2. The target actors' role in the Free Basic Alternative Energy policy implementation

7.6.3. The linking actors' role in the Free Basic Alternative Energy policy

implementation process

7.7. Comparing the key actor characteristics of the implementing, target and linking actors

7.7.1. Summary of comparison of KSD's key actor characteristics

8.5. Nyandeni municipality's indigent households' register and FBAE policy implementation

8.6. The process of FBAE policy implementation by the different actors in Nyandeni

8.6. 1. Implementing actors' role in the Free Basic Alternative Energy policy implementation process

8.6.2. The target actors' role in the Free Basic Alternative Energy policy implementation process

8.6.3. The linking actor's role in the Free Basic Alternative Energy policy implementation process

8.7. Comparing the key actor characteristics of the implementing, target and linking actors 
9.3. Methodology specific to this case

9.5. Mhlontlo municipality's indigent households' register and FBAE policy implementation

9.6.1. The Implementing actors' role in the Free Basic Alternative Energy policy implementation

9.6.2. The target actors' role in the Free Basic Alternative Energy policy implementation

9.6.3. The linking actors' role in the Free Basic Alternative Energy policy implementation process

9.7. Comparing the key actor characteristics of the implementing, target and linking actors 
10.2. Comparing energy access and implementation success in the municipalities 261

10.2.1. Energy for lighting

10.2.2. Energy for cooking

10.2.3. Energy for space-heating

10.2.4. Degree of implementation success

268

10.3. Comparing how actor characteristics influence the process of Free Basic Alternative Energy policy implementation across the municipalities

10.3.1. Analysing the actors motivations

The implementing actors' motivations 275

The target actors' motivations

The linking actors motivations

10.3.2. Analysing the actors cognitions

The implementing actors' cognitions

The target actors' cognitions 288

The linking actors' cognitions 292

10.3.3. Analysing the actors resources 296

The implementing actors' resources 297

The target actors' resources 302

The linking actors' resources 306

10.3.4. Analysing the power attributed to the actors 309

Power attributed to the implementing actors 310

Power attributed to the target actors

Power attributed to the linking actors

10.4. Results of actor characteristics' interaction process

10.5.2. Reflections on the theoretical framework used 
ANNEX 1: PORT ST. JOHNS NOQHEKWANA VILLAGE FOCUS GROUP WITH COMMUNITY REPRESENTATIVES

ANNEX 2: PORT ST. JOHNS LOCAL MUNICIPALITY ALTERNATIVE ENERGY SERVICE PROVIDER 365

ANNEX 3: CHITWAYO VILLAGE RESPONSES DURING FIELD VISIT

ANNEX 4: INTEGRATED DEVELOPMENT PLAN PRESENTATION BY OR TAMBO DISTRICT MUNICIPALITY

ANNEX 5: KING SABATA DALINDYEBO KWAMPUKU INFORMAL SETTLEMENT RESPONSES 375

ANNEX 6: OBSERVATIONS MADE DURING HOUSEHOLD INTERVIEWS AT KWAMPUKU SETTLEMENT

ANNEX 7: TRANSCRIPTION OF LIVE RECORDING OF THE GQWESA VILLAGE MEETING AND OBSERVATIONS

SUMMARY 389

SAMENVATTING 395 ABOUT THE AUTHOR 401 


\section{List of Figures}

Figure1.1: Map showing South African provinces and the location of the OR Tambo District

Figure 2.1: South African policy process timeline from 1994 with a focus on FBAE 28

Figure 2.2: Pre-2000 and Post-2000: Two distinct eras of electricity installation 34

Figure 3.1: Process model with the actor characteristics used in Contextual Interaction

Theory

Figure 3.2: The likelihood of 'adequate application' under Contextual Interaction

Theory

Figure 3.3: Layers of contextual factors for actor characteristics

Figure 3.4: Dynamic interaction between the key actor-characteristics that drive socialinteraction processes and in turn are reshaped by the process

Figure 3.5: Modified CIT process model illustrating the three actor interaction process

Figure 5.1: Map showing the location of Port St. Johns local municipal area in relation to municipalities under the OR Tambo District

Figure 5.2: Dynamic interaction between the key implementing actor characteristics

Figure 5.3: Dynamic interaction between the key target actor characteristics

Figure 5.4: Dynamic interaction between the key target actor characteristics

Figure 5.5: Dynamic interaction between the key linking actor characteristics

Figure 5.6: Dynamic interaction between the key linking actor characteristics

Figure 6.1: Map showing the location of Ingquza Hill local municipal area in relation to municipalities under the OR Tambo District

Figure 6.2: A home with SHSs (left); a malfunctioning battery storage unit which the households cannot repair (right)

Figure 6.3: Dynamic interaction between the key implementing actor characteristics

Figure 6.4: Dynamic interaction between the key target actor characteristics $\quad 154$

Figure 6.5: Dynamic interaction between the key linking actor characteristics. $\quad 158$

Figure 7.1: Map showing the location of King Sabata Dalindyebo local municipal area in relation to municipalities under the OR Tambo District

Figure 7.2: Dynamic interaction between the key implementing actor characteristics

Figure 7.3: Dynamic interaction between the key target actor characteristics. $\quad 184$

Figure 7.4: Dynamic interaction between the key linking actor characteristics.

Figure 8.1: Map showing the location of Nyandeni local municipal area in relation to municipalities under the OR Tambo District 
Figure 8.2: Dynamic interaction between the key implementing actor characteristics.

Figure 8.3: Dynamic interaction between the key target actor characteristics. $\quad 214$

Figure 8.4: Dynamic interaction between the key linking actor characteristics. $\quad 217$

Figure 9.1: Map showing the location of Mhlontlo local municipal area in relation to municipalities under the OR Tambo District

Figure 9.2: Local and district municipality officials collecting household information for the indigent register

Figure 9.3: Dynamic interaction between the key implementing actor characteristics

Figure 9.4: Dynamic interaction between the key target actor characteristics. $\quad 243$

Figure 9.5: Dynamic interaction between the key linking actor characteristics. $\quad 246$

Figure 10.1: Percentage of households using different energy sources for lighting 263

Figure 10.2: Grid electricity use for lighting over time to indicate level of electrification

in the OR Tambo district 264

Figure 10.3: Percentage of households using different energy sources for cooking 265

Figure 10.4: Percentage of households using different energy sources for space-heating

Figure 10.5: Actor relationship in a three-actor model illustration

Figure A7.1: Gqwesa village residents at the meeting

\section{List of Tables}

Table 1.1.: Conducted interviews in the OR Tambo local municipalities

Table 3.1: Operational definitions as used in the thesis and adapted from the CIT framework

Table 4.1: Spheres of government and their representation

Table 4.2: Stakeholder contribution to the FBAE policy implementation process

Table 5.1: Percentages of households using types of energy in Port St. Johns -

Table 5.2: Summary of Noqhekwana village and Mthumbane township influences to

FBAE policy implementation

Table 5.3: Result of interaction process of different actor characteristics

Table 5.4: Result of mutual relations of actor characteristics in the implementation process

Table 6.1: Percentages of households using types of energy in Ingquza Hill 
Table 6.3: Result of mutual influence of actor characteristics in the implementation process

Table 7.1: Percentages of households using types of energy in KSD 175

Table 7.2: Result of interaction process of different actor characteristics

Table 7.3: Result of mutual influence of actor characteristics in the implementation process 195

Table 8.1: Percentages of households using types of energy in Nyandeni - $\quad 204$

Table 8.2: Result of interaction process of different actor characteristics 221

Table 8.3: Result of mutual relations of actor characteristics in the implementation process

Table 9.1: Percentages of households using types of energy in Mhlontlo -

Table 9.2: Result of interaction process of different actor characteristics

Table 9.3: Result of mutual relations of actor characteristics in the implementation process

Table 10.1: Implementation success per municipality

Table 10.2: Comparing actor characteristics and their influence on FBAE policy implementation

Table 10.3: Needing energy services as motivation target actors

Table 10.4: Supporting the community and municipality as motivation for linking actors

Table 10.5: Household information update as a cognition influencing implementing actors' FBAE policy implementation

Table 10.6: Access to information about municipal FBAE plans as an influencing cognition on target actors

Table 10.7: Knowledge of community needs for FBAE service as the linking actors' influencing cognition

Table 10.8: How information from municipality influences linking actors' cognitions in

FBAE implementation

Table 10.9: How insufficient funds and other resources influence the implementing actors' FBAE implementation process

Table 10.10: How target actors depend on implementing and linking actors for FBAE resources

Table 10.11: How linking actors' resources influence FBAE policy implementation 307 Table 10.12: How implementing actors influence the FBAE policy process through their power

Table 10.13: Influence of power on the FBAE policy implementation process

Table 10.14: Results of actor characteristics interaction process

Table 10.15: Implementation success per municipality 


\section{List of Abbreviations}

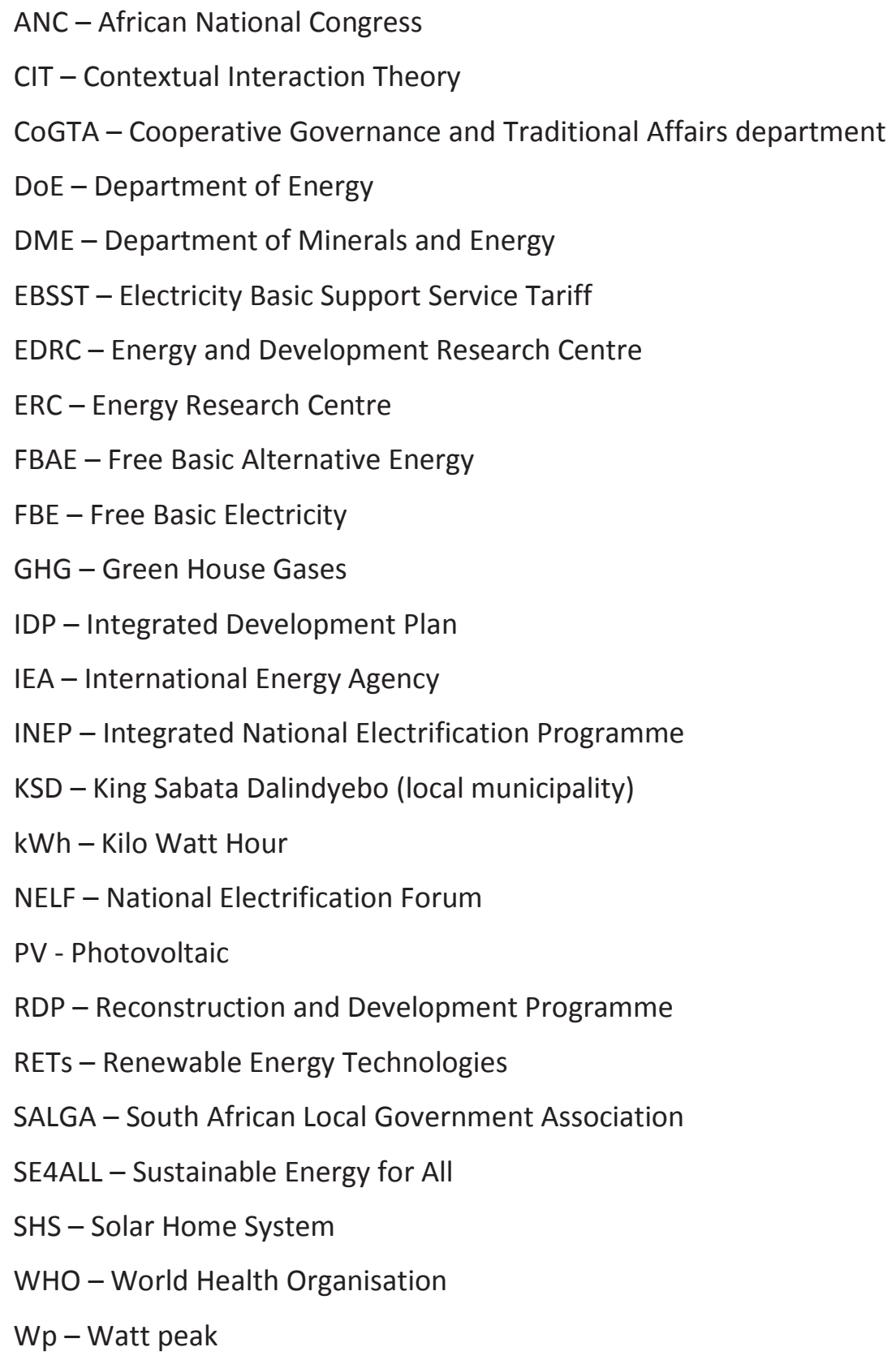




\section{Preface and Acknowledgments}

When the Department of Minerals and Energy (now known as the Department of Energy) announced the publication of the Free Basic Alternative Energy (FBAE) policy in 2007 I was excited. I was excited because, for me, the publication of this policy meant that the government was serious about providing energy sources to all the South African citizens and had come to realise that grid electricity was not the only solution to alleviating energy poverty. This policy also made me happy because it confirmed that the government finally realised that households without access to grid electricity were at a great disadvantage as they could not access Free Basic Energy (also known as free electricity) which is only available to grid electrified households. I also knew that with the publication of this policy would come a lot of work to ensure that it is implemented in a way that ensures that it reaches all the intended beneficiaries. A lot of local municipalities would have to include the implementation of this policy to their 'normal' service delivery schedules. This therefore raised my curiosity, I wanted to find out how the municipalities were coping with this new responsibility and if they were working towards fulfilling government's goals.

My connection to the Eastern Cape's OR Tambo district dates back to 2002 when I first visited the Lucingweni village and Hluleka nature reserve hybrid and mini-grid projects that were officially launched by the Department of Energy. These projects opened up a new world of modern energy services through the use of RETs for many remote rural households located at Lucingweni village and the surrounding areas. Even though many of these households were hoping to get grid electricity connections, the electricity provided by the hybrid mini-grid system (from wind and solar energy) confirmed that they could rely on alternative energy technologies. Unfortunately, due to lack of maintenance the systems stopped working which led to a lot of frustration by the locals and eventually the vandalism of the systems and theft of the solar panels. The sad ending taught project planners an important lesson, that of including all relevant stakeholders to the project. If community members were involved from the beginning of the project where some could have been recruited and given skills to 
maintain the system, the long waiting periods for repairs could have been avoided and people's trust in RETs could have been restored. The local municipality should have also been involved from the beginning so that they could support the project by including it in their Integrated Development Plans and take ownership of it. The Free Basic Alternative Energy policy depends on the local municipalities for its implementation. My knowledge of the circumstances of some households living in some areas in the OR Tambo district, especially in the Nyandeni municipal area raised my curiosity even more. From time to time I would telephone some of the municipal officials to find out if the FBAE policy was being implemented, in what way and what the benefits were for the households. This is because I knew that these households were faced with energy poverty and many of them relied on collecting wood, cow dung and plant residues for cooking and heating. Paraffin and LPG is often too expensive for these households to use and therefore inaccessible. I knew that the best way to find out how the implementation of this policy was taking place would be to plan a project that would provide me with resources to be on the field in order to collect the relevant from the all the stakeholders involved. I also knew that the findings of this enquiry would make a better impact if the study took an in-depth and scientific approach. This led me writing my research proposal, approaching the CSTM for supervision and looking for funding.

This study would not have been possible without the generous scholarship from the Oppenheimer Memorial Trust (OMT). I would like to say thank you OMT for providing me with a chance to advance my knowledge and education while doing work that I am passionate about. Through my work, your contribution has made it possible for many to learn about the Free Basic Alternative Energy policy and its intended purpose of eradicating energy poverty in South Africa.

I consider myself the luckiest person on earth for being supervised by the most wonderful and sincere people, Hans Bressers and Joy Clancy. Hans I thank you for believing in my study and instilling confidence in me to help me see that anything is possible if you put your mind to it. Thank you for 
your tireless explanations about the Contextual Interaction Theory (CIT) which you always managed to provide with a smile. Your guidance throughout this process made my PhD journey a happy one, filled with purpose not only to finish but to make a difference to the policy implementers in the OR Tambo district.

Joy, thank you for going beyond the call of duty. I am thankful for your patience and encouragement throughout my study. Thank you for visiting Port St. Johns while I was on the field, it meant a lot knowing that you could relate to the environment I was writing about. I also thank you for your motherly love that you have extended to me especially when I needed it most during my pregnancy and Simi's birth. Words cannot express my appreciation. I thank you and Giles for all the wonderful meals you have cooked for us and for providing a home away from home for me and my family.

My last year of this PhD study would not have been possible if it was not for Sam Odu. Thank you very much Sam for being a friend and a wonderful partner. I thank you for providing me with financial and emotional support during the most critical time of my study. I thank you for your ability to calm me down during the times of uncertainty which saw me panic about the fear of not finishing my PhD. Ngiyabonga kakhulu sthandwa sami. I thank you for our daughter Simisola and for providing her with care when I couldn't because of everything I had to do to finish writing my thesis. Thank you Simisola for bringing me joy during this period, your presence encouraged me even more to see this study to completion. I love you mntwana wami.

I also have to extend my thanks to the CSTM colleagues, some of whom have become very close friends. Sahar Issa thank you very much for your friendship throughout the four years of our PhD studies. I have great memories of our Saturday shopping eating adventures and the wonderful walks where we talked non-stop. You made the first year in The Netherlands bearable. 
Vera Vikolainen, it was only yesterday that you fetched me from the station the day before I started at CSTM. I will always remember our drive from the station to the campus - it marked the start of a very special friendship that is full of love and laughter. I am glad we shared an office during my first year of study. Thank you very much for being there, for listening and giving much needed advice on everything I have gone through since I started living in Enschede.

Gül and Vicky, I thank you for sharing your writing experiences with me. Vicky thank you for your encouragement when I was writing the theoretical framework chapter, you forced me to believe that it was possible and I appreciate that. I thank you too for the weekends we have spent together at CSTM, just knowing that you would be there gave me a lot of encouragement. Gül I thank you for your input in explaining so many things about the implementation theories and for going through some of my work. I appreciate the both of your very much.

I thank you too Maya van den Berg for being extremely supportive during the writing and completion phase of my thesis. You were always there to make sure that all the boxes are ticked. I thank you for your advice about balancing the PhD with childcare, especially when I thought it was impossible. Your offers to help were a constant reminded that I am not alone and help is a phone call away.

Aldi Hutagalung I appreciate your friendship and for being a colleague I could rely on for a smile. We spent a lot of time during this journey sharing our experiences, ideas, joys and frustrations. Lastly I thank you for inviting me to be paranymph, it was an honour being next to you during one of the most important moments of your career.

I thank you Cheryl de Boer for sharing your garden harvest with me. The zucchini from your garden ensured that I had enough soup to keep me going during the days and nights when towards the end of the writing process when everything was difficult to do and food preparation was near impossible. Your feedback about CIT use was also extremely helpful, thank you for simplifying what seemed impossible to do. 
Thank you Ewert Aukes for translating my thesis summary so promptly and professionally. I appreciate your assistance very much. I also thank you for your tireless lunch calls to us your colleagues and ensuring that we all ate together and shared our PhD experiences. Menno Smit thank you for being a great office mate, I really enjoyed our chats about running. Laura FrancoGarcia thank you for the opportunity you gave me to supervise students in the minor course. I enjoyed the experience and learned a lot from the student's experiences.

Thomas Hoppe thank you for being at the office on weekends. It was always assuring to know that I would not be by myself at the office on a Sunday. Thank you Norma Contreras Hernández for your kindness and agreeing to be my paranymph, I appreciate it very much. Cesar Casiano Flores, thank you for providing our office with laughter, especially during stressful times.

My stay at CSTM would not have been so smooth without the assistance of these three ladies: Annemiek van Breugel, Barbera van Dalm-Grobben and Ada Krooshoop. Annemiek I thank you for being my first point of contact at CSTM and for helping me make sense of the application process and getting all my documents in order. You continued to assist me with my countless needs throughout the four years and I appreciate that. Barbera, thank you very much for your availability and for being always ready to assist and answer questions. Ada thank you for making sure that everything is done according to university guidelines. I also thank you for taking me in when I desperately needed a place to stay after my first round of fieldwork.

Joanne Vinke-de Kruijf thank you for sharing your reports with me when I was confused about the structure of my cases. Beyond the PhD , I thank you for your friendship and for sharing your family with mine. I thank you for your constant support and always providing feedback when I was confused about steps to take towards making future plans.

When I came to The Netherlands in 2010 it was comforting to know that I would meet someone I knew. Thank you Pascale Nieuwland for remaining in contact from the time we first met in 2002 and for being the friendly familiar face I got to see eight years later. Thank you very much for my first 
bicycle in the The Netherlands, I still love it and it has carried me through the thick and thin of my PhD journey. Thank you too for always offering to assist to make my stay easier and for introducing me to your lovely family. Another person I met eight years before I started my PhD is Vin Morar. Thank you Vin for always offering to help me and for storing my bicycle in your home when I had to leave for fieldwork. Thanks to your wife Gerda for making sure that the tyres were full and everything was in order when I fetched it.

Everyone needs to belong to a family and this is very difficult when you are thousands of kilometres away from home. I thank you Ma Fennie and Oom Wim Teunissen for being that family in The Netherlands. You stepped into our lives at the right time when combining my studies with motherhood seemed impossible. Your parental support to my family will never be forgotten.

I thank all the friends I made at the ITC faculty, especially when I first arrived in Enschede. Mosa, Faith, Christabel, Buhle, Abel, Amindo your friendship made the first months bearable. Being able to converse in IsiZulu, IsiXhosa and SeSotho while in The Netherlands during the cold months made it easy to cope with home-sickness. Sibu, thank you my dear for being a friend and a sister. Amaningi anginawo! Through ITC I also met a very special lady, Catherine Lombard. Thank you very much Catherine for your love and care and for helping me understand my past so that I could live in the present and plan for the future.

Magi Matinga thank you for being the inspiration I needed to begin this journey. You made it look so easy to do a PhD at the University of Twente because of all the stories you shared, especially after you had been on fieldwork. Seeing you defend your thesis just two days after I arrived in The Netherlands inspired me so much and made me accept the baton from you with a lot of pride. Ngiyabonga sisi wami.

Thank you Matshepiso Makhabane for your love and support from the beginning until the end of this journey. I thank you for the big well organised farewell party you arranged for me before I left South Africa and I 
thank you for encouraging me to follow my heart and achieve my goals. Dorah Marema and Wendy Annecke thank you for being there when the idea to do a PhD formed in my head and for encouraging me to go ahead and do it.

Jocelyn Muller I don't think a lot would have been possible without you by my side throughout this journey. You gave me constant unconditional love and support and I appreciated that very much. I look forward the beach walks with our big family.

I thank the people at the OR Tambo district for providing me with information and for allowing me to join some of their trips to the villages where I could observe their interaction with the communities they serve. Thank you Cikizwa Tiyo, Zamva Vava and Eric Mzayiya and Zola. Without your willingness to assist, this study would not have been possible. The core of my study is based on the five local municipalities in the OR Tambo district and these are staffed with individuals that are working tirelessly to provide services to many poor households. In the Port. St. Johns municipality I would like to thank Zola Hewu, Zuko Mrwebi, Zama Pato, Cebo Mbilini, the late Mr. Nhlanganiso and Mr. Rhadebe from Noqhekwana village. In Ingquza Hill municipality I would like to thank Mr. Gqada and Mrs. Nodlabi for sitting through the interviews. Mr. Holweni and Chief Mgwili, thank you for accompanying me to the villages that would have been impossible to find on my own. Ndiyabulela bo tata. Your knowledge of the area made it easy to understand the messages you were giving me. In the Nyandeni local municipality my first point of contact with regards to this study was Luxolo Mpongo who has since become a very good friend and a brother. Thank you Luxolo for all your assistance and explaining the politics of the area. I also thank Ncumisa for making time for me and Mrs. Matinise. In the King Sabata Dalindyebo municipality my work was made easy by the Ntombi the ward committee member who opened up the world of KwaMpuku informal settlement to me and providing me with invaluable information. I also thank Mr. Tyalibongo for trying to accommodate me in his busy schedule. Finally, I would like to thank the Mhlontlo local municipality representatives, Ms. Ponco, Nompumelelo Dolo, Juliet Mkwelanga and 
Mazo Phikelela. You provided my study with a great example of a hard working municipality. Ndiyabulela kuni nonke!

At the national level of government I thank Matthews Bantsijang from the Department of Energy for always being welcoming and making information about the FBAE policy available to me. I also thank Collins Malaka from CoGTA for spending the morning with me and helping me to understand CoGTA's role in the implementation of the FBAE policy. At the provincial level I sincerely thank Luthando Fuku explaining the role of the Department of Local and Traditional Affairs and for taking me to different offices to show my how it all comes together.

In Port St. Johns made lasting friendships with people that assisted me with needs beyond this study. Nopasika Ndube and Maureen thank you for always making sure that I had the most suitable accommodation. Thank you Margaret for making Sunlof comfortable for me. Thank you Thabisa aka Thabz Soulstar for singing the lovely tunes which were most welcome at the end of the day after hours of driving and conducting interviews. Smiso Shozi thank you bhuti for your friendship and your helpfulness.

A big thank you to my family, especially my mother Nomsa Xulu for accepting my departure and letting me go even further than Cape Town. Thank you for the phone calls and always checking up on me. Thanks to my sister Thandi Xulu for being there throughout this journey and for understanding my need to accomplish this. I love you nana. Thank you to my precious nieces for understanding my absence.

Nonela Mxokozeli and your family, you have been such an amazing source of support. You made my fieldwork experience bearable and provided me with a home in the Eastern Cape. Ndiyabulela! Thank you for taking care of me when I fell ill, making appointments with your doctor to make sure that I was getting the best medical care. Thank you to your children, Sokhana, Avuyile and Imibongo for always welcoming their Mummy number two and to your mother for opening her home to me. 
To my friends in Cape Town. Ayanda Kulati, Namhla Kuse, Tembakazi Mafeke, Siyamanga and Mandisi Tyumre, Yoliswa Matthews I thank all of you for taking this journey with me. For allowing me to contact you anytime when I got frustrated, excited and home-sick. Part of this work is dedicated to our dearly beloved late friend and sister Fikiswa Mahote. Lala ngoxolo Fiks and thank you for leaving me with the most encouraging words. 



\section{Chapter 1: Introduction}

\subsection{Background}

Energy poverty has no single definition. It is often defined as the "inability to cook with modern cooking fuels and the lack of bare minimum electric lighting to read or for other household and productive activities after sunset" (Modi et al. 2006: 9). The International Energy Agency states that energy poverty is comprised of a "lack of access to electricity and reliance on traditional biomass fuels for cooking" (International Energy Agency 2010: 237). Clancy (2011) explains that households can be considered to be in energy poverty if they do not have "sufficient energy daily to cook enough food to meet nutritional needs and boil enough water for drinking and hygiene purposes" (Clancy, 2011: 1).

Most of the people are living in energy poverty are in Asia and in SubSaharan Africa with the latter having an electrification rate of 31\% while $80 \%$ of people still rely on biomass to meet daily needs (ibid). An indicator of the seriousness of this situation is that, in 2011, the Secretary General of the United Nations established the global initiative of 'Sustainable Energy for All' (SE4All) to address the issue of energy poverty.

South Africa is in a much better position in terms of energy provision to its citizens compared to its counterpart countries in the African sub-continent. With grid electricity as the mechanism of the country's electricity utility company (Eskom) to supply households, $84.7 \%$ of households were using grid based electricity for lighting in 2011 (StatsSA 2011). Even though the electrification figures are higher compared to those in most African countries, it is important not to lose focus of those $15.3 \%$ households without grid electricity services. This percentage represents 2.2 million households still relying on paraffin ${ }^{1}$ and candles for lighting, which are not clean and pose a fire hazard. These households are usually located in lowincome remote rural areas and in informal settlements in the urban areas.

\footnotetext{
${ }^{1}$ Paraffin is the common name in South Africa for the liquid fuel known as kerosene in other parts of the world.
} 
In South Africa, there is continued reliance on wood as the main energy source for cooking and heating in low-income electrified households and even more in households living in the remote rural areas with no access to grid (Matsika et al. 2013).

"In 2000, Government announced its intent to provide free basic services to indigent households. In this regard various services including energy were identified as basic services to be supported by the Government's programmes with respect to indigent households". (Department of Minerals and Energy 2006: 02)

"Access to energy provides benefits to women and men in terms of reducing the physical effort and the time taken to perform the tasks related to their practical and productive needs" (Clancy et al. 2011: 36). This thesis is concerned with contributing to the goal of universal access to modern energy $^{2}$ services for all in the context of South Africa. The study does this by examining how successful the implementation of the Free Basic Alternative Energy (FBAE) policy has been in respect of energy services ${ }^{3}$ in the rural areas of South Africa.

\subsection{Statement of the problem and study objectives}

The Free Basic Alternative Energy policy (FBAE) was published in 2007 by the former Department of Minerals and Energy (DME) now known as the Department of Energy (DoE). Its main purpose is to provide alternative energy services to households not connected to the national electricity grid. The policy refers to these energy services as "alternative", that is energy

\footnotetext{
${ }^{2}$ The term 'modern energy' generally refers to electricity, natural gas, liquefied petroleum gas (LPG) and paraffin (kerosene). Some authors extend this to include other gaseous fuels derived from biomass such as biogas and biofuels (biodiesel and bioethanol).

${ }^{3}$ A clarification of terms: Energy services in this thesis is used to define the services delivered by the service provider through the provision of energy sources to households.
} 
services other than grid electricity. The Department of Energy's recommended (non-exhaustive) list of alternative energy services that should be provided by municipalities as part of FBAE policy implementation includes Liquefied Petroleum Gas (LPG), Bio-ethanol gel-fuel, paraffin, Solar Home Systems fee-for-service payments and coal (DME 2007).

The main problem that has led to this study is that municipalities have not been able to successfully implement the FBAE policy, this is even more so in the municipalities based in the rural areas. Successful implementation refers to a situation where the implementation of the FBAE policy leads to satisfactory delivery of alternative energy services to unelectrified indigent households in each local municipality. In the South African context, indigent households are considered to be "households that lack basic services such as sufficient water, basic sanitation, refuse removal, environmental health, basic energy, healthcare, housing, food and clothing (DPLG 2005: 3). Before I started this study, none of the local municipal areas I focus on in this thesis had been successfully implementing this policy. The research area (OR Tambo district and its municipalities) is of interest to me because I have worked in the area as part of various research projects. I had an opportunity to see at first hand the need for energy services for unelectrified households located in the remote rural areas of this district. Due to their location, low-income status and other factors that contribute to their state of energy poverty, households in these areas have to depend on low quality ${ }^{4}$ energy sources such as wood that they collect, candles and paraffin.

Studies on the implementation of the FBAE policy are scarce. There is no scientific study that analyses the implementation process and outcome of the FBAE policy. Borchers and Dobbins (2007) reviewed the policy immediately after it was published to recommend ways to strengthen it and make it a priority in the government agenda. Their study focused on the implementation of this policy in the urban areas.

\footnotetext{
${ }^{4}$ Smokey and poor calorific value (compared to fossil fuels).
} 
Brynard (2005, 2006, 2007, 2009 \& 2010) acknowledges the lack of scientific policy implementation studies in South Africa and observes that the South African public policy implementation process is closely linked to service delivery. This leads to a need to enhance policy implementation strategies in order to ensure successful service delivery.

One of the issues that will be addressed by this study is what Brynard (2007), Khosa (2003), Mazmanian and Sabatier (1983) refer to as a 'policy gap'. According to Brynard, the policy gap is 'what transpires in the implementation process between policy expectations and perceived policy results' (2007: 358). Brynard mentions that 'the policy gap pertains not only to practice but also to research in the field of policy implementation' (ibid) such as the need for a fully-fledged research approach to policy implementation studies in South Africa with a focus on the Free Basic Alternative Energy (FBAE) policy.

Apart from the specific policy under study in this thesis, there is a lack of studies in the field of implementation and development that concentrate on specific policy implementation processes. It is also often assumed that policy implementation failures (especially in developing countries) are due to lack of or misuse of resources and corruption. In a sense they are so easily understood as an obvious result of poverty. This could lead to a superficial understanding of the causes for the 'policy gaps'. 'Lack of resources' is also an explanation of failure that is often popular among the persons and organizations that are responsible of implementation, not only in poverty situations but also in the rich countries, since it removes the blame from them. Even while some authors (Prittchet, 2010) do concentrate on creating a deeper understanding of the causes for implementation failure in developing countries, they work from the assumption that the issue is mostly about "state capability". In scientific implementation literature from the US and Europe however already for a long time the attention has shifted from the resources of the implementing organizations towards a broader perspectives in with the interaction between implementers and targets groups are set central stage. These 'bottom up' implementation studies were followed by "third generation" 
implementation models that combine elements from various approaches (Goggin, 1990., O’Toole, 2000).

The scientific challenge undertaken in this study is therefore to use a fullyfledged approach to the study of policy implementation in areas that are resource poor. That lack of resources is the obvious cause might still prove to be true, but is no longer presupposed as a sort of bias in the model of analysis. In this study I use the so-called Contextual Interaction Theory (CIT) (mentioned by O'Toole, 2004 - see more in Chapter 3) that focus on the analysis of actor characteristics to show that there are a number of issues that lead to policy implementation failures and successes. In Chapter 3 the model chosen will first be critically reviewed and in some respects modified to make it better apt for the empirical case of FBAE implementation. Nevertheless, using a broad implementation theory that was developed in reflecting upon mostly European cases of policy implementation can however still be seen as a test in itself: to what extent will this approach prove productive in creating a deeper understanding of the implementation of a policy scheme in a very poor region of a developing country?

Therefore, with this study I seek to fill parts of this 'policy gap' by using the Contextual Interaction Theory to analyse the FBAE policy implementation process in the five municipalities under the OR Tambo district by explaining the how and why of the implementation process and its results.

\subsubsection{Study objectives}

The objectives of this study are:

- To identify and analyse the complexities experienced by local municipalities in the OR Tambo District when implementing the FBAE policy;

- To find out how the actors and their characteristics (motivations, cognitions and capacity and power) influence the FBAE policy implementation process; 
- To find out how the contextual factors such as multi-level governance influence the actor's characteristics and how this in turn influences FBAE policy implementation process;

- To find out the usability of a broad implementation theory developed in response to "western" cases for the explanation of policy implementation in a developing country setting;

- To generate a set of evidence-based recommendations emanating from this scientific research study

\subsection{Research questions:}

The primary research question is:

- How do actors influence the Free Basic Alternative Energy (FBAE) policy implementation process in the local municipal areas under the $O R$ Tambo District?

With this question I would like to explain how the actors (as individuals, groups, organisations and institutions) influence the FBAE policy implementation process. In order to do this it is important to pay attention to the drivers of this influence - in this research I use concepts from the Contextual Interaction Theory: the specific actor characteristics of motivations, cognitions and capacity and power. The use of a small number of variables to analyse policy implementation may be seen as parsimonious, however it is advantageous as it allows the analysis to focus on the key areas that are most relevant in an interaction process. Moreover it allows the inclusion of numerous second order factors that work through their influence on the actor characteristics. These factors stem from various layers of context around the actors that are involved in the implementation process.

Thus the secondary question is:

- How do contextual factors influence the implementation of the FBAE policy? 
This question seeks to find out the contextual factors that influence the process of FBAE policy implementation in the five case study municipalities which come under the jurisdiction of the OR Tambo District Municipality. The contextual factors of focus in this thesis include the influence of the geographic location under specific context, multi-level governance under the structural context and the political context which is mostly influenced by the country's recent history.

\subsection{Methodology}

This study's method of research is a qualitative approach where a combination of in-depth and semi-structured interviews with respondents representing the local municipalities in the OR Tambo district and representing the provincial and national government department. There were slight variations in methodologies for each case. The variations and explainations for the adjustments for a specific case are given in the case chapters (Chapters 5, 6, 7, 8 and 9) of this thesis.

\subsubsection{Case selection}

In order to analyse the implementation of the Free Basic Alternative Energy (FBAE) policy, it was important to select an area that is suitable for the implementation of such a policy. In South Africa, poverty eradication is one of the government's key priorities (Bhorat et al. 2012) and the FBAE policy is one of the strategies used by government to address poverty in the low income areas. The province selected for this research is the Eastern Cape, a province situated in the south-eastern part of South Africa.

Despite its dual economy with both developed and underdeveloped regions, the Eastern Cape province remains one of the most impoverished in the country. The Eastern Cape Development Indicators Report (2012) states that, in $2012,57 \%$ of the province's population was living in poverty 
based on the poverty line approach ${ }^{5}$. The OR Tambo District is one of the districts within this province and the focus point of this thesis. This district is characterised by its poverty level and underdevelopment with the official unemployment rate reported to be $44.1 \%$ out of a total population of just over 1.3 million people (ibid) ${ }^{6}$.

Since the FBAE policy is meant to be implemented in areas where there is absence of grid electricity and high levels of poverty, the five municipalities that fall under the OR Tambo District municipality meet these criteria and so are good subjects as the cases for this study. Most of the households in these municipalities are considered indigents as they depend on government social grants such as those for old age, disability and child support. Depending on the municipality, the FBAE subsidy is given to indigent households in the form of alternative energy services ranging from litres of paraffin, maintenance of solar home systems, gel fuel and whatever else the municipality may decide to provide.

The local municipalities that are the focus of the research for this thesis opted to implement the FBAE policy through provision of paraffin for their indigent households. Previously some of the municipalities had provided solar home system maintenance services.

\footnotetext{
5 "Currently no official poverty line exists in South Africa" (Bhorat et al. 2012: 79). Municipalities often determine their own poverty line based on what they can afford to pay as subsidies for basic services delivered to indigent households. ${ }^{6}$ The Eastern Cape and the Limpopo provinces are said to be the poorest provinces in South Africa.
} 


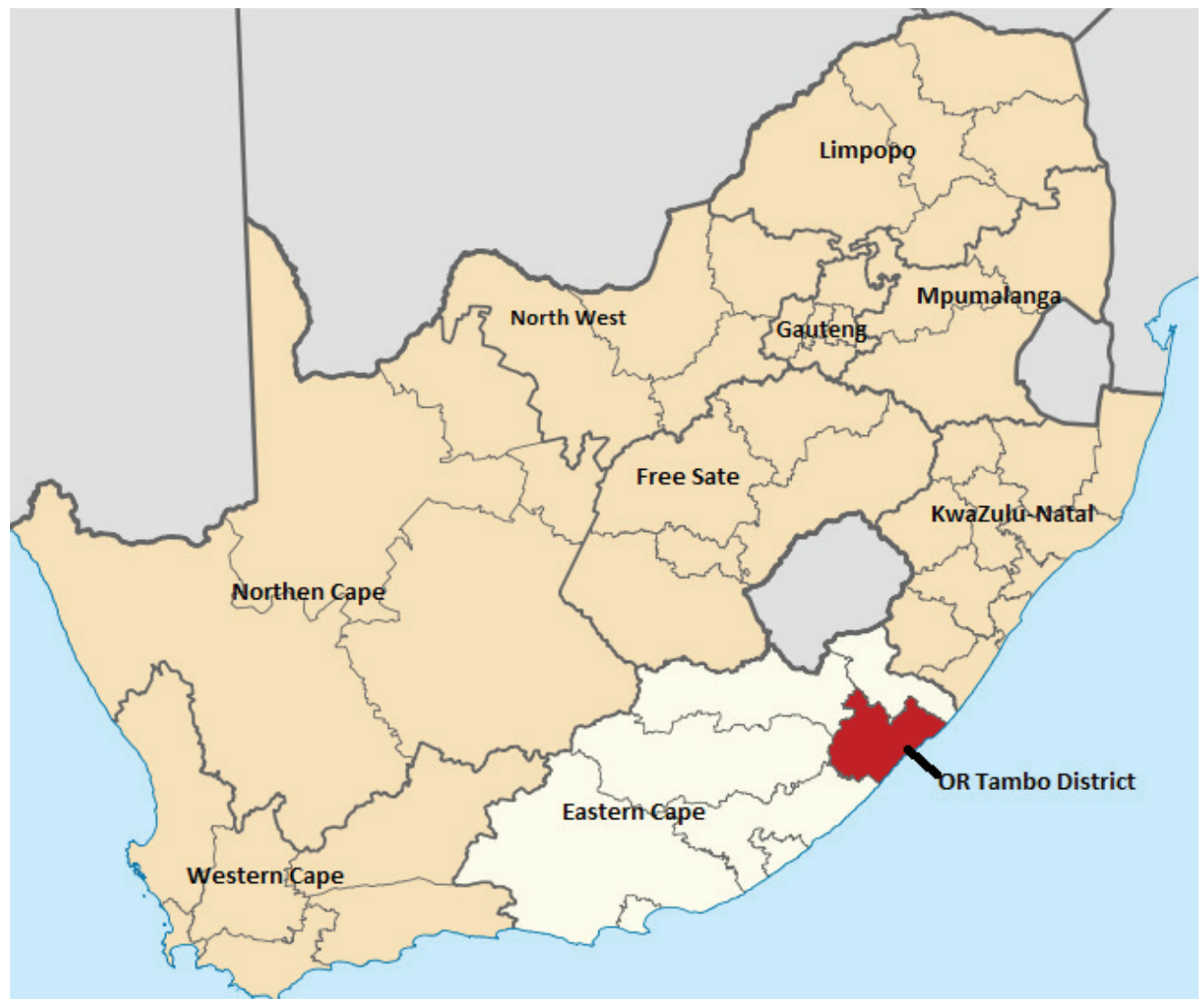

Figure1.1: Map showing South African provinces and the location of the OR Tambo District

According to Yin (2009), using 'case study' as a research method is good for to answer the 'how' and 'why' questions which are mostly found in explanatory studies. Case study design also helps to explain the causal links that would be too complex for study using quantitative methodologies.

Since my research seeks to find the causal links between policy implementation, actors' characteristics and the results of such interaction; case study research methodology is best suited for this purpose. According to Yin (2009:46), there are four basic types of designs for case studies; namely the single-case study design with a single unit of analysis, a singlecase study design with embedded or multiple units of analysis, a multiple- 
case study design with holistic design and a multiple-case study design with embedded units of analysis.

This study uses an embedded case study as it is comprised of sub-units (five units of analysis). The focus of my study is the OR Tambo District Municipal area (single-case) and its five local municipalities (units of analysis). The study will concentrate more on the sub-units of analysis as these make up the areas where FBAE policy implementation is taking place. Furthermore, these sub-units will be compared to each other to identify differences and similarities in the way the policy is implemented by the actors and how the actor characteristics influence what is happening in each sub-unit. Using an embedded case study design is most appropriate for my study as it allows me to concentrate on the single-case and its sub-units. Nevertheless, it is important to acknowledge Yin's warning to scholars who use an embedded case study design (2009). One of the "pitfalls" of using an embedded case study design is that the study tends to focus on the sub-unit level and fails to return to the larger unit of analysis (Yin, 2009: 52). By meticulously comparing the five units of analysis (the local municipalities) I ensure that the larger unit of analysis is not neglected as the results of this comparison give a picture of what is happening in the district municipality as a whole. $\mathrm{A}$ key advantage of this methodological approach is that a great number of variables is held constant so that it is possible to concentrate on the variation among more limited set of factors in the subunits.

\subsubsection{Data gathering}

The data gathering process was spread over a two year period; the first period was in 2011 (4 months) and the second period was in 2012 (3 months). Access to interviewees was often quite problematic, not just in the common issue found in field work of potential informant's willingness to cooperate but often due to the difficulties of travelling in this underdeveloped region with poor infrastructure making journeys long and arduous. Nevertheless in all five cases a sufficient number of interviews were realized to gain satisfactory quantities of information to enable to use the implementation study model. Interviews were conducted with 
respondents within the local municipality areas as well as the national and provincial government departments with responsibilities for the Free Basic Alternative Energy (FBAE) policy. Within the local municipality areas interviews were carried out with municipal officials and representatives (implementing actors), households and community members (target actors) and community leaders and representatives (in this thesis referred to as 'linking actors').

Conducting large sample size household interviews was not the primary intention of this study but it was important to get the views of the target actor and to assess how and the extent that this actor influences the FBAE policy implementation process. In order to get this information I interviewed a small number of households in two of the research areas: Ingquza Hill and King Sabata Dalindyebo. These areas were chosen on the basis of practicality. In King Sabata Dalindyebo the distances to drive were relatively short and it was less difficult to access households, in Ingquza Hill, although the distances were longer, I had better access to field assistance. The interviewed households were not meant to be representative of the households receiving FBAE services in these areas, but their inclusion was purely to provide an insight into households' thoughts on FBAE implementation. Their selection was based on the availability of people in their homes to talk to during the time I was visiting the areas. See Table 1.1. for a summary of respondents in each area. In Noqhekwana village I conducted a focus group discussion with the community representatives where we discussed about the lack of energy services in the area and their knowledge of the FBAE policy.

The provincial and national government departments were represented by respondents from the Department of Energy, the Department of Cooperative Governance and Traditional Affairs as well as the Eastern Cape provincial department of Local Government and Traditional Affairs.

Data was also gathered from secondary sources such as documents collected from the municipality offices and from national and provincial government departments. 


\section{Case areas}

In the five municipal areas that were selected for this study, I interviewed respondents (see Table 1.1.) representing the different actors in each research area.

In Port St. Johns I interviewed the local municipality employees in order to obtain information about the municipality's strategy for FBAE policy implementation. Unfortunately due to the administrative mismanagement within the municipality, I could not interview the same respondents in 2011 and 2012 as these employees had been relieved of their duties.

For respondents representing the views of the households and the community leadership I conducted interviews with Ward Committee members (community representatives) of Wards 6 and 10. Mthumbane township in Ward 6 was selected for two reasons. Firstly, it had some unelectrified households and secondly, it is a low-income area. As a consequence, these households would be classified as indigent households and hence would qualify to receive alternative energy services as part of the FBAE policy implementation process. Noqhekwana village in Ward 10 is completely unelectrified and its households would be classified as indigent as they are low-income. Noqhekwana would be an ideal location for delivery of alternative energy services if the local municipality was implementing the FBAE policy. A transcript on the meeting with the focus group discussion with the community representatives of the Noqhekwana villages can be found in Annex 1 . The interview with the former Port St. Johns alternative energy service provider is in Annex 2 and the Port. St. Johns case analysis can be found in Chapter 5 .

In Ingquza Hill local municipality I conducted interviews with two local municipality employees responsible for the implementation of the FBAE policy on behalf of the municipality. For households and community leadership views on the implementation of the policy I chose Chitwayo village and held interviews with the Chief and the Headman. Four out of the 15 households with solar home systems in Chitwayo village were asked 
questions about FBAE subsidies and their systems. The interviews were held with people that were at home at the time of my visit to the village.

Although similar questions were asked to the households, not all of the respondents were able to answer as they did not have information about the systems. For the local municipality perspective I interviewed municipal employees in charge of the FBAE policy implementation. More on the Chitwayo village responses can be found in Annex 3 . Annex 4 contains notes that I made during the Integrated Development Plan presentation by the OR Tambo district officials to the Ingquza Hill residents. The analysis of the Ingquza Hill case is in Chapter 6. 
Table 1.1.: Conducted interviews in the OR Tambo local municipalities

\begin{tabular}{|c|c|c|c|}
\hline Area & Implementing actor & Target actor & Linking actor \\
\hline $\begin{array}{l}\text { Port St. } \\
\text { Johns }\end{array}$ & $\begin{array}{l}\text { Local municipality } \\
\text { employees: } \\
\text { - Municipal Manager, } \\
\text { - Chief Financial Officer, } \\
\text { - Acting Chief Financial } \\
\text { Officers, } \\
\text { - Free Basic Services } \\
\text { Coordinator }\end{array}$ & $\begin{array}{l}\text { No household } \\
\text { interviews conducted. } \\
\text { Information on } \\
\text { households taken from } \\
\text { focus group discussion } \\
\text { and interviews with } \\
\text { community leaders. }\end{array}$ & $\begin{array}{l}\text { Community leaders - } \\
\text { some employed by the } \\
\text { municipality: } \\
\text { - Ward Councillors } \\
\text { (Wards } 6 \text { and } 10 \text { ), } \\
\text { - Ward Committee } \\
\text { Members (Wards } 6 \text { and } \\
\text { 10) }\end{array}$ \\
\hline Ingquza Hill & $\begin{array}{l}\text { Local municipality } \\
\text { employees: } \\
\text { - Electrification } \\
\text { Programme Manager, } \\
\text { - Electrification Project } \\
\text { Accountant }\end{array}$ & $\begin{array}{l}\text { Interviews with } 4 \text { out of } \\
15 \text { households that } \\
\text { have solar home } \\
\text { systems in the } \\
\text { Chitwayo village }\end{array}$ & $\begin{array}{l}\text { - Chief, } \\
\text { - Headman }\end{array}$ \\
\hline $\begin{array}{l}\text { King } \\
\text { Sabata } \\
\text { Dalindyebo }\end{array}$ & $\begin{array}{l}\text { Employee of the local } \\
\text { municipality: } \\
\text { - Revenue Manager } \\
\text { that is also responsible } \\
\text { for coordinating Free } \\
\text { Basic Services }\end{array}$ & $\begin{array}{l}\text { Out of the } 55 \\
\text { households that make } \\
\text { up the KwaMpuku } \\
\text { informal settlement, I } \\
\text { conducted brief } \\
\text { interviews with seven } \\
\text { households that were } \\
\text { available on the day of } \\
\text { my visit. To support } \\
\text { information from these } \\
\text { households, I also use } \\
\text { the information } \\
\text { collected through } \\
\text { interviews with } \\
\text { implementing and } \\
\text { linking actors as well as } \\
\text { paraffin suppliers. }\end{array}$ & $\begin{array}{l}\text { - Ward Development } \\
\text { Worker }\end{array}$ \\
\hline Nyandeni & $\begin{array}{l}\text { Employee of the local } \\
\text { municipality: } \\
\text { - Community Services } \\
\text { employee responsible } \\
\text { for coordinating Free } \\
\text { Basic Services (which } \\
\text { include FBAE services), } \\
\text { waste removal and } \\
\text { management of } \\
\text { upkeep of cemeteries } \\
\text { within this } \\
\text { municipality. }\end{array}$ & $\begin{array}{l}\text { No household } \\
\text { interviews conducted } \\
\text { and target actor } \\
\text { information is based on } \\
\text { information received } \\
\text { through interviews with } \\
\text { community } \\
\text { representatives and the } \\
\text { service provider. }\end{array}$ & $\begin{array}{l}\text { - Ward Councillor - } \\
\text { Ward 20, } \\
\text { - Former Ward } \\
\text { Councillor - Ward } 11\end{array}$ \\
\hline
\end{tabular}




\begin{tabular}{|c|c|c|c|}
\hline Mhlontlo & $\begin{array}{l}\text { Employees of the local } \\
\text { municipality: } \\
\text { - Chief Financial Officer, } \\
\text { - Free Basic Services } \\
\text { Coordinators. }\end{array}$ & $\begin{array}{l}\text { - Information I collected } \\
\text { during the Gqwesa } \\
\text { village meeting where I } \\
\text { observed how the } \\
\text { community relates to } \\
\text { the local municipality in } \\
\text { discussions regarding } \\
\text { the delivery of services } \\
\text { in their villages. I will } \\
\text { also use the } \\
\text { information collected } \\
\text { through interviews with } \\
\text { implementing and } \\
\text { linking actors as well as } \\
\text { paraffin suppliers. }\end{array}$ & $\begin{array}{l}\text { - Ward Committee } \\
\text { member } \\
\text { - Ward Councillor } \\
\text { - Gqwesa village Chief }\end{array}$ \\
\hline
\end{tabular}

In 2011 I interviewed a municipal employee at the King Sabata Dalindyebo local municipality but it was impossible to have a follow-up interview with this individual in 2012 as he too busy for an interview and claimed that he was occupied with other responsibilities within the municipality. Unfortunately this respondent was the only person in charge of FBAE policy implementation within this municipality, so no other informant could be interviewed.

Some households and the community leader of KwaMpuku informal settlement located in the King Sabata Dalindyebo municipality were interviewed for their input of the role they play in the implementation of the FBAE policy. The households were randomly selected based on the presence and availability of the occupants - this led to seven household interviews out of the 55 households that make up this informal settlement. Respondents were asked generally about the paraffin they were receiving as part of the FBAE subsidy from the municipality. Questions asked include the household's knowledge of the FBAE policy, whether they are receiving paraffin as part of FBAE service delivery, whether they are informed about the FBAE services. A compilation of the responses given to the questions asked can be found on Annex 5 with the observations I made during the interviews. The full case analysis is in Chapter 7. 
My first encounter with the municipal area of Nyandeni was some years before I started this research. Indeed it is there that my curiosity was raised about the implementation of the FBAE policy in the South African ruralbased municipalities. As part of an earlier research project, I had spent some time in the community and had got to know the local municipality staff, the community leadership and some households in this area, so I wanted to find out how far Nyandeni had progressed in their FBAE policy implementation since my previous visit. Before I started my Doctoral research I thought given my prior knowledge of the municipality, Nyandeni would be the first case area in my research strategy where I could test my field methods and research ideas. However, due to a sudden change in community leadership structures caused by the local government elections in May 2011, it became difficult to access the Nyandeni households and community as my key informants were no longer in the leadership positions. In Nyandeni I interviewed the former councillor of Ward 11 and the current councillor of Ward 20 to compile information about the community's role and influence in FBE policy implementation process. To get information about the implementation process from the municipality's point of view I interviewed an employee of the Community Services department within this municipality. An analysis of this case can be found in Chapter 8.

In the Mhlontlo local municipality I held interviews with the Free Basic Services Coordinators to find out how this municipality is implementing the FBAE policy. In this municipality I interviewed the same people in both my field visits of 2011 and 2012 and this provided consistency in following up on the progress of the implementation process. In Mhlontlo there were no household interviews due to lack of resources such as time and funds. I did use an opportunity to visit the local village, Gqwesa, with the local and district municipality representatives on their indigent household information update visit. Here I used the observation technique to collect information on how the implementing actor interacted with the target and linking actors. Notes based on the observations made in Gqwesa village can be found in Annex 7 and the analysis of the Mhlontlo case is in Chapter 9. 
For all the municipality interviews that took place, there was some preplanning involved. In 2011 before going to the field, I made appointments with all the municipal managers. This was in order to introduce myself as a researcher and my study to the municipalities. It also served as a way of requesting permission Most of the conducted interviews were planned

\section{National and provincial government}

Interviews were conducted with the relevant national and provincial government departments. The Department of Energy (DOE) and the Department of Cooperative Governance and Traditional Affairs (CoGTA) were selected due to their relevance to the study. The DOE formulated the FBAE policy and CoGTA co-ordinates policy implementation processes concerned with basic services such as provision of water, energy and sanitation. CoGTA works closely with the provincial government departments as these perform monitoring functions on CoGTA's behalf. The Eastern Cape provincial department of Local Government and Traditional Affairs was selected because it is in charge of monitoring the FBAE policy implementation processes within local municipalities.

\subsubsection{Selection criteria for key informants}

There were a number of factors that influenced the selection criteria for the people interviewed within the municipalities (implementing actors), the community leaders (linking actors) and the households (target actors). Although the initial plan was to conduct interviews with some pre-selected respondents based on their roles in the implementation process of the Free Basic Alternative Energy (FBAE) policy, in practice these were impossible to hold due to the following reasons.

- Senior staff members within the municipalities were often not available due to their work responsibilities therefore, it was often recommended that I contact individuals that dealt directly with FBAE policy implementation as they would have more information that would be useful for my study; 
- It also became clear that some municipalities were not providing alternative energy services at all and therefore not implementing the policy as prescribed by the provincial and national government departments.

\subsubsection{Data analysis}

Since the interviews were open-ended and not based on a tight interview schedule, respondents were free to respond as widely as possible to questions asked. There were a number of common questions that were asked to the majority of the respondents were analysed in a simple matrix format to identify similarities and differences in the answers.

Most of the data (compiled as field notes) was analysed manually by highlighting responses in each section of interest in order to build a narrative. The sections of analysis were grouped according to the Contextual Interaction Theory's concepts of actor characteristics of motivations, cognitions and resources(see Section 1.5.1.). The motivations of actors to implement the FBAE policy were captured as goals that actors wanted to achieve in implementing the policy. Respondents were asked about their goals rather than their motivations to make it easier for them understand and relate the question to their work. In order to find out about the actors cognitions and how they influence the implementation process, respondents were asked about the role of information in the interaction process. For instance, they were asked about the type of information needed to ensure the success of policy implementation as well as the sources of this information and how this information is shared among the actors. The information ranges from specific information about the policy itself, the process of implementation and the information about the households that qualify to receive FBAE services. In relation to resources, respondents were asked firstly about the type of resources they have and secondly the reasons behind the need to implement the policy and how this influences the implementation process. 


\subsection{Use of Contextual Interaction Theory in the research design}

The research design for this thesis is influenced by the Contextual Interaction Theory (Bressers 2004, 2009) to explain the why and how of the Free Basic Alternative Energy (FBAE) policy implementation process and its outcomes in the five chosen cases. Keeping in line with this theory's definitions, I make a distinction between three types of actors, namely: implementing actors, linking actors and target actors. These actors are most important in the interaction process of the FBAE policy implementation and in their unique ways their characteristics influence how the policy is implemented. Although the Contextual Interaction Theory uses a two-actor interaction framework, this study expands the theoretical framework to suit the reality that emerges in this research study.

The basic assumption of the Contextual Interaction Theory is that 'the course and outcomes of the policy process depend not only on the inputs (characteristics of the policy instrument), but more crucially on the characteristics of the actors involved, particularly, their motivation, interaction and power' (Bressers 2004). The emphasis of CIT lies on the social interactions and how they influence the policy implementation processes which are determined by actors and their core characteristics (Bressers 2004, 2009).

The research questions were therefore designed to capture the theoretical framework's core concepts to explain the FBAE policy implementation process as it takes place in the five local municipalities in the OR Tambo district. This study seeks to understand how the actors' motivations, cognitions, capacity and power influence the implementation process and in turn, how they influence each other. In addition the study is interested in the complex relationships between the actors and how these are influenced by the implementation process and by the actor characteristics.

In order to find out the motivation behind the policy implementation process for each actor, the actors were asked about their main implementation goals in order to ascertain what they wished to achieve 
where FBAE is concerned. For instance, the respondents were asked: "As an actor, what are your main FBAE policy implementation goals?". Subsequent questions were asked based on the responses given by each respondent. This open-ended interview technique took into consideration that actors are different and each one of them operates under their own unique circumstances regardless of the fact that they are within the same district. An actor's context such as geographic area within this district, political climate and the influence of multi-level governance is specific to that actor and hence makes each actor's response unique. Asking how the actors planned to achieve their goals made it possible to find out the motivation that drove such goals and how this motivation is dependent and influenced by the other actor characteristics. Actor motivations were also ascertained by assessing the external pressure that actors exposed to and how this pressure influenced the implementation process.

The cognitions variable is mainly concerned with information, frames of reference, interpretations and observations of reality in the CIT framework (Bressers 2009). In this thesis, information proved to be an important element in the FBAE policy implementation process. Cognitions therefore refers to the information processing capacity held by an actor and how this contributes to the interaction process. It is also concerned with how the actors' interpretation of reality influence the interaction process and how information and knowledge about other actors and the given context influence the interaction process. Respondents were asked about the importance of information in the FBAE policy implementation process, the type of information, the collection and processing of the information. The relevance and influence of information in the implementation process and on other variables is revealed in the analysis.

In addressing the capacity and power aspects of the question, the respondents were asked about the resources necessary to implement the FBAE policy. They were also asked about their access to these resources and whether this enables them to participate in the interaction process and how these resources influence the interaction process and affect the other actor characteristics. 


\subsection{Structure of thesis}

Chapter 2 introduces the reader to the Free Basic Alternative Energy (FBAE) policy and the South African energy context. This chapter provides a brief analysis of the South African energy policy development starting in 1994, the year that marks the country's independence, to the current period where I focus on the implementation of the FBAE policy.

Chapter 3 focuses on the Contextual Interaction Theory (CIT) as a theoretical framework used in this study. The chapter starts off with a brief historical background of implementation research and its influence to the current implementation theories. In this chapter I also introduce the threeactor model to the CIT framework as the framework I use to analyse the cases in my thesis.

Chapter 4 provides an overview of how multi-level governance (specific to this study) influences the Free Basic Alternative Energy policy implementation process. This chapter concentrates on the roles of the national and provincial government departments as well as the district municipality's role in this implementation process.

Chapters 5, 6, 7, 8 and 9 focus on Port St. Johns, Ingquza Hill, King Sabata Dalindyebo, Nyandeni and Mhlontlo municipal areas respectively as cases researched for this study to analyse the implementation of the FBAE policy by rural municipalities. In these chapters the Contextual Interaction Theory is extensively used to analyse the dynamic interaction between the key actor-characteristics that drive the social interaction process. These chapters are structured in a similar way to provide information on the similar issues that arise in the analyses of these cases.

Chapter 10 is divided into two parts. The first part (Sections 10.1 to 10.4) provides a comparative analysis of the five cases mentioned above and the second part (Section 10.5) provides the study conclusions. In this chapter I start with the an overview of energy access in the five municipalities researched for this study. I continue to use the Contextual Interaction 
Theory to compare the similarities and differences in the interaction processes and FBAE policy implementation experiences in each case. Based on the analysis results of each case, the implementation success levels of the five cases are compared and rated to create a form of overview summary of the case chapters using a few words that capture and describe the success levels. The Chapter and this thesis concludes with a section on conclusions and outlook (Section 10.5) in which the research questions are answered, the theoretical approach used in this thesis is reflected upon and some possible outlooks for research and practice are presented. 


\section{Chapter 2: Introduction to the FBAE policy and the South African energy context}

\subsection{Introduction}

This chapter analyses the South African energy policy development from the year 1994. The chapter starts off with the focus on the policy changes that took place starting in 1994 when the country became a democratic state led by the African National Congress (ANC). It then focuses on the policy building-blocks or strategies that led to the development of the Energy Policy White Paper of 1998, the outcomes of its implementation and the development of Free Basic Services strategies such as the Free Basic Alternative Energy (FBAE) policy.

\subsection{Policy changes and their impacts}

The beginning of the 1990s saw South Africa going through an important period in its politics. This transition was brought about by the change of government from the infamous apartheid government to a democratic state. The transition was also important in the policy making and implementation processes as most of these had to be adjusted in order to suit the new political order and its objectives, particularly in terms of service provision. Below I provide an analysis of policy change in the transitioning developing countries, taking into consideration the key points made by Brinkenhoff and Crosby (2002) and aligning them to the South African policy making experiences during its own transition.

In their analysis of "characteristics of policy change in developing and transitioning countries", Brinkenhoff and Crosby (2002: 18) identify several characteristics of policy change which they say "hold major implications for implementation". I use these characteristics to relate to the South African context of energy policy transition. The six characteristics that they identify are listed and explained as follows (Brinkenhoff and Crosby 2002: 18-21):

(i) "The stimulus for policy change often comes from sources outside of government". These according to the authors may be new political leaders 
assuming power following a democratic transition. This can be related to South Africa as the signs of policy changes were witnessed while the democratic government was transitioning into power. The policy change can also be brought about by the ordinary citizens, who are indeed outside of government, but have an influence on the types of policies that are made and implemented by government. In South Africa, the policies that followed the transition period were pro-poor and were influenced by the country's citizens, many of whom had suffered inequalities in the distribution of basic services during the reign of the apartheid government.

(ii) "Policy change decisions are highly political". According to the authors, the changes in policy have an influence on the countries' political systems and alter relationships between politicians. In South Africa, it is obvious that policy changes were given rise to by the politics of the country. The fact that the apartheid government did not provide services for the majority of the population was a political stance. On the other hand, the new democratic government made a political (and expected) decision to commit itself to provide all the previously disadvantaged citizens with basic services that they were lacking.

(iii) "...those most actively involved in the formulation of the policy changes tend to be technocrats". Brinkenhoff and Crosby (2002) describe technocrats as those people concerned with technical solutions and rationalizing scarce resources. In some cases, this has led to policies with a heavy emphasis on resource protection aimed at fencing off resources from users. In the South African policy transition phase, although there was an emphasis on ensuring equal access of energy resources for all citizens, there was also an emphasis on ensuring that these energy resources are protected to a certain extent. This is stated clearly on the Energy White paper policy document of 1998 where management of energy related environmental impacts is taken into consideration.

(iv) "Reformers are frequently new to government and unfamiliar with the environment for policy implementation". Here it is explained that due to their unfamiliarity with the workings of government, policy making and implementation processes, reformers, or those that are new in government 
often lose their effectiveness as they continue being in power. In South Africa, this is evident the energy ministry (and other ministries) where policy makers were highly dedicated to the cause of policy making and focusing on the positive changes that these policies would bring to the previously disadvantaged citizens. However, this was short-lived as reality continues to show and prove that policy implementation is a complex process and even the best policies are not easy to implement due to a number of factors, including the loss of effectiveness of those in power.

(v) "In most cases the resources needed to carry out policy change either do not exist or are in the wrong place". Often, resources are allocated to different activities on annual basis without much allowance for change that may arise due to a need for more resource allocation. New activities such as the implementation of a new policy often have to wait for resource allocation from central government coffers who may not have complete information of how much is needed for a certain policy to be implemented. In the South African case, particularly with the implementation of Free Basic Alternative Energy (FBAE) policy, even though resources exist, they are sometimes not enough because of the allocation method used by the central government as well as lack of capacity and other actor characteristics needed for successful policy implementation.

(vi) "Policy change requires that government organisations adapt and modify to new tasks". New policies or modifications in old policies demand a change in processes where implementation is concerned. This change is often accompanied by restructuring of part or whole government departments to accommodate new policies. In the South African case, the policy change brought notable changes in the energy sector where the energy ministry had to provide new energy services whilst using the old system of delivery where Eskom (an old state electricity utility company) was still responsible for grid electrification of low-income rural and urban households which they had previously ignored.

The points mentioned above give an indication of how policy reforms take shape in countries going through transitions like South Africa did in the 1990s. The points also partly illustrate the behavioural change that is 
brought by the transition and how this impacts on the implementation of such policies. This thesis provides more evidence with regards to the impacts of policy changes and their influence in the policy implementation process by focusing on three key actors.

\subsection{A focus on the South African energy policy development starting in 1994}

For the purposes of this thesis and for relevance and justification of basing this study on the Free Basic Alternative Energy (FBAE) policy of 2007, I will describe the South African energy policy background from 1994. One of the main reasons is that the first democratic government came into power in 1994 after the abolishment of the apartheid ${ }^{7}$ government which was in power for 46 years. Another reason is that prior to 1994, the apartheid government had little, or no interest in providing modern energy services such as electricity to the Black population living in the townships and in rural areas. Even though this service would have been easy and inexpensive to provide given cheap ${ }^{8}$ electricity generation costs in the country at that time, it was the apartheid's government goals to provide as little or no services at all to these areas. It is well-documented that the South African energy sector has historically depended on cheap local coal supplies, resulting in some of the world's lowest energy prices (Eberhard and Van Horen, 1995).

Figure 2.1 illustrates a timeline of the energy transition period in South Africa from 1994. This figure concentrates on the policy events that emphasize the government's planning towards pro-poor strategies such as

\footnotetext{
${ }^{7}$ Apartheid was a system of racial segregation which was enforced by the National Party led government that ruled from 1948 to 1994 . This system favoured the White population of the country and hindered the economic development of other races, especially that of Black people.

${ }^{8}$ Eberhard and Van Horen (1995) write about the cheap price of coal in South Africa that has made it easy for the country to generate grid electricity at low costs. They also look at the environmental externalities of using this energy source.
} 
the Electricity Basic Services Support Tariff (EBSST) and the Free Basic Alternative Energy (FBAE) policy.

In this section I first summarise the Reconstruction and Development programme (RDP)which is the overarching policy. I then describe the 1998 White Paper on energy Policy which led to the formulation of the Free Basic Alternative Energy (FBAE) policy (the focus of this thesis). The White Paper was intended as the Department of Minerals and Energy's (DME) response to the RDP.

\subsubsection{The Reconstruction and Development Programme}

The year 1994 saw not only the new government come into power in South Africa, but also the first time that the government provided energy services at a large scale, to the majority of its citizens. The Reconstruction and Development Programme policy (RDP) was one of the first documents drafted by the African National Congress (ANC) led government which set out governments' goals and plans on providing services to the country (RDP 1994). This policy document, like many that were developed by different ministries in the 1990s, focused on rebuilding South Africa's economy while bridging the gap between the rich and poor and bringing equal resources to the citizens. The RDP document also gave a platform for the government to begin the process of refocusing old policy documents to better suit the new political order and deliver all services for the people equally.

The RDPs short and medium-term goals were structured as follows:
a) meeting basic needs,
b) urban and rural development,
c) human resource development,
d) democratization and institutional reform, and
e) economic restructuring. 


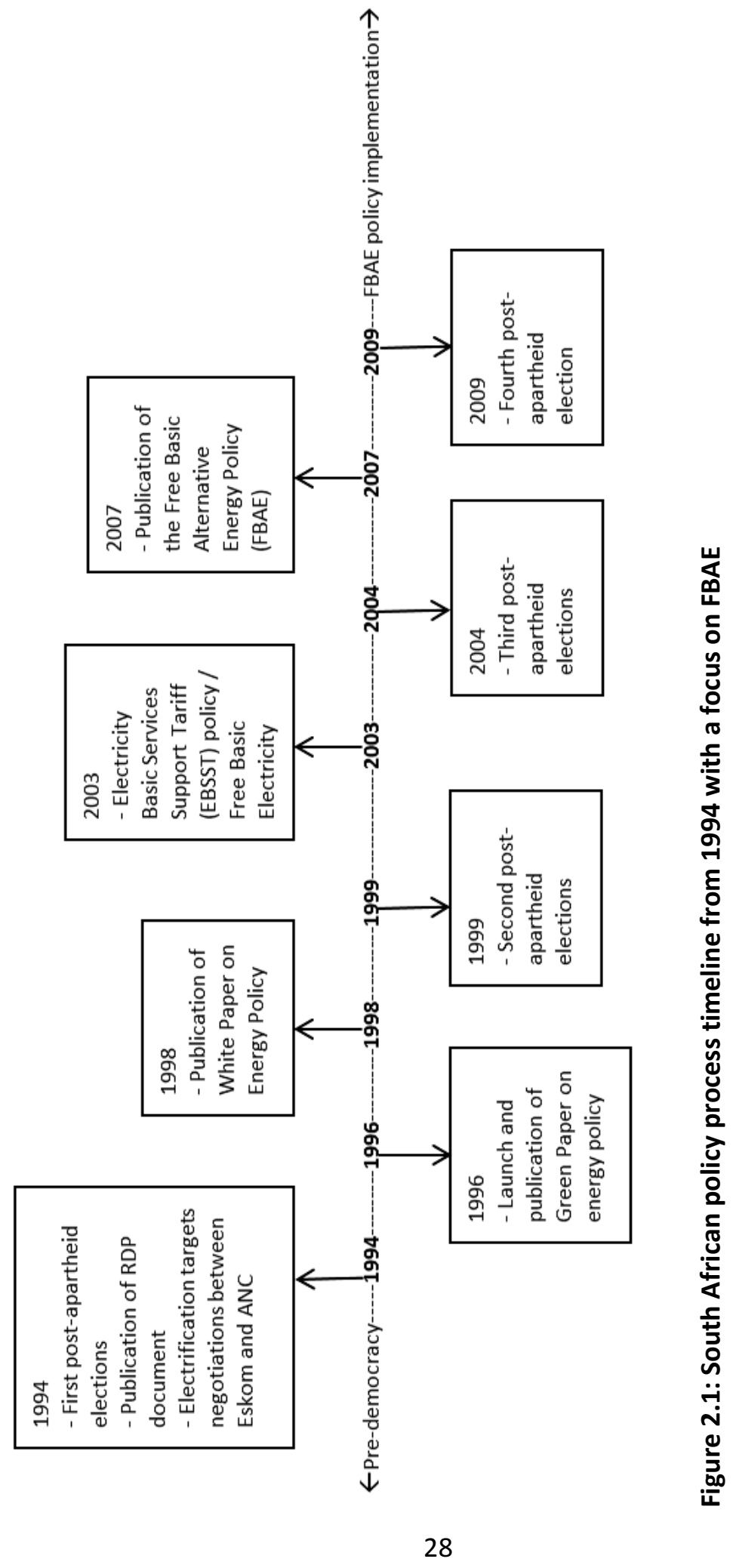


The RDP's aim was to become a stepping stone towards the development of the country based on the above-mentioned goals. These were accompanied by 'lead projects' that the new government saw as important to address the poverty of low-income households including lack of services. The rural development projects were planned to focus on providing services such as water and sanitation especially in provinces where these services had been scarce under the previous government. In the RDP policy document, it is stated that the electrification target was connecting 2.5 million households by the year $\mathbf{2 0 0 0}$ - that translated into a six year deadline for the government and all involved in this electrification programme (RDP 1994: 71). To finance this venture, the policy document proposed a creation of a national electrification fund based on levies and by the introduction of a national domestic tariff structure (ibid).

The South African electrification process was a significant part of the transition period for the country. In Section 2.4 I discuss the electrification process, the stakeholders involved and the achievements made. This section also illustrates the challenges faced by successive governments in implementing the RDP goals with relevance to the provision of energy services to those that were side-lined by the apartheid regime.

\subsubsection{The White Paper on Energy Policy ${ }^{9}$}

In his doctoral thesis, Marquard (2006) gives a detailed outline of what he refers to as the "Evolution of energy functions in government" (2006: 334). In this outline he tracks the energy sector from the 1940s, it is only in 1992 that the government established the National Electrification Forum to focus on the provision of electricity to the previously disadvantage majority of the population. This era of transition followed the lifting of the ban on a number of political parties and the release of political prisoners such as

\footnotetext{
${ }^{9}$ This document was formulated and published by the Department of Minerals and Energy in 1998. It was the first energy policy document formulated by the democratic government and has been used as the basis for energy provision and security initiatives in South Africa.
} 
Nelson Mandela in 1990 and marked a significant change in policies by the entire government.

One of the outcomes of this process was the development and publishing of the White Paper on Energy Policy in 1998. This document provided guidelines on how South Africa was to increase energy security for all its citizens through affordable energy services, improved governance and a better economy. The main objectives of this policy document are listed as follows: (Department of Minerals and Energy, 1998) -

a) To increase access to affordable energy services - This objective is based on the Reconstruction and Development Program policy of 1994 whose aim was to bring energy services to as many households as possible to rectify the inequalities in service delivery that were a result of the apartheid government's policies.

b) To improve energy governance - This objective is aimed at making the energy sector transparent and to get as many stakeholders as possible involved in its governance such as the formulation and implementation of new energy policies (1998:24). Transparency would also ensure that citizens give their input in the development of energy policies and strategies.

c) To stimulate economic development - To achieve this the state ${ }^{10}$ greed on making investments that would expand the energy infrastructure to meet the growing demand which in turn would stimulate the economy. This was seen as a move that would not only benefit big businesses and industries, but would contribute to the economic development of the lowincome households and the vast majority that was side-lined by the apartheid government.

d) Manage energy related environmental impacts - One of the ways to do this is to ensure that energy production does not harm the environment. The government also noted that lack of access to modern energy services by the Black majority led to use of unhealthy and dangerous energy sources

\footnotetext{
${ }^{10}$ State used as a term to indicate government and elements that make up and contribute to the governance of the country in its entirety.
} 
such as wood, coal and plant residues which pose serious health risks as people are exposed to indoor and outdoor air pollution.

e) Secure (energy) supply through diversity - To achieve this the State saw the need to investigate other energy supply options instead of relying on coal-generated grid electricity only. This was also due to a realisation that a greater demand in energy may not be met if other energy supply options are not considered.

The above-mentioned objectives were created to guide the South African energy sector in delivering energy services. They also allowed the government to examine its strengths and weaknesses in order to strategize for the future. These objectives gave rise to a number of activities within the energy sector such as sub-policies that were more specific on how certain objectives would be fulfilled. In Sections 2.4 and 2.5, I discuss some of the activities that were undertaken by the government in order to fulfil some of the set objectives. This includes a narrative on the development of the Free Basic Alternative Energy policy of 2007 which is the main focus of this thesis.

\subsection{Beyond the White Paper on Energy Policy - facing the energy poverty dilemma}

The next step after the formulation of the energy policy was to implement it and ensure that the objectives set out were met. As various studies in policy implementation research have illustrated, policy implementation is a complex process. According to Bressers (2004) - policy implementation is a process of turning focused input (policy) into a number of diffused outputs. De Boer and Bressers (2011) state that implementation is a multi-actor process where the implementers and target groups determine the course and results of the process. With the implementation of the energy policy came challenges which forced the government to review the policy being implemented and come up with alternatives that would make it possible to provide access to modern, safe and affordable energy services for the poor households in rural and urban areas. 
The South African electrification programme was (and is still) the most outstanding achievement by government of a developing country producing results that have not been duplicated by any other developing country. "Prior to 1990, less than a third of the population had access to electricity. By the end of the decade, that proportion had doubled" (Marquard et al. 2007: 7). "... the South African electrification program has differed from electrification programs in other Sub-Saharan African countries, because the country has largely financed its own program" (Matinga 2010: 7). These quotes emphasize the scale of the electrification programme undertaken during the transition of the country from an apartheid to a democratic state.

As most of the country's citizens did not have access to modern energy services such as grid electricity during the time of the transition, the electrification programme became largely target-based with strategies in place to reach a certain number of households within a particular time. This was mainly due to the readily available resources, electricity generation surplus and funds to undertake the electrification programme at a large scale.

The National Electrification Forum (NELF), a multi-stakeholder body that was established in 1992 during the time of the RDP policy formulation, came up with a "vision for an accelerated electrification programme" (Marquard et al. 2007: 11). It is this vision that saw the electricity utility company of the country setting electrification targets with the African National Congress.

The electrification programme that saw millions of households being provided with electricity in the 1990s did not only depend on the power capacity reserves that were built up in the 1980s by the state. The programme also depended on heavy subsidization by the government as the targeted new consumers would not have been able to afford the installation costs. In the early 1990s at the beginning of the electrification programme, financing for the electrification of households was arranged through cross-subsidies from industrial users and bulk electricity sales to urban local authorities. However, after the year 2000, the funding for 
electrification was provided from the national treasury and the Integrated National Electrification Programme (INEP) within the Department of Energy $(\mathrm{DOE})^{11}$, GNESD (2012). In the 1990s, a 20 Amp supply of electricity for a household cost the service provider $\mathrm{R} 3,400.00^{12}\left(\$ 850.00^{13}\right)$ for installation whilst the household paid R120.00 (\$30) for the connection.

Figure 2.2 illustrates the "eras of electrification" in South Africa which Eskom distinguishes between the Pre-2000 era and the Post-2000 era (Noah, 2012). The significance of these eras is that they show the rate of household electrification by government during the transition into the democratic state. The data in Figure 2.2 clearly shows the RDP policy intentions of providing electricity to previously disadvantage households which had no access to modern energy services under the apartheid government. The implementation of this electrification policy was also made possible by the availability of generating capacity and the "creative (low-cost) ways" ${ }^{14}$ that were used by Eskom to electrify low-income rural areas where most of the households had no electricity (Marquard et al. 2007). In fact, the Pre-2000 electrification era (mid 1990s) saw significant levels of electrification happening in urban areas and in the Post-2000 era, Eskom and the government concentrated on bringing electricity to the rural areas. Eskom had to change its operation process from being a reactive ${ }^{15}$ supplier to being pro-active and target-driven while taking into consideration the political concerns associated with the provision of services in the country during the transition period.

\footnotetext{
${ }^{11}$ The Department of Energy (DOE) is the former Department of Minerals and Energy (DME). The name change took place in 2009 where the DME was separated to two departments, the Department of Energy and the Department of Mineral Resources.

${ }^{12}$ Marquard et al (2007).

${ }^{13}$ Using US dollar / South African Rand currency exchange for 1994 average rates as calculated using OANDA currency converter historical exchange rates http://www.oanda.com/currency/historical-rates/

${ }^{14}$ Using single-phase instead of a three-phase connection for low-income areas households as they often use less electricity due to lack of and insufficient incomes.

${ }^{15}$ Installing electricity based on the applications from customers.
} 

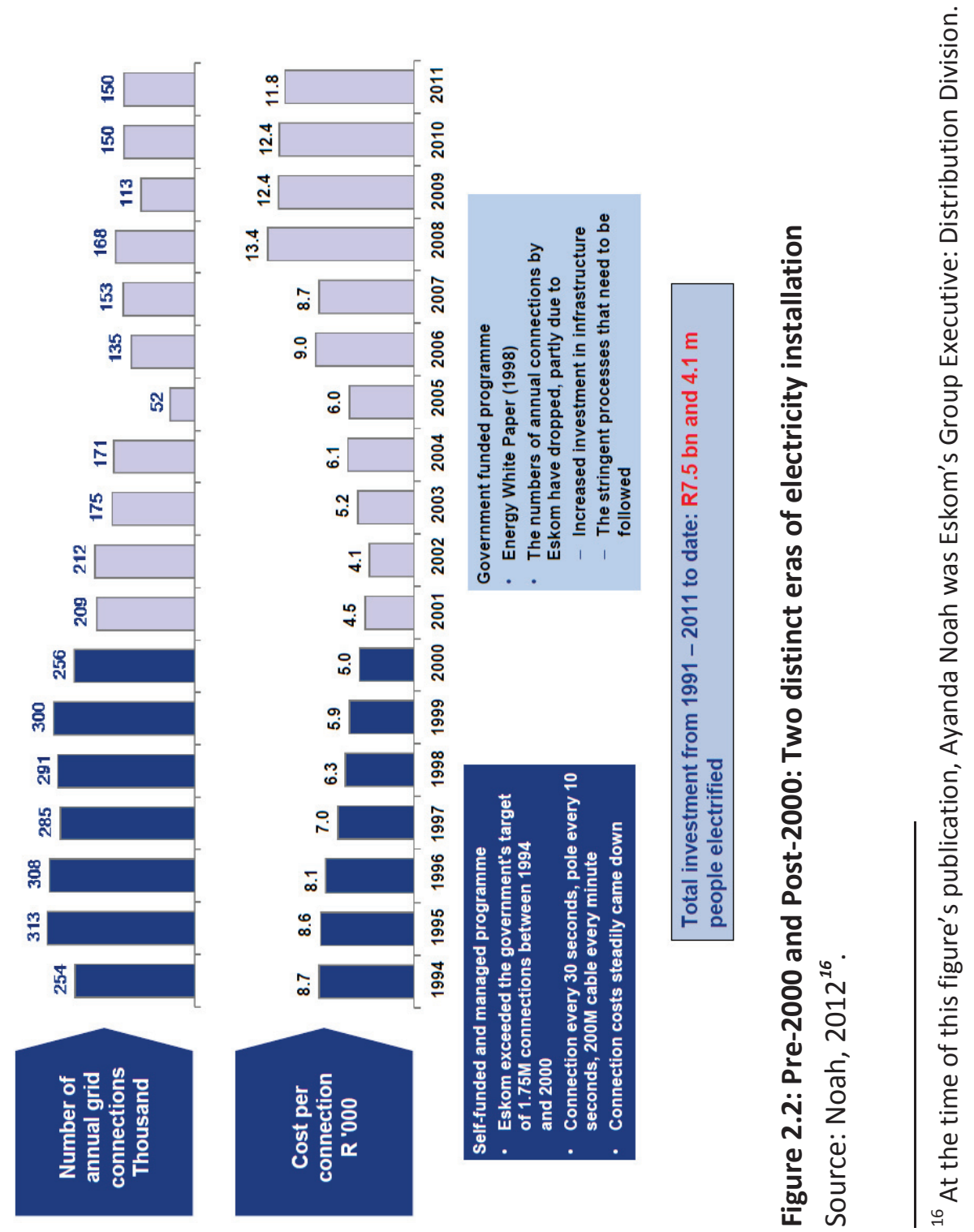
As illustrated on Figure 2.2, there were higher numbers of households electrified between 1994 and 2000 than after 2000. The figure also shows the costs implications of these connections. As many of these electricity connections were made in the urban areas where housing density makes electrification costs lower than in rural areas. However, when electrifying rural areas costs increase because population density makes connections more expensive.

A significant change by Eskom during the electrification process was in its billing system. During the mass electrification of low-income households, Eskom started installing prepayment meters instead of using the traditional conventional meters. The conventional meters allowed the households to consume electricity for a month and would be billed by the service provider for the electricity consumed during that period (Tewari and Shah 2003). The pre-payment metering system on the other hand allowed households to use electricity according to what they could afford. "A customer who wants to buy electricity presents a meter card to a vendor, pays the sum of money that he/she wants to spend. The vending machine then produces a magnetic or keypad token for the customer. The customer can take it home and enter into the meter" (ibid 2003: 914). At first the electricity consumers were wary of this system as they believed that it would force them to use undesirable forms of energy sources such as wood and paraffin if and when they ran out of electricity credit. However, with time and experience, the prepayment credit system proved to be helpful for households as they could manage their energy bills. They can monitor their household electricity consumption and have a clear budget of what they wanted to spend on electricity during a certain period. The prepayment system is appreciated by low-income households and those with unreliable sources of income as they can budget for their energy expenditure depending on their needs and availability of funds.

As previously mentioned, the Post-2000 era as illustrated on Figure 2.2, shows that the electricity connections declined and the costs increased. The other significant change that happened Post-2000 was that a significant 
amount of responsibility for planning and implementing the electrification programme was moved from Eskom to the Department of Minerals and Energy (DME) where it was referred to as the Integrated National Electrification Programme (INEP). Here administration and funding of the programme took place under the direction of the ministry (Marquard et al. 2007).

As part of providing energy services to the low-income households in the rural areas, the INEP programme implemented an off-grid photovoltaic (Solar PV) electrification programme in remote rural areas. Although this programme has not (and will not) provide as many off-grid and non-grid household electricity connections compared to grid electrification - at the beginning, it did provide basic electricity services to a significant number of households in the remote rural areas. Households in these areas would have otherwise had to wait for many years before being provided with grid connections. The latest figures from the national census show that only 51 505 (0.35\%) out of 14450151 households in South Africa are using Solar Home Systems (SHS) for lighting in their homes (StatsSA 2011). This is a very low number considering that an estimated 20\% (3.4 million according to Eskom's 2012 estimations) ${ }^{17}$ of households in South Africa still do not have access to grid electricity. Most of these are located in the rural areas. Even though the government's solar PV electrification programme installed many SHSs at the beginning, the numbers declined as the years progressed. This was due to a number of factors including:

- grid electricity connections arriving faster than expected in areas that were initially marked for long-term Solar PV installations;

- the electrification policy does not allow SHS installations in areas where grid electricity lines are within visible distance;

- fear by local municipalities that if they agree to SHS electrification, their areas will not qualify for grid electrification in the future (Wlokas 2011: 10).

\footnotetext{
${ }^{17}$ Based on the presentation delivered by an Eskom representative at the Eskom Electrification Indaba - 15 March 2012 - Durban, South Africa.
} 
In order to have successful implementation of Renewable Energy Technologies (RETs) in South Africa, policy makers need to be convinced that this type of technology will have positive benefits for the country, especially for those households experiencing energy poverty. So far, the South African government is not under any pressure to reduce Green House Gas (GHG) emissions and to disseminate RETs at a large scale unlike developed countries - but it has made considerable inroads with the country's Renewable Energy policy and making plans for increased capacity using RETs. As Prasad (2007) observes, one of the contributing difficulties in promoting RETs in the country is partially due to large coal deposits currently used for grid electricity generation which is amongst the cheapest in the world (2007: 3). The cheap electricity also contributed to economic growth through energy intense projects and programmes which were vital for the country and to invite foreign investors during the transition from an apartheid to a democratic.

\subsubsection{Energy policy: a focus on the poor}

As it has been illustrated in the previous section, grid electrification in South Africa has played an important role in the transition period and beyond. The South African energy policy's focus was not only on electrification but providing energy security for the country's citizens. This means alternative ways of providing energy sources had to be considered and tested especially when the electrification costs became too high for the government to fund grid installations for low-income remote rural areas. The need for new energy sources for remote rural areas led to government programs that provided solar home systems (ERC, 2004).

\section{Energy poverty in South Africa}

Use of electrical appliances is seen as one of the benefits of electrification. The International Energy Agency (IEA) mentions a number of benefits that households in low-income countries derive from electrification. Use of electrical lights enables households to have longer days which allows them to engage in activities that would be impossible or difficult to perform at night with candle light. These activities may range from the ability for 
children to read their school books and do homework, performing household chores and engaging in small income generating activities (IEA, 2010). For households that can afford the costs of buying and using electrical appliances, the burden of wood collection and use is substantially decreased through electrification.

In the late 1990s, Eskom realised that low-income households especially those in rural areas that were recently provided with electricity in their homes, were not using their electricity supply optimally and to its full capacity. Through technical studies where data loggers were placed in pilot sites and where households' electricity consumption was monitored - it was discovered that newly electrified low-income households were not using their electricity supply the same way as those in the urban areas. To investigate the causes of the behaviour of low-income rural households, a qualitative study commissioned by Eskom was conducted by the Energy Research and Development Centre in a small number of newly grid electrified areas (Thom, 2000). The results showed that most households used multiple fuels such as a combination of paraffin, wood and electricity for different end uses depending on their energy needs. Electricity in these households was mostly used for lighting because this was cheaper for the households and provided light that could be used by all the members of the household. Appliances such as radio and television were also used but for limited periods to listen and watch the news and some entertainment programmes. The main reason for little use of electricity for applications such as cooking is that households did not have energy intensive appliances such as electrical stoves. In cases where there was ownership of these appliances, the households found it too expensive to use them on a regular basis, restricting use for special occasions such as when a member of the household has earned an income, social wage or family members living and working in urban areas had sent remittances (ERC 2002) ${ }^{18}$.

\footnotetext{
${ }^{18}$ Summary framed from the Energy Research Centre report of a study commissioned by Eskom and the Department of Minerals and Energy as well as personal experience from working as a research assistant on some of the research sites where information was gathered.
} 
Energy poverty in South Africa goes beyond the lack of electricity services or the inability to use the available electricity due to unaffordability. In general, energy poverty also affects households in a number of ways such as health, nutrition, education and gender relations within the household. In rural areas, households have to rely on fuels such as wood and plant residues in order to meet their energy demands. A number of studies including those by Matinga (2010), Davis (1998), Cecelski (2003), WHO (2006) have shown that wood use as a household fuel is harmful and often affects women as the users of this fuel. This danger also extends to infants who are often with their mothers and care-givers during fire-making and meal preparation times. According to the World Health Organisation (WHO), an estimated 1.6 million premature deaths per year were directly caused by indoor air pollution from use of solid fuels such as wood (WHO, 2006).

Energy poverty contributes to malnutrition for many people living in developing countries in low-income areas as they cannot afford to pay for modern, energy efficient and safe energy sources to cook their meals. Often, staple foods in many societies around the world, need to be cooked before they are consumed. Lack of energy services to prepare meals leads consumption of unhealthy food by households, including fast-foods that are often overcooked with unhealthy fats which cause dietary problems such as obesity and lack of important nutrients. A study conducted in the lowincome area of Khayelitsha in Cape Town revealed that households applied different methods in cutting down their cooking energy costs and as consequence of this, they compromised their families' nutritional needs. Out of the surveyed households, $26 \%$ said that they cooked once a day or only a couple of times a week, whilst $13 \%$ said they avoid cooking food that takes a long time to cook and $5 \%$ said they cook several types of food in one pot (Cowan and Mohlakoana, 2004).

Wood collection is associated with the state of being poor because in many developing countries, households rely on this source of fuel for their energy needs, especially cooking. Matinga's research in the South African villages 
of the Eastern Cape (Cutwini and Tsilithwa ${ }^{19}$ ) located in two of the local municipalities where my study is based, highlights the health impacts of wood collection and use. Matinga (2010) conducted an ethnographical study which looks at 'the actors' experiences of the health impacts of energy acquisition and use' and 'how these actors perceive and respond to these experiences' (2010: 4). Matinga found that issues relating to the health impacts of wood collection and use were not considered as important at the local and national levels in South Africa and therefore did not receive the same level of attention as programmes focusing on rural electrification. "This reflects the policy symbolism in favour of electrification in spite of the fact that firewood is the most common energy carrier among the poor in rural areas" (Matinga 2010: 209).

In South Africa, low-income urban and rural households are affected by energy poverty in many ways including the ones mentioned above. It is with this realisation that the government has reviewed the energy policies and has introduced a number of strategies to combat the state of energy poverty and assist households that are in need of basic energy services. The following section looks at the strides that have been made by some South African government departments to bring basic services to the poor using subsidies and other forms of interventions.

\subsection{The introduction of households' basic services subsidies}

The transition from an apartheid state to a democratic state brought many changes to the way the government operated, especially in the delivery of household basic services such as water, sanitation waste removal and energy. Other services that the government regards as basic and provides for free or at subsidized rates are houses, some education and health-care. The South African Constitution (1996) states that "everyone has a right to adequate housing" and "access to healthcare services, health care,

\footnotetext{
${ }^{19}$ The villages are $196 \mathrm{~km}$ apart if driving on the short route (R61) which is not always 'safe' due to bends and potholes. The distance is $246 \mathrm{~km}$ if using the long route (R61 and N2).
} 
sufficient food and water and social security" ${ }^{20}$. Although this thesis focuses on energy services, particularly the Free Basic Alternative Energy (FBAE) policy, in this section I give a brief background of another Free Basic Service (Free Basic Water) provided by government after the statement of intent to provide such services was issued in 2000. This shows how the government has found it difficult to deliver its electoral promises

\section{Free Basic Water}

Water is an important resource for many communities in South Africa and the world. As of 2011 only 46,3\% households in South Africa had access to piped water inside their dwelling ${ }^{21}$ (StatsSA, 2011). Due to high poverty levels and difficulties in accessing water services (especially in the rural and informal urban areas), the South African government made a decision to provide a certain amount of water for free to indigent households. In 2001, the government approved a proposal by the department of Water Affairs and Forestry to provide 6000 litres of safe drinking water to indigent households per month (DWAF 2002). According to the implementing department, this strategy was more a success in the urban areas than in the rural areas. The reasons were that most indigent households in the urban areas had access to reticulated and metered water. With the Free Basic Water programme, the service providers (local municipalities) only needed to ensure that these households were not charged (billed) for the first 6000 litres of water they consumed. On the other hand, most rural areas in South Africa do not have easy access to piped water services. Most of them depend on water they collect from rivers, dams, communal water tanks and standpipes. It is also common in the rural areas that the households are not charged for accessing water, especially if the municipality is not providing this service. In rural areas, the Free Basic Water programme provided water

\footnotetext{
${ }^{20}$ South African Constitution of 1996. Section 26 (1) and 27 (a, b, c).

${ }^{21}$ Piped water inside the dwelling indicates that the household has a functioning water reticulation system that allows it to access water inside the house. Most of the households in South Africa depend on water taps located outside their homes and in informal areas they depend on communal water taps.
} 
tanks to communities which would provide the households' share of the 6000 litres per month. Due to lack of resources such as the very water they are trying to provide and transportation, this programme was and is still difficult to implement in rural areas.

\subsubsection{Electricity Basic Support Services Tariff (EBSST)}

According to the Electricity Basic Support Services Tariff (EBSST) policy published in 2003, "the provision of free basic services is primarily a social welfare function which is the responsibility of government" (2003: 6). With the realisation that low-income electrified households both in the urban and rural areas could not afford to use their electricity supply optimally, the government through the Department of Minerals and Energy (DME) proposed the EBSST policy.

After analysing the results of the survey of rural households (see section 2.4.1. of this chapter) to find out why low-income households were not using their electricity supply as much as the electricity utility company had expected, it was decided that "provision of $50 \mathrm{kWh}$ of grid electricity per month (would be made) to all households with concomitant blocked or stepped tariffs for electricity consumption beyond $50 \mathrm{kWh}$ to mitigate the cost implication of the free basic electricity provided" would help fulfil the policy goal (DME 2003: 6). At the time when this policy was passed, the DME and Eskom gave four main reasons why $50 \mathrm{kWh}$ was suitable for the targeted households. The reasons are stated as follows in the 2003 policy document:

(i) " $56 \%$ of households in South Africa connected to the national grid consume on average less than $50 \mathrm{kWh}$ of electricity per month;

(ii) 50KWh per month is considered adequate electrical energy to meet the needs for lighting, media access and limited water-heating and basic ironing (or basic cooking) for a poor household;

(iii) The level of 50kWh had been spoken of generally at national level and had been accepted as a norm in respect to free basic electricity. This 
quantity has achieved widespread political and community acceptance and expectation; and

(iv) The utility of this $50 \mathrm{kWh}$ can be increased by using efficiency lighting interventions and other energy saving initiatives" (DME 2003: 8-9).

When the EBSST policy was first implemented, households were expected to buy electricity for the minimum amount before they could be given their free electricity units $(50 \mathrm{kWh})$. With time it was realised that this was a barrier for some households as in some months they did not have enough money to even buy electricity for the minimum amounts.

The South African Local Government Association (SALGA) indicated that as of January 2012, out of 278 municipalities in the country, 243 have signed a formal free basic electricity provision with Eskom (SALGA: 2012) which indicates that a large number of households benefit from this subsidy. Municipalities implement this policy in different ways. One that is most common is where a municipality gives all households consuming $400 \mathrm{kWh}$ or less a month the $50 \mathrm{kWh}$ as it is believed that low consumers do so because of their inability to afford higher electricity consumption. Although this may be true for some cases, it does not always reflect the true picture of the households' circumstances. For instance, a household may be consuming 400kWh of electricity or less not because it is poor or cannot afford to buy more electricity, but because its occupants do not require to use a lot of electricity. On the other hand, many impoverished households with more occupants may be consuming more electricity because of the household size but may fail to qualify for EBSST as their consumption may be more than $400 \mathrm{kWh}$ per month. Many well established and self-supporting municipalities opt for a blanket approach when implementing the EBSST policy as it is much easier to manage than to identify and pre-select indigent households amongst their consumers. 
In a longitudinal study conducted by the Energy Research Centre at the University of Cape Town on behalf of Eskom and the Department of Minerals and Energy (DME), it was discovered that the low-income households did indeed benefit from the free electricity units (50kWh) provided to them. In the report (ERC 2003: 4-5), the households benefits included the following:

1. Households were using more electricity in the form of lighting and appliances which had been on the decline before the implementation of the EBSST policy;

2. The households' energy expenditure was significantly reduced and this was not only for electricity but also for other energy sources used such as paraffin;

3. Households reported that that the free electricity allowed them to spend their money on other household priorities such as food. The free electricity also had other benefits for household members such as children being able to use electricity lighting for longer than paraffin lamps to do their school work and for household members using appliances such as radio and television for longer;

4. The monitored consumption of electricity by households in the study showed an increase from an average of $29 \mathrm{kWh}$ to $60 \mathrm{kWh}$ per month after the implementation of the EBSST policy.

Although these low-income grid electrified households benefited from the implementation of EBSST policy, there was still a significant number of households in the country that were still living in energy poverty. These are households that were located in the remote rural areas without any grid electricity supply. These households were still using poor quality energy sources such as wood, cow-dung and paraffin and had still not received any energy subsidies or free energy services from the government's programme. 
The next section focuses on the introduction of the Free Basic Alternative Energy (FBAE) policy which was introduced in response to the realisation that households without access to grid electricity were doubly ${ }^{22}$ disadvantaged as they did not receive any energy subsidies or free energy services.

\subsubsection{Free Basic Alternative Energy (FBAE) policy}

The FBAE policy was introduced in 2007 by the Department of Minerals and Energy (DME) as an intervention by national government to ensure delivery of alternative basic energy services aimed at alleviating energy poverty for rural households without grid electricity in South Africa (DME 2007: 7). The objectives of the FBAE policy are stated as follows:

- "to facilitate the provision of basic energy needs to indigent South African households that do not have access to (grid) electricity;

- Where possible, to address a whole suite of socio-economic issues that arise from inadequate provision of energy to households, inter-alia, job creation, etc;

- To minimize health risks by promoting safe use of these energy carriers;

- To ensure that energy carriers chosen are sustainable, safe and easily accessible to the indigent households; and

- To maximize efficient use of energy carriers for the benefit of all citizens" (Department of Minerals and Energy 2007:8)

Chapter two of the FBAE policy document outlines how its implementation should take place as seen by the Department of Minerals and Energy. Funding for successful implementation is seen as critical and should be

\footnotetext{
${ }^{22}$ Doubly disadvantaged because they did not have access to grid electricity which meant they could not access the 50kWh per month as part of the EBSST subsidy.
} 
allocated by the Cooperative Governance and Traditional Affairs (CoGTA) department through the Equitable Share Grant allocated to all municipalities for free basic energy services. The local municipalities should ensure that indigent households benefit from the implementation of this policy through a process of clear and transparent identification. The chapter also outlines the procedures that should be followed by local municipalities in identifying areas that are supposed to benefit from FBAE implementation such as those households far from the electricity grid. According to the implementation guidelines, municipalities are supposed to select suitable energy carriers to be funded and 'delivered' to indigent households whilst taking care that these are safe, accessible, affordable and sustainable.

The responsibility of conducting awareness campaigns about the chosen energy carriers is given to the municipalities 'to inform the beneficiaries on how best to apply them" (DME, 2007: 10). Further to this, municipalities are also expected to ensure that the supply chain for these energy carriers is efficient. In this instance, municipalities can act as service providers if they have the necessary capacity or they can appoint suitable service providers by entering into 'Service Delivery Agreements'. Lastly on implementation of FBAE policy, the municipality must take charge of monitoring the process by verifying the lists of indigent households from time to time and submit these to CoGTA. As part of the monitoring process, the national government will also monitor the implementation of the FBAE policy to measure 'cost effectiveness and quality of services' delivered to the beneficiaries.

Since the municipalities are tasked with administering and providing FBAE subsidies to indigent households within their jurisdiction, one of the strategies that they use to indicate their intentions to implement FBAE is to add these policy's goals to their Integrated Development Plans (IDPs). IDPs are five-year plans that each municipality in South Africa is required to develop according to the Municipal Systems Act of 2000 (Section 35) and they are a method to plan future developments for their areas (Education and Training Unit 2011). IDPs are considered 'super-plans' for an area and give an overall development framework. These plans are reviewed annually 
by the municipalities and its stakeholders including communities who will impact or benefit from such plans. The main aim of having IDPs for municipalities is to coordinate work planned for the municipality with that of the other spheres of government to ensure better quality of life for people living within these municipal areas ${ }^{23}$. Together with coordinating with other spheres of government, IDPs are meant to ensure that that the following happens:

- Effective use of scarce resources by the local municipality;

- Speed up delivery of services especially in the least developed areas such as the remote rural areas;

- Strengthen democracy by ensuring that ordinary citizens participate in decision making in a transparent manner;

- To overcome the legacy of apartheid through providing much needed basic services to previously disadvantaged areas such as the remote rural areas; and

- To attract necessary funds to the municipality from national government and private investors.

Since the publication of FBAE policy, very few local municipalities have been able to implement it successfully, that is, they have not been able to deliver alternative energy services to all indigent households in the rural areas. The latest figures from CoGTA indicate that only 40 local municipalities out of 226 have been able to implement this policy. In the Eastern Cape, according to the provincial department of Local Government and Traditional Affairs, in 2012, there were 14 local municipalities implementing the FBAE policy ${ }^{24}$. This figure includes all five local municipalities under the OR Tambo District where this study is based. In the descriptive chapters in this thesis, I discuss how the implementation of this policy is taking place in these local

\footnotetext{
${ }^{23}$ http://www.etu.org.za/toolbox/docs/localgov/webidp.html

${ }^{24}$ Information based on face-to-face interview with this department's representative on 04 June 2012.
} 
municipalities and analyse the influence of actor characteristics on the policy implementation process.

The implementation of Free Basic Alternative Energy (FBAE) policy is underresearched in South Africa. A documented study conducted by Borchers and Dobbins (2007) in the South African low-income urban areas where the FBAE policy was implemented revealed the following:

1. There is a need for local municipalities to be more effective in identifying the FBAE target group. There is no formal standard procedure of identification and each municipality has their own set criteria.

2. Funding for FBAE policy implementation needs to be properly allocated by national and local government. Currently, funds for FBAE policy implementation are not ring-fenced and municipalities do not necessarily have to make a commitment to provide these subsidies to indigent households.

3. There is a need to build capacity of implementing agencies. Local municipalities and service providers appointed to deliver basic energy services to indigent households as part of the FBAE implementation do not have enough capacity to do so. 'Capacity' may refer to funds and lack of knowledge on the appropriate procedures to follow when implementing such a policy.

4. Lead departments need to take lead responsibility. The national government as the main policy maker and funder of policy implementation needs to take charge and ensure that local municipalities implement the FBAE policy accordingly.

5. There is a need to regulate the price of alternative fuels. Alternative fuels such as paraffin vary in price as they are not properly regulated by government regulatory bodies in the most impoverished areas. Overall, paraffin is one of the most expensive fuels used by low-income households as retailers put a high price mark-up to make profits which puts the poor at a further disadvantage and exacerbates energy poverty. 
6. The is a need to investigate and regulate distribution networks of alternative fuels. Paraffin, alternative fuels (such as gel-fuel), wood, LPG and coal vary in prices throughout the country due to non-regulation.

Although the above-mentioned study focuses on FBAE policy implementation, its primary focus is on local municipalities as the main actors and neglects to include target actors and other stakeholders as active participants in the implementation process. This thesis fills that gap.

The above background of the FBAE policy provides information on why and how this policy came into being and its role in South Africa where energy service provision is concerned. Describing this policy also illustrates how policy processes in the country were and still are influenced by the inequalities in society. This thesis, as mentioned above, will show how the FBAE policy has been implemented in the five local municipalities under the OR Tambo district, the significance of the actor characteristics in the implementation process and provide recommendations based on the scientific analysis of the results.

\subsection{Conclusions}

South Africa is country that has gone through and survived a challenging transition. In fact, the transitioning process is still ongoing and changes according to the different circumstances that the country experiences from time to time. It was clear from the beginning of the 1990s when the democratic government came into power that the focus and the government mandate would change to include the majority of the South African society, which were previously left behind by the apartheid government.

The White Paper on Energy Policy of 1998 is one of the cornerstones of the South African democracy and it has provided the government a platform to come up with sub-policies such as the Electricity Basic Support Services Tariff (EBSST) and the Free Basic Alternative Energy (FBAE) policy. These aim to provide the South African citizens with energy services, especially 
those living in low-income areas and experiencing energy poverty. The formulation of such sub-policies was also influenced by the fact that the implementation of the Energy Policy of 1998 presented the government with difficulties in meeting their original goals. The sub-policies give the government an opportunity to specifically focus on an issue such as the delivery of alternative energy services to low-income households instead of having various policy issues in one document. From Chapter 5 onwards, this thesis will analyse how the local municipalities in the OR Tambo district have been implementing the FBAE policy. 


\title{
Chapter 3: Using the Contextual Interaction Theory as a theoretical framework
}

\begin{abstract}
"Policy failures continue to be prominent, and evidence of implementers' desires to be informed in appropriate ways by the research community suggest that many implementation conundrums remain salient in the world of action" (O'Toole 2000: 265).
\end{abstract}

\subsection{Introduction}

Policy implementation is the main focus of this thesis. It is therefore appropriate to look at policy implementation studies a little closer in order to locate this study's most suitable theoretical framework. This chapter discusses policy implementation from different perspectives through various literature references that explain the different approaches to policy implementation studies. The chapter's main focus turns to the Contextual Interaction Theory (CIT) and makes a case of why this theoretical framework is the most suitable for application in this study.

\subsection{Policy implementation}

In simple terms, implementation is a process of putting a decision or plan into action. Hill and Hupe (2002: 7) refer to implementation as "the stage in the policy process concerned with turning policy intentions into action" and a comparison between the expected and the achieved. Owens (2008) refers to this comparison as an acknowledgement of the dynamic nature of the policy implementation process . In policy studies, policy implementation has been closely scrutinised and written about for decades. The starting point for many being Pressman and Wildavsky (1973) who wrote that implement is simply "to carry out, accomplish, fulfil, produce and complete" (1973: xiii-xv). According to Mazmanian and Sabatier (1983: 2021), "implementation is the carrying out of basic policy decision, usually incorporated in a statute but which can also take the form of important 
executive orders or court decisions. Ideally, that decision identifies the problem(s) to be addressed, stipulates the objective(s) to be pursued, and in a variety of ways, structures the implementation process". In his later writing, it is interesting to note that Sabatier (1999) argues in favour of dropping the stages heuristic as a model of policy studies which he considers ineffective to explain the course of policy processes.

Nevertheless, this chapter will emphasize the importance of concentrating on the implementation process in order to understand how and why the Free Basic Alternative Energy (FBAE) ${ }^{25}$ policy is implemented the way it is in this thesis study areas.

Policy implementation is the ability to forge subsequent links between programs and 'authoritative' action (Brynard 2005) and according to Bressers (2004) - it is a process of turning focused but general input (policy) into a number of diffuse but specific outputs. De Boer and Bressers (2011) write that implementation is a multi-actor process where the implementers and target groups determine the course and results of the process. The authors continue and state that these interaction processes are human interaction processes between actors and include policy implementation management and project realisation. This is in line with O'Toole (2000) who states that to understand implementation requires the recognition of the multi-actor character of policy action. According to O'Toole, policy implementation research that ignores implementation actors, misses out on information regarding what really happens (O'Toole, 2000: 269).

\subsubsection{A summary of the three generations of implementation policy research}

Policy implementation is not a simple process. In an attempt to understand how policy implementation works, it is also important to focus on why policy implementation fails. Failure of policy implementation is relative and

\footnotetext{
${ }^{25}$ FBAE policy implementation is the main focus of this thesis. The subsequent chapters provide an analysis of how this policy is implemented in the rural areas of South Africa.
} 
depends on a number of factors. In implementation studies there are three generations of implementation research that shape the policy implementation studies field. The first generation studies are often referred to as top-down studies as illustrated by the work of Pressman and Wildavsky (1973). The researchers analysed the implementation of a regional employment programme and came to the conclusion that amongst other things, implementation has failed due to poor policy planning. This generation of research assumed that implementation should happen as pure application of earlier decisions and "consisted primarily of solitary case studies featuring negative reports of the way governments implement their own programs" (Owens 2008: 38). This work was seen as having a topdown perspective where policy making was assumed to be automatically followed by (successful) policy implementation. The first generation of implementation studies can also be likened to what Elmore (1979) refers to as forward mapping which assumes that implementation is controlled from the top and stresses factors that emphasize control such as funding formulas and authority relationships. The theory of forward mapping also "assumes that, the closer one is to the source of policy, the greater their influence and authority" (1979: 604).

Goggin et al (1990) state that "the first generation studies have been criticized for being atheoretical, case-specific and noncumulative. They have also been accused of being overly pessimistic... (but) they served several valuable purposes" (1990: 13). According to Goggin et al, the valuable purposes served by the first generation research included:

- shifting the focus and showing how a law becomes a program,

- demonstrating the complex and dynamic nature of implementation,

- emphasizing the importance of policy subsystem and the difficulties that a subsystem creates for coordination and control,

- identified a number of factors that seemed to account for programmatic results which usually fell short of expectations, and

- diagnosed several treatable pathologies that periodically plague implementing actors 
In his analysis of top-down implementation approaches, Sabatier (1986) makes it clear that "the essential features of the top-down approach are that it starts with a policy decision by governmental (often central government) officials and then asks:

1. To what extent were the actions of the implementing officials and target groups consistent with the policy decision?,

2. To what extent were the objectives attained over time i.e. to what extent were the impacts consistent with the objectives?,

3. What were the principal factors affecting policy outputs and impacts?, and

4. How was the policy reformulated over time on the basis of experience?

These are valuable purposes indeed as they are still relevant in the current implementation discourse and have been integrated in the second and third generations of policy research as will be illustrated in this thesis.

The second generation of implementation research moved to an analysis of comparative case studies, unlike the solitary case studies that were analysed by the first generation researchers. As observed by Sabatier (1986), the second generation of implementation research started in the late 1970 s to the early 1980 s where "the bottom-uppers started with an analysis of the multitude of actors who interact at an operational (local) level on a particular problem or issue" (1986: 22). This focused on the strategies pursued by various actors with the aim of fulfilling their objectives. Here the efforts were focused on setting out to record and illustrate the complexities of implementation processes and to show that just because a policy is in existence, it should not be taken for granted that it will be implemented. The second generation of policy research also "featured an increase in comparative analysis" seeking to clarify differences 
in the success of policy implementation through a focus on precise variables and theoretical frameworks, generally upholding the top-down perspective of first generation work (Sabatier, 1986).

Goggin et al (1990) see the second generation of policy implementation research as having contributed uniquely to "the development of analytical frameworks to guide research on the complex phenomenon of policy implementation" (1990: 14). Unlike the first generation of research, the focus here was not only on policy outcome (such as whether the policy implementation process is successful or not) but also on the social interaction. This bottom-up approach emphasizes the role of the smallest actor in the implementation process all the way to the top (Elmore 1979, Barrett 2004 and Lipsky 1980). Lipsky's (1980) work on Street Level Bureaucrats is a near perfect example of a bottom-up approach in policy implementation studies. The study illustrates how civil servants at the lower levels implement policies according to what they think is best, and not according to the directives from the top. This is not as a result of defying authority or going against the rules set by those on top, instead, it is a way in which actors at the bottom cope with the implementation of policies that are otherwise out of their scope because of the way they are planned. As Winter (2003) observes, "the discretionary role in delivering services or enforcing regulations makes street level bureaucrats essential in implementing public policies " (2003: 214). Walker and Gilson (2004) use the street level bureaucrats framework in a study conducted in South Africa where they investigate "how a group of nurses based in busy primary care health clinics experienced the implementation of the free care (the removal of fees) and other South African national health policies introduced after 1996" (2004-1251). Similar to Lipsky's study, Walker and Gibson (2004) also come to a conclusion that civil servants faced with policy implementation use their discretion based on their views and values.

Van Meter and Van Horn (1975) highlight the "systems model of implementation" in which they show that there is more to what influences the performance of a programme or a policy than separate factors. In their list of such factors or influences they include: policy standards and 
resources; support for policies in a political environment; economic and social conditions; characteristics of implementing agencies; communication of policy standards; incentives to promote compliance and policy dispositions of implementing officials. These highlight the importance of giving consideration to the contextual conditions in the policy implementation process. This leads us to the third generation of implementation research and how it combines both the top-down and the bottom-up approaches.

The third generation implementation researchers see implementation as an ongoing process, regardless of the result. The proposal by Goggin et al (1990) for implementation research to "shed new light on implementation behaviour by explaining why that behaviour varies across time, policies and units of government" has largely led to the scientific studies on the third generation of implementation research. Bressers (2004) writes that ad-hoc explanations do not capture the essence of why policy implementation fails and are often incomplete and insufficient in telling and explaining the whole story (2004: 287). The third generation was (still is) about understanding how implementation works and how it can be improved and it includes both the top-down and the bottom-up approaches. Brynard (2005) states that "the realisation of the absence of (and the need for) causal understanding, organizing frameworks, conceptual models, analytical approaches, and explanatory and predictive theories ushered in the third generation of thinking on implementation" (2005: 652-653). In his analysis of the Advocacy Coalition Framework (ACF), Sabatier (2005) presents the synthesis of the top-down and bottom-up approaches where the time factor is taken into consideration. The elements of the ACF framework consider the "policy problem or subsystems rather than law or other policy decision" as to be consistent with the bottom-up approach. The concerns of the top-downers are also incorporated such as the "legal and socioeconomic factors" (Sabatier, 2005: 26). In summary, the synthesis combines the bottom-up unit of analysis, which is the variety of actors involved, as well as the top-down concerns such as the socio-economic conditions and legal instruments and how these affect the implementation process. 
Another synthesis approach has been proposed by Hull and Hjern (1987) referred to as an "inductive approach to match outcomes of politics and their intentions". The authors make some recommendations. They recommend "a systematic interview analysis of relevant actors from the bottom to the top; mapping of implementation activities and structures; evaluation of the purposes of the relevant laws and their achievement; actors' opinions on the implementation process as well as an analysis of how various policies contribute to solve the policy problem in question" (Winter, 2003: 215).

This thesis uses the Contextual Interaction Theory (Bressers 2004, 2009) as its theoretical framework. To a certain extent this study combines both the second generation and the third generation of research in policy implementation. The second generation of research in implementation is illustrated by the identification of Free Basic Alternative Energy (FBAE) policy implementation failures as well as showing complexities related to the implementation of this policy. The cases are studies on the basis of the actual behaviour and the variety of factors influencing this. The third generation of implementation research in this study is illustrated by using the CIT variables (also referred to as the actor characteristics) to understand how FBAE policy implementation works and how it can be improved. By using CIT, this thesis addresses the need for causal understanding while using an analytic approach and applying an explanatory and predictive theory.

\subsection{The Contextual Interaction Theory}

\subsubsection{A brief history of the Contextual interaction Theory (CIT)}

Since its first formulation in 1983, the Contextual Interaction Theory (CIT) has gone through a number of phases that have contributed to its current framework form and its application. Initially, this theory was referred to as the policy instrument theory and used by Bressers and Klok (1988) to "assess and causally link the connections between multiple inputs and 
outputs in a multi-actor process" (Owens 2008: 43). As De Boer (2012) and Owens (2012) observe, CIT has been refined and improved through various work conducted by Bressers and others over the years. The earlier versions of the theory includes works by Bressers and Huzen (1984) where they focus on a political approach to governance instruments. Bressers and Klok (1988) used the theory with a focus on fundamentals for a theory of policy instruments. Earlier versions of the theory also include work by Bressers and Ringeling (1995) as well as by O'Toole (2000). Over the years, the theory has provided a platform for academics to build on theoretical concepts provided by CIT, empirically apply it and further its methodological development. CIT has been used by various scholars on studies with a focus on policy implementation. Researchers such as Bressers (2004); Owens (2008); Spratt (2009); Evers (2011) and De Boer (2012) have all used this theory with the intention of finding out why policy implementation takes a particular direction to what is intended. Some of these researchers have also used this theory as a predictive tool to determine how policy implementation will take place under certain circumstances.

Some examples of the more recent studies that have used CIT as the theoretical framework include Vinke-de Kruijf (2013) who in her thesis focused on how the actors' characteristics, interactions and contextual factors shape the process and outcomes, and influence the effectiveness of international water projects that involve the transfer of knowledge.

Kotzebue (2012) has used the CIT to analyse how EU policies spatially misfit with the place of implementation. The study makes an observation that "the place affects the motivation, perceptions and capacities of implementing actors and the outcomes of implementation processes. During the implementation processes, characteristics of the place can change, especially when the process has a long duration" (2012: 28). Although not an area of deep focus in this thesis, the place is indeed important when considering whether or not the policy being implemented is suitable for the context of application. 
Özerol (2013) on the other hand has used CIT, in conjunction with other theoretical frameworks, institutional resource regime (IRR) and the institutional analysis and development frameworks (IAD), to study the alignment of multiplicities in natural resource governance. The use of CIT in her thesis, provides Özerol with the actor-based conceptualisation of the policy process while the other two frameworks provide an institution based approach.

Some of the stages that the Contextual Interaction Theory (CIT) has gone through have produced valuable contributions to the way policy implementation theoretical frameworks are used. The basic assumption of $\mathrm{CIT}$ is that 'the course and outcomes of the policy process depend not only on the inputs (characteristics of the policy instrument), but more crucially on the characteristics of the actors involved, particularly, their motivation, interaction and power' (Bressers 2004). The emphasis of CIT lies on the social interactions and how they influence the policy implementation processes which are determined by actors and their core characteristics (Bressers 2004, 2009). Figure 3.1 demonstrates the CIT process model with the actor characteristics.

\section{Arena:}

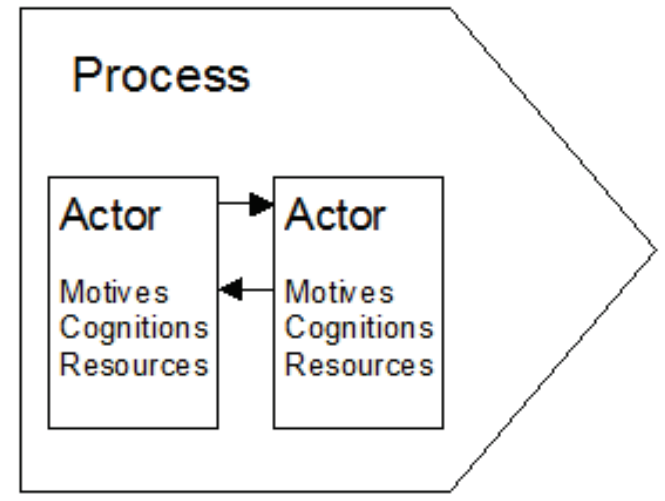

Figure 3.1: Process model with the actor characteristics used in Contextual Interaction Theory

Source: Bressers (2004) 
This theory further acknowledges that policy implementation is an interaction process and motivation, information and power (as actor characteristics) give a critical explanation regarding this process (ibid). The theory assumes that the policy implementation process is not only about achieving implementation, but also about attempts to prevent implementation or to change the character of what is implemented.

The study by Owens (2008) illustrates that 'the strengths of using the theory $[\mathrm{CIT}]$ include its capability to create clear hypotheses for the manner in which actor characteristics influence implementation process and results' (2008: 59). According to Owens, the theory is a consistent tool to analyse implementation processes and allows for replication of the research. Owens (2008) concludes in her analysis that CIT is a "deductive, parsimonious and a realistic theory that can be useful in analysing policy processes"(2008: 42).

\subsubsection{The flow chart two actor model and its applications}

According to Bressers (2004), implementation can be differentiated as to whether there is any implementation at all and whether the implementation is adequate to satisfy the policy aims. Bressers (2004) further explains that "some envisaged implementation never take hold at designated sub-levels, sectors or local sites and some never really get started at all" (2004: 289). Where adequacy of implementation is concerned, CIT focuses on whether the "instrument being applied supports the intended policy incentives" (ibid).

The Contextual Interaction Theory in analysing policy implementation processes uses three core actor characteristics namely motivations, cognitions and power. Bressers' (2004) defence of using these core variables is that they are recognised as critically explanatory variables regarding implementation processes. Of course there are other variables that can be used to explain the implementation processes in policy studies as has been demonstrated by O'Toole (1986: 185-188) where he documents multi-actor implementation studies that use "variables viewed as important 
in the implementation literature". Owens (2008) found the compilation of these variables useful in explaining her choice of using $\mathrm{CIT}^{\prime}$ 's variables to explain interactions. She writes that the CIT variables are "the most valuable points of analysis of actor characteristics" (2008: 44).

In an attempt to demonstrate the likelihood to implement (see Figure 3.2), CIT considers the combination of different core variables and how they influence the kind of implementation that will occur. "The theory attempts to capture the variation here by making a distinction between three types of interaction: cooperation (active, passive or forced), opposition, and joint learning" Bressers (2004: 291). On the other hand, in demonstrating the adequacy to implement using CIT, "a distinction is made between: 'constructive' and 'obstructive' cooperation; 'negotiation' and 'conflict' (opposition); and 'symbolic application', often accompanied by learning (2004: 293).

A strong point of these models is that they are providing an explanatory (and predictive) hypothesis. A restriction is that the models have a twoactor structure, which does not always adequately represent the actual implementation situation.

\subsubsection{The multiple contexts model and its applications}

One of the main qualities of CIT is that it is a theory that provides a systematic framework for factors that affect the ultimately decisive variables. The theory considers that the three actor characteristics (motivations, cognitions and power) are "not only intrinsic to the actors and influenced by the process, but are also influenced by many external factors from a multi-layered context" (De Boer, 2012: 28). To highlight the importance of context, Vinke-de Kruijf (2013) found "an analysis of actor characteristics provides a deeper understanding of the process, but is of limited use if not complemented with descriptions of the process and its context" (2013: 146). 
$\sum_{\substack{0 \\ 0}}^{0}$

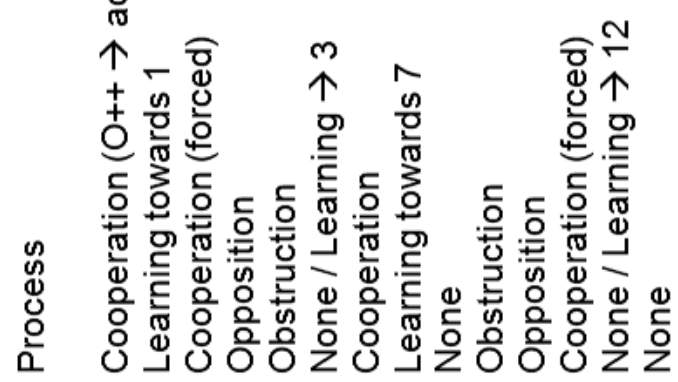

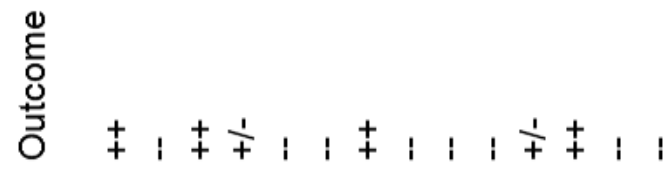

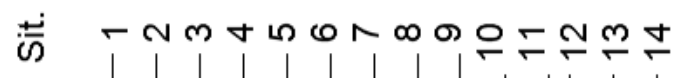

든드응 응

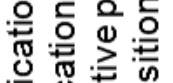

응 응

응응은 튼

ำ 은는 은

Nㅗ은

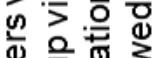

产 을 苞

은 응학

응

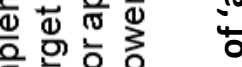

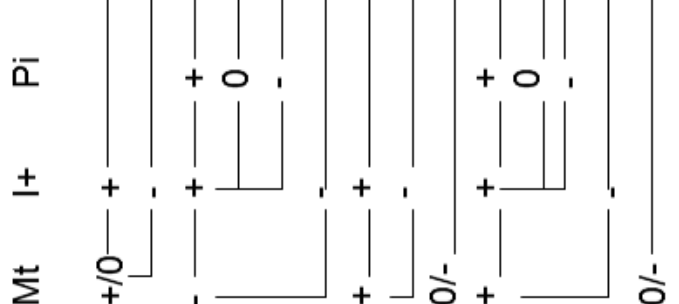

눙응

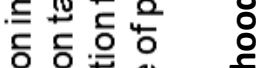

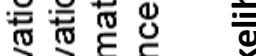

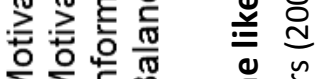

$\sum \sum$ 它 品

" " " "

$\ddot{\sim}$

$\bar{\Sigma} \bar{\Sigma} \pm \bar{a}$

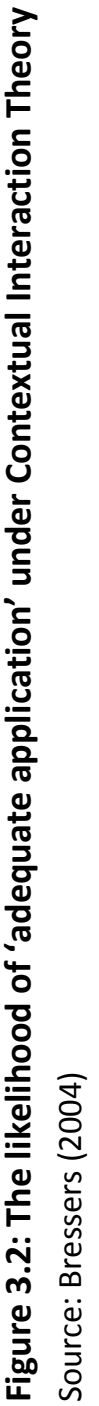




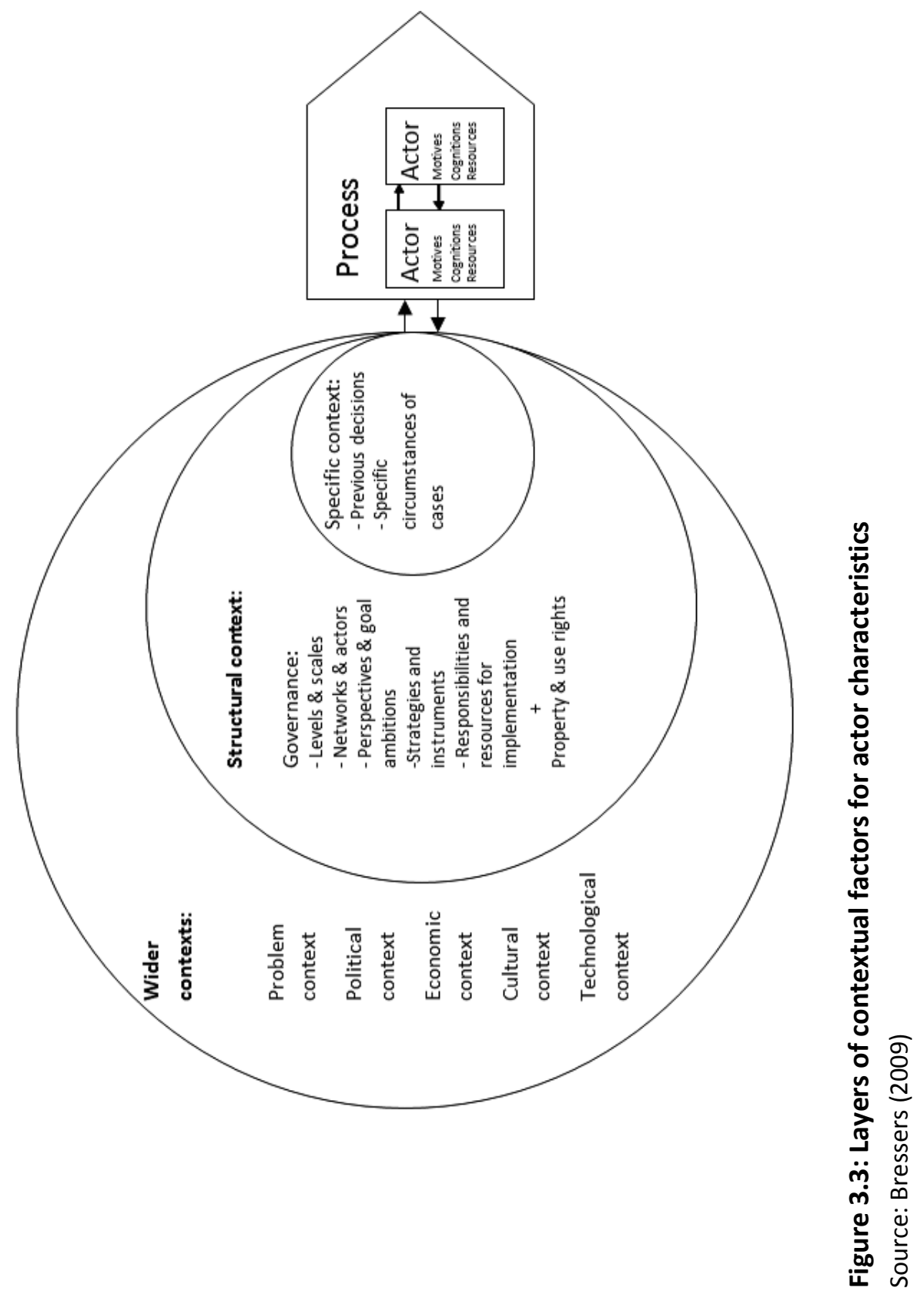


As Figure 3.3 illustrates, context is separated into three parts for better analysis. The first part is the specific context which involves factors such as the characteristics of the geographical place where the project is taking place. In this context it is where previous decisions and the specific circumstances of the particular policy implementation study are to be considered. The structural context on the other hand is made up of multilevel and multi-actor aspects of modern governance (Bressers 2009). These aspects according to Bressers can guide, to some extent, the motivations of the actors in the process, but also serve as a pool of resources they can try to get access to and use for their purposes (2009: 14). The wider context aspects are seen to exert their influence in an indirect way but do affect and influence actor characteristics to a certain extent. While the multiple context (including the governance context) model adds very useful second, third and further order explanatory factors to the model, all of these factors ultimately exert their influence via the stipulated actor characteristics.

\subsubsection{Capturing the interaction of actor characteristics}

One of the ways that $\mathrm{CIT}$ is applied is through the use of the dynamic interaction framework. As Bressers (2009) clarifies, "the actor characteristics are much more elaborated here, not visualised as linked to specific actors and for presentation reasons placed outside of the process box. This enables also to show the mutual influences between these factors and the process itself" (Bressers 2009: 132).

Figure 3.4 shows the actor characteristics and the interaction process that takes place as well as showing how these actor characteristics influence the interaction process and each other. This thesis uses this model extensively in showing how actor characteristics influence the policy implementation process and how they in turn influence each other. This model of CIT also allows the thesis to focus on each individual case and at the end make a comparison of the processes in each case to draw the results and make recommendations. Paying attention to the way the three groups of actor characteristics influence each other makes the explanatory model much 
more dynamic and potentially helpful to understand the development of the process over time.

In Figure 3.4, the motivations box shows the types of actor motivators which include an actor's own goals and values, external pressure and selfeffectiveness. An actor's own goals and values are what the actors aim to achieve concerning the policy in the implementation process. External pressure may refer to the pressure that actors have to implement a policy this can be political, social and other types of pressure depending on the context. Self-effectiveness refers to the actors' measure of their own ability to do a task and "points to the demotivational effect that can occur when an actor perceived its preferred behaviour as beyond its capacity" Bressers (2009: 132).

In this theoretical framework, the cognitions include information, frames of reference, interpretations and observations of reality (Bressers 2009). Spillane (2000) states that "cognitive theory suggest that people use their prior knowledge and experiences to construct new understandings" (2000: 146). This way the implementer not only processes the information received from the policy but other information and knowledge from previous experiences and situations. The Advocacy Coalition Framework (ACF) on the other hand "assumes that actors perceive the world through a set of beliefs that filter in information consistent with pre-existing beliefs and filter out dissonant information" (Sabatier 2005: 28). In this thesis, cognitions refer mainly to information and knowledge and to some extent, to the frames of reference and how these influence the implementation process. 


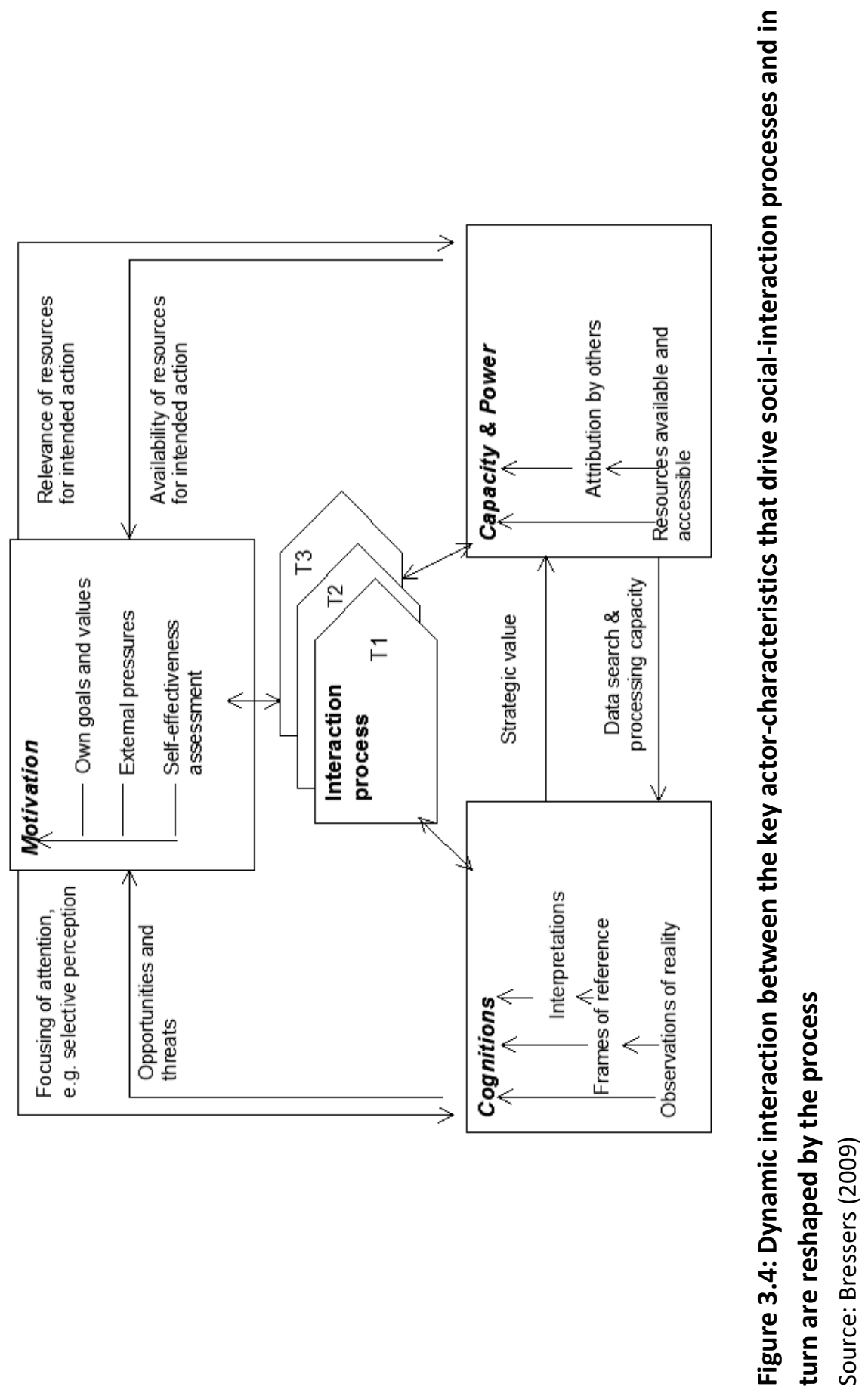


Capacity and power in the multiple relations actor-characteristics model on Figure 3.4 refers to the capacity that is provided by the resources to enable the actors to carry out the implementation process. On the other hand, "power is largely a result of attribution to an actor by others" (Bressers 2009). It is also important to note as Bressers mentions that where this attribution of power is not backed by real resources it is far from stable [and this negatively influence the interaction process]. Between these three groups of factors strong relations exist, that however do not cause the factors to group into one or two, but show their internal dynamics.

Even though the graphical model pays attention to the interaction between the key-actor characteristics, they were never before really used in empirical research to create a more holistic view of the implementation situation.

\subsection{Using the CIT framework for this study}

As discussed in the previous sections, the Contextual Interaction Theory combines both the top-down and bottom-up approaches of implementation research. This makes it a favourable theoretical framework to apply to a study concerned with the policy implementation process that seeks to find out how actors at different levels influence the process.

The CIT framework's focus on the three actor characteristics and how they influence the policy implementation process through their interaction makes it possible to focus on the most relevant variables to explain the interaction process. As Owens (2008) observes, "the theory is receptive to external elements" which can be channelled through the three core variables (2008: 42).

"It is important to note that these variables are not arbitrarily chosen as three important variables among others, but because they have high explanatory power; in essence because they are variables at the core of the interaction processes" (ibid). 
Although the use of such few variables to analyse policy implementation may be seen as parsimonious, it is advantageous as it allows the analysis to focus on the key areas that are most relevant in an interaction process.

The CIT framework also allows this thesis not only to focus on the actor characteristics, but also on the context, in particular, the structural context and the wider context. The structural context consists of elements of governance and the relevant property and use rights (Bressers 2009). It is within this context that an analysis of how multi-level governance influences the policy implementation process. Taking this context into consideration ensures that all elements influencing the policy implementation process are analysed to provide an explanation of the observed results. As expressed by Vinke-de Kruijf (2013), "an analysis of actor characteristics provides a deeper understanding of the [interaction] process, but it is of limited use if not complemented with descriptions of the process and its context" (2013: 146). On the other hand, the wider context consists of elements of problem, political, economic, cultural and technological contexts ${ }^{26}$ (Bressers, 2009). Although this context is not the main focus in this thesis, the political and economic contexts will be acknowledged as playing a role in the influencing of the interaction process.

\subsubsection{Using CIT in a developing country context}

In a literature review study by Saetren (2005) where he seeks to dispel some myths about the origins and nature of implementation research, it is found that "the overall regional bias of implementation research is quiet strong" (2005: 571). The results show that out of all research on implementation, "if Europe is included, then the Western hemisphere accounts for close to 90 percent of all publications [on implementation research]" (ibid). The results also show that although the implementation research has broadened, Asia, Africa, Latin America and Oceania are not studied as much as the West ${ }^{27}$. One of the consequences this 'bias' leads to

\footnotetext{
${ }^{26}$ See Figure 3.3

${ }^{27}$ The West in this context refers to Western Europe and North America.
} 
is that theoretical frameworks in implementation research are often developed to suit the Western contexts. Another consequence is that implementation failure in developing countries is often too easily and onesidedly attributed to lack of resources or corruption, while also other factors might be influential.

Since its development, the Contextual Interaction Theory has been used mainly in studies analysing policy in the environmental context and focusing on sustainable development in Western countries. In the recent years, studies by Spratt $(2009)^{28}$ and Javakhishvili and Jiblaze $(2013)^{29}$ have applied this theory without a focus on the environmental contexts. Similar to Spratt (2009), this thesis applies CIT in a developing country context but with a focus on the dynamic interaction between key actor characteristics. Spratt's study enhanced the CIT framework by including a gender perspective and a use of network mapping. To explore the "face validity" of $\mathrm{CIT}$, Spratt conducted semi-structured interviews related to motivation, information and collaboration. Spratt found that "the key variables of the CIT had face validity in all three countries" (Indonesia, China and Vietnam) (Spratt, 2009: 1). Collaboration in this case refers to a successful relationship with another organisation to implement a policy. This thesis will also test CIT's face validity by analysing data collected through in-depth interviews with actors involved in the implementation of the Free Basic Alternative Energy policy.

In South Africa, when applying the Contextual Interaction Theory to the cases analysed in this thesis the unique issues that shape the South African society had to be kept in mind as these influence the policy implementation process and are part of the actors' motivations, cognitions and capacity / power. Brynard (2005) and Khosa (2003) observe the impact of country's apartheid past and how it has shaped and influenced the period of transition in policy making and implementation. After 1994, the South African government's focus shifted to service delivery in order to provide

\footnotetext{
${ }^{28}$ Using CIT to identify HIV policy implementation barriers in three Asian countries. ${ }^{29}$ Using CIT on a study focusing on actors implementing the anti-domestic violence policy
} 
for those that were disadvantaged by the apartheid government's rule. Policies that were drawn by the new government were target driven in terms of the number of households to be provided with basic services such as electricity, water, housing and sanitation. One of the policies produced by the democratic government in 1994 is the White Paper on Reconstruction and Development better known as the Reconstruction and Development Programme (RDP) policy. This policy document was the initial step where the government outlined all the services that need to be provided in order to eradicate the inequalities of the past. It is also a document that gave rise to the policy making dialogue in the country for various ministries to draft their policy goals and work towards implementation of these.

Applying the Contextual Interaction Theory to analyse the implementation of a policy that seeks to provide basic services aimed at alleviating the effects of energy poverty is a new domain of application. This challenges the CIT theoretical framework's flexibility and tests its adaptability to such an environment. This thesis illustrates CIT's flexibility particularly by adding a third actor to a traditionally two-actor theoretical framework. Using this theoretical framework to analyse a South African policy aimed at providing services for the poor also expands the use of the theory by not only focusing on the contextual factors such as the specific context, structural context and the wider context. Instead, this thesis study gives even more importance to the CIT core variables namely motivations, cognitions (information, knowledge and frames of reference) and capacity and power. The study recognises the importance of such actor characteristics and how they influence the FBAE policy implementation process whilst they influence each other as well. Concentrating on the interaction of these actor characteristics has also made it possible to explore the underlying issues influencing the policy process. This takes the policy analysis process a step further as obvious issues such as lack of funding, capacity and resources are no longer the only issues blamed for lack of providing alternative energy services through the FBAE policy. 


\subsubsection{Definition of concepts}

For clarity, it is important to define the CIT concepts as adapted and used in this thesis. In Table 3.1, I define the variables: motivation, cognitions and resources and power as adapted from Bressers (2004, 2009); Owens (2008); De Boer and Bressers (2011) and Vinke-de Kruijf (2013) . I also define the concepts that I use in the structural context where I analyse the multi-level governance influence on policy implementation in my cases and make a brief reference to the wider contexts.

\subsubsection{Adding and highlighting the third actor}

This section introduces the third actor to a traditionally two-actor theoretical framework. It justifies why in the context of this study it is important to acknowledge the importance of the third actor and to realize their contribution to this particular policy implementation process.

In her study on policy implementation in wetland restoration, Owens (2008) acknowledges that wetland restoration projects often involve multiple actors and she warns that "it is important to be aware of this circumstance and to contemplate before-hand how this might affect the two-actor model found in the Contextual Interaction Theory" (2008: 64). In her research, she makes a decision to include multiple actors but "apply the theory to cases with the ex-ante assumption that within each case, actors can be divided along meaningful lines into actors supporting either a target or implementer perspective for a given issue" (ibid).

With his analysis of the Advocacy Coalition Framework (ACF), Sabatier (2005) also touches on the issue of the third group of actors referred to by the framework as 'policy brokers'. These policy brokers are tasked with finding "some reasonable compromise which will reduce intense conflict" that arise between actors that are aggregated into advocacy coalitions (2005: 28). 
Table 3.1: Operational definitions as used in the thesis and adapted from the CIT framework

\begin{tabular}{|c|c|}
\hline $\begin{array}{l}\text { Variables and } \\
\text { concepts }\end{array}$ & Operational definition (for descriptive purposes) \\
\hline Motivations & $\begin{array}{l}\text { - What are the reasons behind an actors' participation in an } \\
\text { implementation (interaction) process } \\
\text { Sources of motivation include: } \\
\text { - own (internal, personal) goals and values: this contributes to the } \\
\text { realisation of the actors' goals; } \\
\text { - external pressure: the actor may participate because they regard it as } \\
\text { their responsibility to respond to the expectations by other actors } \\
\text { - self-effectiveness assessment: an actor believes that it is within its } \\
\text { capacity to participate in an interaction process. }\end{array}$ \\
\hline Cognitions & $\begin{array}{l}\text { - Refers to the information processing capacity held by an actor and } \\
\text { how this contributes to the interaction process } \\
\text { - How does the actors' interpretation of reality influence the } \\
\text { interaction process } \\
\text { - How information and knowledge about other actors and the given } \\
\text { context influence the interaction process }\end{array}$ \\
\hline $\begin{array}{l}\text { Resources and } \\
\text { power }\end{array}$ & $\begin{array}{l}\text { - What resources do actors have access to that enable them to } \\
\text { participate in the interaction process } \\
\text { - How do these resources influence the interaction process and affect } \\
\text { the other actor characteristics } \\
\text { - How do resources influence the power relations between actors } \\
\text { - How does one actors' attribution of power to another influence the } \\
\text { interaction process and how do resources contribute to this attribution } \\
\text { of power }\end{array}$ \\
\hline Structural context & $\begin{array}{l}\text { - How national, provincial and local government levels influence the } \\
\text { interaction process in an analysis of multi-level governance. }\end{array}$ \\
\hline Wider contexts & $\begin{array}{l}\text { - These are the 'problem, political, economic, cultural and } \\
\text { technological' contexts and "are visualised as having direct connection } \\
\text { with the actor characteristics" (Bressers 2009). }\end{array}$ \\
\hline
\end{tabular}

This thesis modifies the process model by adding a third actor in the policy implementation process. In all the analysed cases for this study, it became clear that ignoring the third actor's contribution to the policy implementation process could leave out important contributions that illustrate how these actors' characteristics influence the implementation process. The essential role of these third actors is discussed further in the following sections. Figure 3.5 illustrates the modified CIT process model which includes the third actor. 


\section{Interaction Process}

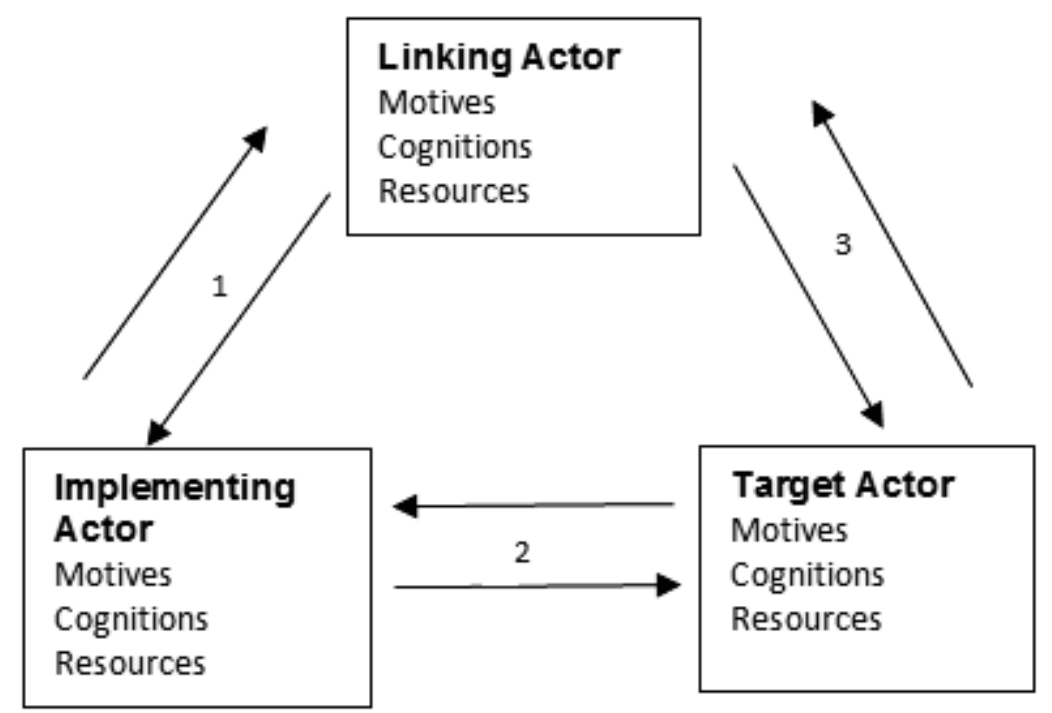

Figure 3.5: Modified CIT process model illustrating the three actor interaction process

Unlike the original CIT process model (Bressers 2004) - in Figure 3.1 which depicts a two-actor interaction process - the illustration on Figure 3.5 is an innovation of this study and shows a three-actor interaction process. In this case, the third actor is referred to as the linking actor. Figure 3.5 presents a general illustration of the interaction process (numbered 1, 2 and 3) between the three actors during the policy implementation process. This figure (particularly the arrows) may vary depending on the context and the circumstances of the interaction process. Through the data analysis process, it became clear that the type of interaction illustrated in this figure does not occur the same way in all the cases analysed for this thesis. In some cases, the interaction between some actors may be illustrated with dashed lines and arrows to show the strengths or weaknesses of the relationships between the actors (see Figure 10.6 in Chapter 10). The indepth relationships between the actors and how their motivations, 
cognitions and capacity and power influence the interaction process will be discussed further in the descriptive chapters that follow (Chapters 5, 6, 7, 8 and 9).

The reason behind adding the linking actor in this study, particularly where I apply the CIT framework, is to show the importance of this actor in the institutional setup of the implementation of the FBAE policy implementation process. It is important to illustrate how this actor's characteristics drive and influence the interaction process and how this actor's characteristics are also influenced by the process itself. The Contextual Interaction Theory has in the past studies been used to analyse policy implementation processes with the focus on key actor characteristics. In some of the studies that have been conducted using this theory, the actors are the implementing actor and the target actor. The implementing actor is often 'in charge' of policy implementation or responsible for driving the process of implementation for policies or strategies usually using top-down approach. On the other hand, the target actor is often a beneficiary in the implementation process. This actor's participation in the implementation process influences the outcome of such a process based on the energy needs of this actor and their level of participation as well as their relationship with the other actors.

Due to the implementation processes observed in this study, it became imperative to add and emphasize the importance of a third actor to the CIT framework in order to thoroughly analyse all the aspects that emerge from observed policy implementation process. The reason for highlighting the inclusion of the third actor is that, this actor shares some characteristics of both the implementing and target actors. This is different from the study of knowledge transfer processes by Vinke de-Kruijf (2013) where the "external actors (2013: 147) have completely different characteristics than the target group and the implementers of the policy process".

The linking actor is also important in the FBAE policy implementation process as a mediator between the implementing and the target actors. In the five local municipalities studied for the purposes of this thesis, the linking actor's mediation role varies from case to case and is highly 
dependent on this actor's characteristics of motivations, cognitions and capacity and power. The reason why I do not refer to these linking actors as mediators is because mediators are often associated with conflict resolution. Linking actors in this study, depending on the circumstances, also have a conflict resolution role but they also (often) function as pure links between implementing and target actors. Some of their roles include passing and exchanging information between the implementing and target actors, working with these actors separately and jointly in order to ensure delivery of services as part of FBAE policy implementation. They also play an advocacy role for the target and implementing actors.

Literature on intermediaries offers a better way to explain the role of linking actors in this study. In a study by Shea (2011), an example is given on how the federal government worked with non-profit intermediaries to deliver services. Shea concludes that intermediaries are identified to work with governments because they are seen as performing, or capable of performing a range of mediating roles. Depending on the situation and conditions, intermediaries play a variety of roles that can benefit a number of actors involved in the process. In the cases studied for this thesis, linking actors are not only linked to the local government (municipalities) but they also have links with the communities they serve and live in. As Shea (2011) observes, intermediaries fulfil different roles depending on their goals - and in my study cases - it also depends on their cognitions and capacity as well as power. It is also important to note that intermediaries, similar to linking actors, may influence the process in different ways. Briggs (2003) defines intermediaries as "people and institutions that add value to the world indirectly, by connecting and supporting - i.e., by enabling others to be more effective" (2003: 2). On the other hand, Szanton (2003) focuses on Intermediary Organisations and observes that the intermediaries roles have a potential to be divisive where the intermediary may serve one party's interests over another. In the cases analysed in this thesis, the divisiveness of a linking actor may be likened to that of the intermediaries analysed by Shea (2011). 
In their study, Javakhishvili and Jiblaze (2013) also identify a need to add a third key actor to the Contextual Interaction Theory. However, in their study focusing on domestic violence in Georgia, the third actor is the victim whilst the implementing actor is the government and the target actor is the non-government organisations. The way their study uses the third actor is different from my study as they apply the predictive model of the theory (Bressers 2004) and concentrate on how the third actor's cooperation and opposition influences the likelihood to implement and the adequacy to implement the anti-domestic violence policy. In my thesis, the emphasis is not placed on the third actor's cooperation with, or opposition to the implementation process but an approach focusing on broader factors that arise from the implementation process. This approach draws on the influence of all actor characteristics on the FBAE policy implementation process and considers the sets of issues (as explained in Section 3.3.4) arising from the interaction of the actor characteristics. This sophisticated approach does not dwell on predicting the likelihood of implementation or the adequacy of the implementation process based on the circumstances that actors operate under. Instead, the approach used in this thesis is realistic enough to illustrate that actor characteristics have a far greater influence on the whole implementation process as their interaction with each other reveals the real underlying issues that lead to different forms of implementation. In this way the root causes of why alternative energy services are not delivered through the FBAE policy as planned and expected are better identified and explained.

\subsubsection{Using the CIT framework to analyse the mutual influence of actor characteristics on policy implementation}

Kotzebue, Bressers and Yousif (2010) show that the actor characteristics are also influenced by the contextual factors and in cases where there is multilevel governance, these issues are important to pay attention to. According to Bressers (2007), using the dynamic interaction framework of CIT helps in showing the "process development (change processes - in the form of the process over time)" (2007:7). In this thesis, even while the case study area 
has been studied with fieldwork in two successive time periods, the process development is not necessarily captured over time but over the different cases represented by the five local municipalities under the OR Tambo district. Viewing and analysing the interaction process through cases provides an opportunity to understand how the FBAE policy is implemented in each municipality and why there are differences and similarities in implementation, taking into consideration the influence of actor characteristics in each case.

Even though this thesis does not concentrate on the layers of contextual factors that influence the policy implementation process as it is typical with studies that have applied the CIT framework, it still regards these as important. The overall role of the national, provincial and district municipalities as well as the other contextual issues such as politics, geographic area, the history of the country are important in explaining the policy implementation process. Using process development is also in line with the Contextual Interaction Theory as it "assumes that the policy implementation process is not only about achieving implementation, but also about attempts to prevent implementation or to change the character of what is implemented" Bressers (2004: 287). Bressers, Klok and O'Toole (2000) illustrate that using a deductive approach such as CIT (basing it on the proceeding Instrumentation Theory) to analyse policy implementation helps in telling the 'whole story' (instead of an ad-hoc explanation) by showing how "identified factors exert influence in combination with other factors which, in and of themselves, need not adversely affect implementation" (2000:8).

Using the 'dynamic interaction of actor characteristics model (Figure 3.4) the interaction results between the actor characteristics are clearly defined. This framework shows how the motivations interact and influence cognitions and how cognitions interact and influence capacity and power and how capacity and power interact and influence motivations. This fluid and highly interactive process goes beyond concentrating on the obvious which is the mere analysis of actor characteristics - but expands to analyse three sets of issues that arise from the interaction of these actor 
characteristics and how they influence each other and the interaction process.

The first set of issues that arise from the interaction of the different actor characteristics concentrate on how each actor characteristic influences the other. The interaction between actor motivations and cognitions give rise to two issues, namely; the focus of attention and the perceptions of opportunities and threats. Focusing of attention refers to how motivations and cognitions shape what the actors focus on within the policy implementation process. In this study, taking into consideration the type of information available, knowledge and frames of reference of the actor this determines, to a certain extent the actor's focus when implementing the policy. On the other hand, perceptions of opportunities and threats come from the information, knowledge and frames of reference that actors have and hold and how these shape and influence the actor's motivations. These perceptions of opportunities and threats are what actors consider when making decisions about implementing a policy and these influence the interaction process.

The second set of issues that arise from the interaction of different actor characteristics are the strategic value of the interaction process and the data search and processing capacity of the actors involved. The strategic value (or the valuable implementation strategy) is influenced by the actor's cognitions and resources (and power). The actor's cognitions as well as capacity and power give rise to an implementation strategy that actors develop while considering the combination and interaction of these characteristics. The data search and processing capacity considers the resources and power characteristics of the actors and how these enable the actors to search and process data and information that shapes and influences the policy implementation process.

The third set of issues that arise from the dynamic interaction process as illustrated in Figure 3.4 is the relevance of resources for intended action and availability of resources for intended action. The actor characteristics of motivation and capacity (and power) influence each other and the whole implementation process - as mentioned with the other actor characteristics 
above. Having adequate resources for the intended action is important for actors to realise their goals. There is also a need for these resources to be available to actors for the sake of achieving their policy implementation goals. As mentioned above, resources provide the capacity to act (De Boer and Bressers, 2011) while their relevance and availability influences the actor's motivations and in turn, influence the whole policy implementation process.

\subsubsection{A summary justifying the use of CIT}

Through the brief summary of policy implementation research, this chapter shows how policy implementation studies have evolved over the years. It is particularly important to point out that studying both top-down and bottom-up approaches assists in finding an appropriate theoretical framework for this study.

The Contextual Interaction Theory was chosen as a theoretical framework for this study for the following reasons:

(i) CIT is the most suitable framework for my study to concentrate on the policy implementation process by focusing on the actors and their motivations, cognitions, capacity and power. This parsimonious approach of focusing on just a few variables provides in-depth analysis of each variable to focus on its influence on the interaction process.

(ii) The framework is flexible enough and in this study it has been adjusted to add the third actor to make it more suitable to analyse the FBAE policy implementation process by analysing characteristics of all the actors involved.

(iii) Using the theory in a South African context demonstrates that theory is applicable in a developing country context, especially in a country where new policies have been formulated to mark the country's transition into a democratic state. 
(iv) The theory integrates the aspects of top-down and bottom-up approaches into one seamless analytical approach.

\subsection{Summary and conclusions}

This chapter has given a brief history of policy implementation studies and has shown how these have developed and applied. The third generation of policy research dominates in this chapter through the use of the Contextual Interaction Theory (CIT) to show how the policy process takes place and why there are particular outcomes to this process. The chapter justifies the use of CIT as a theoretical framework of choice for analysing the cases in this study where the implementation of the Free Basic Alternative Energy (FBAE) policy is taking place. The CIT framework has been adapted by adding the third actor in order to remain relevant to the context and the issues arising in the interaction process that is being studied. The chapter shows how for the first time, the CIT dynamic interaction model is used in empirical research to enable the creation of a more holistic view of the implementation situation. 


\section{Chapter 4: How multi-level governance influences the implementation of the Free Basic Alternative Energy policy}

\subsection{Introduction}

The responsibility of implementing the Free Basic Alternative Energy (FBAE) policy is not only reserved for the local municipalities. The district municipalities as well as the provincial and the national levels of government have important roles to play in ensuring delivery of alternative energy services through the implementation of this policy. This chapter briefly describes the layers of government in South Africa and then gives an overview of how the afore-mentioned layers of government play a role in the implementation of the FBAE policy.

\subsection{The three spheres of government ${ }^{30}$}

South Africa is a democratic state which is run on the Westminster Parliamentary system. The country has three spheres of government, namely the national, provincial and local levels of government which are "distinctive, interdependent and interrelated" (Constitution $1996^{31}$ ).

Table 4.1: Spheres of government and their representation

\begin{tabular}{|l|l|l|l|}
\hline Sphere & Legislature & Executive & Administrative \\
\hline National & Parliament & President and Cabinet & $\begin{array}{l}\text { Directors General and } \\
\text { Departments }\end{array}$ \\
\hline Provincial & Legislature & $\begin{array}{l}\text { Premier and Executive } \\
\text { Council }\end{array}$ & Heads of Department and Staff \\
\hline Local & Council & $\begin{array}{l}\text { Mayor and Mayoral } \\
\text { Committee }\end{array}$ & $\begin{array}{l}\text { Municipal Manager, Heads of } \\
\text { Departments and Staff }\end{array}$ \\
\hline
\end{tabular}

Source: Education and Training Unit ${ }^{32}$

\footnotetext{
${ }^{30}$ Most of the information in this section is extracted from the Constitution of the Republic of South Africa (1996) which officially refers to the layers of government as spheres.

${ }^{31}$ Chapter 3, section 40 (1)

${ }^{32}$ Downloaded from: http://www.etu.org.za/toolbox/docs/govern/spheres.html 21 November 2011
} 
As illustrated in Table 4.1, at the national level of government, Parliament which is made up of the National Assembly and the National Council of Provinces approves laws and policies. At this level, the government departments and ministries are responsible for coming up with laws and policies which they present to Parliament for approval. Once approved, these departments take on the responsibility of implementing these laws and policies using the administrative skills and capacity at their disposal. For this study's relevance, it is important to note that the Department of Energy is one of the departments that only exists at this upper level of government. Another department that is only found at this national level and is relevant for this is study is the Department of Cooperative Governance and Traditional Affairs (CoGTA) as it is responsible for the national co-ordination of provinces and municipalities as well as monitoring and supporting municipalities. This department is therefore very important in the implementation of the Free Basic Alternative Energy (FBAE) policy.

At the provincial level of government, there are different provincial departments each responsible for improvement and delivery of services. According to the "Provincial Growth and Development Strategy Guidelines" developed by the Department of Provincial and Local Government ${ }^{33}$ :

"Provinces have an important role to play in contextualising national imperatives and grounding them within the realities and specificities of each province, and guiding local government in the development and implementation of IDPs and programmes for sustainable development". For this study, the Provincial level of government's importance stems from its responsibility to provide support to the local municipalities in the implementation of the Free Basic Alternative Energy (FBAE) policy by ensuring the delivery of alternative energy services to indigent households.

The local level of government consists of municipalities which are divided into three types, namely; metropolitan municipalities (also known as category A), local municipalities (also known as category B) and district

\footnotetext{
${ }^{33}$ This department is now known as the Department of Cooperative Governance and Traditional Affairs (CoGTA)
} 
municipalities (also known as category C). There are 226 local municipalities which encompass the areas outside the metropolitan municipalities and these are further broken down into wards each of which is represented by an elected ward councillor. District municipalities are made up of a number of local municipalities. The district municipalities co-ordinate development and service delivery in the whole district by working closely with local municipalities.

The following sections will illustrate how the different levels of government, particularly the national, provincial, district and local are relevant in the implementation of the Free Basic Alternative Energy (FBAE) policy.

\subsection{The national level's role in FBAE policy implementation}

The Free Basic Alternative Energy (FBAE) policy was developed by the national Department of Energy ${ }^{34}$ (DOE) in 2007. The role of this department is to facilitate implementation by ensuring that funds are available to the local municipalities for the implementation of this policy. During the time of research for this study, interviews with the Department of Energy revealed that all responsibility for implementation of this policy was passed on to the local municipalities with the understanding that the Department of Cooperative Governance and Traditional Affairs (CoGTA) will assign responsibilities to the relevant provincial department to provide the needed support to the local municipalities. Therefore, in this case, the Department of Energy has two main roles: (i) to develop the FBAE policy and (ii) to 'ensure' implementation by approving funding for the local municipalities.

The responsibility of monitoring the implementation of this policy is passed on to the Department of Cooperative Governance and Traditional Affairs which works with the provincial departments.

${ }^{34}$ Formerly known as the Department of Minerals and Energy (DME) 
According to a Department of Energy ${ }^{35}$ representative,

"the municipalities should be aware and take into consideration that there is not going to be universal access to grid (Eskom) electricity anytime soon. The backlog in electricity connections is most difficult to cover and will be the most expensive for government. This is because the households are very far from the existing grid lines, are sparsely populated and occupied by the poorest of the country, individuals that will not be able to afford electricity supply services. This is reason enough for municipalities to start providing alternative energy services in their areas and to implement the FBAE policy."

The backlog referred to above concerns the number of households that are still without grid electricity. According to the former Minister of this department, "in most of the country's rural areas, the households that remain unelectrified are located in remote rural areas that are difficult to reach and provide with grid electricity" (Peters 2012). According to the electrification estimates, as at 2012, the backlog of unelectrified households just above 3,5 million households (Barnard, 2012).

The national Department of Cooperative Governance and Traditional Affairs $^{36}$ (COGTA) is responsible for coordinating and facilitating government programmes by creating and supporting delivery systems within municipalities. This department works with its provincial counterparts who monitor the ground level implementation of various policies and programmes. This department's role in the implementation of the Free Basic Alternative Energy (FBAE) policy includes close coordination with the provincial departments in charge of monitoring local municipalities service delivery programmes. Among other activities, this department also coordinates funding for the FBAE policy implementation through

\footnotetext{
${ }^{35}$ Based on a face-to-face interview with the department's representative held in Pretoria (Department of Energy's offices) on 19 May 2011.

${ }^{36}$ Most of the information regarding CoGTA's role in FBAE implementation is based on a face-to-face interview with a senior representative from this department on 19 June 2012 at this departments' offices in Pretoria.
} 
mechanisms such as the Municipal Systems Improvement Grant. This grant can be applied for by the municipalities to assist them in the annual gathering of information to compile registers of indigent households and to improve the skills capacity within the municipalities. Besides this grant, the local municipalities receive funding (Equitable Share Grant) from the national government to implement the FBAE policy. The main issue with this funding according to CoGTA is that it is not ring-fenced and therefore can be used for 'any' municipal needs and priorities other than the delivery of alternative energy services through the implementation of the FBAE policy.

\subsection{The provincial level's role in FBAE policy implementation}

The responsibility of Free Basic Alternative Energy (FBAE) policy implementation at the provincial level of government is usually given to a department in charge of monitoring service delivery programmes at the local level. In this study, this is the responsibility of the Eastern Cape provincial Department of Local Government and Traditional Affairs ${ }^{37}$.

This department is mandated by the South African Constitution's Section 154 which directs them to 'provide hands-on support to municipalities' which means, among other things, they have to ensure that local municipalities have systems in place to provide alternative energy services through FBAE policy implementation. In turn, the local municipalities give monthly reports to this department, stating the number of indigent households that have benefited from the provision of FBAE services. These figures are used by this provincial department to account for the money spent by the national government in providing alternative energy services for indigent households.

\footnotetext{
${ }^{37}$ The section on the Eastern Cape's provincial Department of Local Government and Traditional Affairs is based on face-to-face in-depth interviews with this departments' senior representative on 04 July 2011 and 04 June 2012 at the provincial offices in Bisho, Eastern Cape.
} 
The support given to the local municipalities by this provincial department in the delivery of energy services, such as the implementation of the FBAE policy, include encouraging these municipalities to take part in the provincial energy forums. The energy forums are a platform created by the provincial government to involve all relevant stakeholders in decisionmaking concerning the delivery of energy services. Here, the local municipalities can learn about the government's energy policy implementation plans and the role they are expected to play in the delivery of such services. In areas where there are district municipalities, this provincial department has established district level energy forums where district municipalities are in charge of monitoring and providing support to the local municipalities that deliver energy services such as Free Basic Alternative Energy.

One of the main focus points for this department is to ensure that local municipalities have credible indigent policies and credible indigent registers. The indigent policy for each municipality has to be in line with the national guidelines of developing such a policy and it dictates how services are rendered and the quantity (and quality) of what is being delivered to beneficiaries. To ensure credibility of the indigent register, this provincial department encourages local municipalities to update these registers annually in order to deliver services such as FBAE to qualifying beneficiaries and to secure funding from the national government.

\subsection{The district (local) level's role in FBAE policy implementation 38}

The OR Tambo District has a population of about 1.3 million $^{39}$ where it is estimated that $93 \%$ of this population resides in the rural areas with many dispersed homesteads that make provision of basic services such as grid

\footnotetext{
${ }^{38}$ This section is based on the face-to-face interview held with the district municipality representative on 20 July 2011 at the OR Tambo District Municipality offices in Mthatha, Eastern Cape.

${ }^{39}$ Statistics South Africa 2011 census
} 
electricity and piped water expensive. Access to basic services such as potable water, sanitation, electricity and access roads is relatively low ${ }^{40}$. This district municipality is made up of five local municipalities and carries a mandate to deliver water and sanitation services all of these municipalities. "In July 2003, Cabinet declared and pronounced OR Tambo District Municipality a Water Services Authority and Water Services Provider. This therefore means that this district municipality is responsible for planning, implementation, operation and maintenance of water and sanitation services within its local municipalities" (OR Tambo District Municipality 2011: 119). Coupled with other responsibilities, this district municipality is also in charge of planning and governance functions which include Free Basic Services.

In the delivery of alternative energy services through the implementation of the FBAE policy, this district municipality provides support to the local municipalities in a number of ways. The district municipality assists local municipalities in household data collection to verify indigent households that qualify for services such as alternative energy delivered through the implementation of the FBAE policy. Another way that the district municipality provides support is to give local municipalities an opportunity to participate in the district energy forums where provision plans for energy services within municipalities and in the whole district are discussed and the implementation of the FBAE policy.

\subsection{The local municipalities' role in FBAE policy implementation}

The local municipalities as implementing actors make decisions guided by rules and regulations within government, specifically those set in the

\footnotetext{
${ }^{40}$ Department of Water Affairs, South Africa. 2009. Development of Reconciliation Strategies for all Towns in the Southern Planning Region: Summary Report - OR Tambo District Municipality. Directorate : National Water Resource Planning. DWA Report No. P RSA 000/00/15311
} 
Constitution of the Republic of South Africa (Act 108 of 1996) and the Local Government Municipal Structures Act of 1998.

Chapter two of the Free Basic Alternative Energy (FBAE) policy document outlines how this policy should be implemented according to the Department of Minerals and Energy (2007). The local municipalities are expected to ensure that indigent households benefit from the implementation of this policy through a clear and transparent process. The policy document also outlines the procedures that should be followed by local municipalities in identifying areas that are supposed to benefit from FBAE policy implementation such as those households located far from the electricity grid. According to the implementation guidelines, municipalities are supposed to select suitable energy carriers to be funded and 'delivered' ${ }^{41}$ to indigent households whilst taking care that these carriers are safe, accessible, affordable and sustainable. The responsibility of conducting awareness campaigns and information dissemination about the chosen energy carriers is given to the municipalities 'to inform the beneficiaries on how best to apply them", (DME, 2007: 10). Municipalities can act as service providers if they have the necessary capacity or they can appoint private sector service providers by entering into 'Service Delivery Agreements'.

It is important to note that before the formulation of the FBAE policy, South African rural local municipalities were never given the responsibility to provide household energy services. This responsibility was left to Eskom, (the grid electricity utility) and the national government Department of Energy. The FBAE policy requires local municipalities to deliver alternative energy services to households and to integrate this responsibility to their list of service delivery responsibilities.

Lastly on implementation of FBAE policy, the municipality must take charge of monitoring the process by verifying the register of indigent households

\footnotetext{
${ }^{41}$ Made available and physically delivered to the beneficiaries. In instances where municipalities are providing paraffin, the service provider meets with the beneficiaries at a communal location within the village where the fuel is handed to them in 20 litre containers.
} 
from time to time and submit these to the provincial government department. As part of the monitoring process, national government will also monitor the implementation of the FBAE policy to measure 'cost effectiveness and quality of services' delivered to the beneficiaries.

To indicate their intentions to implement the FBAE policy, municipalities add this policy's goals on their Integrated Development Plans (IDPs). IDPs are five-year plans that each municipality in South Africa is required by law to develop according to the Municipal Systems Act of 2000 (Section 35). These plans are a method to plan future developments for their areas (Education and Training Unit 2011). IDPs are considered 'super-plans' for an area and give an overall development framework. These plans are reviewed annually by the municipalities and their stakeholders including communities who will impact or benefit from such plans. The main aim of having IDPs for municipalities is to coordinate future work for the municipality with that of the other spheres of government to ensure better quality of life for people living within these municipal areas ${ }^{42}$. Together with coordinating with other spheres of government, IDPs are meant to ensure that the following happens:

- Effective use of scarce resources by the local municipality;

- Speed up delivery of services especially in the least developed areas such as the remote rural areas;

- Strengthen democracy by ensuring that ordinary citizens participate in decision making in a transparent manner;

- To overcome the legacy of apartheid through providing much needed basic services to previously disadvantaged areas such as the remote rural areas; and

- To attract necessary funds to the municipality from national government and private investors.

\footnotetext{
${ }^{42}$ http://www.etu.org.za/toolbox/docs/localgov/webidp.html - Accessed on 01 March 2011.
} 


\subsubsection{Stakeholders interacting with the local municipalities}

Stakeholder interaction is important for local municipalities as implementing actors that often need assistance and feedback from all the parties affected by the services delivered. The implementation of the FBAE policy is an interaction process that depends on several actors. Although this thesis concentrates on three core actors (implementing, target and linking actors), it is necessary to acknowledge the other actors that contribute to the implementation process. Table 4.2 highlights stakeholders that play a role in the delivery of FBAE services as part of the policy implementation process.

The national Department of Energy (DOE) is in charge of policy formulation as explained above in Section 4.3. This department assists with determining the finances needed for the implementation process and works together with the other government departments such as Treasury and Cooperative Governance and Traditional Affairs (CoGTA) department.

CoGTA is in charge of monitoring the implementation process by using its national and provincial representatives to oversee local governments' performance in providing alternative energy services as part of the FBAE policy implementation process. This department together with the Treasury department and DOE work together to determine the resources needed to make the provision of alternative energy services possible.

The Eastern Cape provincial department of Local Government and Traditional Affairs plays a crucial role by assisting local municipalities in the FBAE policy implementation process. This provincial government department concentrates on providing as much information as possible to the local municipalities on how to follow policy guidelines in providing alternative energy services. It has established energy forums where municipalities and other stakeholders with an interest in energy services meet and exchange information on their activities concerning energy issues in the province. This department is also in charge of monitoring the FBAE policy implementation process by ensuring that local municipalities have 
credible indigent registers and that they receive funding based on the number of indigent households they provide services to.

Table 4.2: Stakeholder contribution to the FBAE policy implementation process

\begin{tabular}{|c|c|}
\hline Stakeholder & Way of interaction \\
\hline $\begin{array}{l}\text { Department of Energy - } \\
\text { National government }\end{array}$ & $\begin{array}{l}\text { - FBAE policy formulation and setting of implementation } \\
\text { procedures } \\
\text { - Assist with financing the alternative energy services that the } \\
\text { municipality is providing i.e. paraffin - this is after the list of } \\
\text { indigent households has been submitted to National Treasury } \\
\text { for approval }\end{array}$ \\
\hline $\begin{array}{l}\text { Cooperative } \\
\text { Governance and } \\
\text { Traditional Affairs } \\
\text { department - National } \\
\text { government dept. }\end{array}$ & $\begin{array}{l}\text { - Provide funding from the national level for implementation } \\
\text { - Ensure that the municipality receives support from the } \\
\text { provincial government department }\end{array}$ \\
\hline $\begin{array}{l}\text { Local Government and } \\
\text { Traditional Affairs - } \\
\text { Provincial government } \\
\text { dept. }\end{array}$ & $\begin{array}{l}\text { - Assist with giving advice and helping with reporting on what } \\
\text { has been achieved by the municipalities and the province as a } \\
\text { whole in Free Basic Services. } \\
\text { - Host Energy Forums (Provincial meetings) that update the } \\
\text { municipality on what is happening and how they need to } \\
\text { implement and strategize on FBAE implementation. }\end{array}$ \\
\hline District municipality & $\begin{array}{l}\text { - Provide support on all local municipality service provision } \\
\text { activities } \\
\text { - Assist with indigent households' information collection } \\
\text { - Give advice and assistance during the regional energy forum } \\
\text { meetings }\end{array}$ \\
\hline Eskom electricity utility & $\begin{array}{l}\text { - Provides the municipalities with grid electrification plans, } \\
\text { costs and time-lines for unelectrified areas. }\end{array}$ \\
\hline $\begin{array}{l}\text { Alternative energy } \\
\text { service providers }\end{array}$ & $\begin{array}{l}\text { - Contracted by the local municipality to deliver paraffin or } \\
\text { provide solar systems maintenance services to indigent } \\
\text { households }\end{array}$ \\
\hline
\end{tabular}

The OR Tambo District municipality is the 'home-base' for the five local municipalities in this study. The district municipality provides administrative support to the local municipalities during the FBAE policy implementation process. This support includes assisting the local municipalities with household data collection and analysis to determine which households qualify as indigents and therefore should be receiving services such as the FBAE. 
Eskom is the national electrification company and it works closely with these local municipalities by providing them with information concerning grid electrification plans. This enables the local municipalities to plan ahead and provide alternative energy services to areas where grid electricity will not be reaching in five to ten years to the future.

The alternative energy service providers are private businesses that are contracted by the local municipalities to provide services such as delivery of paraffin or technical maintenance of solar home systems for indigent households as part of the FBAE policy implementation process.

\subsection{Conclusion}

This chapter has illustrated how the different spheres of government in South Africa influence policy implementation through the different roles they play. The analysis of this multi-level governance influence on the implementation process has deliberately taken a top-down approach to clarify how the local municipalities have come to be responsible for the implementation of the FBAE policy. This chapter has also made it clear that each layer of government is important in the implementation of this policy and the actions they take do affect the FBAE policy implementation process.

The local municipalities are given the responsibility of ensuring the delivery of energy sources so as to provide energy services to unelectrified indigent households through the implementation of the FBAE policy. Even though in the past the local municipalities were not responsible for providing energy services, the FBAE policy forces this sphere of government to integrate energy services into their Integrated Development Plans. The consequences of adding this responsibility to the local municipalities' range of services will be analysed and discussed in the case chapters (Chapters 5, 6, 7, 8 and 9). 


\section{Chapter 5: Port St. Johns: Not according to plan}

“...we are forced to eat everything all at once because food gets spoilt easily if we keep it. When we slaughter a cow for a ceremony, we have to eat everything on that same day. Even if you are full, you have to force the food down and leave nothing for tomorrow, else, it will go bad..." Noqhekwana village resident ${ }^{43}$.

\subsection{Introduction}

As a local municipality located in the rural parts of South Africa, where some of the households do not have access to grid electricity, the Port St. Johns local municipality is expected to implement the Free Basic Alternative Energy (FBAE) policy. The implementation take different forms adjusted to suit the municipality and its residents. The local municipality can implement the policy by providing some paraffin to households without electricity or offer maintenance of solar home systems for households electrified with this technology. This case demonstrates the impact of the influence of implementing and target actors in policy implementation. This case also shows that the physical environment (i.e. geographic area) especially of the target actors, influences the outcomes of their interaction with the implementing actors. The case also shows that information, and how it is handled, is a key factor in providing and receiving municipal services such as the Free Basic Alternative Energy subsidy.

\footnotetext{
${ }^{43}$ A village resident explaining that it is difficult to store food because they do not have electricity.
} 


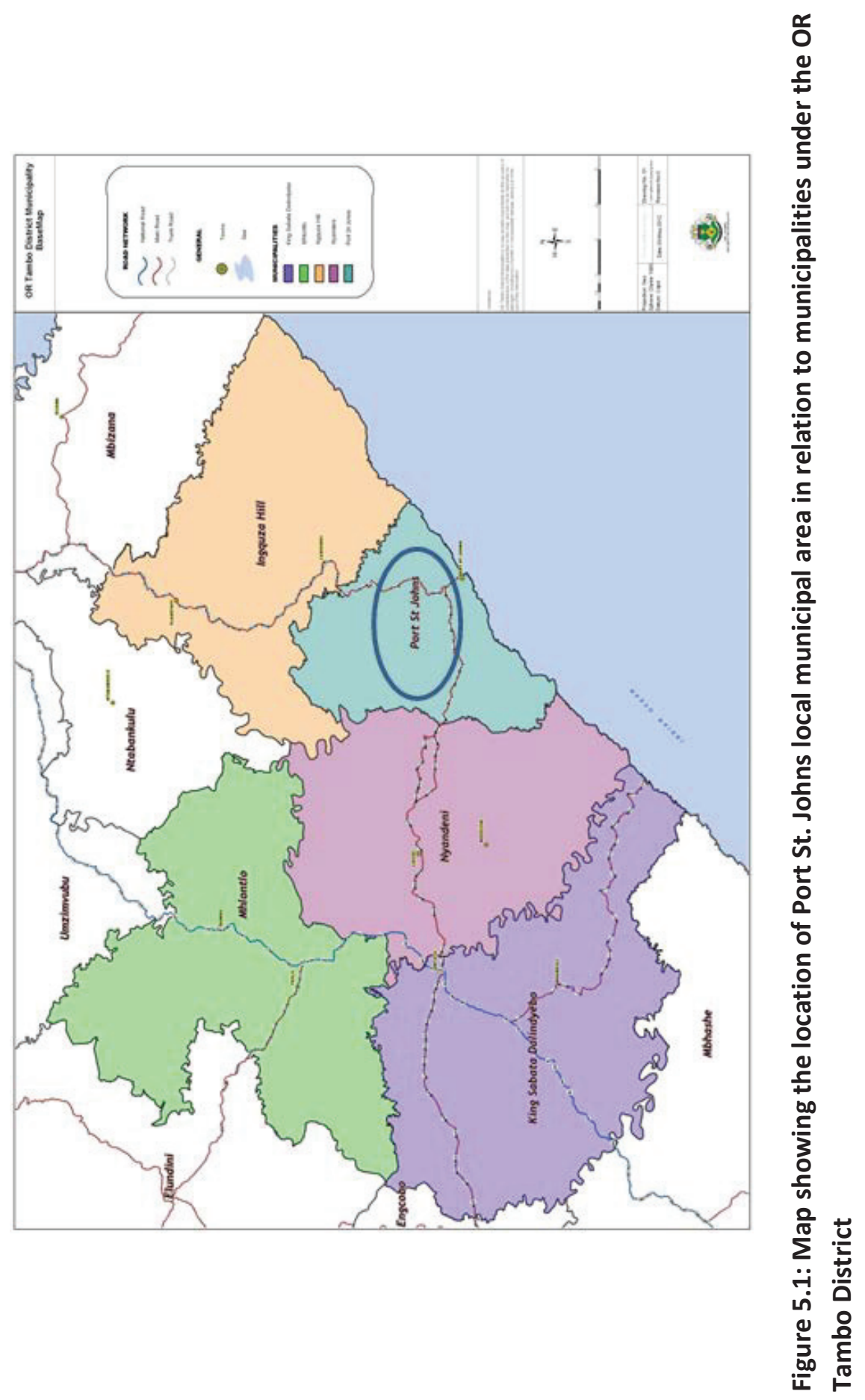




\subsection{Area Description}

Port St. Johns is located on the south-east coast of South Africa. The local municipality covers an area of 1239 square kilometres with a population of approximately 156136 people and 31715 households. It is one of the five local municipalities under the OR Tambo District municipality. The town of Port St. Johns is popular amongst local and international tourists as it is located along some scenic beaches of the Wild Coast. Tourism brings much needed income to this town's community through renting accommodation, restaurants, fishing, arts and crafts. Like many local municipalities in South Africa, Port St. Johns is divided into municipal wards ${ }^{44}$ and has a total of 20 wards. The area has formal and informal residential areas as well as rural villages on the immediate outskirts of the town centre. For purposes of my study, I focus on Wards 6 and 10.

Ward 6 is where the town centre is based. Here as well as the location for the municipal offices, most of the town's economic activities take place here. The built up areas classified as "formal" receive municipal services such as water, sanitation and electricity. The municipality collects revenue for these services. The informal areas comprise of dwellings built on land neither belonging to the occupants nor to the municipality. Dwellings on this land are regarded as 'illegal' and are not provided with municipal services such as grid electricity since the municipality regulations throughout the country do not allow such services to be provided on 'illegal' land.

Ward 10 is home to several villages located among the hills and valleys of Port St. Johns. Most dwellings in these villages are built in a traditional hut style ${ }^{45}$ with materials such as mud bricks, straw and thatch for roofing. Although my research focuses on the village that does not have electricity connections, some of the villages in this ward have grid electricity connections. They are also provided with sanitation services by the

\footnotetext{
${ }^{44}$ Municipal wards are sub-divisions of municipal areas. In South Africa, only metropolitan and local municipalities have ward divisions.

${ }^{45}$ Round-shaped structures commonly known as rondavels in South Africa.
} 
municipality. Sanitation services in this case does not consist of a flush toilet system, but refers to a dry toilet system, also known as Ventilated Improved Pit-latrine (VIP), mostly found in rural areas that have no water reticulation. Land has been in the hands of the people for many generations in these villages and has been traditionally allocated to people local to the area by the community leader (such as the local chief).

\subsubsection{Noqhekwana village}

Noqhekwana is a village located in Ward 10 under the Port St. Johns municipality. It is without grid electricity, hence its selection for this study. Its residents depend on wood, paraffin, Liquefied Petroleum Gas (LPG) and petrol / diesel-powered generators for energy sources in their homes. None of the energy sources mentioned here are subsidized by the government, except for paraffin which is zero-rated ${ }^{46}$ for Value Added Tax (VAT). Although Noqhekwana does not have grid electricity, the households do not receive any Free Basic Alternative Energy (FBAE) subsidies such as free paraffin or other alternative energy sources from the local municipality of Port. St Johns. Of all the basic services that are supposed to be provided by the local municipality, the residents have only received pit-latrines as part of sanitation basic services. They do not have access to piped water sources and depend on rivers around their village for fresh water.

Noqhekwana village is approximately $8 \mathrm{~km}$ from the centre of Port St. Johns. It is a relatively short distance but due to bad unmaintained gravel roads, it takes a long time to travel between the town and this village. Lack of facilities such as a bridge or proper rowing boats to allow villagers to cross the Umzimvubu river ${ }^{47}$ which separates the town and the village makes it difficult to travel between these two points. As a result, a drive from the

\footnotetext{
${ }^{46}$ In South Africa paraffin is zero-rated as it is regarded as a basic fuel used by majority of impoverished people that cannot afford expensive energy sources. Consumers are not charged any VAT on this fuel .

${ }^{47}$ Mzimvubu is one of the key rivers in South Africa. It flows for approximately $400 \mathrm{~km}$ and ends in Port St. Johns where the mouth is approximately 60 meters wide.
} 
town centre of Port St. Johns to Noqhekwana village can take approximately 50 minutes and walking takes two hours. A majority of people from the village do not have cars and often find it costly to use a local taxi ${ }^{48,}$ which costs fourteen Rands (1.4 Euro) for a one-way trip.

\subsubsection{Mthumbane township}

Mthumbane township ${ }^{49}$ is located in Ward 6 on the hilly parts of Port St. Johns. It is densely populated because of limited land that is suitable for building dwellings. Most of the houses in Mthumbane township are standard four-roomed ${ }^{50}$ (usually divided into two bedrooms, living-room and kitchen) with toilets outside. Some people have extended the size of their homes by adding rooms using brick for more permanent structures or using corrugated zinc sheets and wood for temporary ${ }^{51}$ structures. The types of materials used for these extensions also depend on the income and affordability levels of these households. The house extensions are used to accommodate the family as it grows or for rental purposes as a way of generating an income for the householders. Amongst the old houses, there are newly-built government subsidized houses and provided by the national

\footnotetext{
${ }^{48}$ Local taxis are privately owned vehicles that are used to transport passengers from point to point. They can carry up to 14 passengers depending on the size of the vehicle.

${ }^{49}$ In South Africa, township is used to define urban living areas with houses ranging from two to four rooms in size (usually $40 \mathrm{~m}^{2}$ in total size) built by the apartheid government and reserved for non-White people during the apartheid years. These houses were rented to families by the government and were provided with minimum basic services such as water and sanitation. Until the early 1990s, these householders were given title deeds for these houses. The townships influenced the South African landscape and history and remain known as symbols of apartheid and its impacts on Black people. They continue as areas that accommodate lowincome non-White citizens of South Africa.

${ }^{50}$ Historically in South African townships, houses are provided to low-income earners by the national government as part of national housing programmes. These houses are usually up to $42 \mathrm{~m}^{2}$ and are provided with electricity connections and have outside toilets.

${ }^{51}$ It is common for the 'temporary' extension structures to be used for many years depending on the need for the structure by the occupants.
} 
Human Settlements Department for individuals that were living in temporary informal settlements such as shacks.

According to the Ward Committee member interviewed ${ }^{52}$ in Mthumbane township, the majority of people living here are poor and are 'struggling to make ends meet' because of unemployment. A few make a subsistence living by selling fruit, vegetables and small consumables in town. Most households depend on social grants given by the national government such as child grant, old age pension and disability grants. Some of the families depend on the sea where they fish and capture crayfish, mussels and other fish to sell and consume.

Although the Ward Committee Member reported high levels of unemployment in the Mthumbane township, he also said that there have been noticeable changes happening in the town with regards to creation of job opportunities for 'unskilled' people. This is part of the national government's Expanded Public Works Programme which creates employment through infrastructure improvement projects such as building and maintenance of roads, environmental and social work. Although these projects are for short periods of time (a few months at the most), they guarantee employment opportunities and a basic income for local people with no special qualifications and usually with lower levels of education. Amongst other plans to create employment opportunities specifically for the youth, is the establishment of a Youth Radio Station which is planned to expose young people to opportunities that may lead to a better life in the future.

\subsection{Methodology specific to this case}

Face-to-face interviews were conducted with municipal staff members in Port St. Johns. The municipal staff members interviewed were all in management positions and played important roles in the implementation

\footnotetext{
${ }^{52}$ Face-to-face in-depth interview with the Port St. Johns, Mthumbane township Ward Committee Member on 23 April 2012.
} 
of the Free Basic Alternative Energy policy in the areas under this municipality.

For information pertaining households and beneficiaries of municipal service, I conducted interviews with Ward Committee members of Wards 6 and 10. The Ward Committee members of these communities were introduced to me by the Ward Councillors of the aforementioned wards.

The areas I visited in Port St. Johns are Mthumbane township in Ward 6 and Noqhekwana village in Ward 10. There were no household interviews conducted in both areas because:

- None of the households in these two wards (including the rest of Post St. Johns) were receiving Free Basic Alternative Energy subsidies during the time of my fieldwork;

- Upon having conversations with the municipality representatives, Ward Councillors and Ward Committee members, it was clear that households will not have the information I needed for the benefit of my study;

- There was no record of households that had previously benefitted from the implementation of FBAE policy through provision of solar home system maintenance services between 2007 and 2008;

- Although the previous solar home system maintenance provider said that there were villages within Port St. Johns that still had solar systems, attempts to find these villages were in vain as the municipal representatives and the ward councillors said they did not know where these villages are located;

- The previous solar home system maintenance company was no longer operational due to bankruptcy and its manager was not available to assist me in identifying villages that still had solar systems;

- Unlike the other local municipalities under the OR Tambo district, Port St. Johns (and Ingquza Hill ${ }^{53}$ municipality) were not providing their

\footnotetext{
${ }^{53}$ Ingquza Hill local municipality is located in the town of Flagstaff, $85 \mathrm{~km}$ north of Port St. Johns municipality.
} 
indigent households with paraffin as part of Free Basic Alternative Energy policy implementation.

At Noqhekwana village I arranged an interview with the local Ward Committee member but when I arrived at the village church building, the venue for our meeting, he had invited more people. The Ward Committee member had invited other members of the community that represent different interests of people living in this village. He explained that he did not think it appropriate to discuss village matters without other members of the community. Amongst those present at the meeting was a local preschool teacher, a ward committee member representing the youth and some community members not affiliated to any leadership group but representing the community. Their views will be used in this case to represent those of households (target actor).

At Mthumbane township I met with the Ward Committee member who had held office for a year and has been living in this area for more than 30 years which made him the an ideal source of information, hence my decision to interview him.

Since the Port St. Johns local municipality used to implement the FBAE policy through the provision of maintenance of Solar Home Systems to its indigent households, I decided to interview this service provider.

In this case, the actors are defined as follows:

\section{Implementing actors}

The implementing actor in the Port St. Johns case is represented by some individuals employed by the municipality. The individuals interviewed are the Municipal Manager, the Chief Financial Officer, and Acting Chief Financial Officers, the Free Basic Services Coordinator and two Ward Councillors. Due to administration difficulties within the municipality during the time of my fieldwork (May to August 2011 and April to June 2012) in Port St. Johns, the Municipal Manager and the Chief Financial Officer were fired and replaced by new employees. 


\section{Target actors}

Target actors in the case of Port St. Johns are households that make up the communities that are meant to be receiving services that should be delivered as part of Free Basic Alternative Energy policy implementation. Although no household interviews were conducted in the Port St. Johns area, the target actor information will be extracted from the interviews held with other actors.

\section{Linking actors}

The linking actors interviewed are the Ward Councillors and the Ward Committee Members. The Ward Committee Members represent the Ward Councillors in these villages and are well knowledgeable on the affairs of their communities. The Ward Committee Members tend to have closer ties with the communities than the Ward Councillors as they live within these communities. The Ward Committee is led by the Ward Councillor and the members of the committee represent their community structures and groups accordingly.

\subsection{Current energy services}

In Port St. Johns 67.8\% households use grid electricity for lighting and 31.2\% of these households only use this energy source for cooking while $17 \%$ use it for heating (see Table 5.1). This municipality is planning to provide grid electricity to the remaining 32\% households by the year 2014 .

Table 5.1 shows the percentage of households using wood for cooking and heating. A significant number of households in Port St. Johns are not connected to grid electricity and $60 \%$ of them rely on wood for cooking where $68.7 \%$ of these households rely on it for heating (StatsSA 2011). 
Table 5.1: Percentages of households using types of energy in Port St. Johns -

\begin{tabular}{|l|l|l|l|}
\hline & Lighting & Cooking & Heating \\
\hline Grid electricity & 67.8 & 31.2 & 17.1 \\
\hline Gas & 0.4 & 3.0 & 1.5 \\
\hline Paraffin & 1.6 & 4.9 & 5.6 \\
\hline Wood & & 60.1 & 68.7 \\
\hline Coal & & 0.1 & 0.4 \\
\hline Animal dung & & 0.2 & 0.2 \\
\hline Solar & 0.3 & 0.1 & 0.2 \\
\hline Candles & 29.4 & & \\
\hline Other & & 0.2 & 0.0 \\
\hline None & 0.5 & 0.4 & 6.4 \\
\hline
\end{tabular}

Source: Statistics South Africa 2011

According to the Noqhekwana residents, wood use is high in this village. The majority of women depend on wood that they collect from the nearby forest to prepare meals for their families and keep their families warm in winter. One of the Noqhekwana residents said: "Wood is the only thing we know and it is most affordable for us although we have to carry the heavy loads on our heads". Some households have petrol and diesel powered generators but according to some of the people attending the informationsharing meeting, "these generators don't last long and the after a few months of use they break down. It is expensive to repair them and it is also expensive to buy petrol (and diesel) all the time."

\section{Alternative energy services}

Another way that the Port St. Johns municipality is influencing the implementation of FBAE policy shows in the plans that are set out for the future of energy provision in this municipality. The acting Chief Financial Officer echoed the words of his predecessor by saying that:

'The Port St. Johns municipality's intentions are to ensure that households are provided with grid electricity as there are not many of them without grid. We want to make sure that everyone has 
access to grid electricity, and later, we can have a look at the alternative energy sources. The Renewable Energy Technologies will be used to assist where grid electricity fails but they will not be the priority energy supply option given by the municipality to its residents. Installing grid electricity for all households under the municipality will save money for the municipality as alternative energy services such as solar systems are expensive. It is also faster to install grid electricity instead or renewable energy technologies'.

According to the former Chief Financial Officer, Port St. Johns municipality has provided grid electricity to $90 \%$ of its households and they have a standing agreement with Eskom, the electricity utility, that all households within this municipal area will be provided with grid electricity by the end of the year $2014^{54}$. The lack of motivation to provide alternative energy services was demonstrated when the municipality decided to stop the Solar Home Systems (SHSs) maintenance services for the few households that have these systems in their homes. The SHSs were installed in this area as part of the solar concessions programme in the late 1990s.

Solar Home Systems (SHSs) are not a popular nor a common form of providing energy services for households in South Africa. They are not common because the majority of the country's households which are connected to grid electricity, considered it cheaper than the alternatives. In South Africa, the state utility company - Eskom, generates electricity from the 'cheap' ${ }^{\prime 5}$ and ample coal reserves. SHSs are usually provided to households located in remote rural areas. These households perceive them as low-quality energy sources since they cannot satisfy all household needs such as cooking and heating (Energy Research Centre 2004: 35).

In the late 1990s, the national government invited renewable energy companies to bid for contracts that would enable them to provide SHSs to

\footnotetext{
${ }^{54}$ Interview with former Port St. Johns municipality Chief Financial Officer. 16 May 2011.

${ }^{55}$ Although coal is said to be a cheap energy source to generate electricity in South Africa, the external costs of generating this electricity are high in terms of negative health and environmental impacts in the areas surrounding the coal-fired stations.
} 
households in the remote rural areas, especially those located far from the national electricity grid (at least $10 \mathrm{~km}$ or more). These households were seen as having lower chances of being provided with grid electricity in the near future or within the coming five to ten years. A few companies with the technical expertise to provide SHSs were contracted to provide SHSS services to three provinces, one of which was the Eastern Cape province, where this study is located. The companies were given exclusive rights to provide SHS services in their allocated areas for a period of 20 years. The contract conditions were that, the government would pay the full installation amount for each SHS provided to a household that applied for a SHS installation. The service provider would collect the monthly fee-forservice from each household with a SHS. The service provider companies were not allowed to provide SHS to households that were unable to prove that they could afford the application fee and the monthly fee-for-service. Service providers were only allowed to install SHSs to households with sources of income such as monthly old-age state pension or wages from employment. The service providing company would be responsible for the technical maintenance of the SHS for each household, collection of fees-forservices from households and giving detailed reports to the government about the progress of their services to households. It was also emphasized that households provided with these SHSs were not allowed to 'selfmaintain' the systems as this service would be provided by the service providers. If households were found to have 'tempered' with the system, they would be liable for full repair or replacement costs.

Around the year 1999, some villages in Port St. Johns and Ingquza Hill ${ }^{56}$ local municipalities were identified by Eskom as areas that would not be receiving grid electricity in the near future, estimated at five to ten years. Within these villages, households with an interest in receiving SHSs and could afford the service, applied for SHSs to be installed in their homes and entered into a contract with the service provider where they paid their monthly service fees (Mohlakoana 2003: 53). Over a period of five to seven 
years, the company ran into financial problems for a number of reasons, including:

- Quicker than expected grid electrification of some areas that were not electrified previously;

- Removal of SHSs from households with new grid electricity installations as they did not need SHSs any longer. The removal process was costly for service providers as this was not part of the payment they received from either the national government or from the households;

- No allocation of new installation areas by Eskom and the government. The company could not rely on SHSs installation revenue any longer which contributed most to its business;

- Some households were finding it difficult to afford the service fees, therefore they were not paying the fee-for-service as frequently as expected;

- Theft of SHSs (panels and batteries) from households leading to the company having to replace these parts at their own cost.

Although many SHSs have been removed due to the arrival of grid electricity, households in areas where grid electricity has not reached still have their solar systems. This does not necessarily mean that these SHSs are still in working order as it was discovered in Ingquza Hill municipality ${ }^{57}$. The maintenance of the SHSs for the household was taken over by smaller, local-owned and new companies who were appointed by the national Department of Energy and the local municipalities. As part of the Free Basic Alternative Energy (FBAE) policy implementation, households were not required to pay the full fee any longer, the municipality paid up to $85 \%$ of the fee-for-service on behalf of the households. Unlike the initial concessions companies, these smaller local companies were also provided with 'start-up' funds by the national government. These new, relatively inexperienced companies were faced with maintaining systems that had been abandoned for a long time by the original installing companies. Unfortunately for some of these new smaller companies, as it is the case

\footnotetext{
${ }^{57}$ Most of the households visited in Ingquza Hill said that their SHS had stopped working. See chapter 6 .
} 
with the two interviewed as part of this study, they have not been successful in keeping these businesses operating due to problems in generating an income. Based on the interviews with these companies, explanations for lack of income generation include:

- local municipalities not paying the FBAE subsidies to the smaller companies as stipulated in the contract;

- local municipalities refusing to renew contracts with the smaller companies and claiming that they are reviewing whether they need the SHS to be maintained or not;

- disagreements amongst partners of the smaller companies;

- resources insufficient to maintain the upkeep of the companies, especially when there is non-payment of fees by the local municipalities;

- local municipalities wanting to have grid electricity instead of SHSs for their households; and

- not enough mediation by the Department of Energy in resolving issues between the smaller, new companies and the local municipalities.

Research studies conducted during the time of SHS installations in the Eastern Cape found that households benefited from use of these systems. The use of electrical lighting was most appreciated by these households. They could undertake activities previously impossible to perform like opening a home-based business for longer periods of hours, doing school and house work at night (Energy Research Centre: 2003). Households also appreciated the use of radio and television for entertainment and information services as well as being able to charge their mobile-phone batteries, a service much needed since most rural households in South Africa depend on mobile phones for communication services. Households also acknowledged their frustrations regarding SHSs in that they could not use them for their thermal energy needs such as cooking and heating which meant they had to rely on other energy sources such as wood, paraffin and LPG to satisfy their needs. 


\subsection{Port St. Johns' municipality's indigent households' register and FBAE policy implementation}

A representative of the Port St. Johns municipality mentioned that the municipality was facing problems with the delivery of basic services for its people. An example was made by pointing out that Ward 6, the immediate area surrounding the town, has become a 'problematic' area. According to this representative, 'the municipality has come to realize that many of the households in Ward 6 cannot afford to pay for municipal services such as water, rates and refuse removal. These households should be classified as indigent and be on the indigent register because of their low-income and inability to afford service payments'. This emphasizes the need for a valid and credible indigent register, as required by the provincial and national government. The municipality has not started collecting information about its residents to identify those that qualify as indigents, knowing who qualifies as an indigent household is currently impossible.

During the first interview with the Free Basic Services Coordinator, he mentioned that the municipality does not have updated information on indigent households and one of his plans is to ensure that this information is updated as it is vital for the delivery of basic services for the people of Port St. Johns. During the second interview ${ }^{58}$ it was mentioned that the District municipality has provided funds for employment of three people per local ward to collect information that will help complete and keep up to date the indigents register.

According to the Port St. Johns Free Basic Services coordinator, the local municipality is working closely with the district municipality to collect household information that will be used to update the indigent lists. He said that they are aware that:

"By now, the conditions in most households have changed. The people that were on the indigent lists when the district municipality was collecting information, may have increased in numbers due to

\footnotetext{
${ }^{58}$ Second interview with Port St. Johns' Free Basic Services Coordinator. 18 April 2012.
} 
high unemployment levels in the area and they may be living under different conditions currently".

Updating the indigent list will also assist the local municipality in reporting to the provincial department on the services that it has been able to provide.

Although it had been a year between my first and second interviews with the Free Basic Services coordinator, during the second interview he admitted that there had been no change in the implementation of FBAE policy in Port St. Johns. His response was:

"No work regarding the implementation of FBAE has taken place within this financial year [2011/2012]. The municipality does not have concrete plans yet on how to go ahead with the implementation of FBAE policy but we do not intend installing solar homes systems for unelectrified households, but may provide them with paraffin or Liquefied Petroleum Gas. This is something that we have to discuss and plan as a municipality especially because we intend to have all of our households provided with grid electricity by 2014. We also lack staff capacity and resources such as funds to provide households with renewable energy such as solar systems".

This statement adds emphasis to how the municipality has not implemented the Free Basic Alternative Energy (FBAE) policy. As stated earlier, the municipality has made a decision to discontinue with the implementation of FBAE in the form of providing SHSs services to households without electricity. The municipality has also made it clear that they would prefer to have grid electricity for all their households instead of SHS or other energy alternatives.

As it is the responsibility of the municipality to collect and compile information on indigent households, the municipality has established an "Indigent Committee". The committee's responsibilities include updating the indigent register previously received from the district municipality in 2009. The Port St. Johns municipality has not been able to update the 
register with new information due to a lack of resources such as staff, nor have they been able to employ services of consultants due to a lack of funds. The "Indigent Committee" is made up of ward councillors- three executive councillors, three non-executive councillors and the mayor. One of the main responsibilities for the indigent committee is to ensure that the correct beneficiaries are on the indigent register. The committee will also ensure that indigent households know what they are entitled to in terms of services they can access from the local municipality. This information dissemination will also extent to the larger community. The aim is to inform communities about what it means to be an indigent household, and give them information on how they can register if they qualify.

The establishment of the indigent committee is an improvement from the previous year (2011) where the municipal representative had said that there was no capacity to collect data on indigent households and no plans to establish a committee that would assist in this. Not having sufficient information on indigent households in an area like Port St. Johns prevents the local municipality from delivering basic services according to the needs of the people. It also prevents the municipality from knowing the exact number of households that cannot afford to pay for basic services.

\subsection{The process of FBAE policy implementation by different actors in Port St. Johns}

The following sections discuss how the implementing, target and linking actors are involved in the process of implementing the Free Basic Alternative Energy policy in the Port St. Johns case. Similar to the other case chapters in this thesis, the discussion on each actors' interaction process is depicted by the use of the Contextual Interaction Theory's illustration that shows the "dynamic interaction between the key actor-characteristics that drive social interaction processes and in turn are reshaped by the process" (Bressers 2009) - see Figures 5.2., 5.3. and 5.4. 


\subsubsection{Implementing actors' role in the Free Basic Alternative Energy policy implementation}

During the years 2007 to 2009 a service provider worked with the Port St. Johns municipality to deliver Solar Home System maintenance services to remote rural households with solar systems as part of the FBAE policy implementation. Even though the written official contract between the service provider and the municipality was meant to end in 2008, the service provider continued working on the basis of a verbal agreement with the municipality but stopped when payments for services were no longer honoured by the municipality.

According to the municipal representative, the municipality thought it best not to continue with the contract as the service was becoming too expensive for the municipality and the service provider was demanding a higher payment. Apparently, the provider wanted to charge the same rate that was being charged by Eskom for providing Free Basic (grid) Electricity (free electricity units $)^{59}$. The municipality felt that this amount would be too high for the limited electricity service that SHSs provide. In particular, SHSs could not be used to meet household thermal needs such as cooking and heating which are activities that are important in all households.

The municipality also needed to verify the indigent information on the households that were receiving the solar maintenance services. However this was not possible as none of the municipal staff knew the exact number of households with solar home systems in the area, nor their income information or their exact location. According to the municipal representative, stopping the solar maintenance services has provided the opportunity to reflect on whether this is the service they want to provide as a way of implementing the FBAE policy. They are also considering an option where they do not provide FBAE service but wait for grid electricity, which

\footnotetext{
${ }^{59}$ Eskom provides $50 \mathrm{kWh}$ of electricity for free to indigent households. The local municipality pays for the costs of this free electricity.
} 
is expected by the municipality in 2014 since " $90 \%{ }^{60}$ of the villages under Port St. Johns already have grid electricity".

The analysis of the implementing actor's motivations, cognitions (information) and resources (capacity and power) in Figure 5.2 shows how these actor characteristics influence the implementation of the FBAE policy by this municipality. This actor's motivations do not support the provision of FBAE services through the implementation of the policy. Although this municipality had previously provided FBAE services, it later decided that this was not its goal.

This actor's cognitions concentrate on the information availability and use to deliver services to indigent households. Based on the information given by municipal representatives during fieldwork, it was made clear that this municipality does not have information on its indigent households. This makes it difficult to deliver needed services as it is not known the type of services to be delivered and the number of households that need these services. This actor's choice of not providing FBAE services is mainly based on the information that it receives from the grid electricity service provider, which has indicated the possibility of providing grid electricity in this area by the year 2014

The actors' frames of reference, knowledge and information as actor characteristics influence FBAE policy implementation and present an opportunity for the actors to defend their actions. When actors make a decision and back it up with 'evidence' to show that this decision is valid, it becomes easy to convince all concerned that this is the best decision. In the case of the Port St. Johns municipality not wanting to implement the FBAE policy programme through providing alternative energy services, this decision is supported with information that this municipality will have $100 \%$ grid connections by the year 2014. Therefore they see no need to provide alternative energy services.

\footnotetext{
${ }^{60}$ This figure is different for that on Table 5.1 (67.8\% using grid electricity for lighting) with data provided by Statistics South Africa based on the national census in 2011.
} 

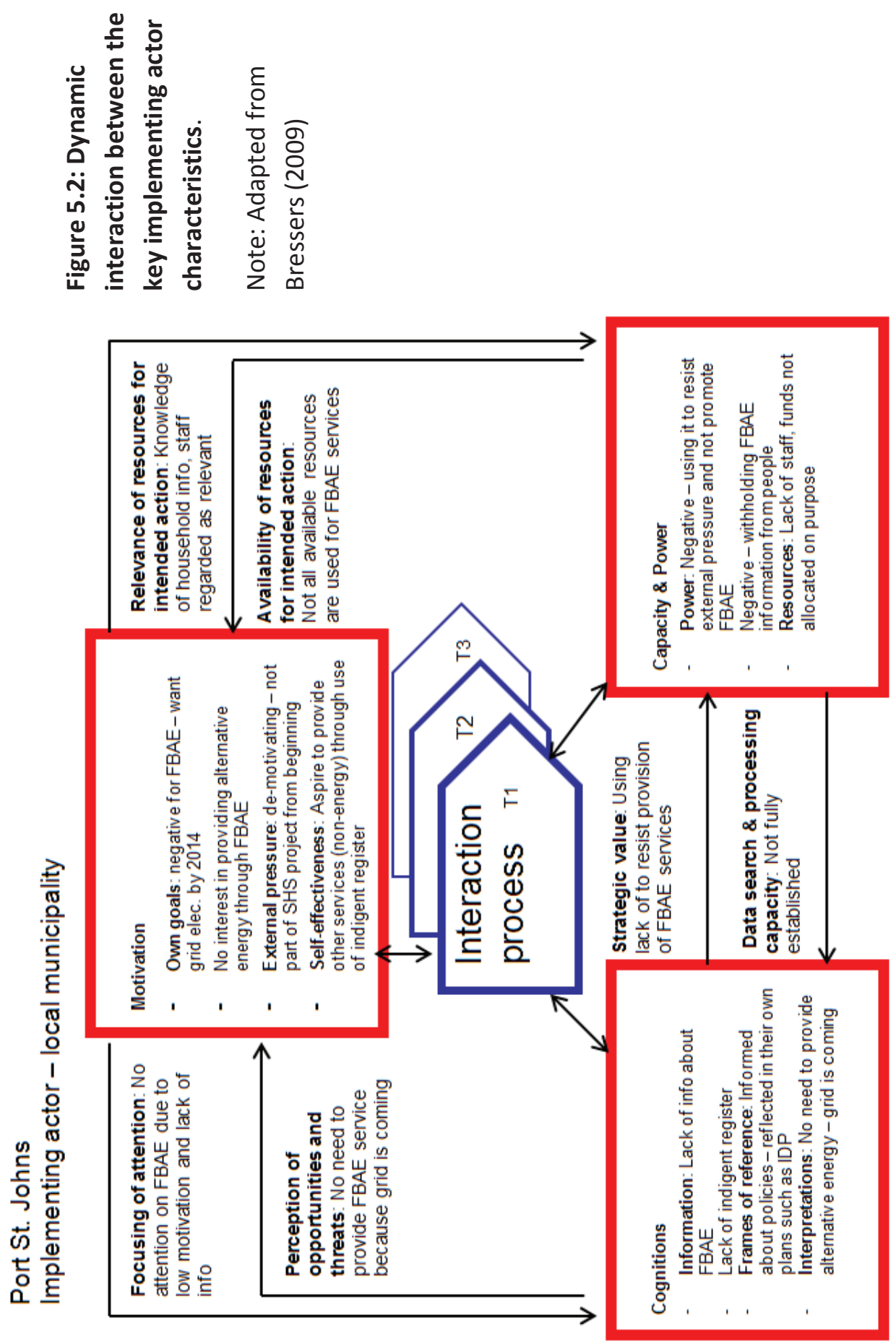
This actor's resources also influence its implementation of the FBAE policy. In fact, this actor mentions that one of the reasons why they as a municipality would rather wait for grid electricity, is that, alternative energy services such as solar are expensive. This municipality's Community Services department which is responsible for the implementation of the FBAE policy among other things, is understaffed. This department was established as a requirement by the provincial government as it needed all local municipalities to have an office responsible and officially in charge of Free Basic Services delivery including FBAE services.

Power attribution by other actors is also influential in the way this actor implements the FBAE policy. This actor uses its position as the organisation with the legal authority to make decisions that it sees as appropriate for the households that it serves. The decision not to provide solar services as part of FBAE implementation is based on this actor's knowledge that the other actors acknowledge it as an actor with power and so accept the municipality's decisions. Evidence to support this is presented later in this chapter where one of the target actors that regards itself as powerless acknowledges that it attributes decision-making power to the implementing actor.

\subsubsection{The target actors' role in the Free Basic Alternative Energy policy implementation}

As previously mentioned, in Port St. Johns, two areas were visited in order to find out the extent of FBAE policy implementation. Noqhekwana village and Mthumbane township provided the study with invaluable information which demonstrates the influence of target actors in the implementation of FBAE as well as the impacts of such on households and communities. 


\section{Noqhekwana village}

As there were no household interviews in Noqhekwana, a few members of the community gathered for an 'information-sharing' meeting ${ }^{61}$ with me at the village church building as requested by the Ward Committee member.

On cognitions (Figure 5.3) with a focus on information that the target actor has regarding the FBAE policy implementation process it was clear that in Noqhekwana village, there was no concrete information received by householders regarding the process. During the meeting some of the people said they had heard that households without grid electricity in other villages outside of Port St. Johns were given paraffin by their municipalities but they did not know why these households were receiving this fuel. The Noqhekwana villagers had also not asked their municipality or their local councillor or ward representatives about why they were not receiving paraffin or any other alternative energy service. This is because they did not know about the Free Basic Alternative Energy (FBAE) policy implementation process $^{62}$.

\footnotetext{
${ }^{61}$ The information-sharing meeting took place on 20 April 2012 at the Noqhekwana Church building.

${ }^{62}$ During this information sharing session, I had to explain to the Noqhekwana residents in attendance what the FBAE policy is and how it is supposed to be implemented according to the national government.
} 

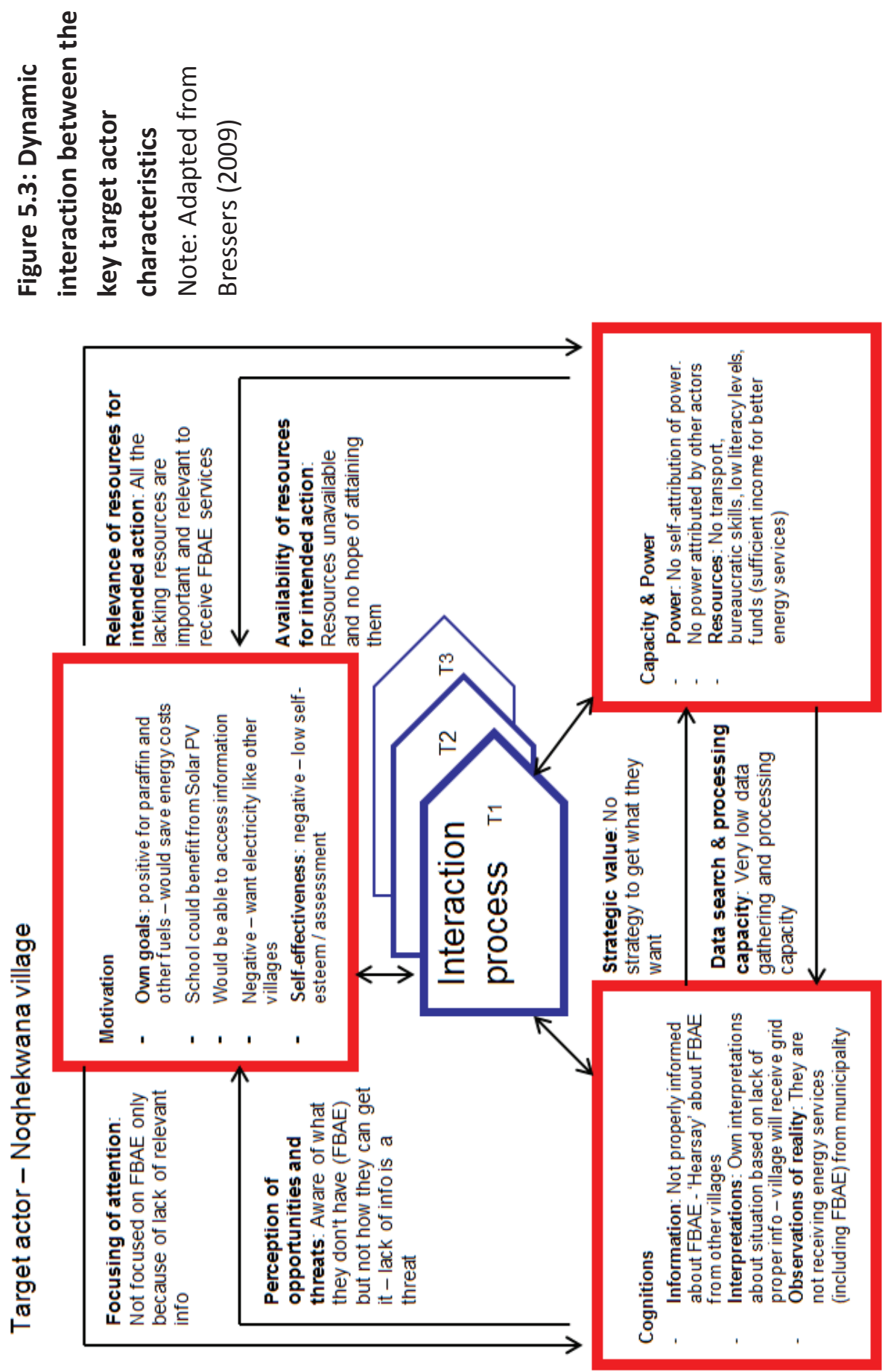
During the meeting the villagers also mentioned that they did not know why their village did not have grid electricity yet while others in the surrounding areas were electrified. They said they found this even more confusing because they are a village located very close to the town centre of Port St. Johns, which is fully electrified, hence they thought it should be easy to provide this village with grid electricity. Some of the people in the meeting speculated that their village may receive grid electricity "at least in the next two years" (by 2014). On probing further, it was clear that their speculation was based on them seeing the power lines that were being erected in the surrounding villages by Eskom, the electricity utility company. This gave the Noqhekwana villagers hope and created an expectation that they will be receiving electricity soon. From what the people were saying, it was clear that they were not informed about the delivery of energy services from the municipality

The issue of information at Noqhekwana village did not only concern the implementation of the FBAE policy but other village issues as well. During this meeting it was mentioned that previously there were conflicts between the former ward councillor and the traditional leaders as well as the residents of this village. The residents said that the former ward councillor had been in his position for ten years (two terms) and "has not done much for the community". The residents said they became frustrated when the former councillor could not respond to their questions concerning electrification of their village. They said the former councillor did not take their concerns seriously as he was not living in their village, therefore he did not experience the hardships of living without electricity.

As mentioned above and in the other case chapters, the indigent register is important for the delivery of basic services such as FBAE as it provides the implementing actor with knowledge of the households and the type of services they need. The target actor did not know about the indigent register except that " people working for the local municipality visited them a long time ago to collect their names and some household information such as income and education levels of occupants". It was not explained to the households why this information was collected. According to the 
villagers, "We thought that they would be coming back to assist us with rebuilding some of our homes that were damaged by the storms. We told them that we need stronger building materials such as bricks and cement but we cannot afford them and continue to live in mud huts".

With regards to motivation, this target actor aspires to have grid electricity or alternative energy services depending on availability. According to this actor, electricity would make a positive impact to their village and contribute to the way they live and generate income. The residents say that they have attempted to established some community-based projects to benefit all the villagers. These have failed because of lack of reliable, affordable and secure energy supply for activities such as jam-making and sewing.

It is not only on households that the lack of electricity and other energy services negatively impacts. The residents mentioned that the local school which enrols students from grade one to eight, also has no reliable and modern forms of energy services. As parents, the residents said that they thought the government would provide solar systems for the school in order for the school to have facilities like laboratories and provide lessons that that depend on electric energy. One of the residents said:

"Our children are left behind when compared to those from other schools that have electricity. Our children do not know what is happening around the world because they cannot watch television and access the internet. They are going to find it difficult to compete with their peers once they advance to higher standards and leave this village." ${ }^{63}$

Linked to the negative impacts that lack of electricity has on the school children's access to information, the Noqhekwana village residents said that due to the high costs of dry-cell batteries used to power their radios, they do not listen to the news programmes and current affairs.

${ }^{63}$ After the visit to Noqhekwana Junior Secondary School I wrote an article which was published online by "The Times", a South African daily newspaper. Please see Annex XX for the full article. 
"We do not listen to the radio or watch the news because it is too expensive to buy batteries for the radio or charge the car battery for television. We cannot afford to do this because there is no money and most people in this village are not employed".

Even though paraffin is zero-rated in South Africa, Noqhekwana residents still perceive it to be too expensive, especially when they buy it from the local shops (within the village). Residents claimed that it is better to buy paraffin in the town's centre of Port St. Johns as it is less expensive but the cost of transport to town is seen as a disadvantage.

To express their need for energy services, one of the residents said:

"The village has great potential in starting a fishing project because most people fish on daily basis. They catch big fish, crayfish, mussels and oysters and they have permits to do this. The problem is that the village has no electricity and this makes it difficult for people to store their catch. If they cannot sell what they have caught, they are forced to give it away or sell at the lowest price. We are living a difficult life here, we are forced to eat everything all at once because food gets spoilt easily if we keep it. If we slaughter a cow for a ceremony, we have to eat everything on that same day... even if you are full, you have to force the food down and leave nothing for tomorrow, else, it will go bad. It is also expensive for us because we have to shop more frequently than necessary... this is costly in transportation and buying smaller portions instead of bulk".

With regards to capacity and power, the Noqhekwana residents as a target actor have acknowledged that they do not have decision-making powers with regards to energy services for their village. The municipality makes this decision on their behalf. Even in situations where they have an opportunity to make this decision like accessing solar energy services from an independent service provider, they often do not have enough funds to pay the capital (initial) costs. This was the case when they were approached by a service provider that asked them to pay an equivalent of $€ 30$ (R300) as an initial cost for solar systems that would provide them with lighting. 
This target actor has a 'strained' relationship with the local leadership which made it difficult for them to press for their area to be provided with alternative energy services. They found themselves 'voiceless' and their needs for energy services were pushed to the periphery. This also renders them powerless. The 'strained' relationship with those in power impacts negatively on information and knowledge. Such households and communities are usually left in the dark about the implementing actor's service provision plans and decisions. This leads back to a lack of motivation on the households' part where they end up seeing it as a waste of time and effort to convince implementing actors to provide them with energy services.

\section{Mthumbane township}

Unlike Noqhekwana village, a majority of Mthumbane township residents have grid electricity connections. According to this area's ward committee member, there are only 67 households in this township without electricity because they were built after the area was provided with electricity through the National Electrification Program headed by the national Department of Energy. This ward committee member perceives these households as small in number and therefore making it unnecessary for the municipality to provide alternative energy services to them. He confirmed that the municipality has plans to provide grid electricity to all households by the year 2014 .

Using the CIT dynamic interaction model to analyse how the target actor's characteristics influence the FBAE policy implementation process, Figure 3.4 outlines the issues raised under each actor characteristic. With respect to motivations towards receiving FBAE services, the Mthumbane target actor is not positively motivated. Due to access to grid electricity for most of the households, this actor has not made an effort to access alternative energy services from the municipality. The few households without grid electricity access their own alternative energy sources and secure some grid electricity 
connections informally from their neighbours, often with the use of extension leads.

This target actor is proactive compared to the Noqhekwana villagers. Concerning its cognitions, in particular access to information, this actor is prepared to approach the local leadership to inquire about service delivery plans. This type of action prompts the municipality to give feedback to these residents most of the time. Information about the FBAE policy implementation process in the area is not given to the target actor because of the implementing actor's belief that grid electricity will be delivered by the year 2014 to all households. The households (target actor) is also not seeking information about the FBAE policy because most of the area has grid electricity connections and they also believe that it is just a matter of time before all households have access to their own grid electricity connections.

According to the ward committee member, the residents of Mthumbane have never asked the leadership about the implementation of FBAE subsidies. The only energy subsidy that they are concerned about is 'Free Basic Energy', where households that are considered to be low electricity consumers are provided with 50 units $^{64}$ (50 kWh) of 'free' electricity per month to meet their household energy need

\footnotetext{
${ }^{64}$ The average cost of a unit of electricity supplied by Eskom in South Africa is 68 cents (6.8 Euro cents) - 68c/kWh.
} 

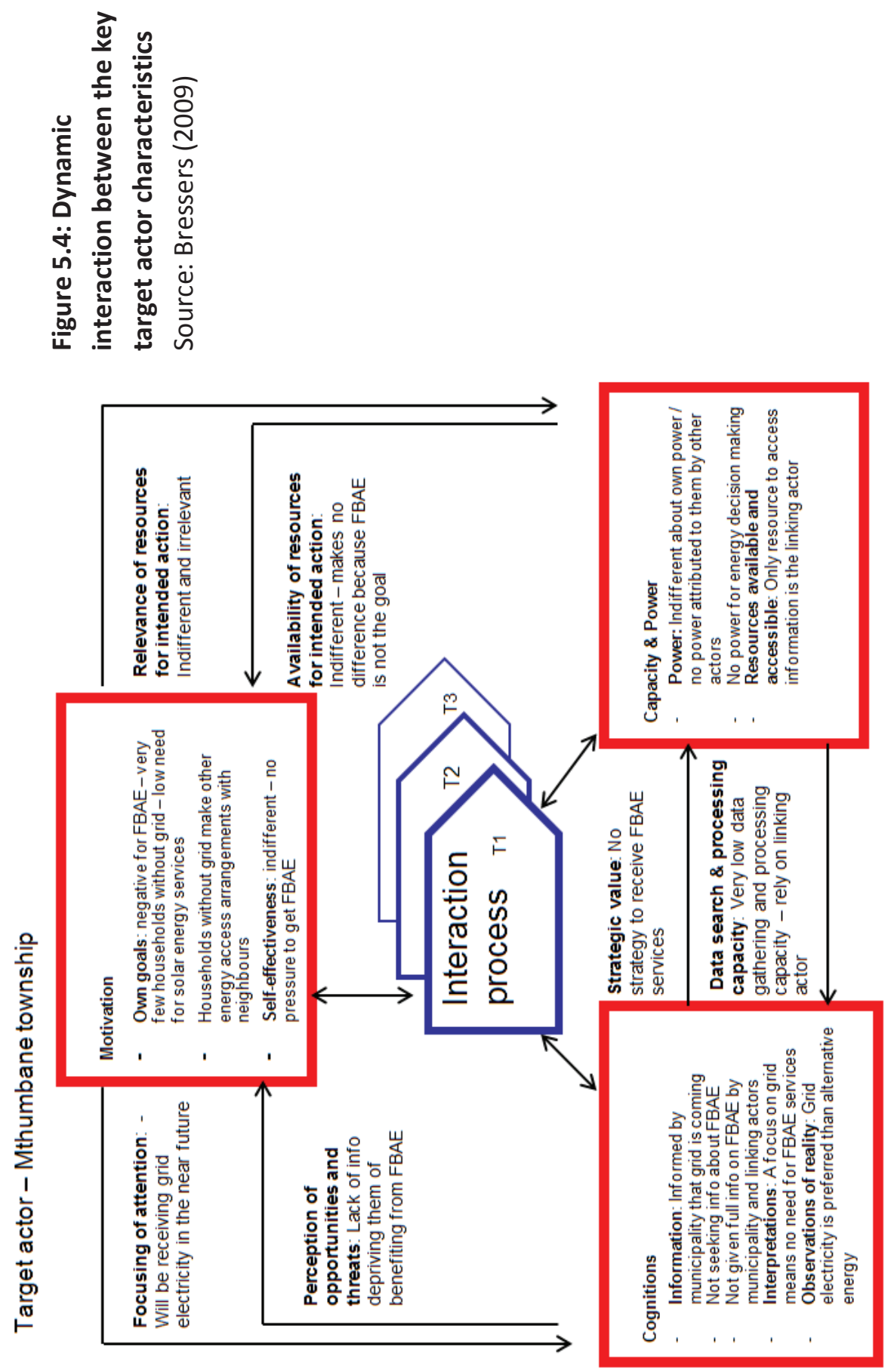
Table 5.2: Summary of Noqhekwana village and Mthumbane township influences to FBAE policy implementation

\begin{tabular}{|ll|l|}
\hline \multicolumn{2}{|c|}{ Noqhekwana village } & \multicolumn{1}{c|}{ Mthumbane township } \\
\hline 1. & No access to FBAE policy subsidies & No access to FBAE policy subsidies \\
\hline 2. & No electricity & Mostly electrified \\
\hline 3. & Traditional dwellings & Modern dwellings \\
\hline 4. & Difficult to access town centre & Easy to access town centre \\
\hline 5. & $\begin{array}{l}\text { Leadership does not have sufficient } \\
\text { information on municipal plans }\end{array}$ & $\begin{array}{l}\text { Leadership is well informed on municipal } \\
\text { plans }\end{array}$ \\
\hline 6. & $\begin{array}{l}\text { Residents not pro-active in energy } \\
\text { services decision-making }\end{array}$ & $\begin{array}{l}\text { Residents active in seeking information } \\
\text { about decisions made regarding energy } \\
\text { services }\end{array}$ \\
\hline 7. & $\begin{array}{l}\text { Leadership not pro-active in seeking } \\
\text { service delivery information }\end{array}$ & $\begin{array}{l}\text { Leadership pro-active and keeping residents } \\
\text { informed }\end{array}$ \\
\hline 8. & School not well equipped - no electricity & $\begin{array}{l}\text { Schools well equipped with electricity and } \\
\text { other facilities }\end{array}$ \\
\hline
\end{tabular}

The analysis of this actor's capacity and power gives an indication of the resources that this actor has access to in order to achieve its goals. In this case, this actor is not concerned about accessing FBAE services because of its access to grid electricity. This leads to this actor not needing resources that will lead to FBAE services but that will help in accessing other services. The main resource that this actor seems to be relying on for information regarding service delivery is the linking actor. The implementing and the linking actors are not attributing power to this actor as they take the role of decision-making regarding energy services on behalf of the target actor. Table 5.2 provides a summary of the differences and similarities on the issues that influence FBAE policy implementation between the two target actors analysed above

\subsubsection{The linking actors' role in the Free Basic Alternative Energy policy implementation process}

For purposes of accessing as much information as possible, interviews were conducted with the community leaders representing the Noqhekwana village and Mthumbane township. These community leaders will be referred to as linking actors in this section as they play a role of linking the communities (target actors) with the local municipality (implementing actor). 
The linking actors' characteristics also play an important role in implementation. How they interact as part of the process aids the implementation process or leads to its failure. In this case, the linking actors' main motivation is their positions. This position gives them access to information, resources and power. However, the influence they have on the policy implementation process depends on how they use this access. If they are motivated to stay in power as community leaders as well as employees of the local municipality, they have to deliver services to communities. If they are however placed in leadership of a 'docile' community, their implementation strategy becomes different from that of leading a more active community.

\section{Noqhekwana village linking actor}

This actor is not positively motivated to implement the FBAE policy and deliver alternative energy services to the indigent households of Noqhekwana village. A number of reasons can be advanced to explain this including lack of interest in the basic services needs of the community and the knowledge that the municipality would rather provide grid electricity than alternative energy services for these households. Figure 5.5 shows that one of this actor's motivations is to assist the implementing actor in achieving its goals which include not providing alternative energy services to indigent households which subsequently translates to not implementing the FBAE policy as prescribed by the national and provincial government departments.

This linking actor also kept FBAE policy information away from the target actor resulting in lack of knowledge about alternative energy services that can be provided through the implementation of this policy. Again, this is a strategy used by this actor to promote the implementing actors' goal of waiting for universal grid electrification instead of providing alternative energy services to households that are currently without access to grid electricity. By ignoring the target actor's requests for energy services, this linking actor strengthens its own and the implementing actors' motivations. 
This also means that this linking actor is ignoring information that it could use to create the much needed indigent register which will assist in the delivery of services for indigent households in this area.

There is power attributed to this actor by the other actors. The implementing actor has given this actor power by providing it with its leadership position and to make decisions that influence energy service delivery and FBAE policy implementation. The target actor also attributes power to this actor and regards them as being in a position of power where their actions (or rather inactions where energy service delivery is concerned) cannot be questioned. This linking actor's available resource is the close relationship it has with the implementing actor which provides it with access to privileged information regarding energy service provision.

\section{Mthumbane township linking actor}

According to the Ward Committee member representing the Mthumbane township community in the Port St. Johns municipal structure, the municipality ensures that relevant information about service delivery is available to households through Ward Councillors, Ward Administrators and Ward Committee Members.

Using the Contextual Interaction Theory (CIT) interaction model (Figure 5.6) to analyse this linking actor's influence on the FBAE policy implementation process it is clear that this actor's motivations are similar to those of the implementing actor. Although this actor is not completely against the provision of alternative energy services through the FBAE policy implementation process, they are also not keen because of the belief that grid electricity will be provided to all households soon. This actor perceives alternative energy such as solar systems as an unnecessary temporary solution because they regard them as more expensive and less useful than grid electricity connections. 

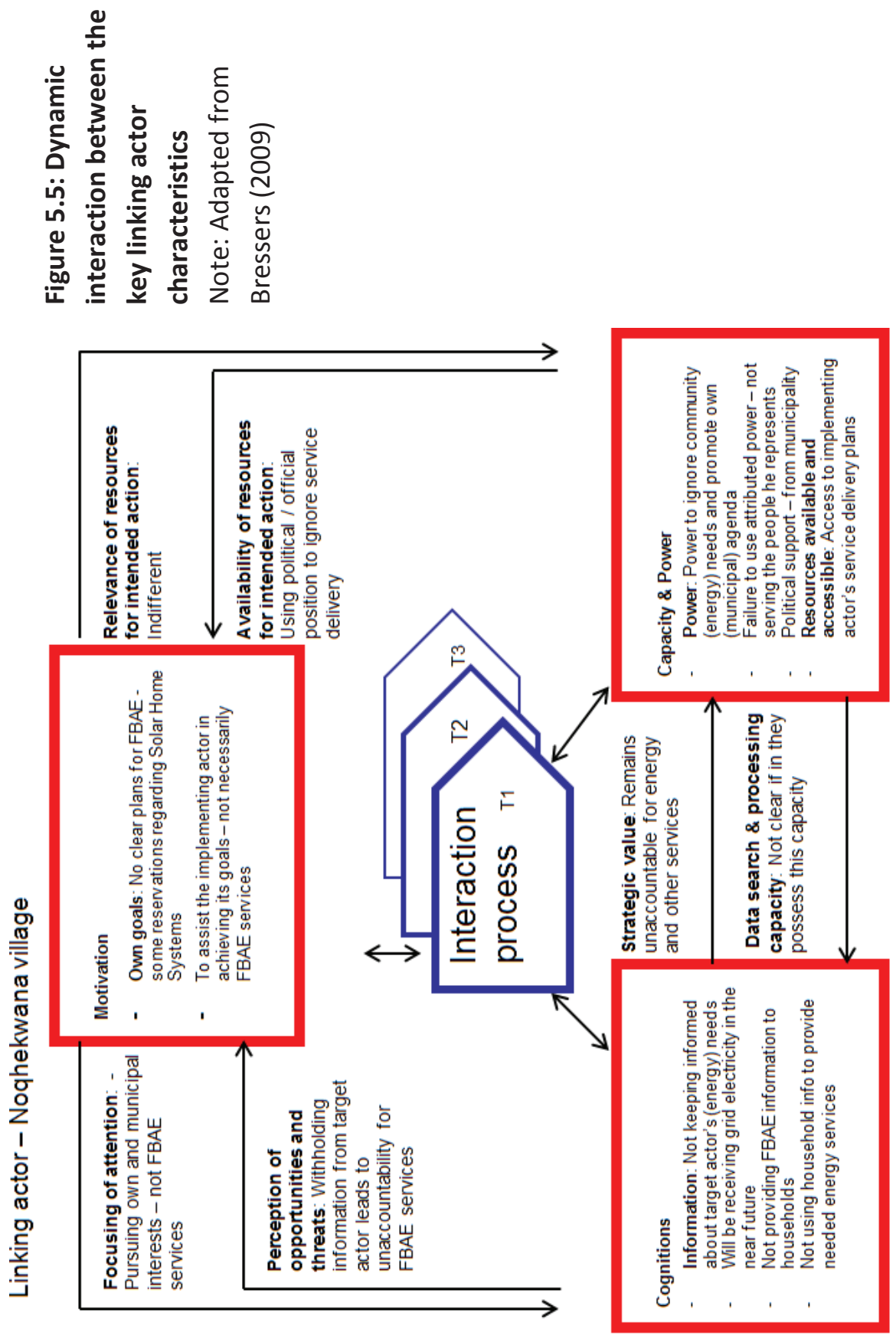

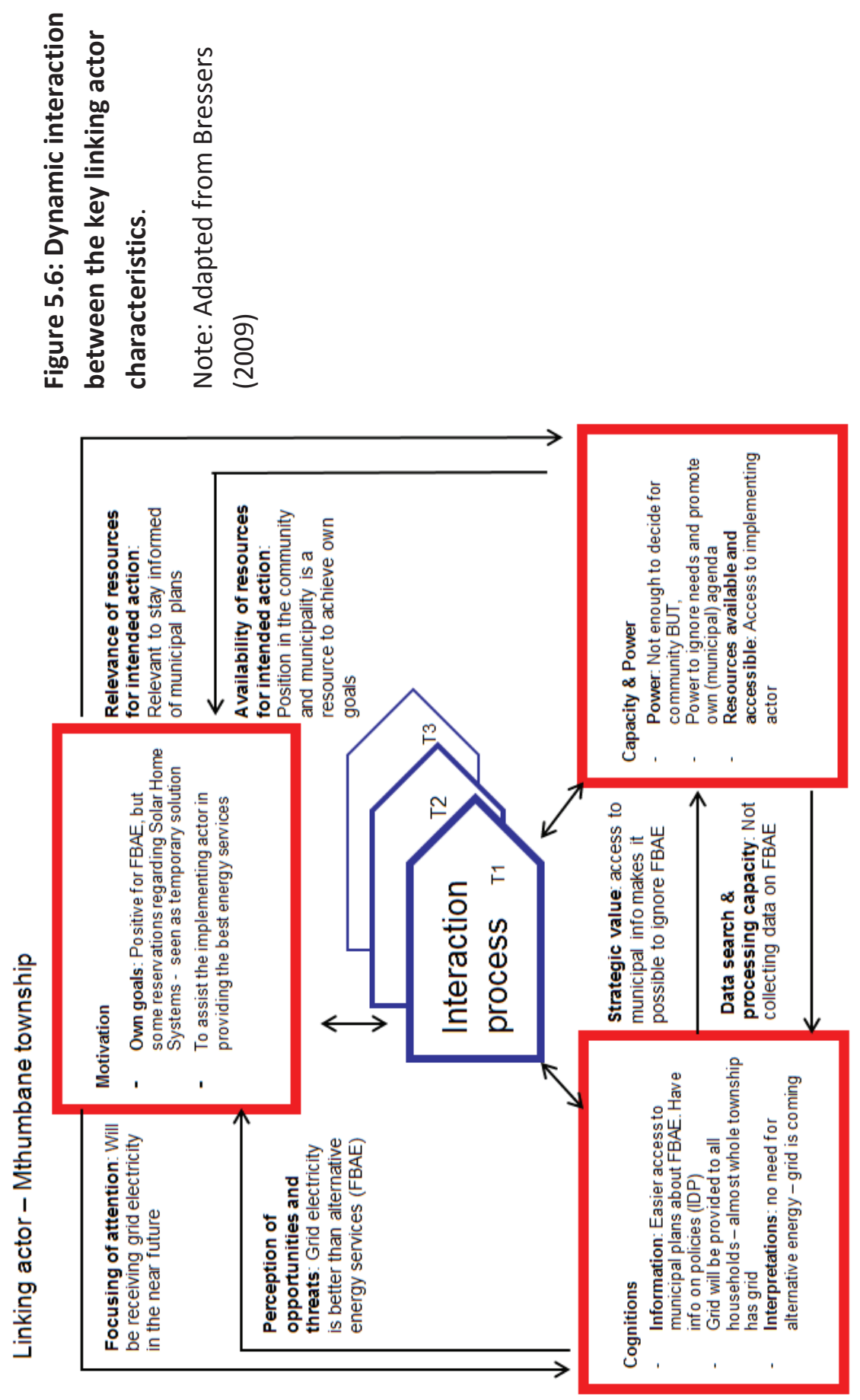
This actor's cognitions focus on the information used in the implementation process of the FBAE policy. This actor has access to information because of the close relationship it has with the implementing actor. It has access to the municipal plans such as the Integrated Development Plans (IDPs) that the municipality has regarding service delivery in the area. It is reported that since changes were made in the municipal administrative structure, information dissemination has improved in the area. In the past the township residents never used to receive any information about the municipality plans. The community representatives (such as this linking actor) were always accused by the community of withholding information. This posed a challenge to the linking actor as the target actor in this area always to know about certain issues concerning service delivery which the linking actor did not have access to. According to the Ward Committee member:

"The previous political leadership and management of the municipality did not interact with the people and the communities. Decisions were made without informing the public and people did not know what was happening. With the change in municipal management, the new municipality is planning on giving information to the people with the motto 'information is service delivery'."

This includes the information regarding the indigent register which will assist in identifying the number of households that are in need of municipal assistance and will help in improving basic services delivered to the people.

As most of the township is electrified, the majority of people in this area are using electricity for lighting and if they can afford to spend more, they use it for cooking and other needs. On the other hand, many households also use a lot of wood because it is 'abundantly available' around the area. Wood is especially used for slow cooking meals such as samp (dried maize and beans), which is a staple and cooked often. 
This actors characteristic of capacity and power shows that although there is some power attributed to this actor by the municipality and the community, it is not enough to make decisions concerning service provision. For instance, this actor cannot decide on their own which types of energy services to be delivered to the target actor as this decision is made by the implementing actor depending on their motivations. This actor's position allows it to have access to information concerning plans that the municipality has. This influences the implementation process as this actor communicates such plans to the households. This also ensures that households do not demand information about services that are not on the implementing actor's plans.

\subsection{Comparing the key actor characteristics of the implementing, target and linking actors}

Using the Contextual Interaction Theory to analyse the key actor characteristics assists in illustrating the FBAE policy implementation process and the influences driving this process. In this section the actor characteristics are compared to see if there are similarities in the way the implementing, target and linking actors perceive the FBAE policy implementation process. A summary of the mutual relations of actor characteristics is also given in detail for each actor to show how the actor characteristics influence the process and how in turn, they are reshaped by the process itself. 


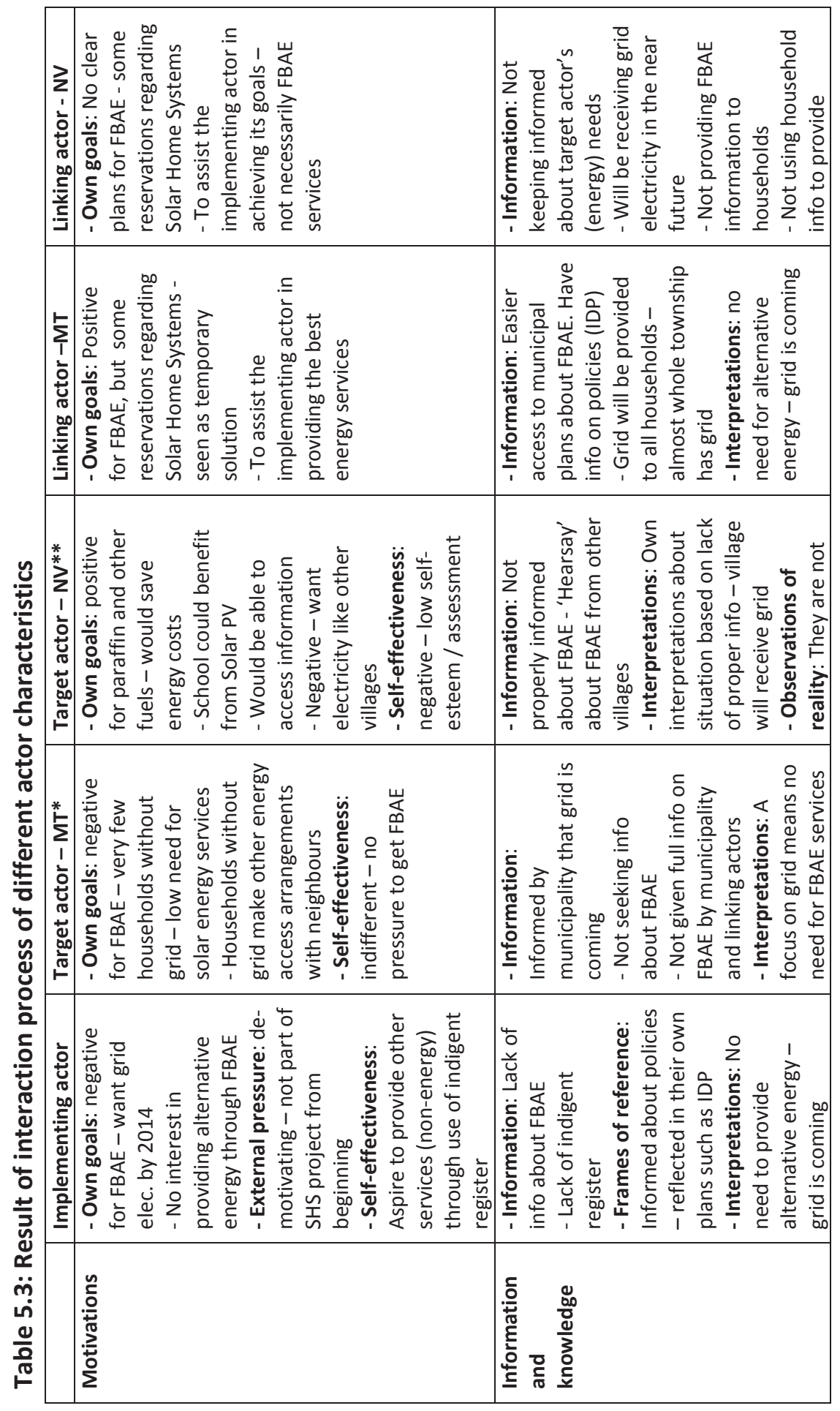




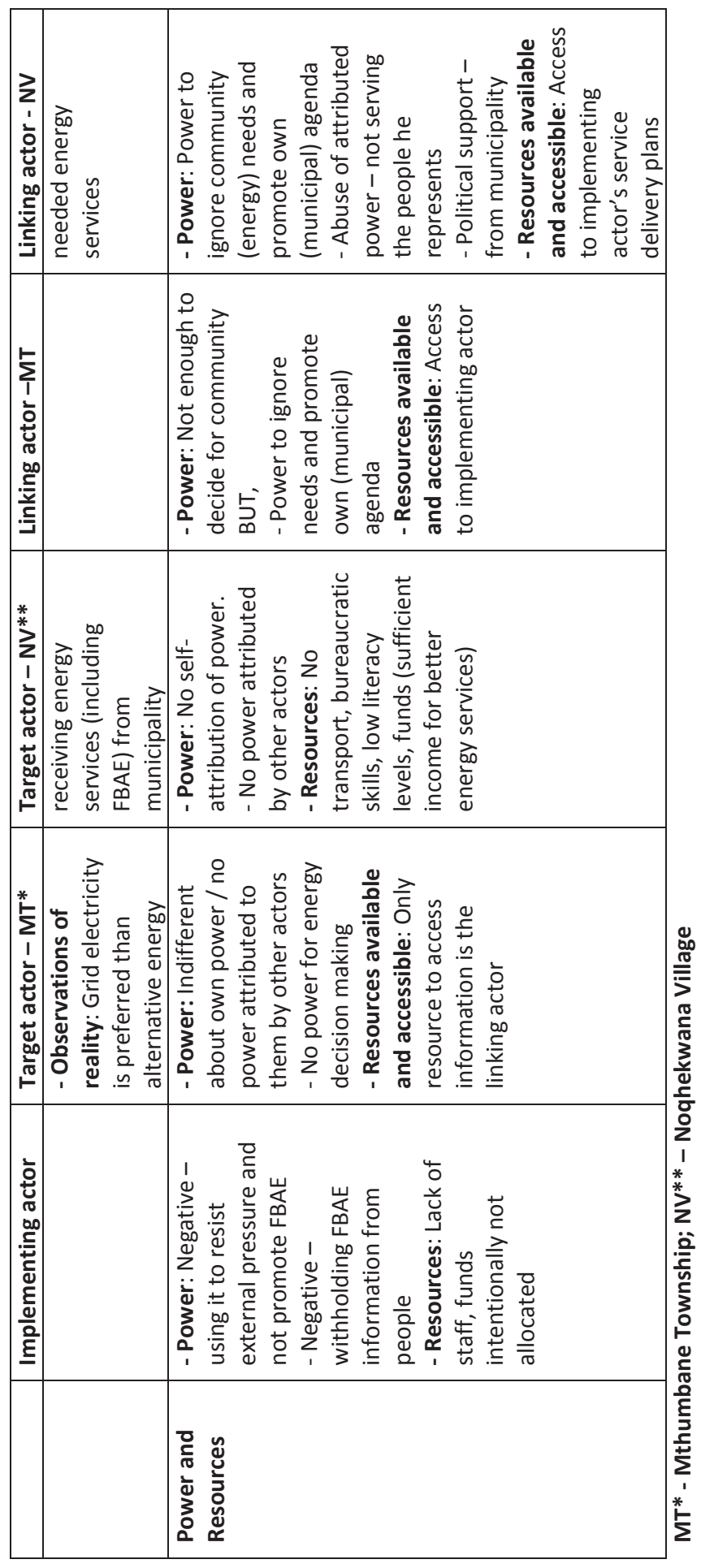




\subsubsection{Summary of comparison of Port St. Johns' key actor characteristics}

In Table 5.3 the motivations, cognitions and capacity of the actors are compared to find similarities and differences in the way these actor characteristics influence the interaction process.

The implementing actor's characteristics influence the implementation of the FBAE policy. The actors motivations in ensuring that the Port St. Johns area has grid electricity by the year $\mathbf{2 0 1 4}$ has led them not to provide and support alternative energy services such as maintenance of existing SHSs, installation of new SHSs and other renewable energy technologies. It has also resulted in this municipality's lack of providing paraffin unlike the other municipalities within the OR Tambo district.

The actors' motivation for FBAE policy implementation depends on various reasons such as the type of energy services they currently have access to and their relationship with the other actors. The implementing actor in this case has chosen not to provide alternative energy services as part of FBAE policy implementation. This actor's motivations have influenced the linking actors motivations and to some extent, the target actor's goals as well. The target and linking actors display lack of knowledge about the FBAE policy and how this benefits the indigent households if implemented by the municipality.

With regards to cognitions, the information that the actors have about the FBAE policy and its process of implementation as well as the knowledge about grid electricity provision seems to influence the actors' attitudes towards alternative energy services. The implementing actor's claim that they are not receiving relevant information about the FBAE policy implementation process from the national and provincial government departments gives this actor a reason not to deliver alternative energy services. This in turn influences the information that this actor disseminates to the target and linking and actors. In this case, the implementing actor provides information about grid electrification and not about alternative energy services as this would imply that they are implementing the FBAE policy. 
The lack of information about the FBAE policy is also evident in the target actors from Noqhekwana village and Mthumbane township. Access to energy services such as grid electricity influences target actors in two ways. Unelectrified households in grid electrified areas tend not to be encouraged to demand alternative energy services that could be delivered through the implementation of FBAE policy. Such households are convinced that they will get access to grid electricity 'soon' because they can see evidence from their 'neighbours' or households in their communities. On the other hand, households without grid electricity and located in non-electrified areas or where the arrival of grid electricity is not certain, tend to be motivated towards wanting alternative energy services even if they lack knowledge about the FBAE policy. The linking actor's motivations seem to be influenced by the implementing actor's views of the FBAE policy implementation and their aspirations to have grid electricity for all households.

The analysis of power and resources shows that only the implementing and linking actors have some power attributed to them by the target actors. The implementing actor freely makes decisions with regards to provision of energy services and is supported by the linking actor. The target actor, due to lack of information about alternative energy services and the FBAE policy, accepts the decisions made by the implementing actor in choosing grid electricity. This also means that there is no power attributed to the target actor by the linking and implementing actors. In this case, the target actor's power and resources are also dependent on their geographical location as this dictates the types of services delivered. The geographic location provides these target actors (Noqhekwana village and Mthumbane township) with capacity (or lack of) that determines their access to FBAE services. The Mthumbane township target actor has more information than the Noqhekwana village actor because they are close to the sources of information such as the linking and implementing actors. This also makes this target actor more active in seeking information and using this knowledge to gain an understanding of why they are receiving grid electricity instead of alternative energy services. On the other hand, being located far from the decision-making centre makes the Noqhekwana target 
actor lose out on the information and knowledge about the plans for service delivery. Their location also makes this actor less pro-active and less likely to have the needed capacity to bring it (alternative) energy services.

\subsubsection{Summary of mutual relations of actor characteristics} Beyond providing a picture of the dynamic interaction of the actor characteristics, Figures 5.2, 5.3, 5.4, 5.5 and 5.6 also show the result of this interaction and how the actor characteristics mutual relate to each other. In Table 5.4 the analysis of this mutual interaction for all actors in this case is given.

The 'focus of attention' by all the actors in this case is not on the implementation of the FBAE policy. The implementing actor is focused on getting grid electricity connections for all households under this municipality and has stopped all activities concerning the delivery of alternative energy services and the implementation of the FBAE policy. This in turn influences the linking and target actors' focus of attention. The linking actor is also focused on grid electricity connections that they believe will be possible to deliver to households soon. The target actor receives this information from the linking and implementing actors as well as from other sources and this pushes them to pay attention to the coming grid electricity connections instead of alternative energy services that they could be receiving as part of FBAE policy implementation.

The actors' 'perceptions of opportunities and threats' depend on their cognitions, in particular, the information they have about the subject of the interaction process and on motivations. In this case, the implementing actor is using the information (or lack of) about the FBAE policy and the grid electrification process to avoid providing alternative energy services. This actor perceives the provision of FBAE services as a threat that will delay their receipt of grid electricity connections and as a service that will demand funds and other resources that they are not planning on investing 
in. the target actor's lack of access to information about the FBAE policy threatens their knowledge about the services they are entitled to as indigent households without grid electricity connections. On the other hand, the linking actor perceives the provision of grid electricity as a better option than alternative energy services. This actor withholds information about FBAE services from the target actor as this may influence the target actors' perceptions about alternative energy services which may lead to demand of such services instead of waiting for grid electricity connections.

The 'strategic value' of the information that is available to the actors is determined by the availability of this information as well as the actors' resources. The implementing actor uses the information it has about the imminent grid connections to ignore and avoid implementing the FBAE policy and therefore not providing alternative energy services. On the other hand, the linking actor uses their position as a member of the municipal staff as well as being a community leader to distance themselves from issues that the municipality is not supportive of, such as the provision of alternative energy services. Instead this actor's strategy is to safeguard the implementing actor's stance and not give relevant information to the target actor. This also protects this actor's position within the municipality even though it puts the target actor at a disadvantage.

For all the actors in this case, 'the data search and processing capacity' is low. The implementing actor has not fully established its capacity to collect and process household information that is essential for the development of the indigent register. The implications of the lack of an indigent register are that the municipality cannot determine the number of households that qualify as indigents and lacks the knowledge of the types of services that are needed by these households. The target actor has no capacity to search for information (data) and is less likely to look for information pertaining to the FBAE policy implementation, especially if the implementing actor is not keen on disseminating this information. This is obvious in the case of the Noqhekwana target actor. Even though this actor observed and heard about alternative energy services received by some households in other 
municipalities, this actor could not process this information and realise that these services are linked to the implementation of the FBAE policy.

The 'availability of some resources' is important and relevant for meeting the goals that actors set for themselves or what they are motivated towards. The implementing actor in this case has mentioned that providing alternative energy services is an expensive option for this municipality but this is not the main reason for the lack of implementation. The main reason is that this municipality believes that it will be provided with grid electricity soon enough hence no need to invest in the implementation of the FBAE policy. So, resources such as funds are currently available to this municipality but there is lack of willingness to use this resource towards the provision of alternative energy services. For the target actors, having resources does not make much of a difference as decisions about the types of energy services they receive are chiefly made by the implementing actor and supported by the linking actor. The linking actor's position within the municipality and in the community is a resource that provides it with access to information and some decision making power.

\subsection{Conclusion}

The Port St. Johns local municipality is one of the two local municipalities (in this study) that have implemented the FBAE policy by providing Solar Home System's maintenance services. It is the only municipality that has failed in its implementation process and given up on providing FBAE services to its indigent households. Regardless of the need of energy services in some of the areas within this municipality, the implementing actor has decided not to implement the FBAE policy even though this would provide the much needed alternative energy services for households that are experiencing energy poverty. 


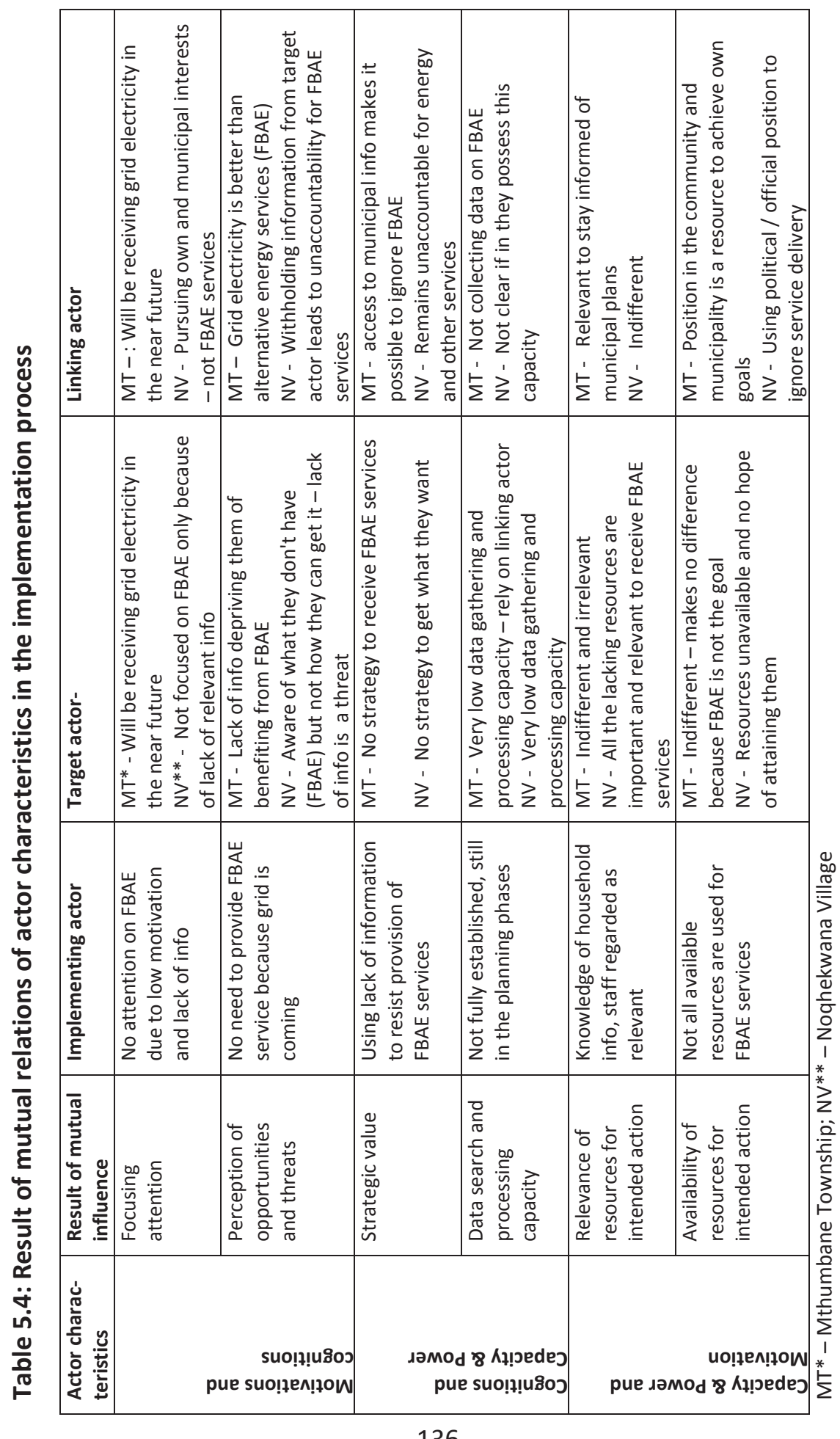


As a municipality with $60 \%$ of households depending on wood for cooking and where most households can barely afford the costs of paraffin and gas, the implementation of the FBAE policy would provide the unelectrified indigent households with alternative energy services such as solar systems and paraffin. However, this municipality (implementing actor) displays lack of intention to provide such services. With the claim that grid electricity will be provided to all households and therefore there no need for alternative energy services, this municipality defies implementing the policy makers' goals. This also illustrates that a top-down policy implementation approach is not always the suitable for everyone - regardless of its intentions. The Port St. Johns case also illustrates that policy implementation is a complex interaction process (Goggin et al. 1990; Sabatier 1986; Bressers 2004, 2009; De Boer and Bressers 2011). The use of $\mathrm{CIT}$ to analyse this case's interaction process has therefore provided an opportunity to focus on all actors involved in the implementation - as well as showing how their characteristics influence the FBAE policy interaction process. In this case, the implementing actor's decision not to provide alternative energy services through the FBAE policy negatively affects the target actor as their energy needs are not met and places the linking actor in a position where they side with the implementing actor while disregarding the target actor's needs.

The case shows that resources are not the reason why policy implementation fails. Factors which have contributed to a failure to implement the FBAE policy include:

- Municipality's unwillingness to provide FBAE services,

- Weak relationship between the key actors,

- Out-of-date indigent register,

- Target actor giving up on the possibility of receiving energy services,

- Linking actor favouring the implementing actor and neglecting the target actor's needs,

- FBAE funding from government not ring-fenced and therefore used for other municipal services. 


\title{
Chapter 6: Ingquza Hill case: Weighing the options
}

\begin{abstract}
"We don't know what is wrong with this solar home system. We were told not to touch it because if it breaks, we will be held responsible and we will have to pay for the damages". Chitwayo village household member.
\end{abstract}

\subsection{Introduction}

Ingquza Hill local municipality is faced with competing priorities where service provision for its residents is concerned. Energy provision is just one of the services that is important both for the municipality to deliver and for the residents to receive. It has also become clear that having a policy stating the importance of energy service provision does not guarantee that this service will be delivered. The implementation of Free Basic Alternative Energy (FBAE) policy for the Ingquza Hill's un-electrified households has been halted by the municipality for reasons that will be discussed in this chapter. Through the information collected from implementing (local municipality), target (household members) and linking (community leaders) actors, this case will reveal how policy implementation processes impact on service delivery. 


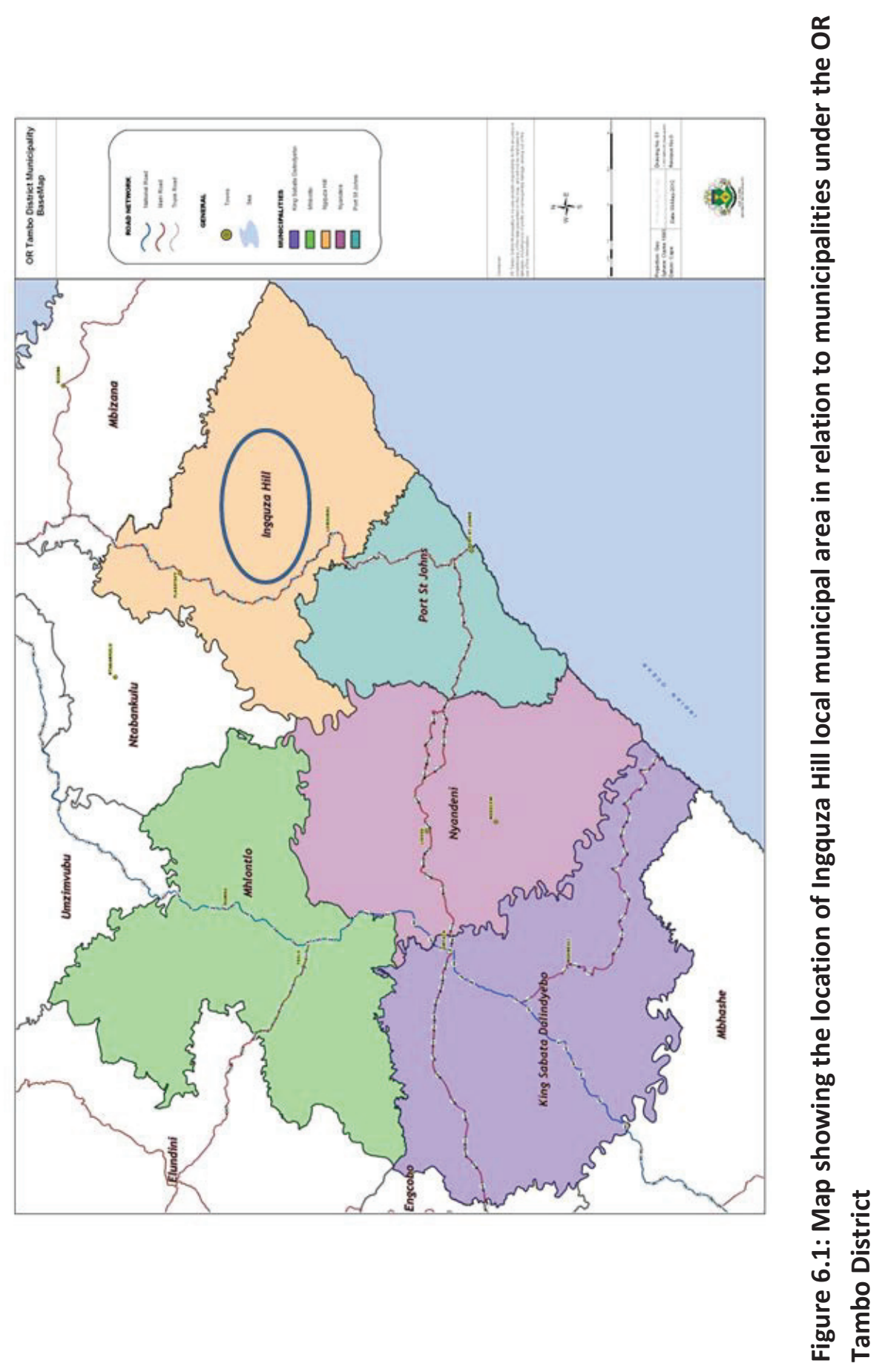




\subsection{Area Description}

Ingquza Hill local municipality covers an area of approximately 2500 square kilometres with a population of 280000 people and 56213 households. The municipal offices are located in the town of Flagstaff in the Eastern Cape province of South Africa. The areas under this municipality vary widely from sea-side villages and nature reserves to villages located inland amongst mountains and valleys. There is subsistence and commercial agricultural activities where local people depend on the land to survive. The Ingquza Hill municipal area is home to a few and important heritage sites which are significant in the South African history. It boast birth places of a number of struggle veterans that were important in the fight against the apartheid regime. The name itself, Ingquza Hill, refers to a hill where the native Mpondo people of this area gathered and held strategic meetings against the apartheid government ${ }^{65}$.

The Ingquza Hill local municipality is mostly rural with many villages. A village I visited as part of this study is named Chitwayo village which is located 56 kilometres to the east of Flagstaff, the main municipal town of Ingquza Hill. The village has 60 households and it's very remote. The gravel roads make the terrain difficult to navigate so reaching the village is not easy. In this village approximately 15 households have Solar Home Systems (SHS).

\subsection{Methodology specific to this case}

In-depth face-to-face interviews were conducted with the municipal staff of Ingquza Hill. The interviews took place during the first and second fieldwork sessions in 2011 and 2012. There were only two staff members in charge of the provision of energy services within the municipality and their portfolio concentrated mainly on providing and managing electrification programmes within this municipal area. The Free Basic Alternative Energy (FBAE) policy implementation programme was made part of their responsibility as an extra service since they were already managing the

\footnotetext{
${ }^{65}$ Information accessed from: http://www.archivalplatform.org/blog/entry/ngquza hill/ on 06 December 2012.
} 
provision of Free Basic Electricity ${ }^{66}$ for grid-electrified households under the municipality.

During the first phase of fieldwork (May to August 2011), I conducted an interview with the manager of a Solar Home System company that was previously contracted by the local municipality to provide solar system maintenance services to some households. Due to logistical problems and an expired contract with the municipality, the solar system company manager no longer visited households that had solar systems. As a result I was not able to visit and conduct a follow-up interview with this manager.

During the second phase of fieldwork (April to June 2012), I again conducted interviews with the municipal staff in charge of the FBAE policy implementation process. At this point in time they were in the process of handing over some of their responsibilities to another department. The transfer of responsibilities was due to management changes within the municipality and the instructions from the provincial government department to shift FBAE service provision to the Community Services departments within the municipalities.

During this field visit, I was able to interview households with solar home systems in Chitwayo village.

In this case, the actors are defined as follows:

\section{Implementing actors}

The implementing actor in the Ingquza Hill case is represented by the employees of the municipality. These include the Electrification Programme Manager and the Electrification Project Accountant, both within the Infrastructure Department. Due to restructuring of departments within the local municipality, I was informed that these two individuals will no longer be in charge of the implementation of the Free Basic Alternative Energy policy as this responsibility was being transferred to the Community Services department.

\footnotetext{
${ }^{66}$ Provision of $50 \mathrm{kWh}$ of electricity for free to grid electrified, low-income indigent households.
} 


\section{Target actors}

Target actors are represented by some of the Chitwayo village households that I interviewed during fieldwork. Some of the information about the target actor was provided by the municipal representatives and some community leaders. The general views about service provision from the target actor's point of view will be extracted from the detailed transcript of the proceedings of the Integrated Development Plan (IDP) information dissemination session that was presented by the district municipality to the residents of Ingquza Hill. During this session, the residents had an opportunity to comment on the municipality's plans and to speak about the services they needed the municipality to provide for them.

\section{Linking actors}

The role of the linking actor is represented by two community leaders, one a village Chief and the other in charge of community matters. These community leaders have been personally involved with the delivery of alternative energy services to the rural areas of Ingquza Hill in the past, including Chitwayo village. They worked with a company that was contracted by the municipality to provide maintenance services of solar systems as part of the FBAE implementation process. The Chief is a linking actor because of his close links to the local municipality as well as with the community. As these are traditional communities, the roles of Chiefs and other traditional leaders are still highly regarded and the involvement of these leaders is essential when long-term developmental decisions have to be made. Traditional leaders in this area are held in esteem because of the important roles they played prior to 1994 in ensuring that land and other resources were safely guarded against the apartheid government. After the country's independence, traditional leaders also gained political recognition and their status was even more enhanced.

\subsection{Current energy service provision}

The 2011 census results reveal that $62.8 \%$ households in Ingquza Hill use grid electricity for lighting and just above $34 \%$ of households in this municipal area use candles for lighting. Table 6.1 shows that up to $51 \%$ of 
households rely on wood for cooking and $60 \%$ rely on it for heating (StatsSA 2011). Only $36.2 \%$ of the households use electricity for cooking and $19 \%$ use it for heating.

Table 6.1: Percentages of households using types of energy in Ingquza Hill

\begin{tabular}{|l|l|l|l|}
\hline & Lighting & Cooking & Heating \\
\hline Electricity & 62.8 & 36.2 & 19.0 \\
\hline Gas & 0.2 & 3.6 & 1.5 \\
\hline Paraffin & 1.8 & 7.5 & 12.1 \\
\hline Wood & & 51.4 & 60.4 \\
\hline Coal & & 0.3 & 1.1 \\
\hline Animal dung & & 0.5 & 0.4 \\
\hline Solar & $\begin{array}{l}0.3(138 \\
\left.\text { hhs }^{67}\right)\end{array}$ & 0.1 & 0.2 \\
\hline Candles & 34.3 & & \\
\hline Other & & 0.2 & 0.0 \\
\hline None & 0.5 & 0.2 & 5.3 \\
\hline
\end{tabular}

Source: Statistics South Africa 2011

Out of the five municipalities, Ingquza Hill was the only one where the municipal representatives knew the number of households with Solar Home Systems. In this area, wood is a fuel of choice for the majority of households for cooking and heating needs. The remote rural households with grid electricity connections are often not able to afford the use of electricity appliances because of the costs of appliances and the costs of energy to operate them. Gas use (Liquefied Petroleum Gas), similar to the other municipalities in this study, is low. This is mainly due to the high costs of gas as a fuel, the high costs of its appliances and the high costs of transportation which is not helped by the difficult terrain and poor road infrastructure.

\footnotetext{
${ }^{67}$ The figure of 138 households was supplied by the municipality representatives during the interviews I held with them.
} 


\subsection{Ingquza Hill municipality's indigent households' register and FBAE policy implementation}

In 2011, the implementing actor acknowledged that this municipal area's indigent register needed to be updated with new information that would reflect the needs of the people and the services that should be delivered by the municipality. Similar to all local municipalities in the country, in order to be able to deliver basic services to the poor, a credible register showing all the households that qualify for subsidies, is required to deliver services such as FBAE. The main difficulty faced by the local municipality at the time of fieldwork was that the register consisted of households that no longer qualified as indigents. In other words, these households may be earning a higher income than what an indigent household should be earning in order to be considered for government benefits such as Free Basic Services. On the other hand, there are people that qualify to be on the list because they have lost incomes due to unemployment and other issues, but are not on the register because it has not been updated. This municipality was expecting the number of indigent households to rise in three to five years as there were no prospects of employment in the area. The municipality observed that more people were losing employment and this forced households to depend on government subsidies and grants such as Free Basic Alternative Energy.

The Infrastructure and Engineering Services department had started collecting household information to identify those qualifying as indigents and had plans in place on how they would capture and process this information. Ward Councillors, Ward Committee Members and administrators as well as local traditional leaders such as chiefs (linking actors) were considered as key stakeholders in assisting the local municipality in collecting indigent household information for the register. An indigent committee consisting of municipal officials as well as community representatives was also established to ensure a credible indigent register was well formulated. 
This process of information collection was interrupted by the transfer of services such as the implementation of the FBAE policy to the Community Services department. Some of the reasons for the interruption include:

- The responsibilities for FBAE policy implementation were handed over to the Community Services department. However the department was not provided with training at the time of the hand-over. They did not know the amount of work that had gone into the preparations for FBAE policy implementation,

- Stakeholders working with this municipality on the implementation of the FBAE policy were not aware of the transfer of responsibilities.

\subsection{The process of FBAE policy implementation by different actors in Ingquza Hill}

The following section presents the description of how the different actors are involved in the Free Basic Alternative Energy policy implementation process in Ingquza Hill. The Contextual Interaction Theory is used to analyse the influence of actor characteristics in the implementation process.

\subsubsection{The implementing actors' role in Free Basic Alternative Energy policy implementation}

The implementation of Free Basic Alternative Energy (FBAE) policy is important in that it involves key financial decisions that have to be made by the municipality in agreeing to subsidize and carry-out the activities associated with implementation. The municipality undertaking the implementation of the FBAE policy should be prepared to dedicate staff members to this role and ensure that they have the necessary skills, capacity and have the necessary resources. The municipality also has to ensure that the service planned for delivery as part of the FBAE policy implementation is needed by the targeted indigent households.

When the municipality first decided to implement the FBAE policy, the responsibility was given to the Electrification Infrastructure department . 
Since this department was already responsible for an energy services, the FBAE services were seen to be better placed here. This department was also working with Eskom, the electricity utility, in the delivery of Free Basic Electricity to indigent households which the municipality was in charge of paying for.

Although current statistics show that less than one percent of households under this municipality use solar home systems for lighting Stats SA (2011), there were in fact more households that had solar systems installed in their homes as part of the Department of Energy's Integrated National Electrification Programme (INEP) programme in the late 1990s. As part of the solar systems installation contract between the households and the service provider - the households are not allowed to tamper with any of the system equipment, which includes fixing it if broken. This responsibility is left to the service provider. The municipal representative noted that the SHSs are getting older and are becoming difficult to maintain as they need new parts which are expensive to replace. His recommendations was that these systems be replaced with new ones instead of being repaired so that better and advanced technology can be used. 

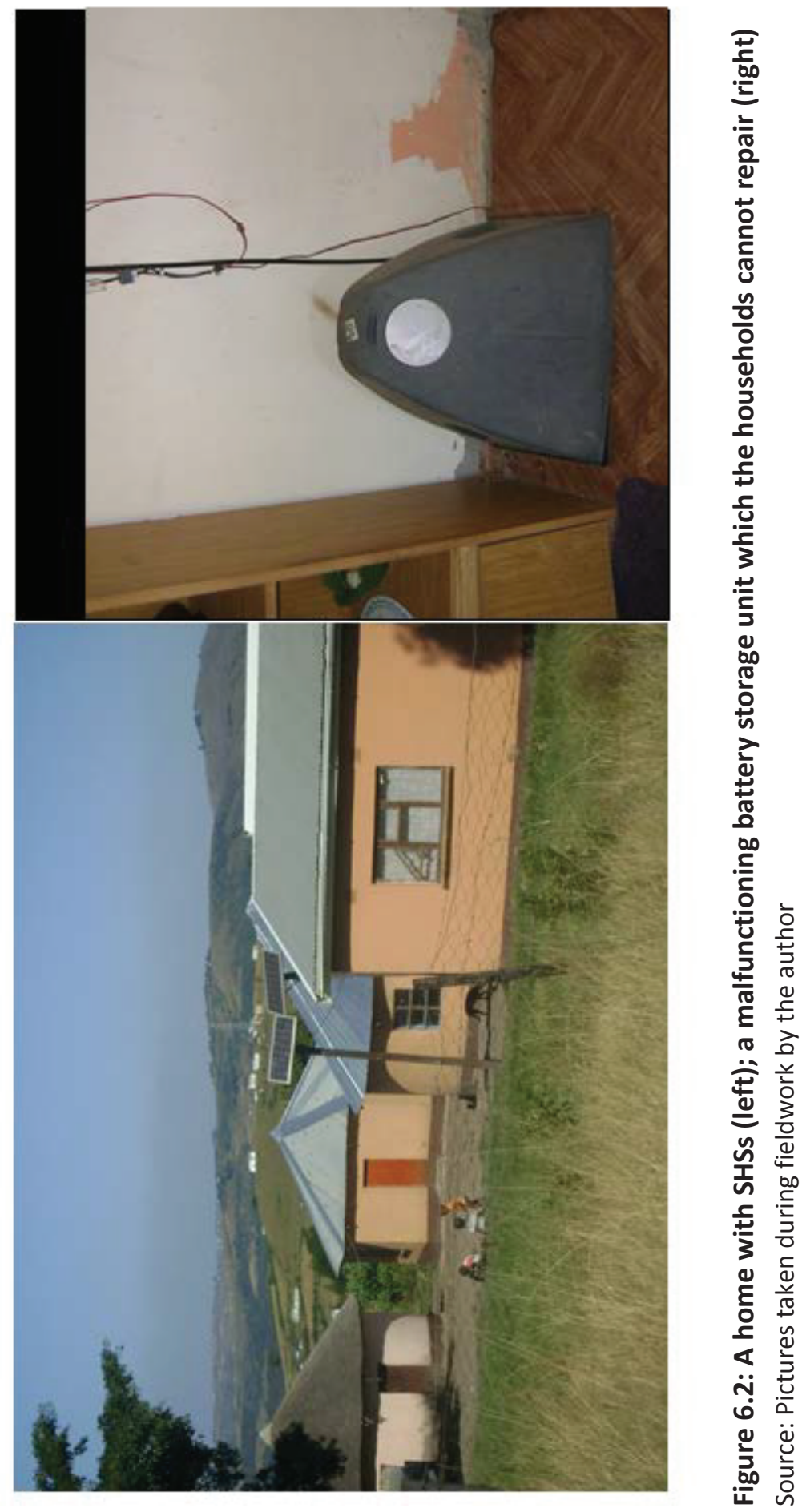
Between 2007 and 2009 the municipality paid part of the service fee on behalf of the indigent households as part of the FBAE policy implementation process. The arrangement was for households to pay the minimum amount for solar system maintenance whilst the municipality paid the most amount of the invoice. The invoice payment was structured in the following way: the municipality paid R50 $\left(€ 5^{68}\right)$ and the household paid R10 (€1), which gives a total amount of R60 (€6) paid to the service provider per system maintained. Although this may not seem like a high amount to pay for an energy service, especially the contribution expected from households, it is worth noting that this local municipality has an unemployment rate of 51.6\% (StatsSA 2011). Those employed are usually in part-time, short-term and unreliable employment and are paid very little hence making it difficult to dedicate large sums of money to paying for energy services without the local municipality or government's assistance. The 2011 census results show that the average household income in this municipality is R3132 (€313) per month. For many households, this income is not in the form of wages received through employment, but social grants that are given to low-income (indigent) households and individuals by the government in an effort to relieve the poverty burden.

In explaining the FBAE policy implementation process using the Contextual Interaction Theory - Figure 6.3 shows the actor characteristics and their influence in this process.

${ }^{68}$ Based on the 2011-2012 Rand/Euro exchange rate - www.oanda.com 

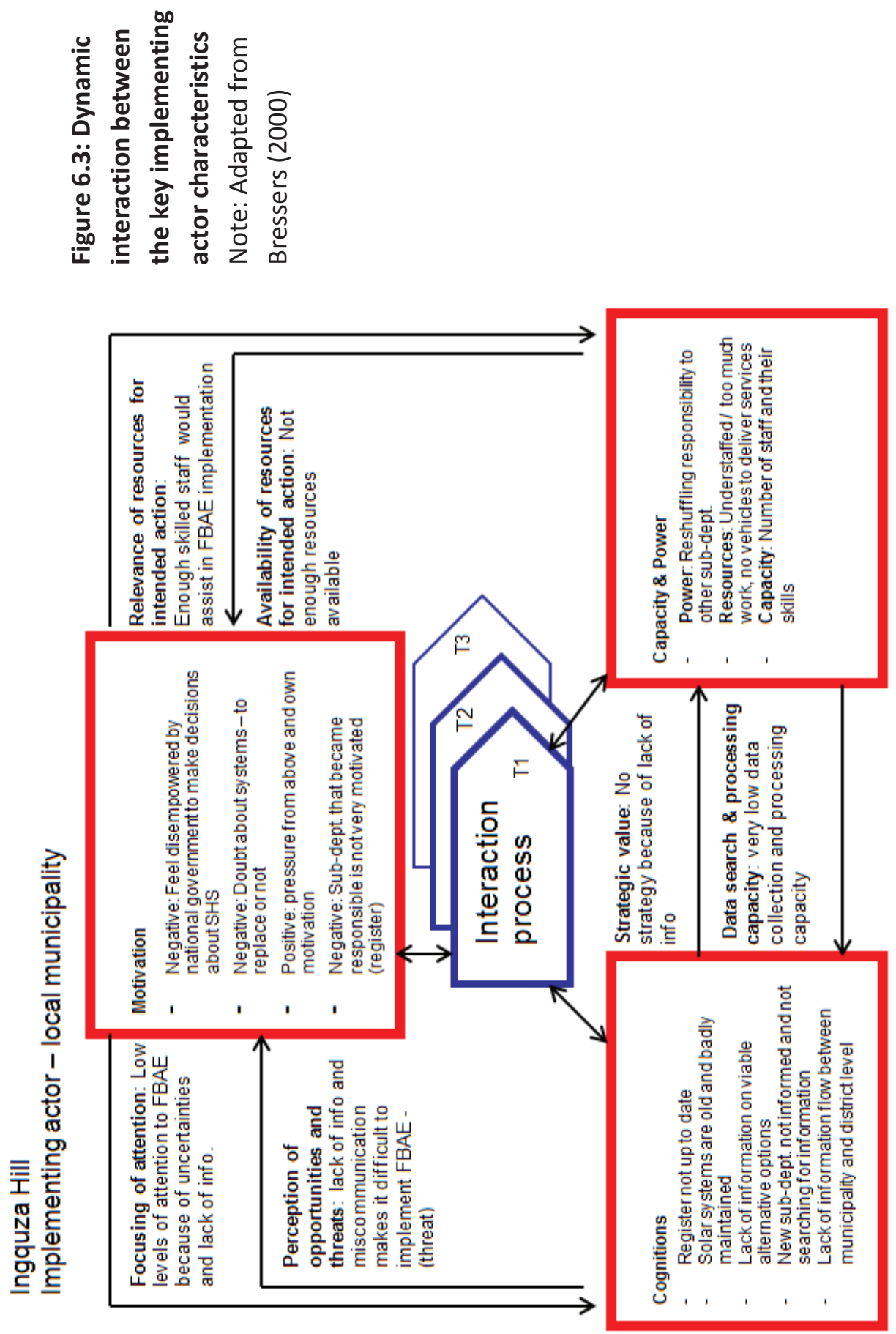
The analysis of the implementing actor's motivations show that this actor is not motivated positively to provide alternative energy services as part of the FBAE policy implementation process. This case shows that it is not only resources such as funding that contribute to lack of implementation or service provision. Issues such as the inability to make decisions like assigning of responsibilities to different departments have an impact in the way FBAE services are delivered. Another challenge faced by the municipality is that there is a shortage of staff. Although there is a high unemployment rate $(51.6 \%)$, the illiteracy levels are also high in this municipality with only $5.2 \%$ of the population finishing high school in 2011 and only $12.7 \%$ having a higher education qualification

As mentioned previously, the current staff working on implementing FBAE and other energy policies and programmes in this municipality were not employed specifically for this. These responsibilities were added to their daily responsibilities. An example of this is that the Electrification Manager and his colleague, who was employed as a Project Accountant were expected to manage the implementation of the FBAE policy. This makes it unrealistic to expect that such a task of implementation of the Free Basic Alternative Energy policy will take priority where staff members are already overwhelmed with their current duties.

The strain on staff members and the negative effect it has on implementing the FBAE policy was evident during my second fieldwork visit period (April to June 2012) to the Ingquza Hill local municipality. A municipal representative mentioned that the energy subsidy responsibilities such as FBAE policy implementation were moved to the Community Services Department within the municipality, as per the requirements of the provincial department. However this caused disputes because the "management took the decision without any consultation with the staff members involved". Although this is a decision that was made to follow the rules set by the provincial government on implementation of subsidy programmes such as FBAE policy, the representative felt that the municipality was not ready yet to go through this process. The Community Services Department "does not have the capacity nor interest to 
implement" Free Basic Services, especially those concerning household energy. "This department has only worked on delivery of sanitation and water basic services for households under this local municipality and have never handled Free Basic Energy services". It is evident that this process will pose problems during implementation as without skills and training on how to implement energy subsidy programmes, chances are that the services will not be delivered to the beneficiaries. As a result of the confusing handover, the old department continued to 'handle' enquiries received by the local municipality on energy subsidies, hence I was also directed to them for an interview regarding this subject.

\subsubsection{Target actors' role in Free Basic Alternative Energy policy implementation}

Of the 15 households that had solar home systems in Chitwayo village, only four had household members at home that I could interview. As explained in the methodology section, I could not make further arrangements to return to the village on another day because the people had accompanied me could not be available and it would be difficult to reach the village on my own due to the rough terrain.

Households in this village do not have grid electricity and there are currently no plans by the local municipality and Eskom to provide this service in the near future due to the remoteness of this village. The distance, the type of road to the village and the hilly terrain make it expensive to construct network lines that would enable grid electricity distribution. Households in this village rely on collecting wood from the surrounding areas for cooking and space heating. They also use paraffin, candles and those that can afford the costs of Liquefied Petroleum Gas (LPG) use it for their thermal energy needs such as cooking and space heating.

The households explained that they used to pay a full monthly amount for maintenance when the solar systems were first installed. During the year 
2007 the local municipality informed them that they would have to pay only part of the amount and the rest would be paid to the service provider by the municipality as part of the FBAE policy implementation process. The households said they were told that as part of the energy subsidies given to impoverished households, the government paid for some free electricity units for households with grid electricity and provided alternative energy services for households without grid electricity - such as the households in Chitwayo village.

The CIT analysis shows that this actor's cognitions (information) are not sufficient to enable them to act and make informed choices about the FBAE policy implementation process (see Figure 6.4). The information provided to them by the municipality and the service provider does not explain the arrangement of the services provided to them. For instance, the target actor does not know why the maintenance services were stopped and whether they are expected to pay the service provider themselves for solar system maintenance services. The municipality has not provided information on whether they will be fixing the systems that are currently not functioning or whether these households will be provided with grid electricity in the near future.

With regards to the information available to the target actor, the households know that the solar systems do not belong to them. This has created a low motivation towards the use of solar home systems despite knowing that this energy can benefit the households in the absence of grid electricity. A household representative said "the children used to benefit the most from using the lights when doing their homework or reading at night. Now, they have to use candles or paraffin lamps". 

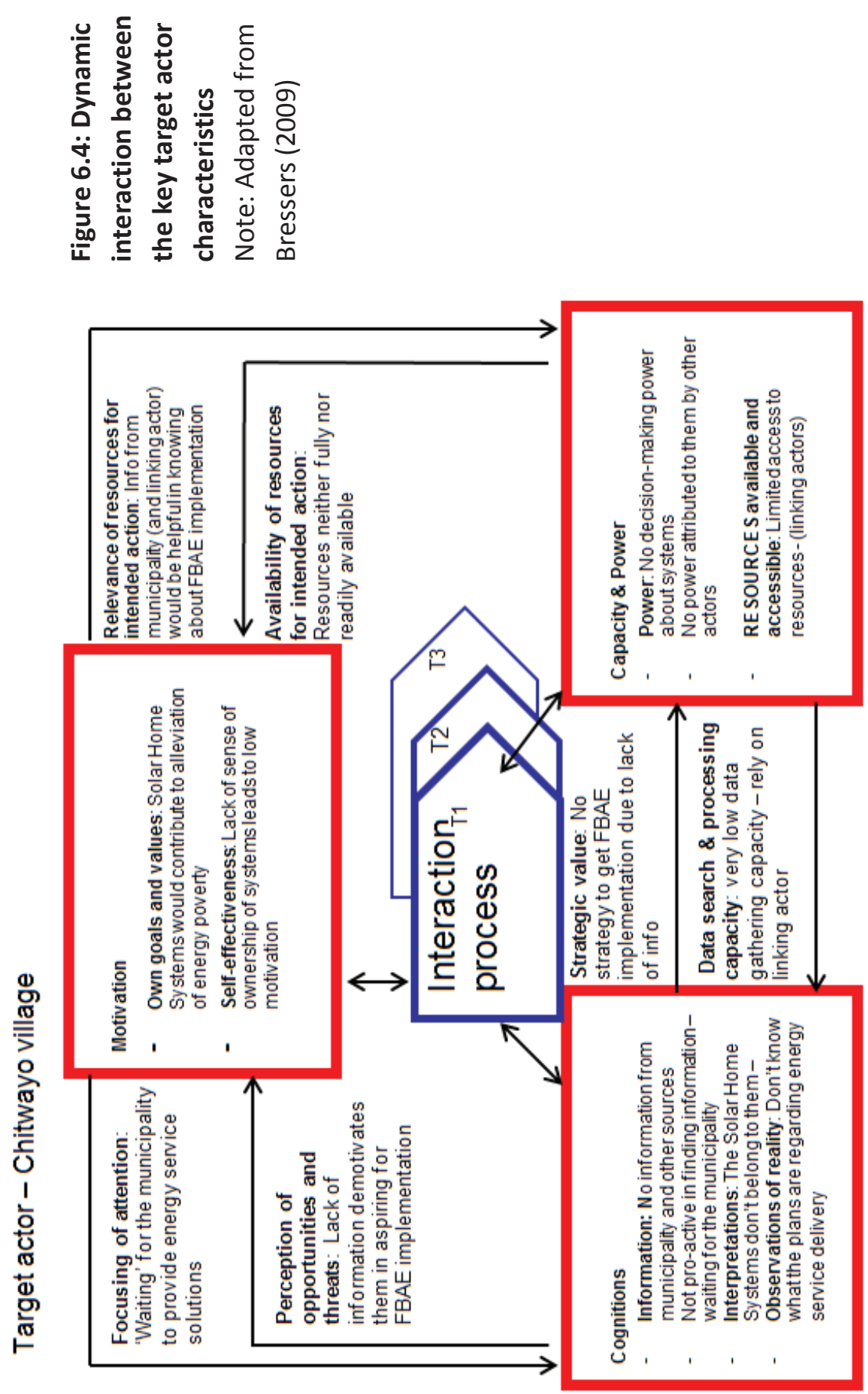
The people interviewed said they did not know if their household information is on the indigent households register. A household representative said, "We are not sure whether we are an indigent household or not, as we do not have information on how we can identify ourselves as such". If the municipality does not have a credible indigent register, it is impossible to know which households qualify for government subsidies especially the delivery of basic services. In the case of providing subsidies for maintenance of solar systems, the municipality treated all the households with the systems as indigents and paid the service provider on their behalf. This action was convenient for the municipality as they did not have the capacity and resources to collect household information to determine if these were indigents or not.

Where the capacity and power of the target actor is concerned as an actor characteristic, it is clear that the target actor lacks capacity in ensuring the delivery FBAE services. No power is attributed to this actor by the implementing and linking actors concerning the provision of alternative energy services. The target actor has no decision-making powers regarding the delivery of alternative energy services, especially those that are part of the FBAE policy implementation.

\subsubsection{Linking actors' role in Free Basic Alternative Energy policy implementation}

The linking actors in this municipality are important in connecting the implementing (municipalities) and target (communities and households) actors. In Ingquza Hill local municipality, the linking actor representatives interviewed ${ }^{69}$ were the Headman and the Chief. They explained that their roles involve many responsibilities towards both the local municipality and the communities. The municipality regards the linking actor as an assistant

\footnotetext{
${ }^{69}$ Face-to-face interviews with the Chief and the Headman, community leaders representing the linking actor. Date and venue: 03 May 2012 at Holy Cross community hall, Ingquza Hill local municipality.
} 
that helps with providing municipal services to the intended beneficiaries. On the other hand, the communities rely on the linking actor to act on their behalf and be the voice that can clearly state their service needs to the municipality. At the same time, the linking actor is a part and member of the community. They receive the same services that the rest of the community is receiving. Their position as a linking actor provides them with a privilege of knowing the municipality's plans before the rest of the community.

As they are members of the community, the linking actors go through similar experiences as the other households in terms of service delivery from the local municipality. With the implementation of Free Basic Alternative Energy policy, the Headman said his household felt the immediate benefit of having to pay only a small part of the maintenance fee whilst the substantial amount was paid by the local municipality. He mentioned that, "At first I used to pay R56.00 $\left(€ 5.60^{70}\right)$ for the maintenance of the solar system when they were first installed in 1999. In 2006, I started paying R10.00 (€1.00) as the municipality was subsidizing the maintenance payment to the service provider as part of FBAE policy implementation". At the time of the interview, he said that his system was still in working order even though it has not been maintained since the service provider was no longer contracted by the local municipality. One of the main reasons why his system was still functioning is that he knows how to service the SHSs due to his previous work experience as a SHS maintenance service provider. This also means that he has disregarded the warning by the SHS installers that 'households should not maintain the systems themselves'.

The Headman said it made a big difference to him to pay part of the amount for his SHS use because the full costs was expensive and sometimes his household could not afford it. He said, at first the systems had prepayment meters but once the municipality started subsidizing the households, the prepayment feature was removed. This means that even

\footnotetext{
${ }^{70}$ Based on the 2011-2012 Rand/Euro exchange rate - www.oanda.com
} 
when households were not able to pay the R10, they could still continue using the systems and pay the service provider at a later date

Figure 6.5 illustrates the interaction process of the linking actor characteristics and how they influence the implementation of the FBAE policy. This interaction process is discussed further in Section 6.7.

As community leaders working closely with the local municipality, both the Chief and the Headman said that they have to ensure that the community receives information on all the services provided by the municipality by holding meetings and inviting municipal representatives from time to time. An example of such meetings is the information dissemination drive of the Integrated Development Plan ${ }^{71}$ by the O.R. Tambo District municipality which was taking place on the day I was conducting this interview. For such a meeting, these two community leaders had to invite communities from different villages to gather at the place of the meeting where the OR Tambo Councillors and representatives presented the regional annual plans on service delivery ${ }^{72}$. This meeting provided the community a chance to interact with municipal and regional leadership and express their feelings regarding the services they receive as residents under this local municipality. .

\footnotetext{
${ }^{71}$ This is a plan that documents development plans of all the local municipalities under the OR Tambo District Municipality.

${ }^{72}$ See Annex 4 for full notes that I took during the Integrated Development Plan meeting on 03 May 2012 at the Holy Cross community hall, Ingquza Hill local municipality.
} 

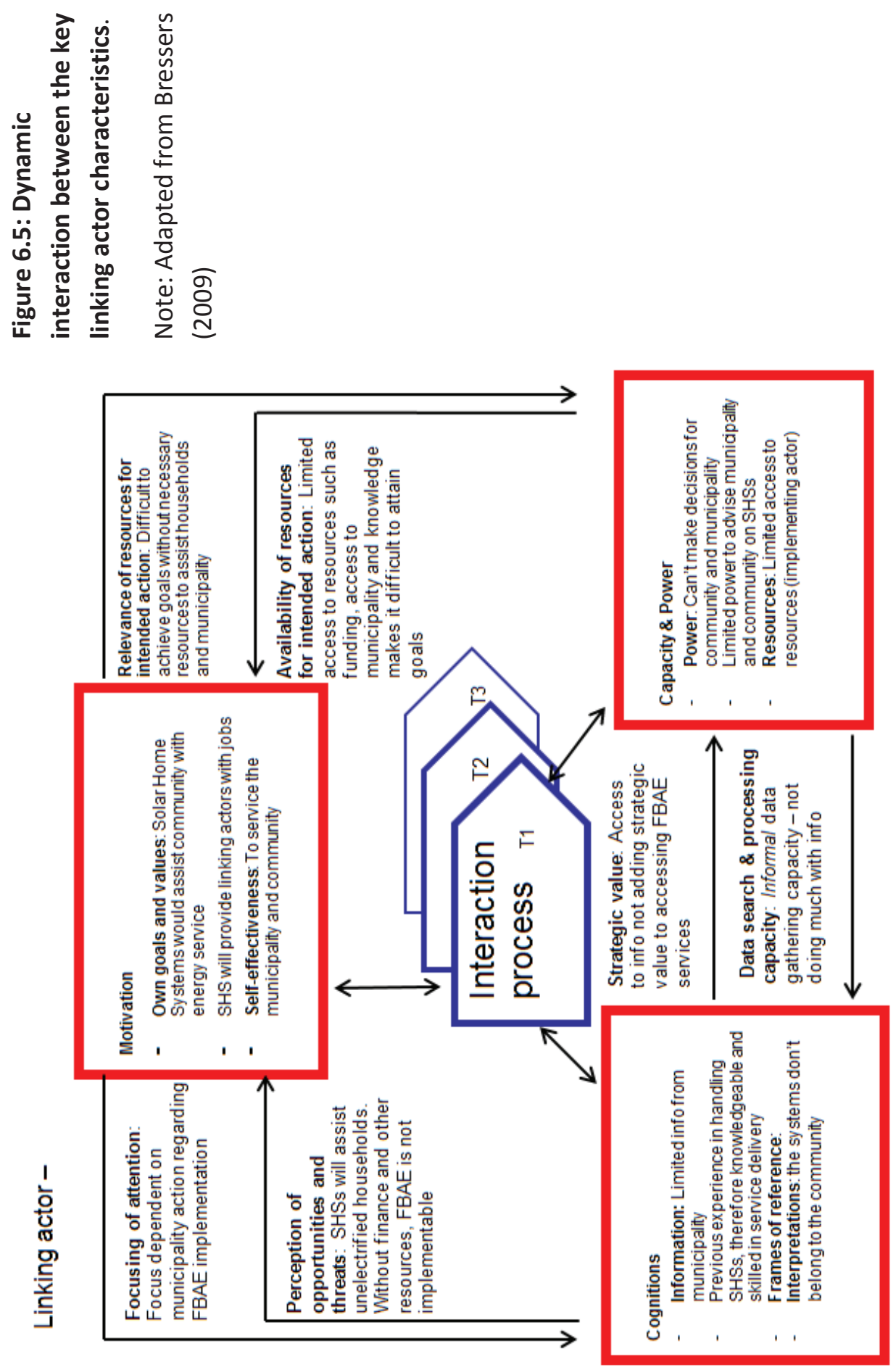


\subsection{Comparing the key actor characteristics of the implementing, target and linking actors}

This section analyses and summarises the FBAE policy implementation process in Ingquza Hill with the use of the Contextual Interaction Theory framework. The results of the interaction process are summarised from Figures $6.3,6.4$ and 6.5 and they compare the motivations, cognitions and the resources of all the actors. On the other hand, the results of mutual influence in Section 6.7.2 summarise how the actor characteristics influence each other and in turn, influence the whole policy implementation process.

\subsubsection{Summary of comparison of Ingquza Hill's key actor characteristics}

When comparing the motivations of the actors involved in the implementation process of the FBAE policy in Ingquza Hill it is clear that actors are not all positively motivated. The implementing actor finds it difficult to set goals that will contribute to the delivery of alternative energy services such as solar home systems. This is because this municipality does not feel empowered by the national and provincial government departments to make its own decisions regarding the delivery of alternative energy services. The installation of solar home systems in the households under this municipality was done by the national Department of Energy through its own service providers and the local municipalities were not involved in the implementation. The municipality, similar to the target actor, does not take ownership of the SHS and maintaining these systems as part of FBAE policy implementation is not a priority. Although the linking actor has goals to deliver the SHS maintenance services, it has no power to make such decisions and is dependent on the decisions made by the implementing actor.

The information available to all the actor regarding the implementation process of FBAE is not consistent. The implementing actor (municipality) is given some information by the national and provincial government departments but there is no real monitoring of how this information is used and disseminated. The target and linking actors rely on the implementing 
actor to provide them with information but they not always given full information about FBAE and the alternative energy services they qualify for. Another source of information that would make it possible to deliver alternative energy services to indigent households is the indigent register. This municipality does not have an updated register and this makes it impossible to identify the households that qualify for free basic services such as the maintenance of solar systems.

The target actor in this case does not have power in making decisions about the solar system maintenance services from the municipality, neither do they have the power to choose alternative energy services that suit their needs best. On the other hand, the implementing actor has the power to decide and prioritize the delivery of alternative energy services depending on their capacity, goals and other influences such as the relationship they have with other stakeholders. 
Table 6.2: Result of interaction process of different actor characteristics

\begin{tabular}{|c|c|c|c|}
\hline & Implementing actor & Target actor & Linking actor \\
\hline Motivations & 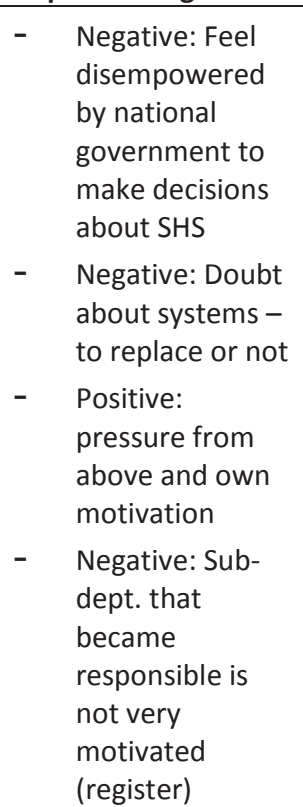 & 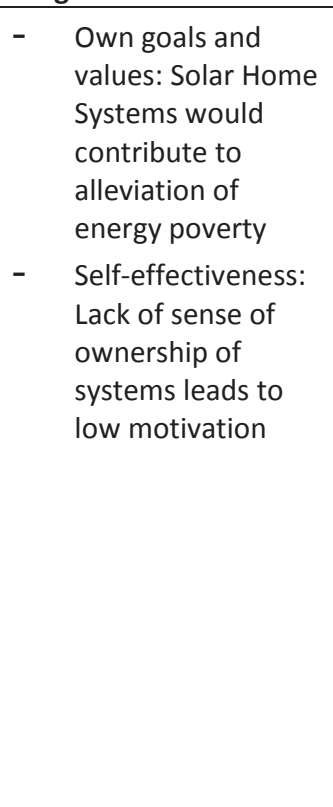 & 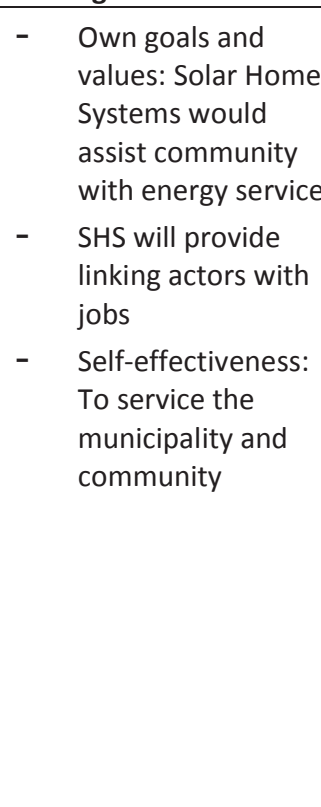 \\
\hline $\begin{array}{l}\text { Cognitions } \\
\text { (Information } \\
\text { and } \\
\text { knowledge) }\end{array}$ & 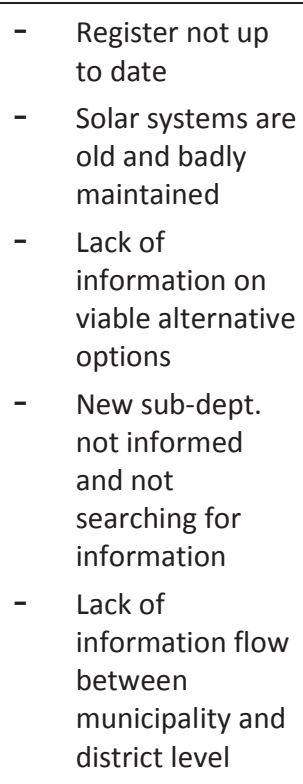 & 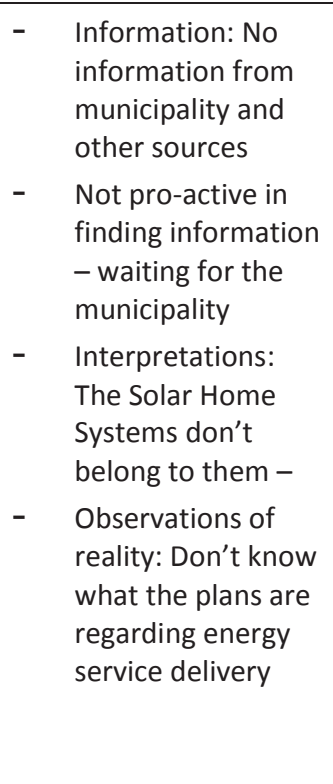 & $\begin{array}{ll}\text { - } & \text { Information: } \\
& \text { Limited info from } \\
\text { municipality } & \\
\text { - } & \text { Previous } \\
\text { experience in } \\
\text { handling SHSs, } \\
\text { therefore } \\
\text { knowledgeable } \\
\text { and skilled in } \\
\text { service delivery } \\
\text { - Interpretations: } \\
\text { the systems don't } \\
\text { belong to the } \\
\text { community }\end{array}$ \\
\hline $\begin{array}{l}\text { Power and } \\
\text { Resources }\end{array}$ & $\begin{array}{ll}\text { - } & \text { Power: } \\
& \text { Reshuffling } \\
& \text { responsibility to }\end{array}$ & 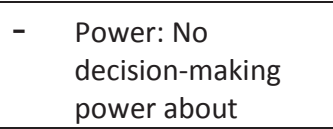 & $\begin{array}{l}\text { - Power: Can't make } \\
\text { decisions for } \\
\text { community and }\end{array}$ \\
\hline
\end{tabular}




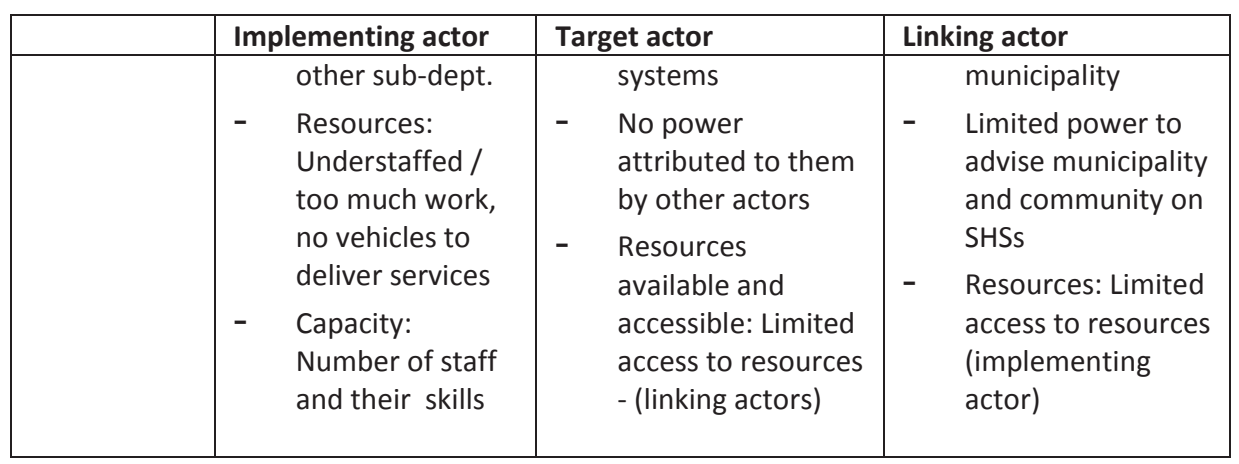

\subsubsection{Summary of mutual relations of actor characteristics}

The summary of mutual influence shows how actor characteristics influence each other in the process of policy implementation. In this, pulling together and analysing motivations and cognitions (Table 6.3) reveals what the actors focus their attention on what they perceive as opportunities and threats. A comparison of the actors' focus of attention shows that all the actors give the FBAE policy implementation process low levels of attention. The implementing actor does this because it is not certain about what is expected of it by the national and provincial government departments in terms of maintaining the existing SHSs. The shift of responsibilities from one department to another is also another reason why the implementing actor is reluctant to fully provide the alternative energy services. The target actor does not focus much on receiving alternative energy services as part of the FBAE policy process because of its lack of information. This actor does not make its own decisions regarding the energy services that are delivered by the government and therefore relies on the implementing actor to provide a way forward. 


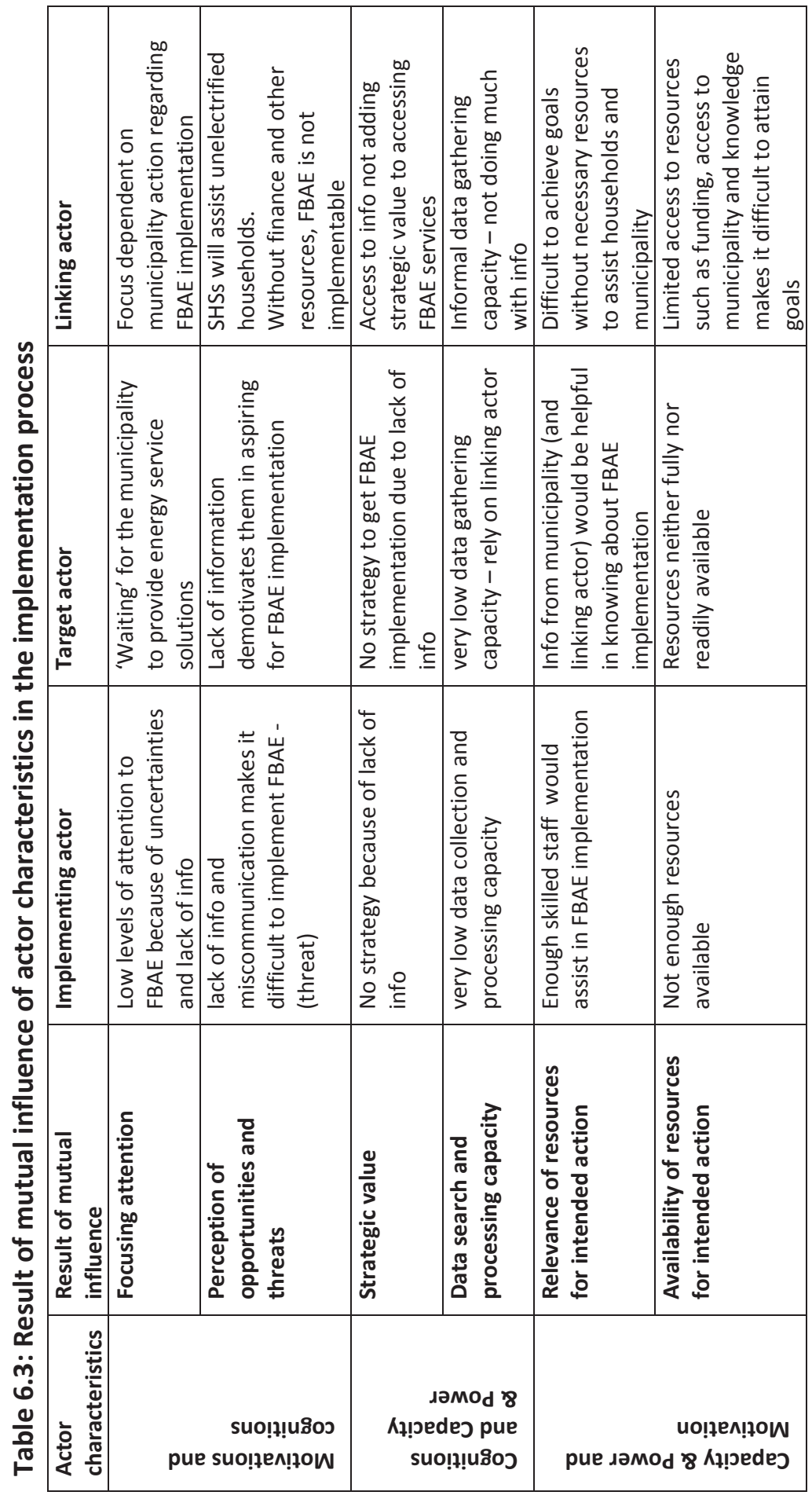


The perception of opportunities and threats is influenced by the information that is available to the actors and how this information is used and interpreted to achieve goals. The lack of information for all actors in this case is a threat to the delivery of alternative energy services through the FBAE policy. Lack of information such as the indigent register makes it hard to identify the households that are in need of basic energy services and to determine the type of needs they have. An opportunity as identified by the linking actor is that if the SHSs maintenance services are revived, the households will have access to an energy service that may meet part of their basic energy needs.

For these actors, information and resources (capacity and power) does not add any strategic value. Instead, lack of relevant information makes it difficult for the implementing actor to come up with a strategy that will ensure the delivery of alternative energy services and guarantee positive implementation of the FBAE policy. The target actor also lacks a strategy to ensure that alternative energy services such as the maintenance of their SHSs are delivered to households by the municipality. The data search and processing capacity of these actors also depends on the information available to them and the means to get this information. The implementing actors has very low data collection capacity and lacks processing capabilities. This is seen in the way this actor lacks the ability to compile an indigent register. The target actor is not able to collect data in the form of information that it needs to enable it to access alternative energy services from the municipality. Even though the linking actor has access to household information - it cannot use this information to deliver alternative energy services to households unless the municipality decides to offer these services.

The relevance and availability of resources for intended action is important as it determines whether the actor's goals are achievable or not. For this implementing actor, some of the relevant resources include availability of skilled staff that can collect and process household information as well as have knowledge about the FBAE policy and alternative energy services. For 
the target actor, the relevant resources include the knowledge about the services they could receive from the implementation of the FBAE policy.

\subsection{Conclusion}

The Ingquza Hill local municipality once provided alternative energy services as part of the FBAE policy implementation process. Similar to the Port St. Johns municipality this implementing actor opted to stop this service but for different reasons. In Ingquza Hill the implementation process did not stop completely - it was placed on hold while the implementing actor assesses if providing solar home system maintenance as an alternative energy service, is the best option for the municipality and other actors. During the time of this study this municipality reportedly considered other energy services and technologies that would better benefit the unelectrified indigent households - but never got to the implementation or delivery phase due to a number of reasons. Again, here we see the complexities involved in the process of policy implementation. Each actor's characteristics influences the implementation process and results through their motivations, cognitions and capacity and power. This case also illustrates successful policy implementation does not depend on resources only but other factors such as the actor-interaction and the relationships actors have with each other are also important.

Even though this municipality is open to implementing the FBAE policy according to the policy makers' (national government) recommendations, the lack of clarity and indecisiveness by the national and provincial government departments makes this municipality less active in positively implementing the FBAE policy.

Some of the factors that contribute to low levels of implementation in this case are:

- The indecisiveness of the national and provincial government departments about renewable and alternative energy services,

- The weak relationship between some of the key actors, 
- Lack of a credible indigent register,

- Shifting of responsibilities from one department to the other without proper consultation and hand-over procedures. 


\title{
Chapter 7: King Sabata Dalindyebo case: An unbalanced act
}

\begin{abstract}
"The local municipality should not filter the lists according to the numbers of people that qualify per quarter but should ensure that they know people's living conditions as they often leave out people that are in real need. They don't know people's living conditions and needs because they do not visit these villages themselves" ${ }^{\prime 3}$.
\end{abstract}

\subsection{Introduction}

The King Sabata Dalindyebo case is important as it shows how the different actors influence the FBAE policy implementation process. Here, it is clear that although all the actors would like for the FBAE policy to be positively and successfully implemented - each actor has their own implementation issue to deal with. The analysis of the actor characteristics assists in exploring the underlying issues experienced by the actors in the interaction process and how this directs the process into different directions. The King Sabata Dalindyebo case shows that there are various complexities that contribute to low levels of implementation success and they are not all attributed to lack of resources. .

\footnotetext{
${ }^{73}$ Quotation taken from an interview with the paraffin service provider contracted by the King Sabata Dalindyebo local municipality. Interview date: 19 July 2011.
} 

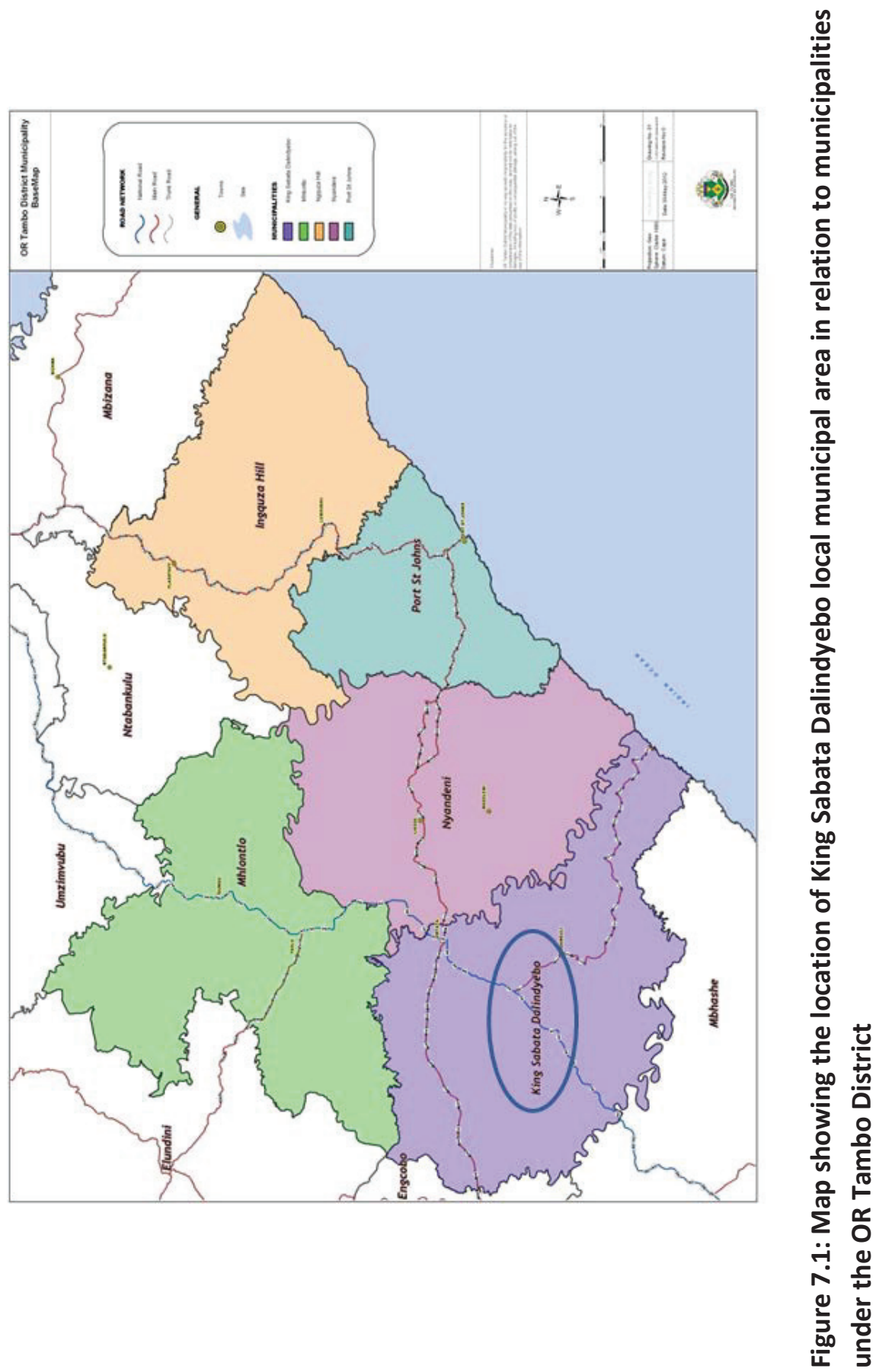


\subsection{Area description}

King Sabata Dalindyebo (KSD) Local Municipality is one of the five local municipalities under the OR Tambo district municipality in the Eastern Cape province (see Figure 7.1). The local municipality offices are based in the peri-urban town of Mthatha along the N2 freeway, one of the major national roads in South Africa. Mthatha is the former capital town of Transkei, a state within South Africa that was set aside for people of the amaXhosa ethnicity between 1976 to 1994 by the apartheid government. After 1994, Mthatha ceased being a homeland and became part of the Eastern Cape province and was subject to laws governing the rest of South Africa. The King Sabata Dalindyebo local municipality is divided into 32 municipal wards all with their own elected Councillors and it occupies a total area of 3019 square kilometres and consists of 105240 households (Stats SA 2011).

This municipality is slightly different from the rest of the local municipalities in the OR Tambo district. Some of the facts that make it different are that it is in a peri-urban area where an urban area with economic and administrative activities is surrounded by rural areas. The urban area, Mthatha, is the centre of this municipality where some people from surrounding areas and other local municipalities seek employment and business opportunities here. Both the King Sabata Dalindyebo local and OR Tambo district municipalities offices are based here. As expected, households that are in the 'urban' area of this municipality have access to better household services than the other local municipalities. Most households in the 'urban' centre have access to grid electricity, clean water from taps, sanitation services and better road infrastructure. Those on the outskirts and falling under the rural areas have limited access to grid electricity and are provided with water by the municipality through communal water tanks and sanitation services that provide a dry toilet system, also known as Ventilated Improved Pit-latrine (VIP)

\subsubsection{KwaMpuku informal settlement}

KwaMpuku is an informal settlement that has been in existence since 1994 within the urban area of Mthatha under this local municipality. This 
settlement has just over 50 homes built with different materials such as wood, corrugated iron, mud, asbestos boards and cardboard. The land where these home structures are built on belongs to Department of Public Works and not the local municipality. Land ownership is important as it determines the type of services that will be provided to households. If homes are on land that does not belong to the local municipality, the municipality does not provide such households with services such as grid electricity. The argument is that this land may be sold later by its owner and the investments on electricity services, especially for low-income households, may be lost. The only services that have been provided by the local municipality are communal toilets and water taps.

All of the households in this settlement are classified as low-income and are recorded on the indigent register. People tend to settle in this area when they come to Mthatha from their respective rural areas to look for work opportunities. They usually leave this area once they have more secure employment and have found a better place to live. Currently, the local municipality does not allow more structures to be built on this site in an effort to stop the expansion of this settlement.

Some of the people living in KwaMpuku have been living here for years and some only stay a few months. People started building on the open unused land which was adjacent to some derelict housing structures that belonged to the national government. People that moved here did so because of the convenient location of the area as it is very near the urban area, Mthatha. Often, people that settle here have come to this area to seek employment in Mthatha as it is the economic hub of the north-eastern part of the Eastern Cape province.

The Ward Committee Member for this area said that there is always a movement of people in this settlement. Some people do not stay for long periods depending on whether they find employment or whether their economic and social situation changes. This becomes obvious during the updating of the indigent register as new people occupy dwellings left by people that have moved out of the settlement. As people decided to settle on this land without the permission of either the local municipality or the 
government department that owns the land, they do not have to pay for services such as land rental, water and sanitation services - especially because the municipality has classified them as indigents. Some people do pay for the use of shack structures which have been left behind by people that have found better accommodation elsewhere. In such cases, this has become a form of income generation where people move from the settlement without moving their structure and because of space limitations, new people are left with no choice but to rent an existing shack.

There were different reasons given by people that were interviewed for living in KwaMpuku informal settlement. Some of the reasons are as follows:

- The settlement is nearer to the good schools which are located in Mthatha where the fees are also affordable,

- It is temporary shelter until they find better and affordable accommodation,

- This is the only affordable area in Mthatha as they can walk to work instead of paying for transportation.

\subsection{Methodology specific to this case}

In King Sabata Dalindyebo municipality I conducted an interview with the Revenue Manager who is also in charge of coordinating Free Basic Services for the municipality ${ }^{74}$. There were no other municipality representatives available for interview but I was given information of a paraffin service provider that I could contact for more information on FBAE implementation.

The paraffin service provider was interviewed in Mthatha regarding the service they are providing as contracted by the local municipality ${ }^{75}$. The snowballing method was used for identifying additional informants. It

\footnotetext{
${ }^{74}$ Face-to-face interview at the King Sabata Dalindyebo municipality offices on 16 May 2011.

${ }^{75}$ Face-to-face interview on 19 July 2011 at Mthatha town.
} 
enabled me to find informants in a time efficient manner who could provide information about their experiences with FBAE.

It was recommended to me by the paraffin service provider to conduct an interview with a Community Development Worker of KwaMpuku informal settlement. This person was one of the key informants for my study and assisted in providing information on how FBAE policy implementation was taking place in an informal settlement ${ }^{76}$.

In 2012, as part of the second fieldwork phase, I conducted brief interviews with seven out of 55 households at KwaMpuku informal settlement. The interviews were conducted with household members that were found at home on the day of my visit. The times of the interviews were not planned nor scheduled, instead, the Community Development Worker suggested that I walk around the settlement and talk to people that were willing and available to give their time for a brief interview.

Compared to the other local municipalities where I conducted interviews, King Sabata Dalindyebo was easier to reach in terms of distance and accessible roads, even though it was more difficult to secure appointments with the municipal representatives.

In this case, the actors are defined as follows:

\section{Implementing actors}

Similar to many local municipalities in South Africa, King Sabata Dalindyebo's main role is to deliver much needed basic services to its households. The King Sabata Dalindyebo implementing actors are employees of the local municipality and have been given the responsibility to facilitate the implementation of the FBAE policy. An implementing actor interviewed in this municipality is the Revenue Manager that is also responsible for coordinating Free Basic Services that are delivered by the local municipality.

\footnotetext{
${ }^{76}$ Information based on face-to-face interviews held on 21 July 2011 and 13 May 2012.
} 


\section{Target actors}

Target actors in the case of King Sabata Dalindyebo are communities that are meant to be receiving energy services that should be delivered as part of Free Basic Alternative Energy policy implementation process. For this case, out of the 55 households that make up the KwaMpuku informal settlement, I conducted brief interviews with seven households that were available on the day of my visit. The interviews were intended to find out whether households knew about the FBAE policy implementation process and to get their opinions on the paraffin they have been receiving as part of this policy subsidy. To support information from these target actors, I will also use the information collected through interviews with implementing and linking actors as well as paraffin suppliers.

\section{Linking actors}

The main linking actor in this case is the Ward Development Worker that represents the KwaMpuku informal settlement. She suits the definition of a linking actor because she works with the municipality to deliver services to the settlement as she is regarded as the main point of entry. She is also important for the people living in this informal settlement as they approach her for matters concerning their area and interaction with the local municipality.

Amongst other responsibilities that she has as a Ward Development Worker, she has to collect and regularly update the list of people living in this settlement for submission to the local municipality. This list adds to the indigent register that the municipality is collecting for all the municipal areas. The list also works as a control mechanism where the municipality ensures that there are no new people moving into the settlement.

\subsection{Current energy service provision}

Due to being a peri-urban area with the highest number of households compared to the other local municipalities studied here, King Sabata Dalindyebo local municipality has the highest number of households using electricity for lighting compared to the other four municipalities under the 
OR Tambo district. The peri-urban nature of the area puts it at an advantage to access services that are usually difficult for remote rural areas. Current statistics show that about $73,3 \%$ of the households in this municipality use grid electricity for lighting and out of these households, $57.5 \%$ use this energy source for cooking and only $19,9 \%$ use it for heating (see Table 7.1). Based on the percentage of households that use electricity for lighting, it can be concluded that out of the total number of households in King Sabata Dalindyebo, just over $73 \%$ have grid electricity connections. Compared to the other local municipalities on this study, this is a significantly high number considering that this is the most populous municipality. At the time of research, it was not clear whether the local municipality will be able to provide grid electricity to the remaining estimated $27 \%$ households or these households would be provided with alternative electricity services.

Table 7.1 shows responses given by households when they were asked what their main fuels were for different household applications (StatsSA $2011)^{77}$. The table shows that $20 \%$ of the households use wood for cooking as their main fuels source and $28.9 \%$ use it for heating. Again, these figures are significantly lower compared to the other local municipalities in this study which emphasizes the high numbers of grid electrified households in this municipality. Although there is a reliance on wood, it is much less compared to the other municipalities in this study and some households depend on paraffin and electricity - energy sources that are too expensive for households located in remote rural areas. Although some households do have electricity, not all of them can afford to cook with it as it is seen as an expensive fuel.

\footnotetext{
${ }^{77}$ The StatsSA study only asked households about their main fuels and did not consider the multiple-fuel use for different applications in the household.
} 
Table 7.1: Percentages of households using types of energy in KSD

\begin{tabular}{|l|r|r|r|}
\hline & \multicolumn{1}{|l|}{ Lighting } & \multicolumn{1}{l|}{ Cooking } & \multicolumn{1}{l|}{ Heating } \\
\hline Electricity & 73.3 & 57.5 & 19.9 \\
\hline Gas & 0.3 & 5.0 & 2.1 \\
\hline Paraffin & 9.0 & 12.5 & 37.7 \\
\hline Wood & & 20.3 & 28.9 \\
\hline Coal & & 0.1 & 0.5 \\
\hline Animal dung & & 3.8 & 0.9 \\
\hline Solar & 0.2 & 0.1 & 0.1 \\
\hline Candles & 16.8 & & \\
\hline Other & & 0.4 & 0.0 \\
\hline None & 0.4 & 0.3 & 10.0 \\
\hline
\end{tabular}

Source: Statistics South Africa 2011

The King Sabata Dalindyebo's Approved Indigent Policy dated 25 March 2010, states that "in the event of a household not receiving any electricity either from Eskom or the KSD Municipality, all registered indigents will be provided with alternative energy sources including, but not limited to: paraffin (kerosene), fire gel, liquefied petroleum gas, etc.", KSDLM (2010: 09). This municipality provides paraffin through the implementation of Free Basic Alternative Energy (FBAE) policy. This is the only energy service provided by the municipality as grid electricity is provided by Eskom, the national electricity company.

\subsection{KSD municipality's indigent households' register and FBAE policy implementation}

In the process of FBAE policy implementation, the indigent register is important. This register lets the municipality know which type of Free Basic Services it should deliver to households and the number of households in need of such services. Compiling and keeping this register updated and credible is one of the most challenging tasks for rural local municipalities and evidence of this is given in this chapter and the rest of the case chapters. 
The coordinator of Free Basic Services at this municipality said that, even though the district municipality assists in collecting indigent household information to compile lists for the local municipalities, there were still problems. The main problem was the duplication of work as the municipalities themselves also collected their own lists. In the case of this local municipality, the information collected by the district municipality does not match the information collected by the local municipality. These disparities raise difficulties where reporting about the implementation of basic services is concerned. The district municipality ends up reporting incorrect figures about the local municipality which then affects the allocation of funds.

KwaMpuku informal settlement provides an example of delayed FBAE policy implementation process even though the indigent register was complete and updated. In 2008 the Community Development Worker (linking actor) was instructed by the local municipality to compile a list of all households living in KwaMpuku settlement. All the households in this settlement were considered as indigent because they earned below the municipality determined poverty line. Even though the register was ready in 2008 as requested by the local municipality, the households only started receiving FBAE services in 2011.

For some people, this settlement is seen as a temporary home where they live whilst looking for work or whilst having short-term employment. This results in a constantly changing list of people as it is continuously updated by the Community Development Worker.

Although new people occupy the empty homes through (verbal) rental agreements with the previous tenant or "landlord ${ }^{78,}$, it is not easy to add the new names to the list. Sometimes this leads to 'too many' people on the list and with a fixed quantity of paraffin to distribute it leads to some

\footnotetext{
${ }^{78} \mathrm{~A}$ landlord in such cases is someone that was the first occupant of the shack and has used their own building materials in the construction of the dwelling. People tend to leave these shacks behind when they move out of the area, especially if they can afford to do so. This is a form of income generation for them as they rent these shacks to new people.
} 
households not receiving their share of paraffin. The Community Development Worker tries to manage the situation by asking those that had received paraffin the previous time to 'sit-out' (not collect paraffin) the current allocation and benefit the following time. People get irritated by this. A responded reacted as follows:

"as it is, the paraffin is not available on monthly basis and it is not much. When people get skipped during the distribution time, they have to wait six months for paraffin instead of three months".

In other areas within the King Sabata Dalindyebo municipality the supplier was given a list of people in different villages who should receive paraffin. There were a few problems with the lists as some people claimed that they were registered indigent households but were not on the lists. In other cases, some households were receiving more than a share of their supply which also made it difficult for the supplier to work as some people complained about this 'unfairness'. The main problem that the service provider noted was that the register did not contain names of all people that qualified as indigent households. This was due to a 'filtering process' where the municipality picks a certain number of households from the list depending on the available funds for paraffin distribution. This was seen as unfair by target actors. In some cases, people were excluded regardless of their need for paraffin but the decisions not to include them were taken without considering their circumstances.

"The local municipality should not filter the lists according to the numbers of people that qualify per quarter but should ensure that they know people's living conditions as they often leave out people that are in real need. They don't know people's living conditions and needs because they do not visit these villages themselves". 


\subsection{The process of FBAE policy implementation by different actors in King Sabata Dalindyebo}

Using the Contextual Interaction Theory, the following sections analyse the influence of key actor characteristics in the King Sabata Dalindyebo FBAE policy implementation process.

\subsubsection{Implementing actors' role in the Free Basic Alternative Energy policy implementation}

The King Sabata Dalindyebo (KSD) local municipality has chosen to deliver 20 litres of paraffin to indigent households four times a year or every quarter. The municipality contracts service providers to distribute paraffin to indigent households as there are not enough staff members and vehicles for the municipality to do this itself. The appointed service provider delivers paraffin to households on the indigent list provided by the local municipality. On delivery days, the service provider interacts with the local Ward Councillors and Ward Committee Members to assist in verifying the indigent lists and to ensure that the intended beneficiaries receive the paraffin.

During an interview with a municipal representative in charge of Free Basic Services, it emerged that this municipality would be delivering paraffin for the first time in May 2011. Even though the policy to provide indigent households with FBAE subsidies through basic energy services had been in effect since 2007, it had taken this local municipality four years to implement. The main reason given for this delay was that there was no capacity $^{79}$ within this municipality to oversee the FBAE policy implementation and there was no credible indigent list. A noticeable coincidence is that the paraffin was to be distributed for the first time a day before the local government elections.

\footnotetext{
${ }^{79}$ The indication was that there were not enough staff members within this municipality to take responsibility for the implementation of the FBAE policy implementation process.
} 
According to the service provider, paraffin had been distributed to 5585 households at the previous ${ }^{80}$ delivery process and to a total of nine municipal wards. The households delivered to were located in remote rural villages and had no access to grid electricity. As Table 7.1 shows, $27 \%$ of households in this municipality without access to grid electricity.

An analysis of the interaction process concerning the implementation of the FBAE policy in KSD shows how the different actor characteristics interact with each other and influence the process. Figure 7.2 shows the implementing actors' motivations, cognitions and capacity and power. Similar to the other case chapters in this thesis, the actor characteristics are based on the implementation of the FBAE policy in these municipalities. The implementing actor's goals are to provide energy services such as FBAE for indigent households. This actor is motivated by its own goals of ensuring service delivery in the area and it is also motivated by external pressure namely area politics. The analysis of other actor characteristics will show that this actor, although motivated to deliver energy services, it hindered by a number of issues such as lack of people dedicated to working on the implementation of the FBAE policy in this area.

In this case, the cognitions refer to information that the implementing actor has with regards to the implementation of this policy. This includes household information that is used to create the indigent register that assists the municipality in better delivery of free basic services such as FBAE. The other type of information is that which is withheld from the linking and target actors by the implementing actor. During the interviews held with all the actors in this area, it was clear that there was some information that the implementing actor did not share with the linking and target actors. This led to these actors not knowing what to expect from the implementing actor with regards to the FBAE policy implementation process. Figures 7.3 and 7.4 will show how the target and linking actors are affected by this information withheld from them.

\footnotetext{
${ }^{80}$ I conducted the interview with the service provider on 19 July 2011 and they had delivered paraffin in May 2011.
} 

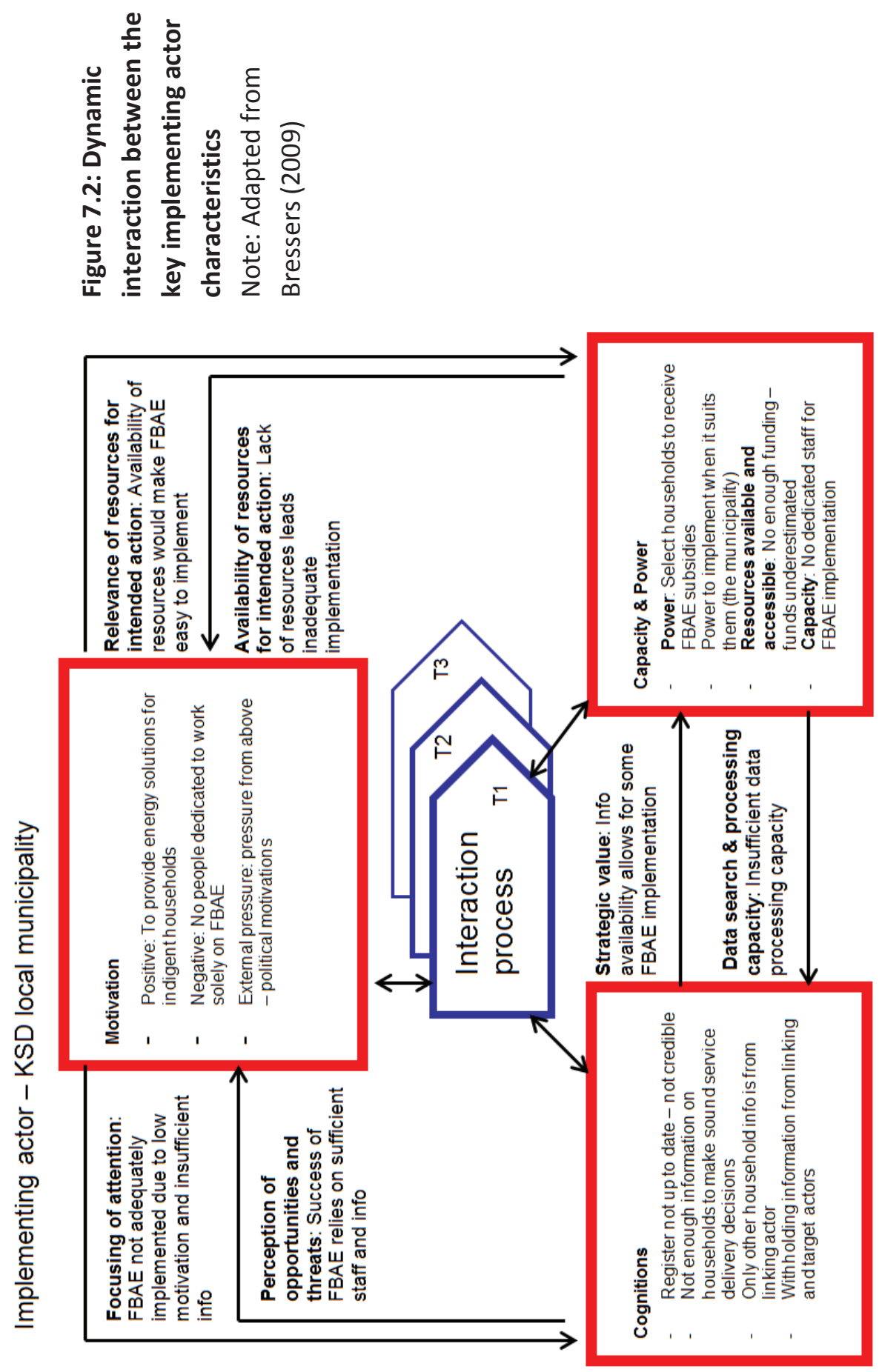
Capacity and power in this case refers to the capacity this actor has to implement the policy and the power this capacity gives to this actor. Here the implementing actors' resources are analysed to see how they influence the policy implementation process. In KSD there was clear lack of capacity as there was only one person within the whole municipality in charge of coordinating Free Basic Services. Even though this person was tasked with FBAE policy implementation, this was just one of his responsibilities as he had been employed as Revenue Manager and not the Free Basic services coordinator. This is a common practice amongst some local municipalities, where they do not have capacity to implement new policies and strategies, staff resources are usually pulled from the existing staff members. They are expected to continue with the work they were employed to undertake and add these new tasks to it. This municipality had plans to employ a person that would be responsible for implementation of Free Basic Services by July 2011, however, in May 2012 during this study's second fieldwork visit, the situation had not changed and no one had been employed.

In order to be able to deliver paraffin to households as part of FBAE policy implementation, this municipality contracts external service providers. These service providers have their own resources such as vehicles and paraffin containers to ensure efficient delivery of this fuel. According to the service provider, some of the villages are very remote and far from the rural towns where the roads are gravel only and in most cases, these roads are not maintained. This puts stress on the cars they use for delivery of paraffin. As the service provider put it:

"It took us three days to deliver paraffin to Ward 20 as it is very far from town and the roads are very bad. The villages within this ward are far from each other and this makes the travel time longer. Ward 21 had the most households and all the villages here did not have grid electricity. We had to deliver paraffin to all households in this ward".

It is obvious that it would be impossible for this municipality to deliver paraffin as part of FBAE policy implementation without the assistance of the contractors. These municipalities don't have resources such as vehicles 
and staff capacity. They are also faced with competing priorities where different types of services needed by communities are concerned.

\subsubsection{The target actors' role in the Free Basic Alternative Energy policy implementation}

In this case, the fifty-five households located in KwaMpuku informal settlement represent the target actor. Since May 2011 as part of FBAE policy implementation by the local municipality households in this informal settlement receive paraffin every quarter of the year. These households do not have access to grid electricity because the land they live on is not theirs. According to the law, the municipality cannot install permanent services such as grid electricity to households that do not own the land where their homes are built on. The municipality has provided the households with communal toilets and water taps as these are not considered permanent services but basic enough for people without adequate dwelling structures. Even though this settlement has been in existence since 1994, its occupants still do not have ownership rights to the land. Its residents are still not provided with grid electricity even though it is within a town area that is classified as urban.

The interviewed residents of KwaMpuku did not know of the Free Basic Alternative Energy (FBAE) policy. However, they think they were receiving paraffin from the municipality because they did not have grid electricity connections. They were informed by the Ward Committee Member (linking actor) that the municipality was assisting them because "it was obvious that they were living in poverty".

Using the Contextual Interaction Theory to analyse the dynamic interaction between the key target actor characteristics in Figure 7.3, it is possible to see how the motivations, cognitions and capacity and power of the target actor influence each other.

The target actor's goal is to have access to more paraffin as part of the FBAE policy implementation process. Households expressed their appreciation 
for the paraffin they received from the local municipality. In this settlement, it is common for households to use paraffin most of the time for cooking and heating since wood fuelled fires are not allowed due to fear of burning down the settlement as the materials used for building catch fire easily. Nevertheless, there have been some cases where shacks have burnt down due to uncontrollable spread of fire between neighbours as they build in close proximity to each other ${ }^{81}$. Sub-standard paraffin stoves are usually blamed for shack fires in the South African informal settlements (Truran, 2008).

A two-person household where a young man of 18 years shared a shack with his younger brother, used paraffin all the time. Their view about the paraffin they received from the municipality is:

"The paraffin we receive assists us because we usually cannot afford to buy so much for ourselves. We buy 10 to 15 litres of paraffin every month but this does not last the whole month. When it runs out, we have to buy a litre at a time, until we receive enough money to buy it in bulk again. Receiving 20 litres from the municipality allows us to save some money and makes it possible for us to use paraffin for the whole month without worrying. It would help to receive this 20 litres on a monthly basis instead of once in three months."

\footnotetext{
${ }^{81}$ Shack fires are common in South Africa due to high use of candles and paraffin, which when left unattended, cause devastating fires that spread easily through the tightly built and highly populated shack settlements.

http://dispatch.newspaperdirect.com/epaper/viewer.aspx -accessed 12 January 2013.
} 

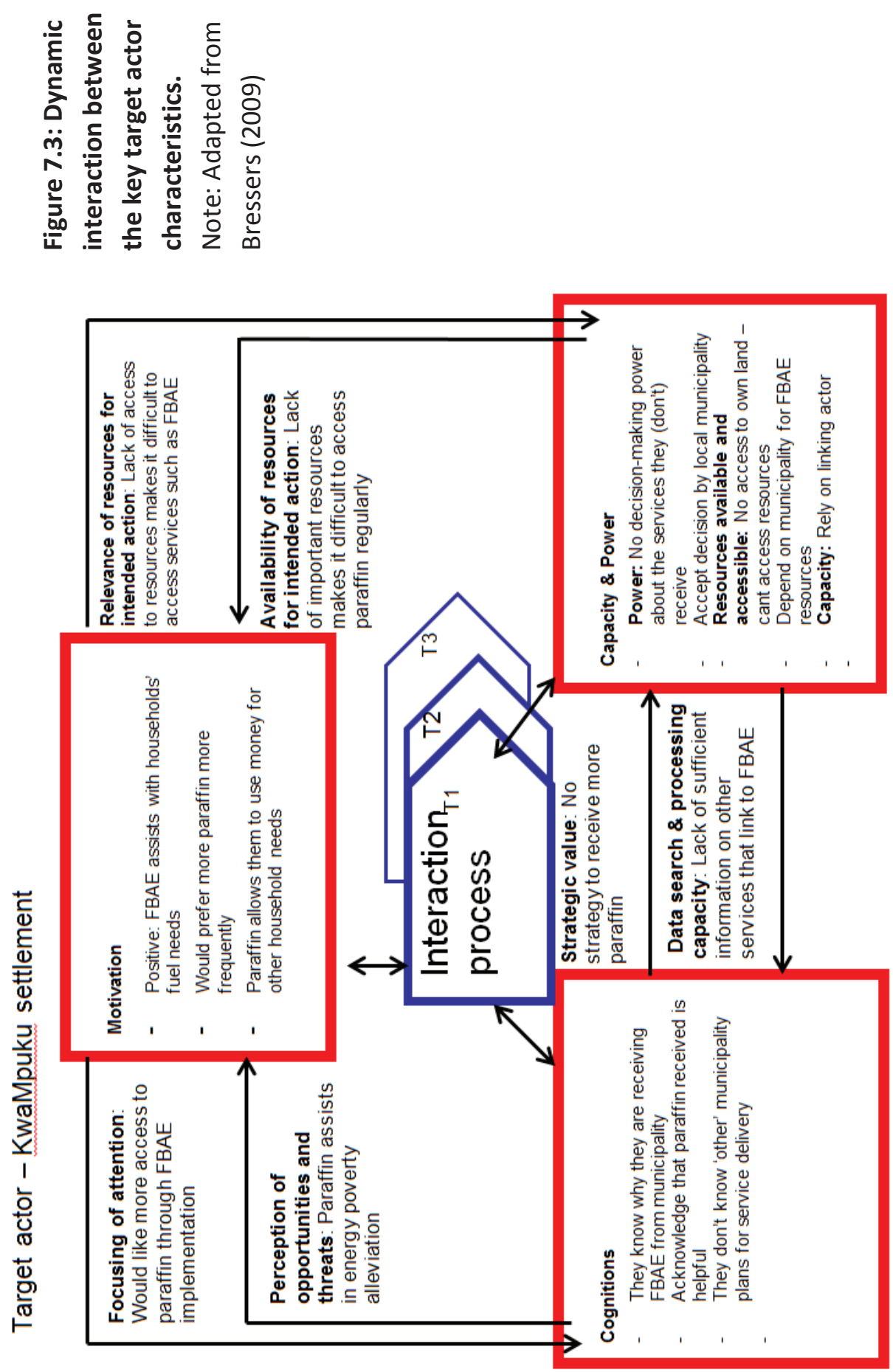
The amount of paraffin that these households use highly depends on their income and family size. A single man living in the settlement and working as a security guard in Mthatha said he could comfortably afford to buy five litres of paraffin per week to use for lighting. He also bought Liquefied Petroleum Gas ${ }^{82}$ (LPG) for cooking and space-heating. He was also grateful for the paraffin received as part of FBAE subsidy as this saved him some money which he could send home to his family in the rural areas.

Although obvious that the paraffin received by these households is helpful and contributes towards their daily energy needs, it is also clear that what they receive is insufficient to meet even basic needs due to the frequency of distribution. The household members reported that they had spoken to the Community Development Worker to express their dissatisfaction with the frequency of paraffin delivery to their settlement. As one of the householders said:

"We have asked many times for paraffin to be delivered monthly because it would help us to buy less than what we are buying now. This would save us a lot of money that we could use for other things [referring to other household needs]."

These households depend on the linking actor to assist them in receiving better services from the local municipality - even though this is not always within her ability to do so. The land ownership issue puts these households at a further disadvantage and forces them to accept what they are given without contest and demand for more.

Information is also important in the implementation process for the target actor. This actor has some access to information about FBAE policy implementation because the linking actor shares this with the households. However, this information is usually not enough to provide these households with the power to make their own decisions about the amount of paraffin they receive to influence the frequency of distribution.

\footnotetext{
${ }^{82}$ LPG is not commonly used by low-income households as it is considered expensive.
} 
As discussed above where service delivery is concerned, this target actor's location places it in a vulnerable position. Since the households living in KwaMpuku do not own the land, their access to services such as water, sanitation and energy is determined by the municipality. Lack of land ownership also means that this target actor has no decision-making powers regarding service delivery. This actor does not have the resources nor the capacity to change its status and living conditions and therefore depends on the linking and the implementation actors.

\subsubsection{The linking actors' role in the Free Basic Alternative Energy policy implementation process}

The linking actor in this case plays an important role where delivery of services is concerned in this area. The Ward Committee Member of the area is the main contact person that connects the municipality and the community as both rely on this linking actor for their different needs.

The Ward Committee Member is in charge of collecting and updating household information on a list that is submitted to the local municipality for households to be registered as indigents. This activity requires her to be aware of peoples movements within this settlement as this enables her to constantly update the residents lists. The updated list is submitted to the municipality but due to lack of staff within the local municipality, this list is not often used to update the indigent register. This poses a problem on paraffin delivery days as some people on the register are no longer living in the settlement, and the new ones are often not on the list. It is often left up to the linking actor to negotiate with the paraffin distributer to provide paraffin to the new people as they replace the ones that have left the settlement. This gives her some power where decision making about service delivery is concerned. 

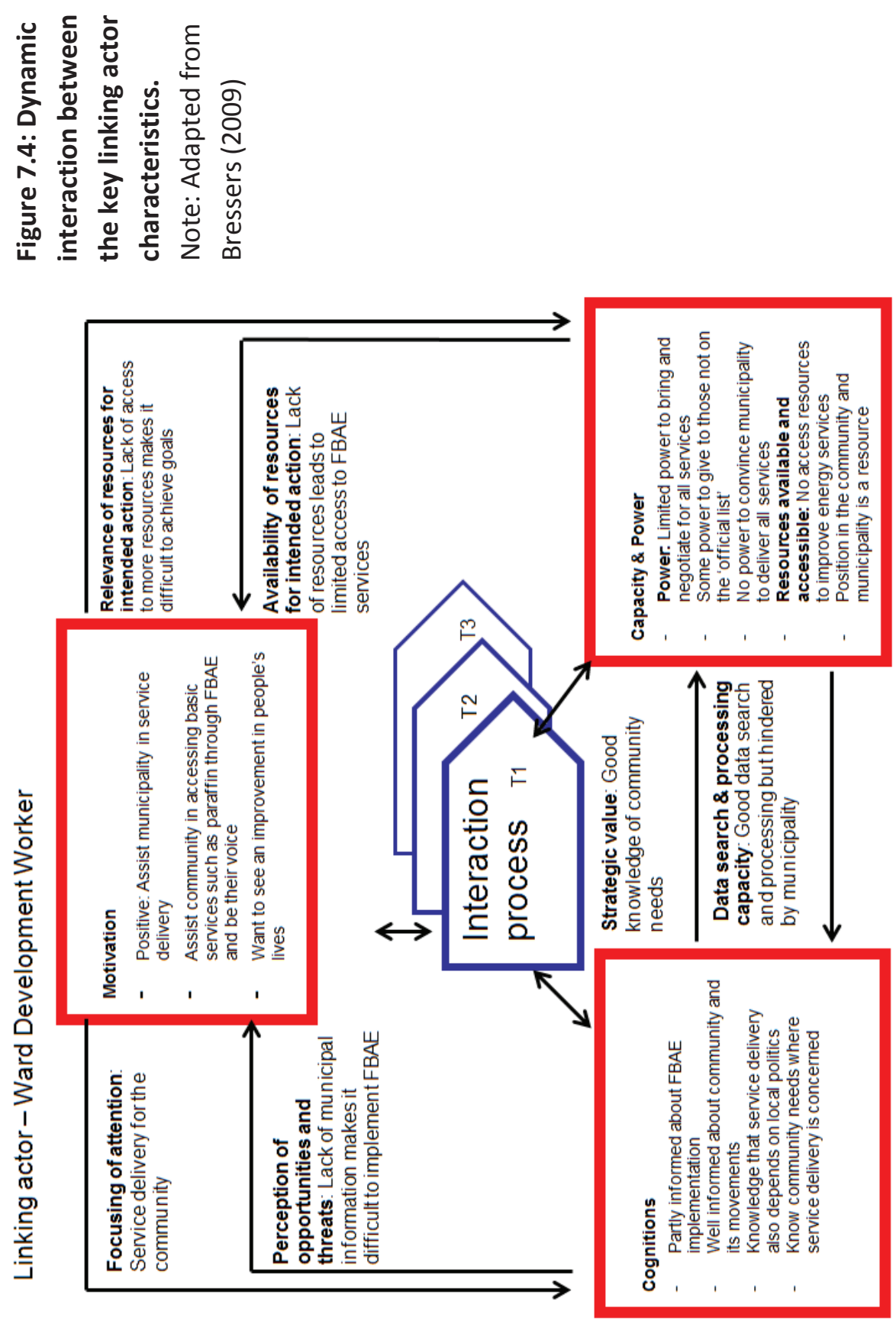
Figure 7.4 shows the linking actors' characteristics and their interaction and influence in the FBAE policy implementation process. Similar to the other actors, the linking actor is also motivated to have the FBAE services delivered to the indigent households under the KSD municipality. This actors' motivation is to assist the municipality with the delivery of this service by ensuring that they keep the implementing actor informed of the needs of the target actor. The linking actor also ensures that they provide the target actor with households' information to compile a credible indigent register that will make it possible to deliver FBAE services.

People living in this settlement acknowledge that the FBAE policy provides them with quantities of paraffin they would not be able to afford. According to the linking actor, this is obvious for her as she knows about the economic status of the majority of people living there.

Amongst other issues concerning general service delivery in KwaMpuku settlement, the linking actor did not have access to all the information from the local municipality regarding planned development for the settlement, especially of basic services due to be delivered to the households. Another issue is that of politics and how they influence service delivery in some areas and to an extent, affect the implementation of policies such as the FBAE. The linking actor explained:

"It is common during the local elections period for politicians to try and attract votes by doing 'favours' for people, especially in the poor and vulnerable communities. On the other hand, people in powerful positions within the local municipality become spiteful if a community leader does not do what they expect, or does not favour them, and they somehow stall service delivery processes. There are also internal party politics that play a big role in how services are delivered. It depends on the area and the type of political party that its majority follows".

On capacity and power, the linking actor does not have access to resources that provide her with capacity to deliver FBAE services in a way that is needed by the target actor. The lack of resources such as knowledge of the 
municipality's plans regarding FBAE policy implementation puts this actor in powerless position in the eyes of the implementing actor. On the other hand, this actor has some power attributed to it by the target actor as the households in this area depend on this actor for facilitating FBAE service delivery and for being the link they use to interact with the local municipality.

\subsection{Comparing the key actor characteristics of the implementing, target and linking actors}

This section brings together all the interaction processes experienced by each actor on this case and compares as well as summarizes how their actor characteristics influence the FBAE policy implementation process. A summary of the mutual relations of actor characteristics is also given in detail for each actor to show how the actor characteristics influence the process and how they are reshaped by the process itself.

\subsubsection{Summary of comparison of KSD's key actor characteristics}

Table 7.2 shows that the overall actor motivations for FBAE policy implementation are positive in that they want the provision of energy services, in this case, the delivery of paraffin to indigent households. There are a number of reasons for this. The implementing actor wants to implement the FBAE policy because it is required and expected that it takes responsibility for implementation even though it does not have enough dedicated staff to work on this. On the other hand, the target and linking actors are motivated to have this policy successfully implemented because it assists in meeting some of the household energy needs that the target actors have as well as ensuring that the linking actor fulfills her mandate in facilitating the provision of services to indigent households. 
Table 7.2: Result of interaction process of different actor characteristics

\begin{tabular}{|c|c|c|c|}
\hline & Implementing actor & Target actor & Linking actor \\
\hline Motivations & $\begin{array}{ll}\text { - } & \text { Positive: To } \\
\text { provide energy } \\
\text { solutions for } \\
\text { indigent } \\
\text { households } \\
\text { - } \quad \text { Negative: No } \\
\text { people dedicated } \\
\text { to work solely on } \\
\text { FBAE } \\
\text { External pressure: } \\
\text { pressure from } \\
\text { above - political } \\
\text { motivations }\end{array}$ & 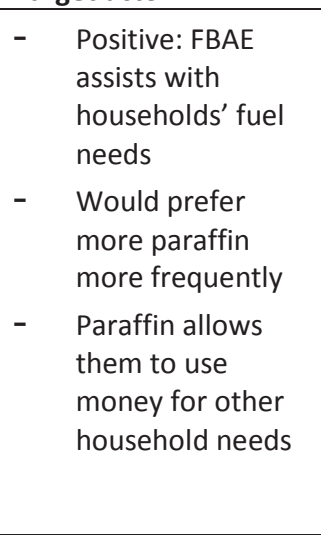 & 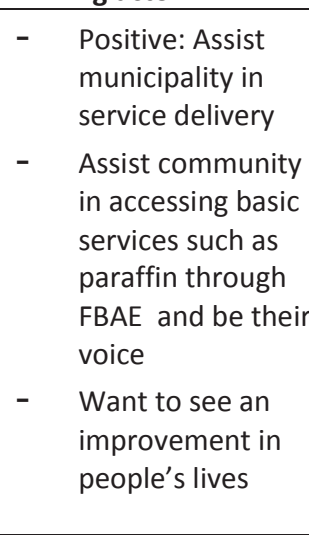 \\
\hline $\begin{array}{l}\text { Cognitions } \\
\text { (Information } \\
\text { and } \\
\text { knowledge) }\end{array}$ & $\begin{array}{ll}\text { - } & \begin{array}{l}\text { Register not up to } \\
\text { date - not } \\
\text { credible }\end{array} \\
\text { - } & \text { Not enough } \\
\text { information on } \\
\text { households to } \\
\text { make sound } \\
\text { service delivery } \\
\text { decisions } \\
\text { - Withholding } \\
\text { information from } \\
\text { linking and target } \\
\text { actors }\end{array}$ & $\begin{array}{l}\text { - They know why } \\
\text { they are receiving } \\
\text { FBAE from } \\
\text { municipality } \\
\text { - Acknowledge that } \\
\text { paraffin received } \\
\text { is helpful } \\
\text { - They don't know } \\
\text { 'other' } \\
\text { municipality plans } \\
\text { for service } \\
\text { delivery }\end{array}$ & $\begin{array}{ll}\text { - } & \text { Partly informed } \\
\text { about FBAE } \\
\text { implementation } \\
\text { - } \quad \text { Well informed } \\
\text { about community } \\
\text { and its } \\
\text { movements } \\
\text { Knowledge that } \\
\text { service delivery } \\
\text { also depends on } \\
\text { local politics } \\
\text { Know community } \\
\text { needs where } \\
\text { service delivery is } \\
\text { concerned }\end{array}$ \\
\hline $\begin{array}{l}\text { Power and } \\
\text { Resources }\end{array}$ & $\begin{array}{ll}\text { - } & \text { Power: Select } \\
\text { households to } \\
\text { receive FBAE } \\
\text { subsidies } \\
\text { - } \\
\text { Power to } \\
\text { implement when } \\
\text { it suits them (the } \\
\text { municipality) } \\
\text { Resources } \\
\text { available and } \\
\text { accessible: No } \\
\text { enough funding - } \\
\text { funds } \\
\text { underestimated } \\
\text { Capacity: No } \\
\text { dedicated staff for } \\
\text { FBAE }\end{array}$ & $\begin{array}{ll}\text { - } & \text { Power: No } \\
\text { decision-making } \\
\text { power about the } \\
\text { services they } \\
\text { (don't) receive } \\
\text { - } \\
\text { Accept decision } \\
\text { by local } \\
\text { municipality } \\
\text { - } \\
\text { Resources } \\
\text { available and } \\
\text { accessible: No } \\
\text { access to own } \\
\text { land - can't } \\
\text { access resources } \\
\text { Depend on } \\
\text { municipality for } \\
\text { FBAE resources }\end{array}$ & $\begin{array}{ll}\text { - } & \text { Power: Limited } \\
\text { power to bring } \\
\text { and negotiate for } \\
\text { all services } \\
\text { - } \\
\text { Some power to } \\
\text { give to those not } \\
\text { on the 'official list' } \\
\text { No power to } \\
\text { convince } \\
\text { municipality to } \\
\text { deliver all services } \\
\text { Resources } \\
\text { available and } \\
\text { accessible: No } \\
\text { access resources } \\
\text { to improve energy } \\
\text { services }\end{array}$ \\
\hline
\end{tabular}




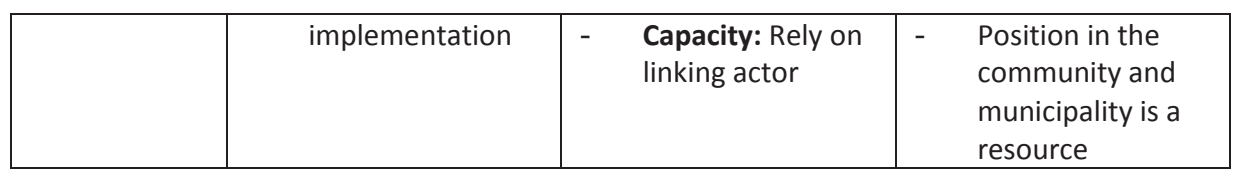

Cognitions as an actor characteristic play an important role in the implementation of the Free Basic Alternative Energy policy. In this case, cognitions are translated to information and knowledge as these are what affect all the actors the most. Critical information in this municipality is that of indigent households and comes in a form of an indigent register that is formulated by collecting household information to determine who qualify as indigents. This allows households to receive Free Basic Services such as FBAE. The implementing actor has some difficulty in implementing the FBAE policy because the indigent register in not up to date (therefore not credible) - due to lack of capacity in terms of sufficient staff members to process the information. This also poses problems for this implementing actor as there are difficulties in accessing funds that enable implementation due to underestimated budgets based on an 'incomplete' register. On the other hand, information is crucial and is also important for target and linking actors. When target actors know why they are receiving a service from the municipality, it shows that they are informed of their situation and status. This also leads them to reflect on whether the service they are receiving is helpful or not and this information can be fed back to the implementing actor to improve the services it is delivering. The linking actor in this case shows that knowledge of the community assists in the delivery of services as part of FBAE policy implementation. This knowledge also allows the linking actor to improvise, be flexible and influence service delivery to ensure all households receive their entitlement.

Influencing service delivery is tightly linked to the power dynamics. Power in this case refers to the power to make decisions, power attributed to an actor by other actors and the power that some actors have over other actors. The linking actor has some power, although limited, to decide and persuade the service provider to give people paraffin, even though they are not on the list. This is justified by her knowledge of people's living conditions and needs, and in this particular area, the fact that people move in and out of the settlement all the time. On the other hand, the linking 
actor does not have the power the convince the implementing actor to deliver services in a way that is needed by the community - that is, to deliver services that would satisfy all the energy household needs of these indigent households. Being part of a community that does not have any legal claim to land also makes the linking actor powerless because as a community member living in an area not legally zoned for housing in nonmunicipal land, the power to negotiate for services is somewhat diminished.

The target actor, in this case the community of KwaMpuku settlement, is even more disadvantaged than the linking actor because they do not have full access to information on plans that the municipality has for the area where they are living. The lack of power to ask for and negotiate for better living conditions and access to services such as FBAE forces the target actor to accept whatever decision is made by the implementing actor. This is closely linked to the resources available for the target actor. At KwaMpuku settlement, the most important resources that would be helpful in accessing proper energy services would be access to land. Land would give this community legal recognition to access municipal services or at least, be in the municipality's official plans such as the Integrated Development Plan that guides the implementing actor on the type of services needed by communities under each municipality.

\subsubsection{Summary of mutual relations of actor characteristics}

Table 7.3 illustrates how the actor characteristics influence each other and the results of their interactions. The summary is the result of the mutual relations arising from the interaction processes analysed in Figures 7.2, 7.3 and 7.4 .

For the implementing actor, although the 'focus of attention' is on the implementation of the FBAE policy, this is difficult for a number of reasons including lack of capacity and information. Capacity in this case refers to lack of staff members dedicated solely on delivery of FBAE services within the municipality. The implementing actor has competing priorities and lack 
of support. On the other hand, the target actor's focus is on receiving FBAE subsidies in the form of paraffin. The economic status of these households puts them in a position that they need the distribution of FBAE services, but receipt of this service makes them realize that they are in need of more energy services. The linking actors' attention is focused on facilitating service delivery for households in KwaMpuku settlement. This is based on this actor's goals to assist the municipality with service delivery and the knowledge that these households are in need of these energy services.

There is a difference in how the actors perceive opportunities and threats where FBAE policy implementation is concerned. For the target actor, paraffin presents an opportunity to ease the energy costs burden. However this actor is threatened by the lack of information concerning the plans that the municipality has for the households in this settlement. On the other hand, the implementing actor's successful implementation is threatened by lack of capacity in terms of staff and insufficient information which weakens its knowledge of the target actor's needs. For the linking actor lack of municipal information threatens the implementation process and makes it difficult for this actor to achieve their goals.

Each actor has to have a strategy in implementing the FBAE policy but this depends on number of factors such as resources, capacity and motivation. For the implementing actor, household information has a strategic value that would enable this actor to deliver FBAE services to the target actor. Availability of household information for the indigent register makes it possible for the implementing actor to strategize on its service delivery strategy. This also gives this actor an idea of resources needed to achieve its goals. For instance, this actor's concern was that household information collected by and received from the district municipality underestimated the actual number of indigent households in the area. Therefore funds provided to implement the FBAE policy were lower than needed - showing that inadequate information leads to inadequate strategizing. The target actor's lack of information from the municipality about FBAE service delivery plans leads to this actor's lack of strategy in receiving FBAE services. This actor 
has to depend on the implementing and linking actors for the delivery of services. For the linking actor, information proves to be important and has a significant strategic value. For this actor, the household information gathered for the purposes of an indigent register, provides knowledge that can be used to strategize on FBAE service delivery. This actor's knowledge of the community leads to improvising and flexibility in providing paraffin for the community. This actor can also inform the implementing actor about the number of households that need FBAE services and about these households' living conditions.

Data search and processing in this case refers directly to the household information collected for the purposes of creating an indigent register and information exchanged between actors about the implementation of the FBAE policy. The implementing actor lacks data processing capacity as can be seen in the way this actor deals with the compilation of the indigent register. The fact is that there are not enough people within this municipality to work on analysing household information to determine those with indigent status. This in turn affects this actor's goal achievement as it makes it difficult to deliver FBAE services. The target actor does not have any capacity to search and process data on their own. As this actor depends on the implementing and linking actors for everything regarding service delivery, it is somehow rendered powerless in this interaction process. The linking actor, because of their position in the community, has good data search and processing abilities. This actor collects household information and uses it to gain knowledge of the household's needs. Due to lack of resources (and power), this actor is unable to use this capacity to deliver FBAE services in a way that would satisfy the target actor's needs. 
Table 7.3: Result of mutual influence of actor characteristics in the implementation process

\begin{tabular}{|c|c|c|c|c|}
\hline $\begin{array}{l}\text { Actor } \\
\text { characteristics }\end{array}$ & $\begin{array}{l}\text { Result of } \\
\text { mutual } \\
\text { influence }\end{array}$ & $\begin{array}{l}\text { Implementing } \\
\text { actor }\end{array}$ & Target actor & Linking actor \\
\hline \multirow{2}{*}{ 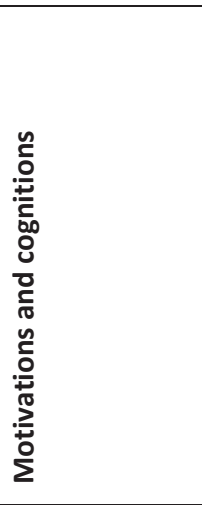 } & $\begin{array}{l}\text { Focusing } \\
\text { attention }\end{array}$ & $\begin{array}{l}\text { FBAE not } \\
\text { adequately } \\
\text { implemented due } \\
\text { to low motivation } \\
\text { and insufficient } \\
\text { info }\end{array}$ & $\begin{array}{l}\text { Would like more } \\
\text { access to paraffin } \\
\text { through FBAE } \\
\text { implementation }\end{array}$ & $\begin{array}{l}\text { Service } \\
\text { delivery for } \\
\text { the } \\
\text { community }\end{array}$ \\
\hline & $\begin{array}{l}\text { Perception of } \\
\text { opportunities } \\
\text { and threats }\end{array}$ & $\begin{array}{l}\text { Success of FBAE } \\
\text { relies on sufficient } \\
\text { staff and info }\end{array}$ & $\begin{array}{l}\text { Paraffin assists } \\
\text { in energy poverty } \\
\text { alleviation }\end{array}$ & $\begin{array}{l}\text { Lack of } \\
\text { municipal } \\
\text { information } \\
\text { makes it } \\
\text { difficult to } \\
\text { implement } \\
\text { FBAE } \\
\end{array}$ \\
\hline \multirow{2}{*}{ 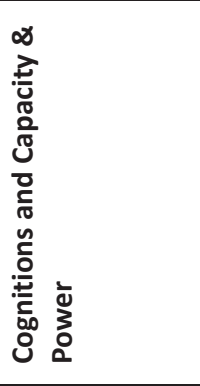 } & Strategic value & $\begin{array}{l}\text { Info availability } \\
\text { allows for some } \\
\text { FBAE } \\
\text { implementation }\end{array}$ & $\begin{array}{l}\text { No strategy to } \\
\text { receive more } \\
\text { paraffin }\end{array}$ & $\begin{array}{l}\text { Good } \\
\text { knowledge of } \\
\text { community } \\
\text { needs }\end{array}$ \\
\hline & $\begin{array}{l}\text { Data search } \\
\text { and processing } \\
\text { capacity }\end{array}$ & $\begin{array}{l}\text { Insufficient data } \\
\text { processing } \\
\text { capacity }\end{array}$ & $\begin{array}{l}\text { Lack of sufficient } \\
\text { information on } \\
\text { other services } \\
\text { that link to FBAE }\end{array}$ & $\begin{array}{l}\text { Good data } \\
\text { search and } \\
\text { processing } \\
\text { but hindered } \\
\text { by } \\
\text { municipality }\end{array}$ \\
\hline \multirow{2}{*}{ 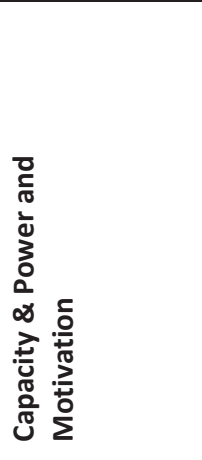 } & $\begin{array}{l}\text { Relevance of } \\
\text { resources for } \\
\text { intended action }\end{array}$ & $\begin{array}{l}\text { Availability of } \\
\text { resources would } \\
\text { make FBAE easy } \\
\text { to implement }\end{array}$ & $\begin{array}{l}\text { Lack of access to } \\
\text { resources makes } \\
\text { it difficult to } \\
\text { access services } \\
\text { such as FBAE }\end{array}$ & $\begin{array}{l}\text { Lack of access } \\
\text { to more } \\
\text { resources } \\
\text { makes it } \\
\text { difficult to } \\
\text { achieve goals }\end{array}$ \\
\hline & $\begin{array}{l}\text { Availability of } \\
\text { resources for } \\
\text { intended action }\end{array}$ & $\begin{array}{l}\text { Lack of resources } \\
\text { leads inadequate } \\
\text { implementation }\end{array}$ & $\begin{array}{l}\text { Lack of important } \\
\text { resources makes } \\
\text { it difficult to } \\
\text { access paraffin } \\
\text { regularly }\end{array}$ & $\begin{array}{l}\text { Lack of } \\
\text { resources } \\
\text { leads to } \\
\text { limited access } \\
\text { to FBAE } \\
\text { services }\end{array}$ \\
\hline
\end{tabular}

Having resources for the FBAE policy implementation process is relevant as it would be impossible to deliver services without the necessary resources. Resources are important in supporting the actor's motivations. The implementing actor in this case lacks an important resource, namely; staff 
members responsible for FBAE service delivery. Having staff members working solely on the implementation of this policy would provide an opportunity for this municipality to strategize on the delivery of FBAE services. Dedicated staff members would ensure that the indigent register is credible, households are informed of the FBAE services and the services are delivered. The target actor also lacks resources that would be useful for accessing FBAE services. This actor's only available resource is the linking actor through the provision of some information regarding service delivery - but this resource is not enough to ensure that the target actor can access sufficient FBAE services to meet their needs. The linking actor has knowledge of the target actor as well as access to the implementing actor as resources. These however, are not enough in ensuring delivery of FBAE services without difficulty. This shows that an actor may possess resources but if these are not relevant, the interaction process (policy implementation) may be negatively affected.

\subsection{Conclusions}

Among the five municipalities in this study King Sabata Dalindyebo is the last to start provision of alternative energy services as part of the FBE policy implementation process. As a municipality based in a more developed area compared to the other four, one would expect that its delivery of services processes would be more successful. To illustrate the FBAE implementation process in this case, the KwaMpuku informal settlement is used as a target actor. The analysis reveals that this local municipality has very low level of success in the implementation of the FBAE policy. This means, although there is some delivery of alternative energy services to indigent households, the implementation process is faced with a number of complexities that arise from the interaction of actors and their characteristics.

In King Sabata Dalindyebo, the implementing actor's relationship with the linking and target actors is weak. For instance, the linking actor is not always informed about the implementing actor's plans regarding the delivery of alternative energy services as part of the FBAE policy implementation process. On the other hand the target actor is not involved 
in the decision-making process regarding alternative energy services. This means that the time of delivery of alternative energy services is often at the discretion of the implementing actor. For the linking and target actors the delivery timing can appear unpredictable and lacking of rationale.

Among other issues that lead to this case's low implementation success level is the lack of a credible indigent register due to a failure to update details of households even though the information is provided by the linking and the target actors. The indigent register's lack of credibility is also caused by the use of 'unreliable' data received from the district municipality. Other factors that lead to low implementation success for this municipality are:

- The implementing actor is subject to political external pressure from the national government to deliver services in order to boost voter confidence in favour of the ruling political party. This influences the process of service delivery including the delivery of alternative energy services as part of the FBAE policy implementation process.

- The implementing actor does not have a dedicated department focusing on the implementation of FBAE services. The responsibility of implementing this policy is given to staff that already have other responsibilities and priorities within the municipality.

- The target actor is unable to participate in decision-making and voice its service delivery concerns. This lack of voice is rooted in their vulnerable position due to living in an informal settlement without rights to receive 'permanent' energy services. 


\section{Chapter 8: Nyandeni case: Stuck in the Middle}

"Financing the policy implementation is a challenge as the funders (national government) don't know what is happening on the ground. They do not have a sense of how the money is spent and often think that what they give is enough and will satisfy all the implementation needs" ${ }^{83}$.

\subsection{Introduction}

Nyandeni local municipality implements the Free Basic Alternative Energy (FBAE) policy through the provision of paraffin to households that it has classified as indigents. Like other municipalities in this study, the provision of energy services, specifically alternative energy, is something that this municipality is not familiar with as this is not traditionally the responsibility of rural-based local municipalities. Although this municipality started FBAE policy implementation in 2009, there are constant hurdles that hinder satisfactory implementation and delivery of energy services. Similar to the other case chapters, this case analyses how the different actors and their characteristics influence the FBAE policy implementation process.

\footnotetext{
${ }^{83}$ Quotation taken from an interview with the Coordinator of Community Services
} at Nyandeni on 08 May 2012. 


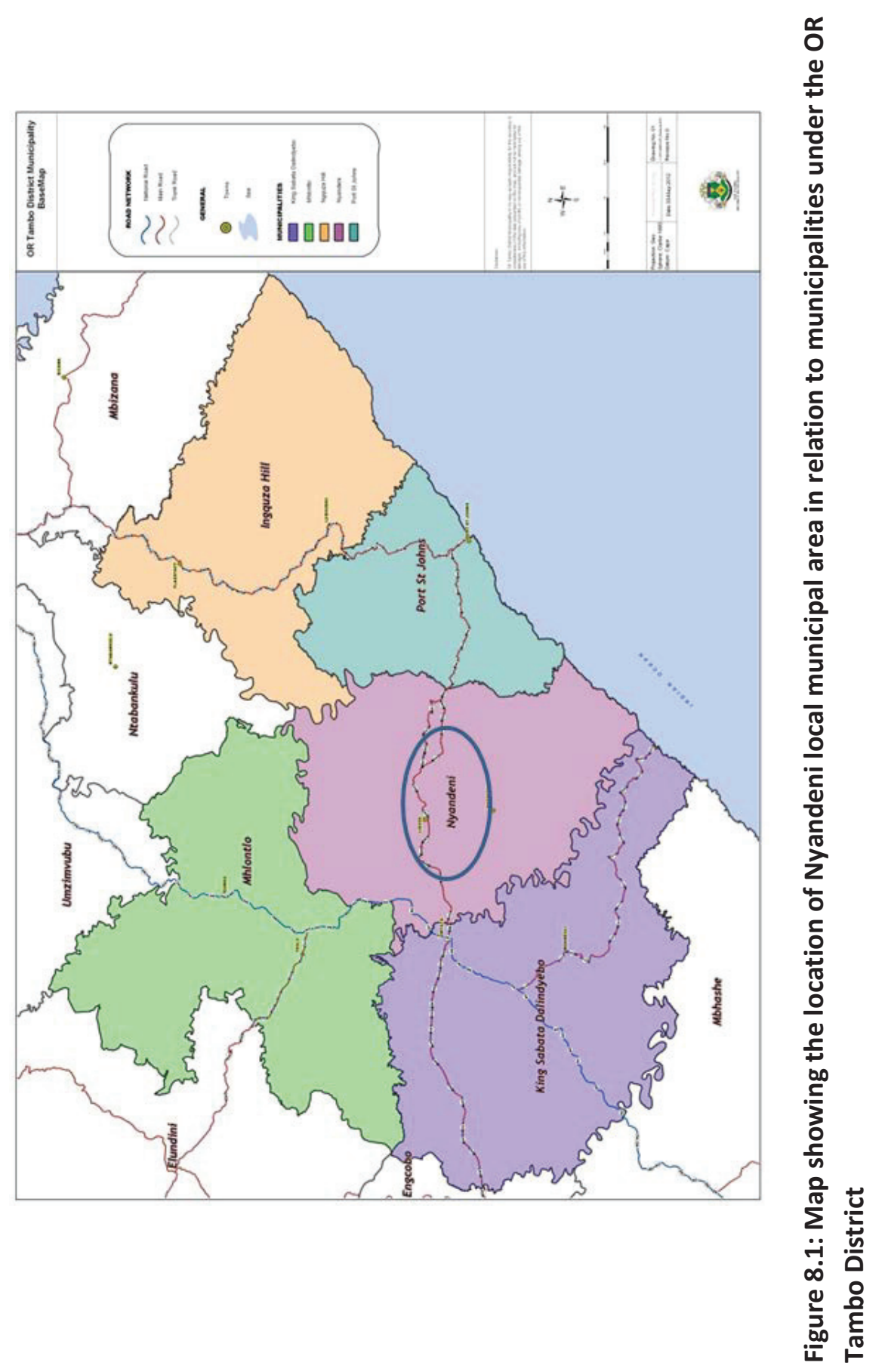




\subsection{Area description}

Nyandeni local municipality is located in the rural areas of the Eastern Cape under the OR Tambo district municipality. The municipality is divided into 31 wards and it covers a land area amounting to 4231 square kilometres with a population of 290390 people and an estimated 61647 households (StatsSA 2011). It consists of a combination of coastal and land-locked areas where in some parts it offers tourist attractions such as nature reserves with indigenous wild plant and animal life. Nyandeni has two small towns known as Libode and Ngqeleni which offer administrative services such as the police station, municipality and a small magistrate court. Nyandeni is a rural municipality and it is often difficult to access the remote rural villages due to bad, unmaintained gravel roads. Most people living under this municipality depend on government social grants such as old-age pensions and child-care grants for survival. Nyandeni has very limited employment opportunities but its close proximity to Mthatha ${ }^{84}$ allows some households to access job opportunities and run their own small informal business such as selling goods and food on the side of the road.

\subsection{Methodology specific to this case}

In this area, interviews were conducted with local municipality and community representatives as well as the service provider sub-contracted by the municipality to deliver paraffin as part of FBAE policy implementation. At the local municipality, interviews were first conducted in 2011 followed by another round in 2012 with the same respondents. The second interviews were conducted in order to find out whether the municipality had fulfilled the goals it had set the previous year concerning energy provision and FBAE policy implementation.

The community representatives interviewed spoke on behalf of both the community (target actors) and the municipal community representatives

\footnotetext{
${ }^{84}$ Mthatha is the biggest town in the OR Tambo district where the district municipality offices are based. During the apartheid government rule, Mthatha was the capital town of the Eastern Cape province.
} 
(linking actors) such as Ward Councillors in their respective communities. As this municipality is providing paraffin to indigent households as part of its FBAE policy implementation, an interview with the paraffin service provider was conducted. The main reason behind this interview was to find out information on how this service provider, as a representative of the local municipality, interacts with the community and its representatives. Information about the implementation of the FBAE policy in this area was accessed through the municipal Integrated Development Plan (IDP) documents.

Similar to the other cases in this study, the method of respondent selection varied depending on the conditions on the field. Some of the respondents were selected purposely because they were the only people with the relevant information, especially within the municipalities. Some of the respondents were selected through a snowballing method where they were recommended by other people I had interviewed and identified as people with the information relevant for my study.

In this case, the actors are defined as follows:

\section{Implementing actors}

The Nyandeni implementing actors are employees of the local municipality and have the responsibility, whether directly or indirectly, to facilitate the implementation of the FBAE policy. An implementing actor interviewed in this municipality is the Community Services employee responsible for coordinating Free Basic Services (which include FBAE services), waste removal and management of upkeep of cemeteries within this municipality.

\section{Target actors}

Target actors in the case of Nyandeni are communities receiving energy services that are delivered as part of Free Basic Alternative Energy (FBAE) policy implementation process. For this case, no household interviews could be conducted and target actor information is based on information received through interviews with community representatives and the service provider. 


\section{Linking actors}

The main linking actor role in this case is represented by a current Ward Councillor and a former Ward Councillor. These individuals represent their communities in the municipal formal structures in charge of decisionmaking. They also represent the municipality in their respective communities where they inform households about the municipal activities. These linking actors represent Wards 11 and 20 and their responses are specific to their communities.

\subsection{Current energy service provision in Nyandeni}

Current statistics from the national census survey of 2011 show that about $71 \%$ of the households in Nyandeni use grid electricity for lighting and out of these households, only $40 \%$ use this energy source for cooking and only $15.5 \%$ use it for heating (see Table 8.1). It should be noted that households with grid electricity also use this energy source for powering television, radio and charging cellphone batteries. However, the use of other appliances highly depends on whether the households have the appropriate appliances and if they are able to afford the costs associated with using grid electricity for end-uses such as cooking and heating. Lighting, cooking and heating are regarded as the most basic, essential and important household energy services, hence prominently reported on by Statistics South Africa (2011) on the national census data. Lighting statistics are also used as an indication of the areas' electrification level or access to electricity. One can safely conclude that out of the total number of households in Nyandeni, an estimated $71 \%$ have grid electricity connections. This also means the municipality has a household electrification backlog of $29 \%$. Regardless of the high costs associated with grid electrification of remote rural areas, this municipality has not made decisions to provide these unelectrified households with Renewable Energy Technologies. 
Table 8.1: Percentages of households using types of energy in Nyandeni -

\begin{tabular}{|l|r|r|r|}
\hline & \multicolumn{1}{|l|}{ Lighting } & \multicolumn{1}{l|}{ Cooking } & \multicolumn{1}{l|}{ Heating } \\
\hline Electricity & 71.0 & 40.0 & 15.5 \\
\hline Gas & 0.2 & 3.1 & 1.4 \\
\hline Paraffin & 5.1 & 9.5 & 22.5 \\
\hline Wood & & 45.4 & 52.9 \\
\hline Coal & & 0.1 & 0.7 \\
\hline Animal dung & & 1.3 & 0.5 \\
\hline Solar & 0.2 & 0.1 & 0.1 \\
\hline Candles & 23.0 & & \\
\hline Other & & 0.2 & 0.0 \\
\hline None & 0.4 & 0.3 & 6.3 \\
\hline
\end{tabular}

Source: Statistics South Africa 2011

The lack of modern energy services is reflected on Table 8.1 which shows the percentage of households using wood for cooking and heating. Cooking is an important activity for most if not all households whether in urban or rural areas and it demands an energy source that is reliable and available at all times. As there are still households that are not connected to the grid for electricity in Nyandeni, a number of households have to rely on wood for cooking and heating. Up to $45.4 \%$ of households use wood as their main cooking fuel source and almost $53 \%$ use wood as their main fuel for heating their homes. Wood use indicates that the area is very rural and has a significant availability of fuel-wood within its surroundings even though the distances from the villages to the wood collection areas are long.

\subsection{Nyandeni municipality's indigent households' register and FBAE policy implementation}

The indigent register is an important tool for all municipalities in South Africa. Without a credible indigent register, a municipality cannot compile an indigent policy nor can it have knowledge of the services needed by the communities and households under it. With regards to compiling a credible indigent register, Nyandeni is experiencing difficulties similar to those faced 
by the other local municipalities studied in this thesis. Although there are attempts by the Community Services department to compile an indigent register, this proves difficult without the sufficient resources. Occasionally, the Nyandeni local municipality relies on information gathered by the district municipality to compile its indigent register, however, this information is not always reliable as it understates the number of households qualifying as indigents. The King Sabata Dalindyebo municipality representative also made a similar claim about the indigent register that is compiled by the district municipality ${ }^{85}$. If the municipality relies only on this information, it often experiences financial problems where budget allocations fall short of the actual number of households in need of subsidies. One of the ways that the information from the district municipality is used, is by combining it with information collected by community representatives and verified in order to produce a close-tocredible indigent register.

One of this municipality's goals is to use the indigent register to create an exit strategy that will enable people to find employment or engage in other forms of economic activities that will assist them in exiting the indigent register. With this, the municipality hopes that it will lower the number of households on this list which will result in fewer households depending on the municipality for Free Basic Services such as FBAE programmes. According to the Community Development Worker, an exit strategy is a plan by the municipality to ensure that households on the indigent list do not remain there, but opportunities for employment are found or created for them through the help of government employment creation programmes and the private sector. The main problem the municipality is facing in creating this strategy is that the whole municipal area is impoverished and employment opportunities are scarce. There are no factories and industries in the surrounding areas and entrepreneur opportunities are limited.

The household information collected by the municipality to develop its indigent register, is also used to document community needs and make

${ }^{85}$ See Chapter 7, Section 7.5. 
these part of the Integrated Development Plan - a document outlining the municipality's plans for each year.

In a quest to ensure the credibility of their indigent register, the Nyandeni local municipality has devised some strategies that will assist the Community Services department. One of the planned strategies was to host a summit to start a dialogue about the indigent services provided by the local municipality and discuss the draft Indigent policy with relevant stakeholders. Such stakeholders include ward representatives such as Councillors, Ward Committees and everyone involved in the chain of providing basic services through the indigent policy framework. The intention is to discuss and make concrete plans that will assist in updating household information on the indigent registers. The municipality also viewed this as an opportunity where energy service provision could be discussed, especially in providing sustainable alternative energy to households without grid electricity as part of FBAE policy implementation.

As with other local municipalities, Nyandeni also relies on linking actors such as Ward Councillors and other community representatives to keep the constant flow of information in order to update the indigent register. The linking actors note all the changes in the households within the communities they represent and forward it to the implementing actor. Realistically, this process does not happen as smoothly as stated above, and in most cases, there are often no resources such as funds and staff to update the indigent register on the municipality's records. This hinders the service delivery plans that include Free Basic Services such as FBAE services. In some cases, households whose circumstances have changed for the better (no longer indigents), may still continue benefit from such subsidies that are meant for the poor because the register is not updated.

\subsection{The process of FBAE policy implementation by the different actors in Nyandeni}

The Nyandeni FBAE policy implementation process is discussed in the following section where the Contextual Interaction Theory is used to analyse the influence of the key actor characteristics in this process. 


\subsection{Implementing actors' role in the Free Basic Alternative Energy policy implementation process}

The role of the local municipality as the implementer of the FBAE policy, is to ensure that indigent households benefit positively from receiving energy sources delivered to assist them to fulfil some of their household energy needs. The Nyandeni municipality has been implementing the FBAE policy through the provision of paraffin to its indigent household since 2009. Similar to the King Sabata Dalindyebo and Mhlontlo local municipalities, this municipality also provides 20 litres of paraffin quarterly to indigent households.

With approximately $30 \%$ of households (see Table 8.1 ) without access to grid electricity, the Nyandeni municipality needs to provide some form of energy services that will assist households in fulfilling their basic energy needs such as lighting, cooking and heating. This is one of the reasons given by the municipality in justifying the provision of FBAE services to its lowincome indigent households. This municipality is aware that it will take long to provide grid electricity to the remaining households and this process will be expensive as the households are located in remote rural areas. The sentiment expressed was:

\section{"Eskom is taking too long!"}

FBAE service provision is seen as a solution for the interim period whilst people wait for grid electricity.

As optimistic as this local municipality is about providing FBAE services to its indigent households, the reality is that often, it is difficult to achieve its goals due to a number of factors as will be illustrated in the following analysis.

In order to deliver paraffin to low-income households that qualify as indigents and that are on the municipality's register, Nyandeni municipality sub-contracts service providers. The service provider interviewed ${ }^{86}$ for this study has paraffin tankers that he uses to distribute the fuel to the villages.

\footnotetext{
${ }^{86}$ Face-to-face interview with Nyandeni paraffin service provider at Mthatha on 22 July 2011.
} 
Household members are gathered by the linking actors to assemble at distribution points where their details are checked against the indigent register and before being handed the fuel. Such a paraffin distribution process takes up to four days and may be up to 2000 households per service provider depending on the number of households without grid electricity in the villages.

Using the Contextual Interaction Theory to analyse the Nyandeni case, the relationships between the implementing actors' core actor characteristics are elaborated (see Figure 8.2). This illustration shows how the actor characteristics influence each other in the policy implementation process.

Figure 8.2 shows that this implementing actor is motivated both positively and negatively. The positive motivation is that this actor's goal really is to provide energy services to the indigent households. The negative aspect of this motivation is that the delivery of FBAE services is not always a relative priority for this actor. As this is an interaction process, it is important to acknowledge that the actor motivations are influenced by the other characteristics, namely cognitions and capacity and power.

A focus on cognitions reveals how the interaction process also relies on this actor characteristic. Here, the focus is on the information that the implementing actor has and uses in order to implement the FBAE policy. In this box, information such as the indigent register and the information from the national government department is taken into consideration. This actor makes an effort in ensuring that households are informed about the basic services they qualify for such as FBAE. There are active information sharing sessions organised by the municipality in the villages to inform people of Free Basic Services. Again, it is important to note the influence that the other actor characteristics have on the cognitions and use of information by this actor.

The box addressing capacity and power looks at the resources that this actor has in order to have capacity to implement as well as power. The power referred to here is that which is attributed by the other actors and that is catalysed by the resources available to the actor. 

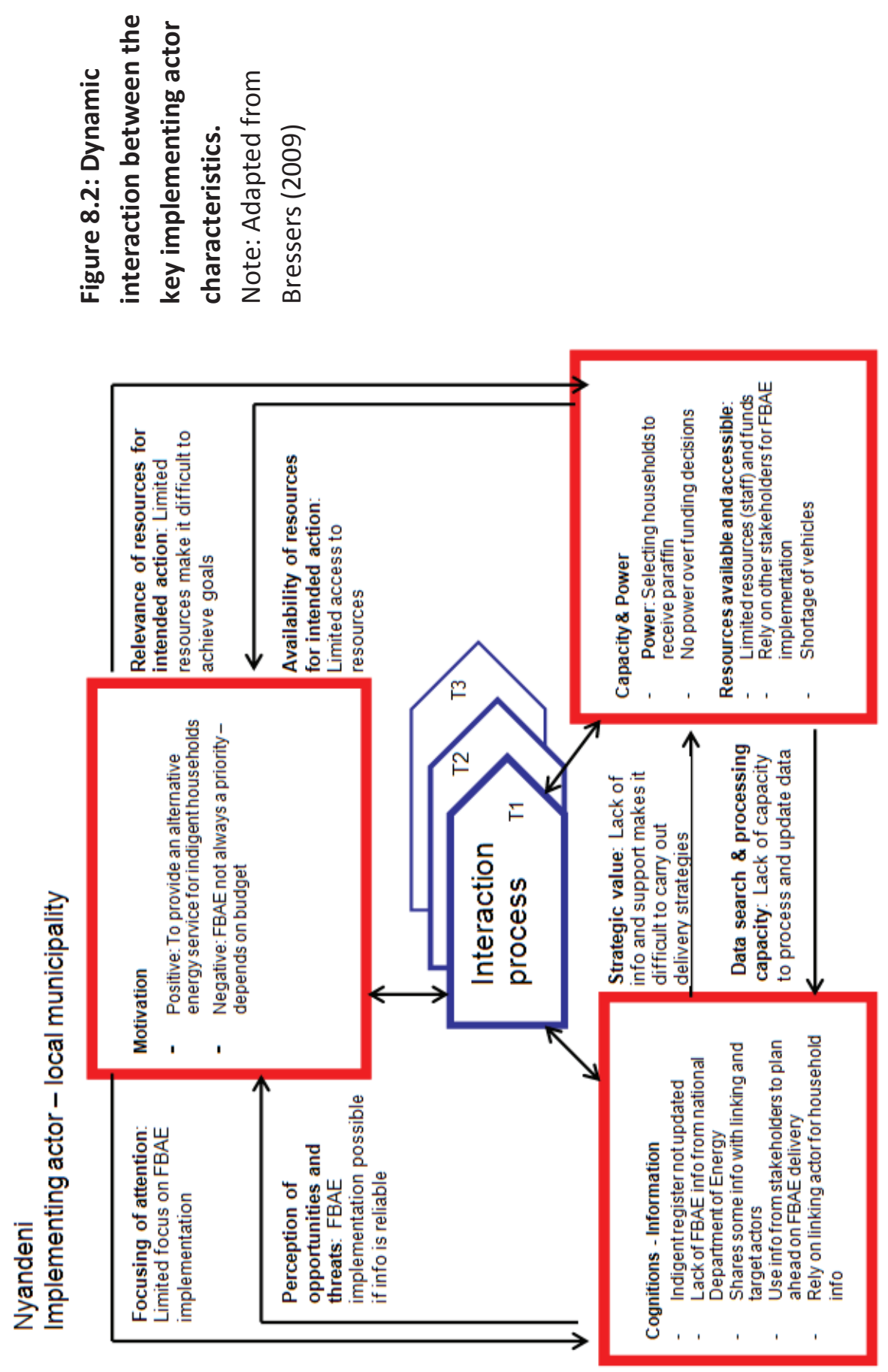
Although the Nyandeni local municipality had a Community Services department that is in charge of Free Basic Services, there were not enough people working within this department to fulfil the roles and responsibilities. This has led to difficulties in service provision, especially, those that depend on the indigent register. It was difficult for this local municipality to keep their indigent register updated, even though new information was being received from the linking actors. Due to lack of staff to capture and update this information, the register was not credible.

As this department has other responsibilities beyond FBAE policy implementation, the coordinator was always under pressure to weigh the needs according to the urgency and availability of resources to fulfil a task. To a great extent, decision-making remained crucial and it was influenced by a number of factors.

Similar to the other local municipalities under the OR Tambo district, having households located in some remote rural areas poses challenges where resources are concerned. Nyandeni did not have enough vehicles to reach the villages, hence sub-contracting the paraffin service provider to deliver paraffin. The problem with lack of vehicles is that the municipality hardly gets an opportunity to visit the villages to see for themselves the kind of conditions that people live under and the types of services that they need. For this information, they rely on the linking actors.

Although the plan is to provide this paraffin to indigent households in each quarter, according to the municipal representative, it is sometimes impossible to achieve this goal due to a number of reasons which include:

- Shortage of funds allocated to FBAE policy implementation,

- Not enough staff members to work on the implementation strategy and process,

- Failure to update the indigent register with new information received from linking actors,

- Competing priorities within the Community Services department where some services have to be prioritized above implementation, 
- Lack of information and support from the national Department of Energy where implementation is concerned,

- Lack of transport.

Due to a shortage of funds within the municipality, when implementing strategies and policies such as FBAE service, the municipality has to make a decision on a number of indigent households it can provide energy services to - even though all of those in the register qualify for services. These decisions have to be made in order to ensure that at least some people receive the services, just for the municipality to meet some of its goals. The Coordinator within the Community Services was concerned about the financing framework used to fund activities such as Free Basic Alternative Energy Services. The funds given by the national government are often not enough to cover the costs of implementation and provide services to all the households in need. To express the problems caused by this, she said:

"Financing the policy implementation is a challenge as the funders (national government) don't know what is happening on the ground. They do not have a sense of how the money is spent and often think that what they give is enough and will satisfy all the implementation needs".

\subsubsection{The target actors' role in the Free Basic Alternative Energy policy implementation process}

Target actors in the case of Nyandeni are communities receiving energy services that are delivered as part of Free Basic Alternative Energy (FBAE) policy implementation process. For this case, no household interviews were conducted and target actor information is based on information received through interviews with community representatives, the municipality and the service provider.

Households receiving FBAE services in Nyandeni are considered indigent because of their low-income status and dependence on government social 
grants such as old-age pensions and child-care grants. These households do not have grid electricity connections because they are located in remote rural areas, which places them at a disadvantage as they cannot access services and are far from places with job opportunities. Target actors have expressed to their community representatives and to the municipality that they would like to receive more paraffin (monthly distribution instead of quarterly) as part of the FBAE policy implementation process. The main reason is that most households in this area live in poverty and the distribution of paraffin brings relief on their energy expenditure.

Figure 8.3 depicts the target actors' motivations, cognitions and capacity and power. As stated above, this target actor's goal is to receive FBAE services which are delivered in the form of paraffin in these areas. They would like to receive this more often than once a quarter as this will have a greater impact on easing their energy poverty and lowering their energy expenditure. As it is expected, the actor's motivations drive the policy implementation process but they are also affected and influenced by the other characteristics such as cognitions and capacity and power. This actor's motivation or goal to receive FBAE service, depends on its information and knowledge as well as the resources that provide it with capacity to access these energy services and the power that is attributed by the other actors.

On analysing this actor's cognitions and focusing on the information that is available to enable the implementation of the FBAE policy, it is clear that information is important in the interaction process. In this case, the target actor relies on information given by the implementing and linking actors regarding the implementation of the FBAE policy. This information ranges from explaining what FBAE is, to making target actors understand why they receive FBAE services, to explaining why and how the indigent register is important for the delivery of FBAE services.

During the interviews it was revealed that when the FBAE services were first delivered in this area in 2009, there were approximately 1000 households on the indigent register. At the time, the municipality could only afford to distribute paraffin to this number and underestimated the 
number of households that were in need of this service and that the register was incomplete. Since then, the municipality has decided to deliver to more households although it is hoping that this number will reduce as people's circumstances change for the better. There are still problems associated with the indigent register and this leads to disagreements and tensions within the communities as it affects service delivery to indigent households. The Ward Councilor said that when people realize that their names are not on the paraffin distribution lists as they should be, they get upset by this. In some instances, they refuse to let the paraffin distributer leave the area before everyone receives the fuel.

"This was a problem for the distributor because it caused delays and meant that the beneficiaries in the next location would not receive their share of paraffin".

In such cases, the role of the linking actor is very important as they are the only people that can calm the community and explain why their names are not on the list. This also puts the linking actor in a difficult position as they have to defend themselves when accused by the community for not submitting their names to be updated in the indigent register (see next section). Even though this is not the linking actor's fault, but a problem caused by the municipality's failure to update the indigent register with new information. The matter is often exacerbated by the absence of municipal representatives in the villages during the paraffin delivery days and the problem is left unexplained and unresolved.

Capacity and power of this actor depends on the resources that are available to it. This actor does not have access to resources to implement the FBAE policy according to its goals. This is due to lack of capacity which affect access to resources as well as lack of power attributed to this actor by other actors. Resources such as access to information to make informed decisions about FBAE services would assist this actor in actively participating in the FBAE implementation process. 

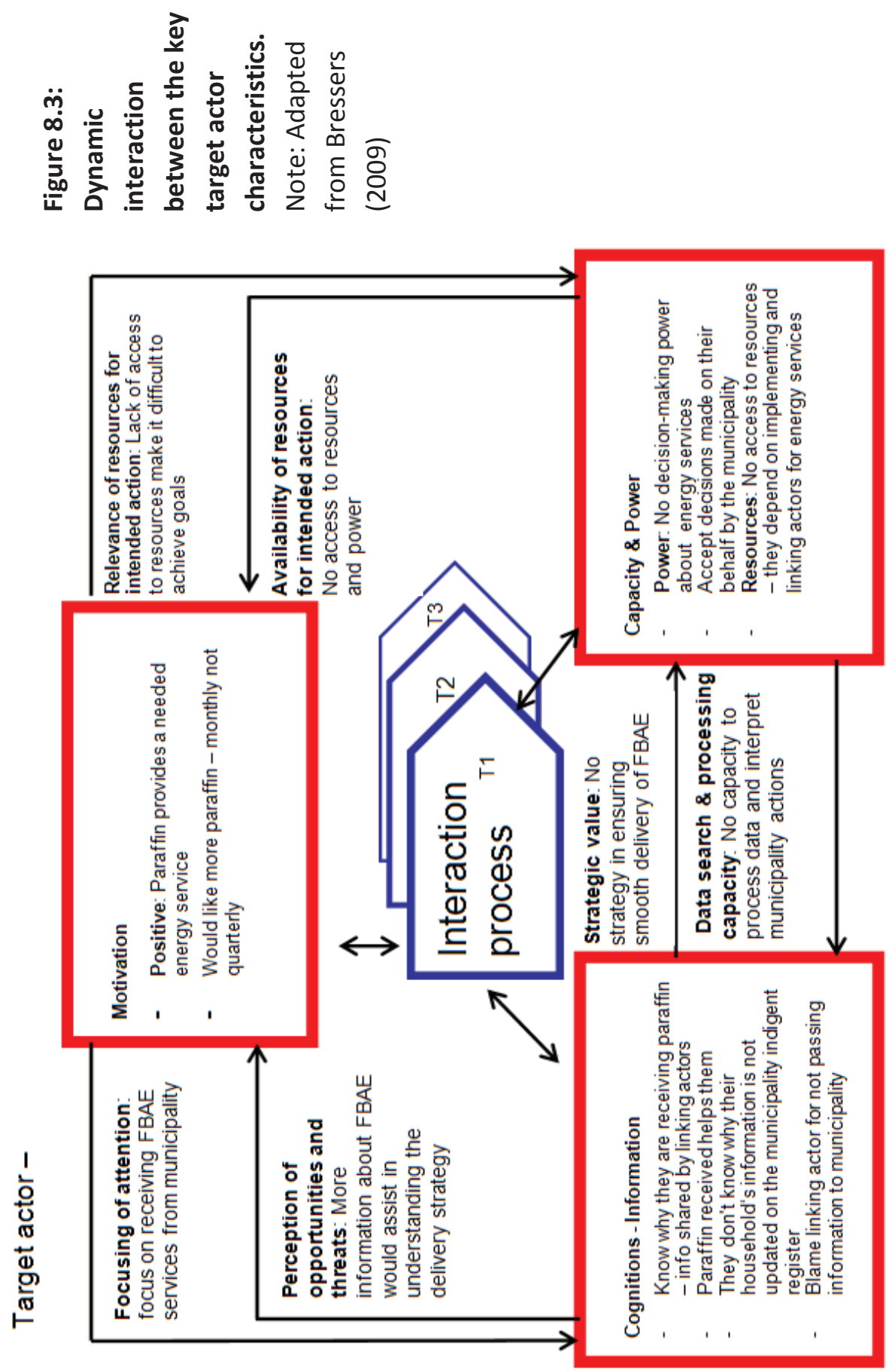
The target actor in this case does not have an 'active' role in terms of the implementation of the FBAE policy. Piecing together information collected from different sources about the target actors' role reveals that decisions about FBAE policy implementation are mainly made by the implementing actor. The Contextual Interaction Theory analysis of this case shows that the target actor's lack of sufficient information regarding the delivery of FBAE services and lack of resources leaves this actor without capacity and power over the implementation of this policy.

\subsubsection{The linking actor's role in the Free Basic Alternative Energy policy implementation process}

The main linking actor's role in this case is represented by a current Ward Councillor and a former Ward Councillor ${ }^{87}$. These individuals represent their communities in the municipal formal structures that are in charge of decision-making. They also represent the municipality in their respective communities where they inform households about the municipal activities. These linking actors represent Wards 11 and 20 and their responses are specific to their communities.

There were mixed reactions and feelings from the linking actors about the way FBAE services were delivered to the communities. Even though these services benefited households who would have otherwise not been able to buy this much needed fuel for themselves, they were delivered in an unsatisfactory manner. The main identified problem was the indigent register, especially where people that were supposed to be on delivery lists were not there. The linking actors said this brought discomfort and made them seem dishonest to the community. This was because the linking actors were in charge on updating the household information on the lists that were handed to the municipality in order to update the indigent register. Due to lack of capacity within the municipality, this information is

\footnotetext{
${ }^{87}$ Face-to-face interviews were conducted with both Ward Councillors 13 July, 21 July and 01 August 2011 at different locations in Nyandeni.
} 
never updated on time, which leads to the use of outdated lists on paraffin distribution days. As one of the Councillors explained:

"It is as if we are not doing our job and are giving people false information when we tell them that their names will be on the list during paraffin delivery days. This causes tensions within the community as sometimes people with better circumstances benefit more than those that are very poor".

Figure 8.4 shows the dynamic interaction between the linking actors' key characteristics in the implementation of the FBAE policy. The linking actors interviewed said that although there is an important role in connecting the communities to the municipality, it was important to involve the traditional leaders as well, because of their role in rural communities. This role is sometimes undermined by the municipality which can prove detrimental to the municipality in getting communities to understand and accept their policies. People in such remote rural areas still follow traditional ways of living and consulting traditional leaders such as Chiefs and Headmen is an important part of that practice. The linking actors felt that the local municipality did not properly consult with these traditional leaders in introducing the FBAE policy implementation strategies. Traditional leaders can influence how people respond to government programmes and if there are discrepancies, these leaders always blame the municipality for lack of consultation. This is linked to the power attributed by others in the interaction process. If the linking actors feel that the implementing actor is not consulting them properly in the policy implementation process - this may show that not much power is attributed to the linking actor by the implementing actor. 

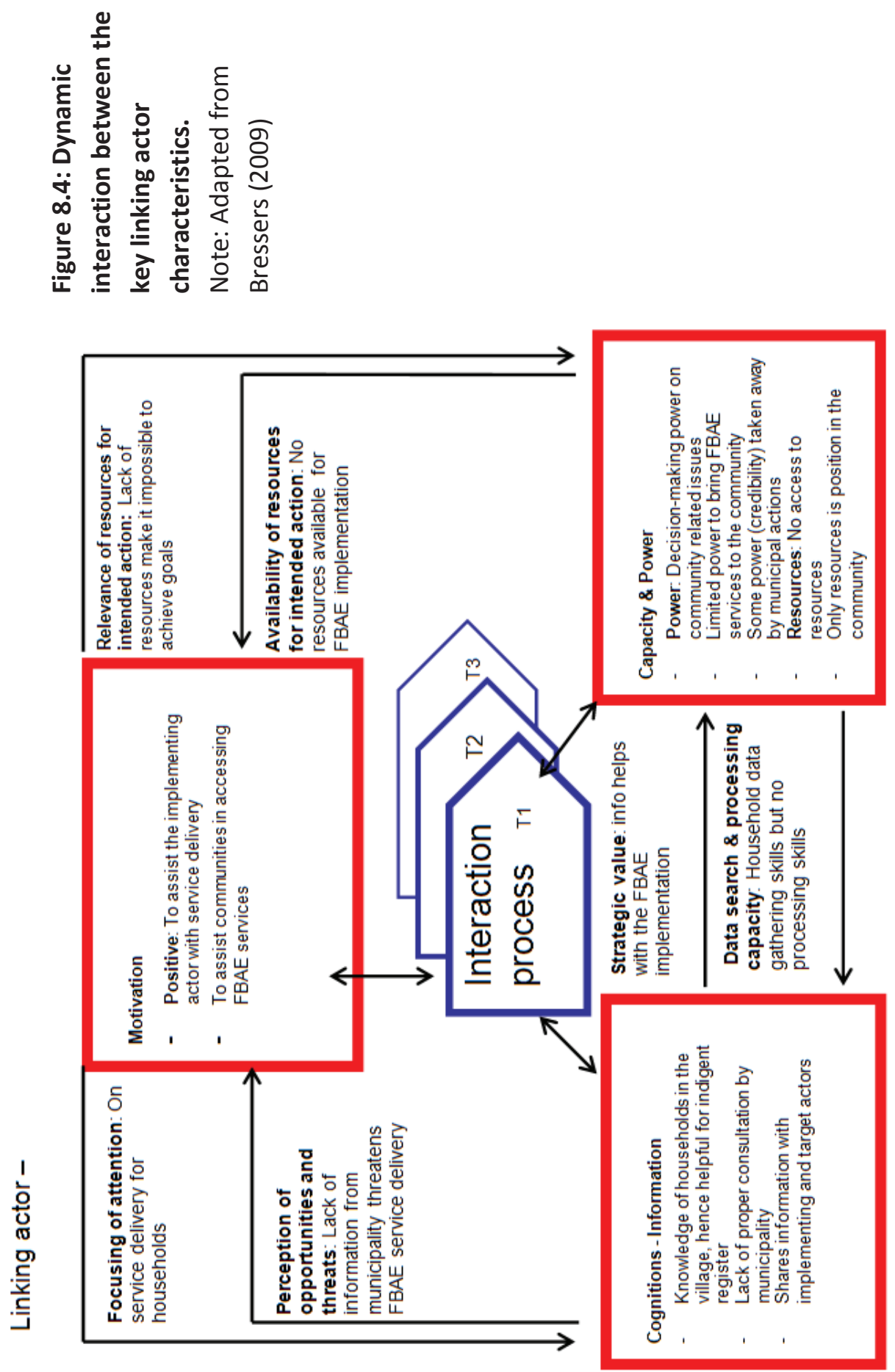
This actors' goals are clearly to assist the implementing actor with the delivery of FBAE services for the benefit of target actors. It is therefore important that this actor has resources that make it possible to have some capacity to implement this policy. The interaction process on Figure 8.4 shows that this actor does not have the resources. It is also clear that this actor does not have much power attributed to them by the implementing actor, therefore making its implementing efforts weak, in the sense that it does not reach its goals. This also affects this actors' relationship with the target actor in a negative way, which affects motivation.

On cognitions, the linking actor plays an important role as a source of information. This actor has information about the target actor and this is used for the compilation of the indigent register which in turn is used to deliver FBAE services by the implementing actor. On the other hand, this linking actor has some information about the municipality with regards to FBAE policy implementation, which it shares with the target actor. Although not mentioned under 'capacity and power', the knowledge based on this information is a resource for the linking actor. The linking actor can use this knowledge to benefit its position and relationships with the implementing and target actors.

Similar to the other actors, the linking actors' interaction process shows the importance of how the core actor characteristics rely on each other to activate and influence the policy implementation process.

\subsection{Comparing the key actor characteristics of the implementing, target and linking actors}

Using the Contextual Interaction Theory to analyse the Nyandeni case allows for an in-depth look at how the actor characteristics (motivations, cognitions and power and resources) influence the implementation of the Free Basic Alternative Energy policy. Below, the key actor characteristics of the different actors are compared and analysed to determine whether there are differences and similarities in their goals concerning the 
implementation of the FBAE policy. Their information access and use is also compared as well as their capacity and power.

\subsubsection{Summary of comparison of Nyandeni's key actor characteristics}

Table 8.2 shows that actor motivations for FBAE policy implementation are positive in that they all want the provision of energy services, in this case, the delivery of paraffin to indigent households. For the implementing actor, it is important to deliver alternative energy services to households without grid electricity, but, as can be observed in the Table 8.2, FBAE implementation, is not always a priority. This is due to lack of sufficient funds to provide such services as this municipality has competing priorities and needs that require the attention of the implementing actor. The target actor is motivated by the need for affordable, reliable and accessible energy services in the remote rural areas of Nyandeni. For these households and communities, even though the supply of paraffin is not as frequent as they would like, the little that they receive makes a difference in their energy consumption and household budgets. The linking actor is motivated to assist both the target and implementing actors because this has a positive impact for this actor. If the linking actor ensures that the local municipality delivers energy services and assists the community to access these services, they build strong relationships with both actors.

The actor characteristic focusing on cognitions, which for this case covers information and knowledge, is both positive and negative for all three actors. The implementing actor relies on information from its stakeholders, especially the linking actor for the update of its indigent register. As mentioned earlier in this chapter, a credible indigent register is important for efficient delivery of services for all municipalities that offer subsidies to their low-income and poor households qualifying as indigents. However, even though the information on indigent households is supplied to the implementing actor, updating the register fails to happen for reasons that can be considered to be linked to motivation, resources and capacity. The implementing actor also does not receive information from the national 
government departments that are supposed to be playing the key roles in implementing the FBAE policy. This lack of support impacts negatively on the work expected to be achieved by the local municipality.

Although the target actor knows that the implementing actor is supposed to deliver FBAE services, it is not clear to them why this service is delivered with difficulty. Even though lines of communication between the target and implementing actors are open (through linking actors), they are often not as transparent as they should be. In most cases, the target actor is not informed as to why the names of some households are not on the indigent register even though they are on the linking actors' lists. This creates conflicts between the target and linking actors as well as between the linking and implementing actors. The result of this is lack of efficient delivery of FBAE services to households and tensions between the linking and target actors.

Where power and resources are concerned as actor characteristics, this case shows that all three actors do not have (sufficient) access to resources, therefore making the implementation of the FBAE policy difficult. Although the implementing actor has power to select households that qualify for paraffin distribution at a given time, this leads to flawed distribution and in most cases excludes households that are in need of this fuel. The municipality also lacks power to make funding decisions and has to accept decisions proposed and made by the provincial and national government departments - even though these departments lack full knowledge of the local municipality level. Where decision-making power is concerned, this case illustrates that actors need to be able to make decisions pertaining choice and delivery of services, otherwise they are left with responsibilities they cannot fulfill. 
Table 8.2: Result of interaction process of different actor characteristics

\begin{tabular}{|c|c|c|c|}
\hline & Implementing actor & Target actor & Linking actor \\
\hline Motivations & $\begin{array}{ll}\text { - } & \text { Positive: To } \\
& \text { provide an } \\
\text { alternative energy } \\
\text { service for } \\
\text { indigent } \\
\text { households } \\
\text { - } \\
\text { Negative: FBAE } \\
\text { not always a } \\
\text { priority - depends } \\
\text { on budget }\end{array}$ & $\begin{array}{ll}\text { - } & \text { Positive: Paraffin } \\
\text { provides a } \\
\text { needed energy } \\
\text { service } \\
\text { - } \quad \text { Would like more } \\
\text { paraffin - } \\
\text { monthly not } \\
\text { quarterly }\end{array}$ & 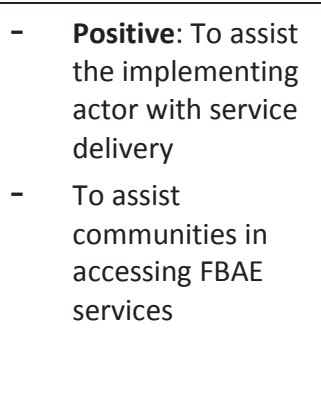 \\
\hline $\begin{array}{l}\text { Information } \\
\text { and } \\
\text { knowledge }\end{array}$ & $\begin{array}{ll}- & \text { Indigent register } \\
\text { - } & \text { not updated } \\
\text { Lack of FBAE info } \\
\text { from national } \\
\text { Department of } \\
\text { Energy } \\
\text { - Shares some info } \\
\text { with linking and } \\
\text { target actors } \\
\text { Use info from } \\
\text { stakeholders to } \\
\text { plan ahead on } \\
\text { FBAE delivery } \\
\text { Rely on linking } \\
\text { actor for } \\
\text { household info }\end{array}$ & $\begin{array}{l}\text { Know why they } \\
\text { are receiving } \\
\text { paraffin - info } \\
\text { shared by linking } \\
\text { actors } \\
\text { - } \quad \text { Paraffin received } \\
\text { helps them } \\
\text { - } \quad \text { They don't know } \\
\text { why their } \\
\text { household's } \\
\text { information is } \\
\text { not updated on } \\
\text { the municipality } \\
\text { indigent register } \\
\text { Blame linking } \\
\text { actor for not } \\
\text { passing } \\
\text { information to } \\
\text { municipality }\end{array}$ & 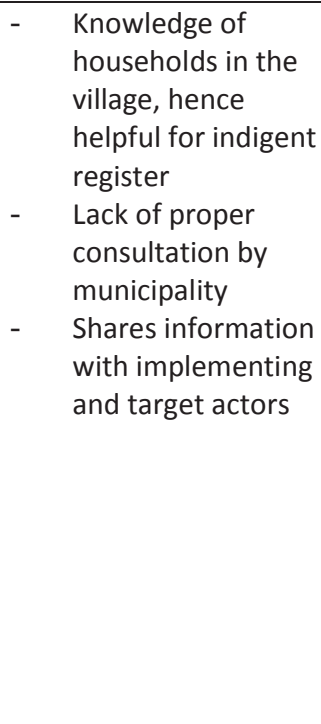 \\
\hline $\begin{array}{l}\text { Power and } \\
\text { Resources }\end{array}$ & 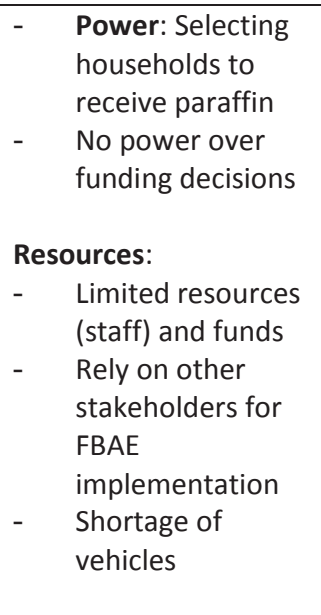 & $\begin{array}{ll}\text { - } & \text { Power: No } \\
\text { decision-making } \\
\text { power about } \\
\text { energy services } \\
\text { - Accept decisions } \\
\text { made on their } \\
\text { behalf by the } \\
\text { municipality } \\
\text { Resources: No } \\
\text { access to } \\
\text { resources - they } \\
\text { depend on } \\
\text { implementing } \\
\text { and linking } \\
\text { actors for energy } \\
\text { services }\end{array}$ & $\begin{array}{ll}\text { - } & \text { Power: Decision- } \\
\text { making power on } \\
\text { community related } \\
\text { issues } \\
\text { - } \quad \text { Limited power to } \\
\text { bring FBAE services } \\
\text { to the community } \\
\text { - } \quad \text { Some power } \\
\text { (credibility) taken } \\
\text { away by municipal } \\
\text { actions } \\
\text { Resources: No } \\
\text { access to resources } \\
\text { Only resources is } \\
\text { position in the } \\
\text { community }\end{array}$ \\
\hline
\end{tabular}




\subsubsection{Summary of mutual relations of actor characteristics}

In Table 8.3, the results of the mutual relations arising from each interaction process (i.e. from Figures 8.2, 8.3 and 8.4), are placed side-byside to compare how the actor characteristics of the Nyandeni actors influence the FBAE policy implementation process.

The 'focus of attention' for the three actors on the implementation of the FBAE policy. There is a difference in the way each actor focuses their attention on this process and this depends on the other actor characteristics that influence the whole interaction process. Lack of information from the national department as well as the inability to update the indigent register for efficient service delivery result in the limited focus of attention on FBAE policy implementation by the implementing actor. The target actors' focus on FBE policy implementation is based on the services this actor receives from the implementing actor. This actors' attention focus is influenced by the information delivered to it by the implementing and linking actors regarding FBAE policy implementation. It is also influenced by this actor's need for more energy services (in this case, paraffin). The current amount received is not enough to satisfy their household energy end-use needs. The linking actors' attention is focused on providing (energy) services for households (target actor). This is influenced by this actors' role in the implementation process as it is concerned with assisting the implementing actor with service delivery as well assisting the households to access FBAE services. This actor's knowledge of the implementing and target actors situation in this process influences the decision to focus attention on delivering FBAE services for the target actor. 
Table 8.3: Result of mutual relations of actor characteristics in the implementation process

\begin{tabular}{|c|c|c|c|c|}
\hline $\begin{array}{l}\text { Actor } \\
\text { characteristics }\end{array}$ & $\begin{array}{l}\text { Result of } \\
\text { mutual } \\
\text { influence }\end{array}$ & $\begin{array}{l}\text { Implementing } \\
\text { actor }\end{array}$ & Target actor & Linking actor \\
\hline \multirow{2}{*}{ 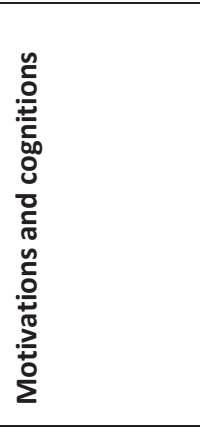 } & $\begin{array}{l}\text { Focusing } \\
\text { attention }\end{array}$ & $\begin{array}{l}\text { Limited focus on } \\
\text { FBAE } \\
\text { implementation }\end{array}$ & $\begin{array}{l}\text { Focus on } \\
\text { receiving FBAE } \\
\text { services from } \\
\text { municipality }\end{array}$ & $\begin{array}{l}\text { On service } \\
\text { delivery for } \\
\text { households }\end{array}$ \\
\hline & $\begin{array}{l}\text { Perception of } \\
\text { opportunities } \\
\text { and threats }\end{array}$ & $\begin{array}{l}\text { FBAE } \\
\text { implementation } \\
\text { possible if } \\
\text { information is } \\
\text { reliable }\end{array}$ & $\begin{array}{l}\text { More } \\
\text { information } \\
\text { about FBAE } \\
\text { would assist in } \\
\text { understanding } \\
\text { the delivery } \\
\text { strategy }\end{array}$ & $\begin{array}{l}\text { Lack of } \\
\text { information } \\
\text { from } \\
\text { municipality } \\
\text { threatens FBAE } \\
\text { service delivery }\end{array}$ \\
\hline \multirow{2}{*}{ 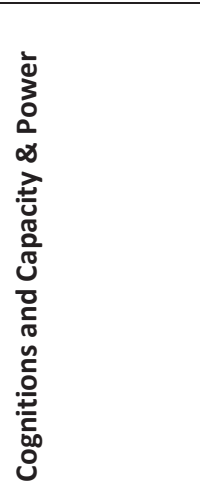 } & Strategic value & $\begin{array}{l}\text { Lack of } \\
\text { information and } \\
\text { support makes it } \\
\text { difficult to carry } \\
\text { out delivery } \\
\text { strategies }\end{array}$ & $\begin{array}{l}\text { No strategy in } \\
\text { ensuring } \\
\text { smooth } \\
\text { delivery of } \\
\text { FBAE }\end{array}$ & $\begin{array}{l}\text { Info helps with } \\
\text { the FBAE } \\
\text { implementation }\end{array}$ \\
\hline & $\begin{array}{l}\text { Data search } \\
\text { and processing } \\
\text { capacity }\end{array}$ & $\begin{array}{l}\text { Lack of capacity } \\
\text { to process and } \\
\text { update data for } \\
\text { indigent register }\end{array}$ & $\begin{array}{l}\text { No capacity to } \\
\text { process data } \\
\text { and interpret } \\
\text { municipality } \\
\text { actions }\end{array}$ & $\begin{array}{l}\text { Household data } \\
\text { gathering skills } \\
\text { but no } \\
\text { processing skills }\end{array}$ \\
\hline \multirow{2}{*}{ 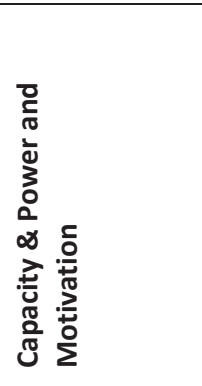 } & $\begin{array}{l}\text { Relevance of } \\
\text { resources for } \\
\text { intended } \\
\text { action }\end{array}$ & $\begin{array}{l}\text { Limited resources } \\
\text { make it difficult } \\
\text { to achieve goals }\end{array}$ & $\begin{array}{l}\text { Lack of access } \\
\text { to resources } \\
\text { make it difficult } \\
\text { to achieve } \\
\text { goals }\end{array}$ & $\begin{array}{l}\text { Lack of } \\
\text { resources make } \\
\text { it difficult to } \\
\text { achieve goals }\end{array}$ \\
\hline & $\begin{array}{l}\text { Availability of } \\
\text { resources for } \\
\text { intended } \\
\text { action }\end{array}$ & $\begin{array}{l}\text { Limited access to } \\
\text { resources }\end{array}$ & $\begin{array}{l}\text { No access to } \\
\text { resources and } \\
\text { power }\end{array}$ & $\begin{array}{l}\text { No resources } \\
\text { available for } \\
\text { FBAE } \\
\text { implementation }\end{array}$ \\
\hline
\end{tabular}


In this case, the 'perception of opportunities and threats' for the actors is based on their cognitions, which influence their goals and motivations. The way the actors interpret information, observe reality and consider as their frames of reference will direct them in what they see as an opportunity to achieve their goal or a threat to achieving this goal(Bressers 2009, De Boer and Bressers 2011). The implementing actor's perception of opportunities regarding FBAE policy implementation is that, it is possible to implement if there is reliable information. The information referred to here by this actor is household information for the development of the indigent register as well as information from the national department about the FBAE policy. The target actors' perception of opportunities and threats is also based on their cognitions and their motivation. Similar to the implementing actor, the target actor perceives availability of information about the FBAE policy as key in understanding the service delivery strategy. This may assist in the households' understanding why they receive the amount of paraffin they are currently receiving from the municipality and why this amount cannot be increased. For the target and the linking actors, not having enough information poses a threat to the interaction process as it affects the actor's motivations and in this case, it affects the relationships the actors have with each other.

"Information can serve a strategic purpose" (Bressers 2009: 134) in the interaction process. Actors with information can use it in ways that can assist them to achieve their goals. For instance, information about households, such as an indigent register, can be a resource that can be used by the implementing actor to deliver FBAE services to households. The implementing actor in this case lacks information from the national government about the FBAE policy implementation and does not have enough households information to develop a credible indigent register. This makes it difficult to develop a concrete service delivery strategy which reduces the actors' capacity to realize its goals. Information available to the target actor's lack is not enough for this actor to develop a strategy to ensure that they receive FBAE services from the implementing actor. This affects the target actor's position in the interaction process and in this case, it hinders this actor from having decision-making powers. Lack of access to 
resources also makes it difficult for the target actor to have a strategy to access FBAE services. On the other hand, the linking actor finds that having access to information (knowledge of households' living conditions) has a strategic value which makes FBAE policy implementation possible. For the linking actor, the knowledge of households becomes a resource they can use in assisting the implementing actor to deliver FBAE services to households - which is one of this actors' goals.

'Data search and processing capacity' is important in the FBAE policy implementation process. For the implementing actor, this was crucial as it influenced the implementation process and service delivery. The analysis of the dynamic interaction of actor characteristics shows that the implementing actor lacks capacity to process and update data. The data referred to here is the households' information which is collected with the help of the linking actor and is supposed to be processed to determine which households fall within the indigents category in order to receive free basic services such as FBAE. Due to lack of capacity such as staff members, funds and vehicles to access the villages, this actor has difficulties in searching and processing data.

For the target actor, data search and processing capacity refers to this actor's access to information regarding FBAE policy implementation. Although some information is passed on to this actor by the implementing and linking actors, it is often not enough for this actor to know exactly what is happening with the implementation of this policy. Relying on the other actors for information and processing (interpreting) it renders this actor powerless as it is incapacitated. The analysis shows that the linking actor has data gathering skills but lacks data processing skills. For this actor, collecting household information in order to compile an indigent register is easy as they live in the same areas as the households that are targeted to benefit from the FBAE services. Processing this information in order for it to be in a usable form for the municipality is often not easy as the linking actor does not have the capacity to analyse and verify which households are to benefit from the FBAE services. 
In order for the actors to achieve their goals, it is important to have enough resources. 'Availability of resources for intended action' assesses whether the actor has enough resources for the actions it would like to undertake in the policy implementation process. Lack of resource availability can be a strong demotivating factor and thus not just causes failed attempts to act, but moreover even not even trying. At the same time, it is important to assess the 'relevance of resources' as this determines which resources actually matter in the interaction process. The implementing actor in this case has limited access to resources which makes it difficult to provide FBAE services with ease. On the other hand, the target actor has no access to resources needed to access FBAE services to fulfil all its household energy needs. This actor relies on the implementing and linking actors and so accepts decisions made by these actors with regards to FBAE service provision. Therefore, the analysis shows that resources are relevant for this actor to achieve its goals. The linking actor does not have all the relevant resources for the implementation process. The main resources this actor has is its knowledge of households and the relationship it has with both the implementing and target actors. The knowledge of households is relevant in achieving the goal of providing FBAE services by compiling a credible indigent register.

\subsection{Conclusions}

The Nyandeni local municipality's strategy of implementing the FBAE policy has resulted in mediocre implementation success where several issues stand in the way of ensuring complete implementation success.

The indigent register used by the municipality to select households that qualify for subsidized services such as FBAE lacks credibility because household information is not updated. Although this municipality has attempted to put measures in place to ensure credibility of the register this has not helped in making implementation a complete success. In this case, the implementing actor has a good interaction relationship with the linking actor where both actors exchanged information vital for the implementation process. The linking actor provided household information 
to the implementing actor in order to update the indigent register - despite the fact that the updating process has not been performed successfully. The target actor lacked understanding about the implementing actors' failure to update the indigent register leading to a poor interaction relationship between the target actor and the implementing actor.

The Community Services department within the Nyandeni municipality lacked internal support ${ }^{88}$ from within the municipality and from the national government department with their efforts to implement the FBAE policy. As a consequence, the implementing actor's motivation towards implementing the FBAE policy was affected negatively. This can be considered to have influenced the interaction process which had led to the mediocre implementation success.

Other factors that have influenced this implementation result are:

- The target actor not having meaningful participation in the implementation process,

- The linking actor's lack of influence on the indigent register procedures, and

Lack of transparency concerning the selection of households that benefit from alternative energy services.

\footnotetext{
${ }^{88}$ Lack of internal support was in the form of failure to appoint staff that would assist with the implementation of Free Basic Services which include providing alternative energy services as part of the FBAE policy implementation process.
} 


\section{Chapter 9: Mhlontlo: Making it possible}

\subsection{Introduction}

As a local municipality, Mhlontlo is mandated to providing basic services to its households. Most important for these households are the basic services such as energy provision, access to clean water and sanitation services. Free Basic Alternative Energy (FBAE) policy implementation is one of the many responsibilities at the shoulders of this local municipality. Like most rural local municipalities in South Africa, Mhlontlo has not achieved universal grid electrification of all its areas. Those remaining to be provided with grid electricity are located in the remote rural areas where the costs of extending the grid are high. These households are forced to rely on energy sources that are not provided by the municipality or national government. Although the municipality plans to provide all of its households with grid electricity by 2015 , this is not guaranteed as electrification target dates tend to be postponed throughout the country. , this is not guaranteed. and this is. In the meantime, it appears that the only option for the municipality until the arrival of grid electricity to meet its obligations is to provide households with alternative energy services. 


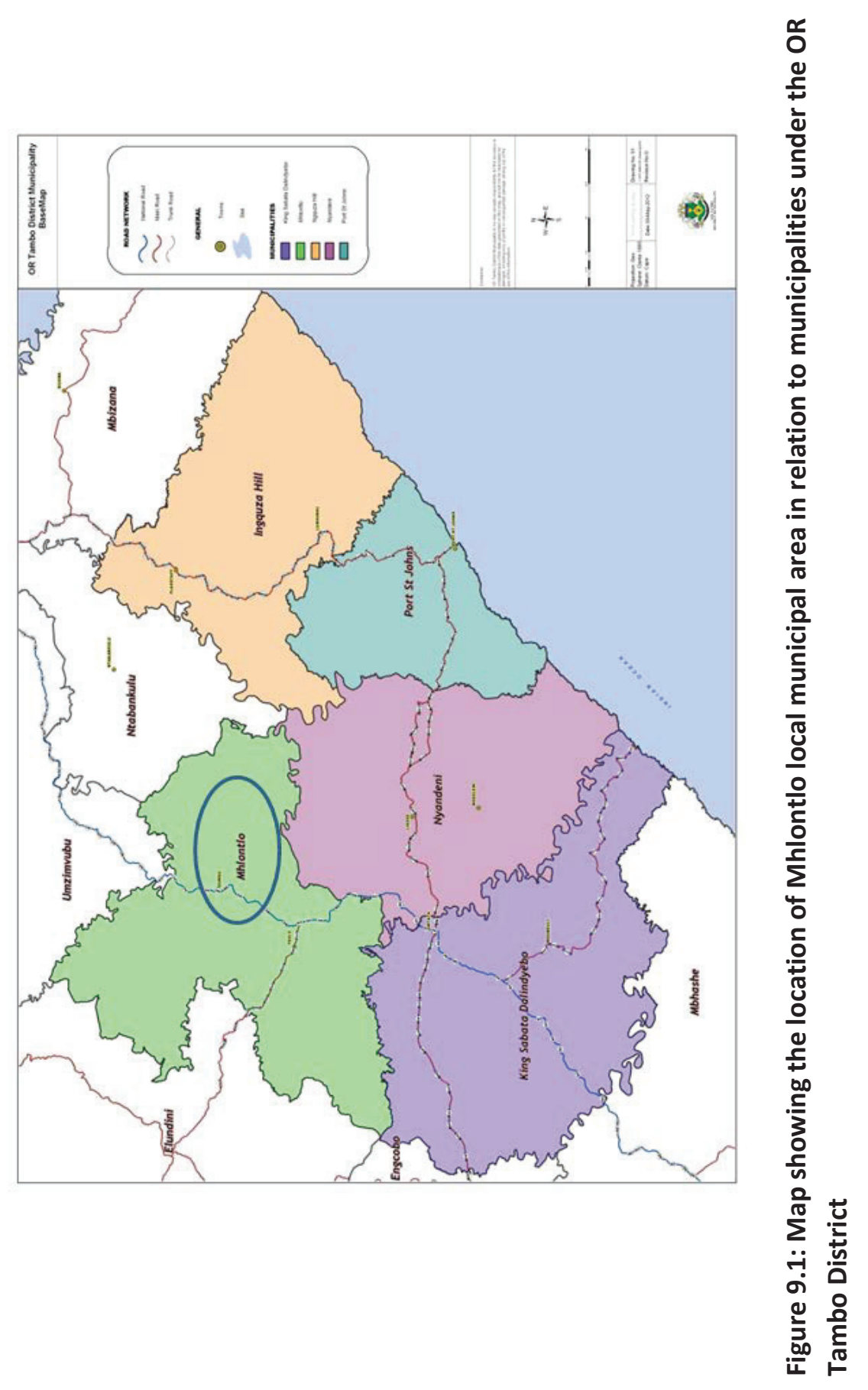




\subsection{Area description}

Mhlontlo Local Municipality is one of the five local municipalities under the OR Tambo district municipality in the Eastern Cape province. The local municipality offices are based in the rural town of Qumbu along the N2 freeway, one of the major national roads in South Africa.

Mhlontlo is divided into 26 municipal wards, occupying a total area of 2868 square kilometre with 46414 households (Stats SA 2011). As with many rural municipalities in the Eastern Cape province, poverty levels are high, employment levels are low and delivery of basic household services by the municipality does not always meet policy objectives. Infrastructure such as well-maintained roads, electricity, water and sanitation services is not readily available for residents. The Mhlontlo town is surrounded by a number of villages all of which depend on basic services provided by the local municipality.

\subsection{Methodology specific to this case}

During my fieldwork trips in 2011 and in 2012, I travelled to the Mhlontlo local municipality offices in Qumbu. At the municipality I interviewed staff responsible for the implementation of Free Basic Services, as well as the implementation of the Free Basic Alternative Energy (FBAE) policy. In 2011, I conducted face-to-face interviews with the Chief Financial Officer and the Free Basic Services Co-ordinator. During this time I also conducted interviews with two paraffin suppliers that were contracted by the municipality to deliver paraffin to households as part of the Free Basic Alternative Energy implementation strategy. In this case, as it is in others, a snowball sampling method was used to identify key informants. I was advised to contact and interview a Ward Committee member of Mvumelwano village, which is one of the villages receiving paraffin as part of the FBAE policy implementation.

In 2012 during the second phase of my fieldwork I conducted a follow-up interview with the Free Basic Services Co-ordinator. During this period I had 
an opportunity to accompany the Free Basic Services staff members together with the OR Tambo District municipality staff on their joint visit to Gqwesa village. The visit was to allow the municipal staff to collect information that would be used to update the indigent household register. The village trip gave me an opportunity to make observations on how the register is compiled as well as to see the type of information exchanged between the households and the local municipality. I conducted a key informant interview with the village chief who also shared some information regarding the type of assistance needed in the villages compared to the level of service delivery they currently receive.

In this case, the actors are defines as follows:

\section{Implementing actors}

The Mhlontlo implementing actors are employees of the Mhlontlo Local Municipality who have the responsibility, whether directly or indirectly, to facilitate the implementation of the FBAE policy. The implementing actors I interviewed in Mhlontlo are the Chief Financial Officer and employees working as Free Basic Services Coordinators.

\section{Target actors}

Target actors in the case of Mhlontlo are communities who are meant to be receiving energy services that should be delivered as part of Free Basic Alternative Energy policy implementation process. I will use the information I collected during the Gqwesa village meeting where I observed how the community relates to the local municipality in discussions regarding the delivery of services in their villages. I will also use the information collected through interviews with implementing and linking actors as well as paraffin suppliers.

\section{Linking actors}

The linking actors in this case are the Ward Committee member who is partly employed by the local municipality and the Ward Councillor - who is also paid by the local municipality. The Ward Committee member is responsible for collecting household information in the village to assist the municipality with compiling the indigent register. She is also in charge of 
verifying households' information on days when paraffin is delivered to the villages by suppliers contracted by the local municipality.

At Gqwesa village, the chief takes the role of the linking actor. Although the chief is not employed by the local municipality, he is highly respected within the community and recognised as the head of the village where traditional and everyday village affairs are concerned. The local municipality also gives him recognition in his role as a chief.

As community members, linking actors have an interest in the services delivered by the municipality as they benefit as much as the community.

\subsection{Current energy services}

Current statistics show that $72.6 \%$ of the households in Mhlontlo use grid electricity for lighting and out of these households, almost $45 \%$ use this energy source for cooking and $15 \%$ use it for heating (see Table 9.1). Grid electricity is also used for providing additional energy services such as television, radio and charging cellphone batteries. However, the use of other appliances is highly dependent on whether a household is able to afford firstly to purchase the appliance and then secondly the costs of grid electricity for using these appliances.

Table 9.1 shows lack of modern energy in Mhlontlo which is reflected by the percentage of households using wood for cooking and heating. A significant number of households in Mhlontlo are not connected to the grid while $33.3 \%$ of them rely on wood for cooking as well as for heating (55\%) (StatsSA 2011).

Where grid electricity is concerned, the municipality plans to achieve universal grid electrification by 2015 . The municipal representative said that the municipality had already approached the national Department of Energy and the electricity utility (Eskom)for funding that will assist in the electrification programme of the Mhlontlo local municipality. 
Table 9.1: Percentages of households using types of energy in Mhlontlo-

\begin{tabular}{|l|c|c|c|}
\hline & Lighting & Cooking & Heating \\
\hline Electricity & 72.6 & 44.8 & 15.0 \\
\hline Gas & 0.3 & 5.0 & 1.4 \\
\hline Paraffin & 3.4 & 12.7 & 21.3 \\
\hline Wood & & 33.3 & 55.0 \\
\hline Coal & & 0.1 & 0.5 \\
\hline Animal dung & & 3.3 & 1.4 \\
\hline Solar & 0.2 & 0.1 & 0.1 \\
\hline Candles & 23.1 & & \\
\hline Other & & 0.3 & 0.1 \\
\hline None & 0.4 & 0.3 & 5.3 \\
\hline
\end{tabular}

Source: Statistics South Africa 2011

\subsection{Mhlontlo municipality's indigent households' register and FBAE policy implementation}

Although this municipality is using a register which enables them to deliver paraffin to households, the Free Basic Services coordinators admitted that the register has some flaws that need to be corrected. The coordinators said that in order to update the indigent register household information is regularly collected with the assistance of the Ward Councillors and Ward Administrators as well as community leaders. I was shown registration books that are used to collect household information which is later stored in an electronic database and regularly updated. The coordinators said they were striving towards a register that could be easily updated with new information about households which will ensure that all qualifying households are provided with basic services.

In order to ensure that all indigent households under this municipality receive paraffin and hence benefit from the implementation of the FBAE policy, a rotation system has been formulated. There is no guarantee that all indigent households will receive paraffin on a quarterly basis, as required by the FBAE policy. However, it is more likely that they will receive an allocation less than four times a year. With this system the aim is to ensure 
that everyone on the register receives some fuel at some point during the year.

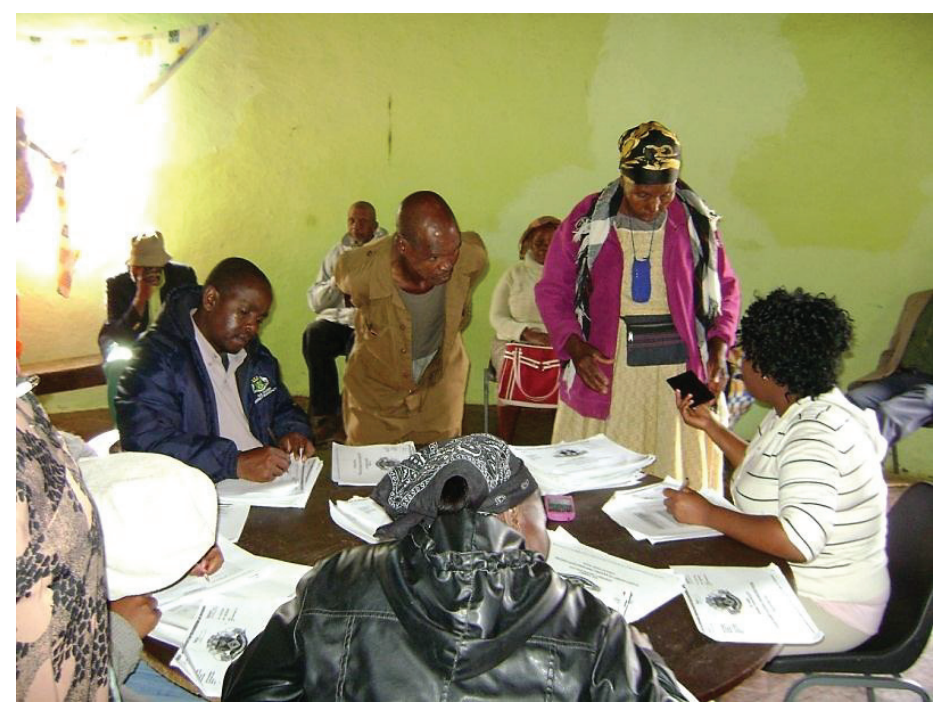

Figure 9.2: Local and district municipality officials collecting household information for the indigent register

Source: Picture taken by the author during fieldwork

During my fieldwork visit to Mhlontlo in 2011, the Free Basic Services coordinators informed me that they had never been to the villages themselves to collect information for updating the indigent registers. They had also not visited the villages during the paraffin distribution days because they did not have enough time for such visits as they had other responsibilities. They did say that it helped to have Ward Councillors and administrators in the villages as these people assisted in collecting indigent households' information and ensured smooth delivery of paraffin to the intended beneficiaries. In 2012 during the second phase of my fieldwork, this municipality, with the support of the district municipality, had gathered enough resources for the Free Basic Services coordinators to visit the villages and collect information to be used for the indigent register. They also used this opportunity to inform households on Free Basic Services 
that they qualify for as indigent households as well as explaining the local municipality's role in service delivery ${ }^{89}$.

The municipality representatives informed me that it was very important for them to keep the indigent register up to date because it has a dual purpose. The register is not only used to list low-income households that cannot afford to pay for their municipal basic services but also it is used as a register of skills and education levels of household members. This list is used to identify work opportunities for the unemployed Mhlontlo residents when such opportunities are available within the municipality.

\subsection{The process of FBAE policy implementation by different actors in Mhlontlo}

In order to understand how the FBAE policy is implemented in Mhlontlo, the key actor characteristics are analysed in the following sections to identify their influence in the interaction process.

\subsubsection{The Implementing actors' role in the Free Basic Alternative Energy policy implementation}

The local municipality is in charge of ensuring implementation of the Free Basic Alternative Energy (FBAE) policy by providing alternative energy services to households without grid electricity connections. As presented earlier in this chapter, the current energy statistics show that just approximately $27 \%$ of households within this municipality do not have grid electricity (StatsSA 2011). This municipality has opted to provide these households with paraffin as the alternative energy source (through the implementation of the Free Basic Alternative Energy policy) until grid

\footnotetext{
${ }^{89}$ See Annex 7 for a full transcript of the Free Basic Services information meeting held by the district and local municipality with Gqwesa village residents. After the meeting, the municipal officials verified households information to add to the indigent register.
} 
electricity is installed in these areas. Due to claimed lack of resources such as funding, this municipality provides households with 20 litres of paraffin once a quarter (once in three months instead of monthly), which is delivered by the municipality appointed service provider.

Within the municipality, the Free Basic Services coordinators' office is in charge of collecting information about all households in order to compile the indigent register. Once the register is compiled, this office passes the information to the Municipal Speaker's Office which determines the exact number of households that each quarter will benefit from the FBAE paraffin subsidies. The explanation given for this is that because there are insufficient funds each quarter to provide everyone on the register with paraffin, it is necessary to select a number of households depending on what the budget allows. Through a project tendering system, the municipality appoints service providers to deliver paraffin to central points in the villages where the selected households gather to collect it on given dates. Paraffin is delivered to up to 3000 households at a time over a period of a few days depending on the number of villages and their ease of accessibility. One of the complaints raised by the paraffin distributers was the poor state of the gravel roads, which made it difficult to travel and access villages as well as causing damage to their vehicles.

Even though this implementing actor is not well informed about the types of alternative energy carriers, the municipality is also keen to explore other sources of alternative energy to offer as part of FBAE policy implementation. They were in discussion with alternative energy service providers to explore energy carriers other than paraffin.

Using the Contextual Interaction Theory to illustrate the dynamic interaction of the key actor-characteristics (see Figure 9.3), it is possible to see how this actor's motivations, cognitions and capacity and power influence the implementation of the FBAE policy. The Mhlontlo implementing actor is motivated to provide alternative energy services to households that do not have grid electricity. This actor is well motivated to provide services, in doing this it receives and uses support from the district municipality to reach households that need energy services. 
Similar to the other cases in this study, the cognitions refer to the information available to this implementing actor regarding the implementation of the FBAE policy. Interviews with representatives of this actor revealed that this actor ensured that they were always informed about FBAE which they gathered this information from the national and provincial departments of government. This actor's interpretation of the FBAE information received from national and provincial departments was that the households are in need of energy services. This information also gives this actor the ability to determine how much it will costs to deliver FBAE energy services to indigent households. Information also refers to the household information that is collected to compile an indigent register. Of all the local municipalities analysed in this thesis, the Mhlontlo local municipality was the only one that regularly and consistently collected and updated household information on their indigent register.

Mhlontlo local municipality is the only municipality within the OR Tambo district that had a full staff complement dedicated to the implementation of Free Basic Services, which includes the implementation of Free Basic Alternative Energy policy. The municipality has employed a Manager and two Coordinators of Free Basic Services. These people are in charge of implementing policies that fall under their portfolio and interacting with various stakeholders to make it possible to implement polices programmes and strategies. 


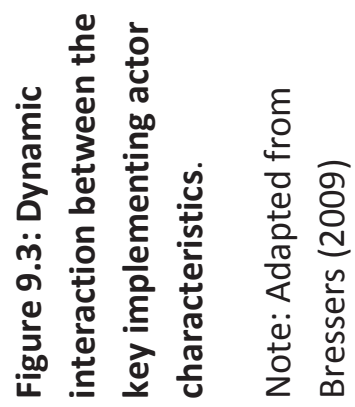

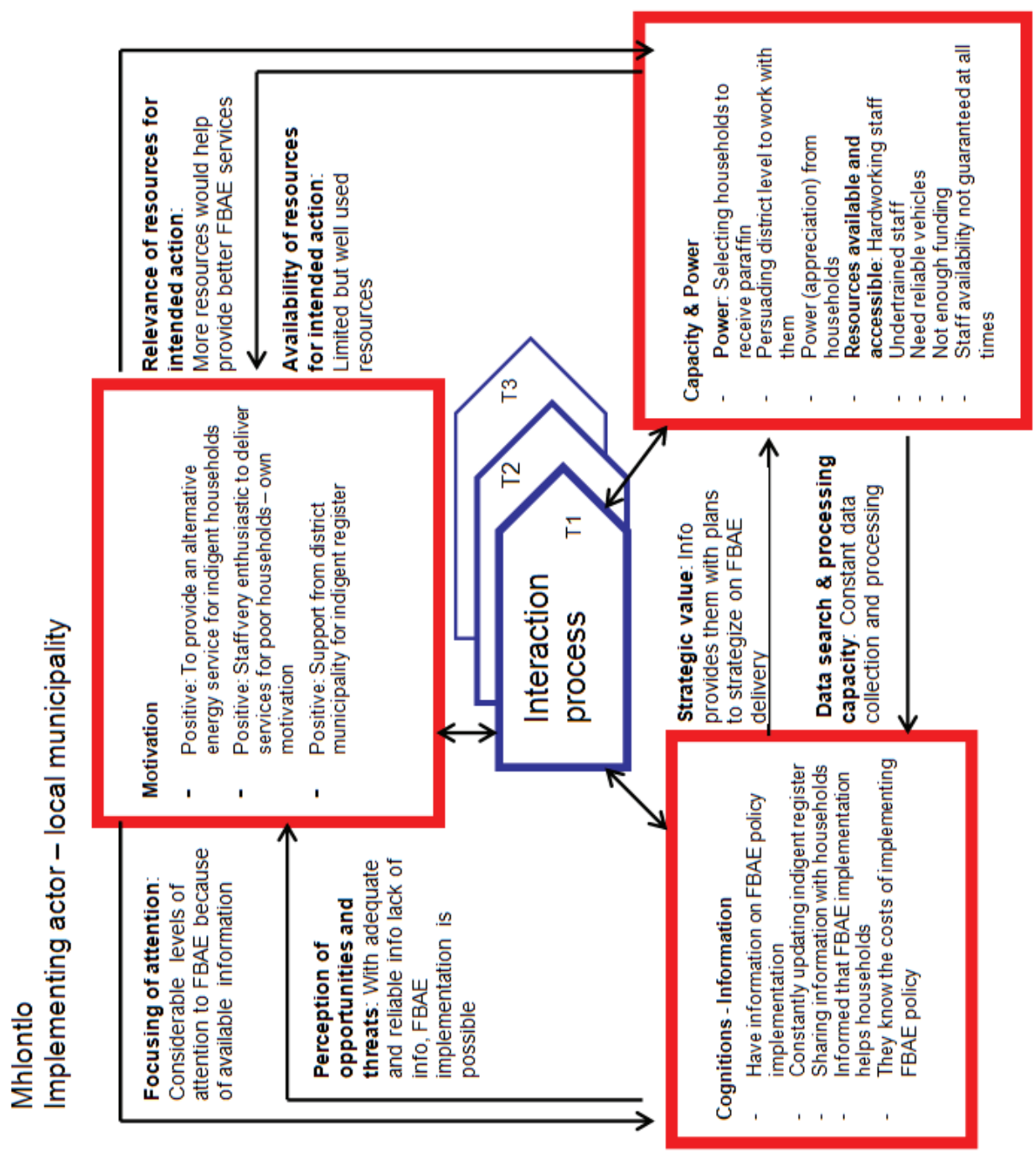


Regardless of having a full staff complement, the municipal representative admitted that there was a great need for staff training. She said, however, the work that the Free Basic Service coordinators are employed to do is intensive and so does not allow enough training time. At the time of the first field interviews in 2011, the coordinators were supposed to work within the framework of the indigent policy and were still familiarising themselves with what was then a new policy. This means all basic services (including FBAE) were to be delivered to indigent households according to the new and unfamiliar indigent policy. Ward Councillors and their administrators in the villages and communities also need $t$ training on how to properly collect household information for compiling the indigent register as well as to be able to handle work properly on paraffin distribution days.

The municipal representative also claimed that there were insufficient funds to deliver basic services to all households. The money they receive from the government's Equitable Share Grant is not enough to cover all the expenses associated with delivery of Free Basic Services. This restricts the maximum delivery to meeting only part of the households' energy needs.

In 2011, prior to the local government elections, the municipality representatives I interviewed raised concerns about the uncertainty brought by political influences. The main concern around election time was that the local municipality was not sure whether the Ward Committee structures would be phased out or not after the local elections. If these structures are phased out, the fear was that there would not be enough capacity in the communities to assist the municipality with service delivery, especially the collection of data for the indigent register. This would negatively impact on the municipality's capacity to deliver Free Basic Services including Free Basic Alternative Energy.

During my second field trip to this municipality in 2012 , it was made clear to me that lack of vehicles was a problem. Although there were cars available for staff to use in the attempt to deliver services to households, efforts were hindered because these cars were not always available. The municipal cars are mostly driven on gravel roads which mean the cars need frequent 
repairs. . However, due to 'red tape' within government departments, when vehicles break down it is often difficult to repair them immediately. I observed this happening with a vehicle that the Free Basic Services coordinators were supposed to use for the trip to Gqwesa village to collect household information in order to update the indigent register. Eventually the planned departure to the village was delayed by four hours whilst the coordinators had to wait for a rented vehicle which had to come from a town $50 \mathrm{~km}$ away. This also meant that if the villagers wanted their names and information updated on the indigent register, they had to wait at the reception point for the arrival of the municipal staff.

\subsubsection{The target actors' role in the Free Basic Alternative Energy policy implementation}

The target actors are residents of villages under the Mhlontlo local municipality. Those without grid electricity receive 20 litre of paraffin once every three months. In most cases, without this paraffin, these indigent households collect and use wood and cow dung for cooking and heating.

Figure 9.4 shows the influence of the target actor characteristics on each other. When assessing the characteristics of this target actor, their motivations show that they would like to have more paraffin that they are currently receiving as this fuel provides them with the much needed energy services which they cannot afford. This echoes what was said during the interviews with the local municipality representatives who said that if there were more funds available for FBAE implementation, the municipality would provide more households with paraffin on monthly basis instead of quarterly. Paraffin distributers ${ }^{90}$ contracted by the municipality also confirmed that households were in need of energy services and the paraffin they delivered was most welcome by households. They said it was obvious that these households were very poor and needed all the assistance they could access from the local municipality.

\footnotetext{
${ }^{90}$ Face-to-face interviews conducted on 28 June 2011 with two paraffin distributing companies contracted by the Mhlontlo local municipality
} 
For this actor, information is also important. According to the Ward Committee member, households do not have much access to information about the Free Basic Alternative Energy policy. They see the energy services delivered to them as a gesture of goodwill from the government. This is because typically in South Africa, provision of energy services usually refers to grid electricity installations and in some cases, installation of Solar Home Systems. Provision of paraffin, although done by some municipalities as part of FBAE policy implementation, is not common. According to data received from the provincial department of Local Government and Traditional Affairs, only 14 out of 37 local municipalities implement FBAE policy and only six of the 14 provide paraffin to households. It is therefore important for the implementing actor to constantly inform the target actor about the FBAE policy which will explain to the households why they are receiving paraffin from their municipality.

With regards to the FBAE policy implementation process, this target actor has no power attributed to it by the other actors. Instead, this actor relies on the implementing and linking actors to make it possible to have access to basic alternative energy services. The interview with the chief and the observations made at Gqwesa village provide some evidence that households in the rural areas under the Mhlontlo local municipality are poor and do not have access to modern energy services. At the meeting where the local and district municipality staff were collecting information to update the indigent list, many of the household representatives present qualified to be on the indigent register. Most of them are unemployed, illiterate and depend on government grants such as the state pensions and children's grants. This also means that they have limited resources (access to information, knowledge, education and funds) and capacity to ensure the delivery of these services for their households. Here, it is already obvious that the lack of information for this actor negatively influences access to resources and contributes to this actor's lack of capacity. 


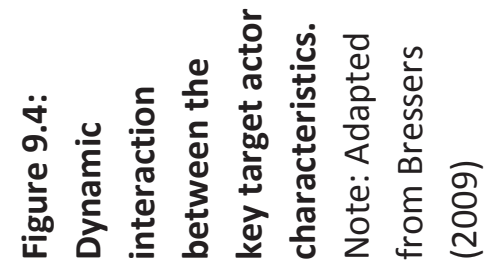

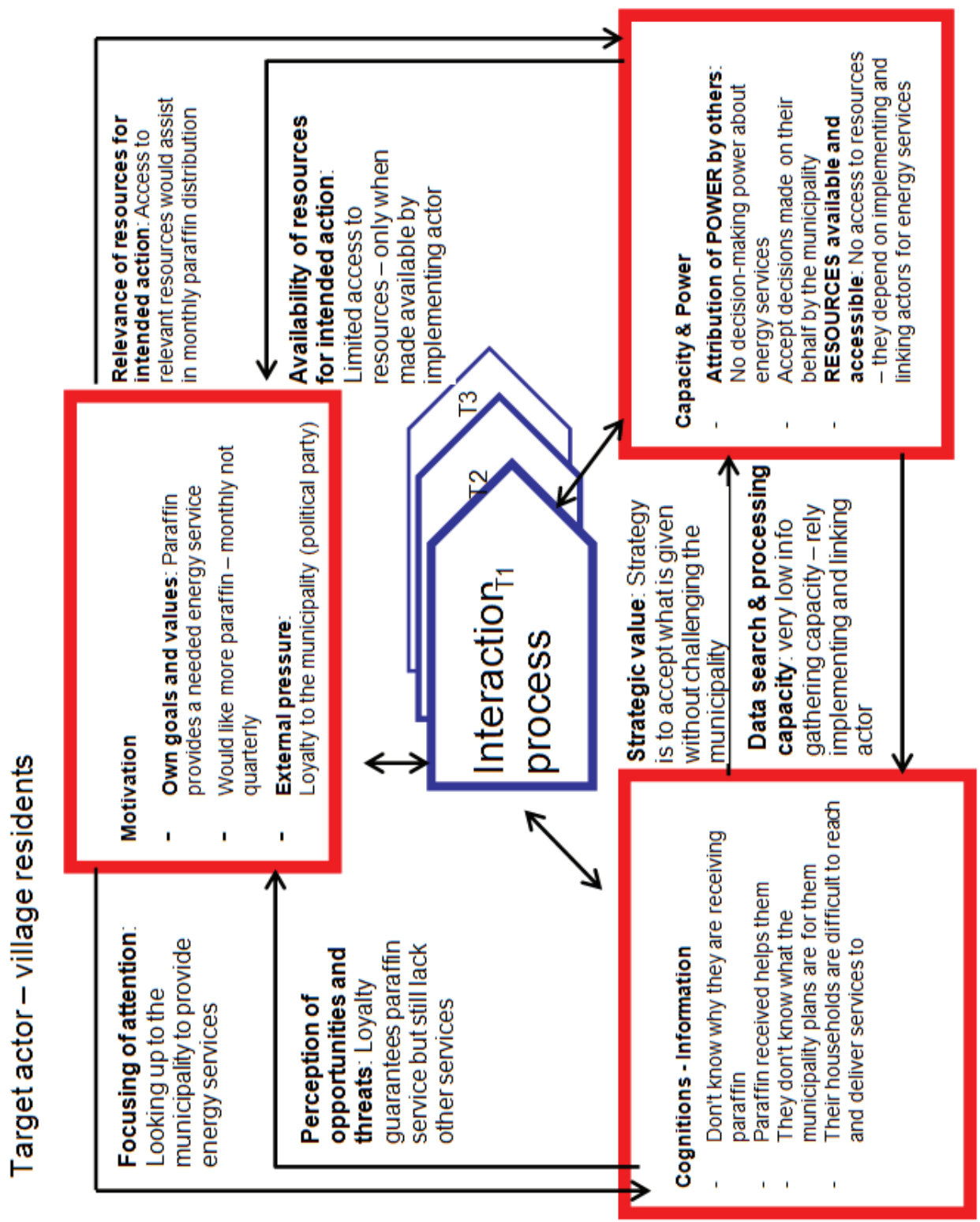




\subsubsection{The linking actors' role in the Free Basic Alternative Energy policy implementation process}

The linking actors in the Mhlontlo case are the Ward Committee member and the Chief of Gqwesa village. As mentioned above, Ward Committee members belong to structures that are recognised and work together with the local municipality. At the time of our meeting ${ }^{91}$, the Ward Committee member was not certain whether she would retain her position in the Ward due to local municipality elections that were upcoming at the time. She had been responsible for collecting household information in her village to be used by the municipality to update the indigent register. She was also responsible for ensuring that indigent households received their share of paraffin when it was distributed by the service providers contracted by the local municipality.

Figure 9.5 shows the dynamic interaction between the key linking actorcharacteristics. This illustrates the actors', motivations, cognitions and capacity and power. Similar to the implementing and the target actors, this linking actor's goal is the implementation of the FBAE policy by providing alternative energy services to indigent households. As this actor (particularly the Ward Committee member) works closely with the target actor, it is easy for them to know what the energy needs of households are. The target actor looks up to the linking actor for support and relies on this actor to bring the energy services through the municipality (implementing actor). The linking actor's goal is to serve both the implementing and the target actors - and in this case, this is done by delivery of FBAE services through policy implementation.

On cognitions, the linking actor is important in ensuring the update of the indigent register. This actor is in charge of collecting information that is used to compile a credible indigent register because of their knowledge of the households in their areas. According to the linking actor, it is very important for the local municipality to keep their indigent register updated because this was the only way they knew which households qualified to be

\footnotetext{
${ }^{91}$ Face-to-face interview conducted on 21 July 2011 at on the outskirts of Qumbu town.
} 
given Free Basic Services. As the municipality was using a rotation system to provide paraffin, it meant that not all households that qualified to be on the indigent register received paraffin every quarter. Sometimes the very poor households would be left out of the list of paraffin recipients. In such cases, the linking actor would intervene and plead with the service provider to provide some paraffin for these households even though not on the list. In this way, the linking actor uses their knowledge of the community and interpretations of the households' living conditions to justify the provision of FBAE services.

The Ward Committee member said that people (households) lacked information about FBAE and other basic services that are provided by the municipality. People did not know why they were being given free paraffin and to a certain extent were afraid to inquire with the fear that their names may be taken off the indigent register. The Ward Committee member informed her community as much as possible about the services they were receiving and subsidies they qualified for as indigent households. Households that often rely on wood for fuel appreciate the convenience of cooking with paraffin, which they usually cannot afford to buy for themselves. People appreciate what the government is doing for them, "it is unlike the previous government that did not provide us with energy services". 

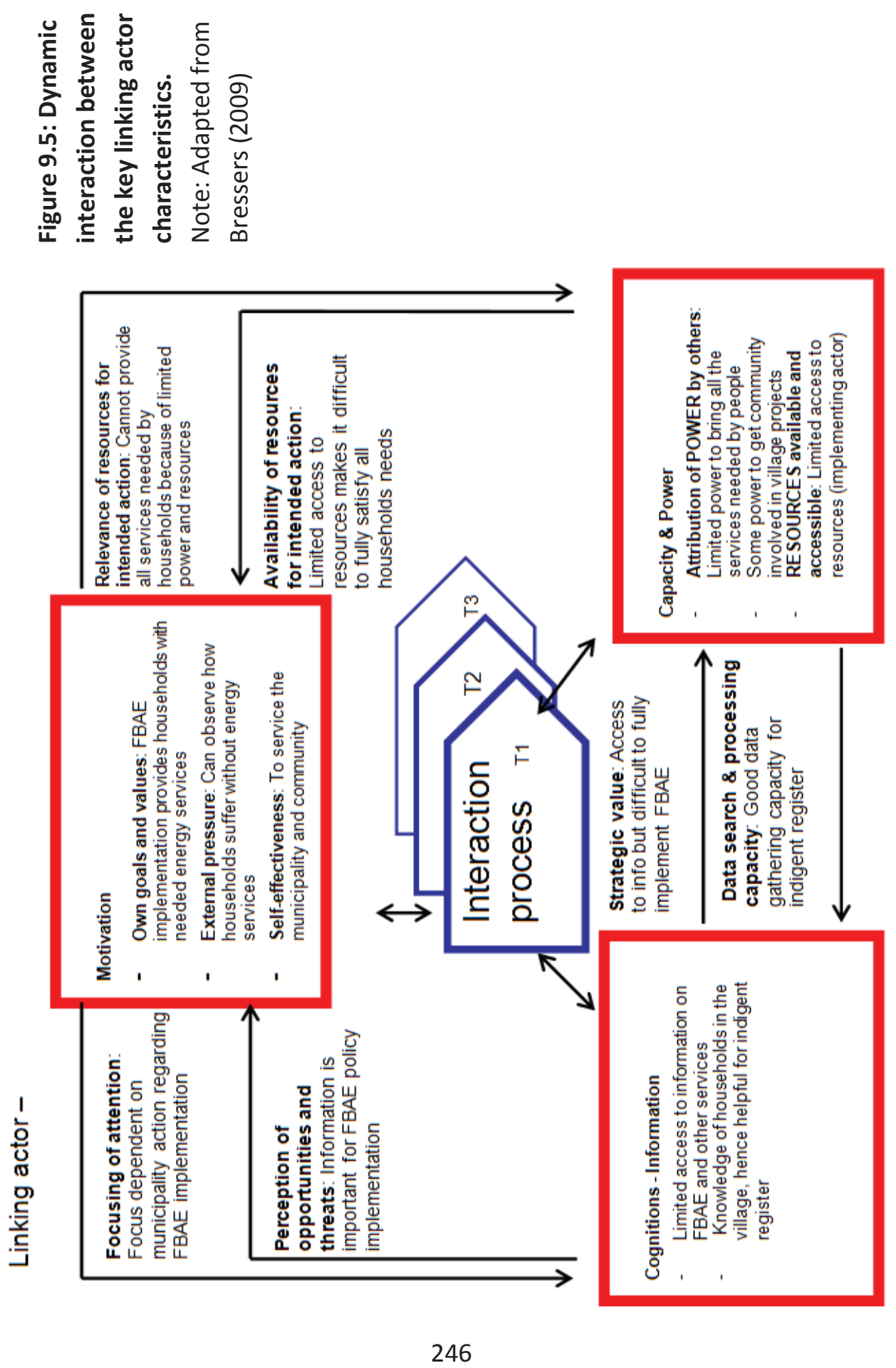
The Chief of Gqwesa village, where the local and district municipality representatives had agreed for me to join them on their Free Basic Services awareness campaign and information collection for the indigent register, was not happy about the state of service delivery in this area ${ }^{92}$. He complained that they do not have clean drinking water in the area and have to rely on rivers which are far from the homesteads. Although the municipality installed communal standpipes for water, these were not working. Their relying on the river means that they have to use the same water source with their livestock, as these animals also depended on this water. Due to this, the Chief claimed that many people from the village have fallen ill and it is especially worse in winter when water is scarce as there are no rains.

The municipality promised to assist the villagers with fencing of their community gardens. This was a problem because their own livestock fed on the crops they planted for household consumption. This caused a situation where households ended up with little to eat as most households cannot afford to buy food. Another complaint was that the roads connecting villages were in bad condition and the gravel was not maintained. This made it difficult especially for school children to go to school which is located in another village. The school bus can no longer access some of the villages and the children are forced to walk long distances which leads to lack of motivation for them to stay in school.

Although the Chief did not mention the implementation of Free Basic Alternative Energy policy directly, he was obviously not pleased with the lack of service delivery in his area. He said pleading with the local municipality was also discouraging as it did not guarantee that action to correct the situation would be taken. This illustrates that there is limited power attributed to this actor by the implementing actor. At the same time, the target actor attributes much more power to this actors' capacity to

\footnotetext{
92 Face-to-face brief interview conducted on 14 May 2012 at Gqwesa village after a meeting with the local and district municipality representatives.
} 
bring FBAE services to their households. Like most implementing actors in this study, this actor has very limited resources to make it possible for the households to access FBAE services as desired by the households to satisfy their energy needs.

\subsection{Comparing the key actor characteristics of the implementing, target and linking actors}

In this section I compare and summarize the interaction processes as illustrated in Figures 9.3, 9.4 and 9.5. This discussion will show how similar or different the actor characteristics of the implementing, target and linking actors are and how these similarities and differences influence the FBAE policy implementation process. It will also reveal the reasons behind the way FBAE policy implementation has been taking place in this municipality.

\subsubsection{Summary of comparison of Mhlontlo's key actor characteristics}

In Table 9.2 the summary of interaction of independent variables is presented. This table shows how the motivations, cognitions (information) and power and resources (capacity) of the actors compare to each other with regards to the implementation of the FBAE policy.

Starting with the motivations for the implementation of the FBAE policy, the implementing actor is positively motivated as it is this actor's goal to provide alternative energy services to its indigent households. This positive motivation is also evident in the staff members' enthusiasm for the delivery of such services. As mentioned in the sections above, this is the only implementing actor in this thesis study that has employed staff to work specifically on the delivery of Free Basic Services which include FBAE services. 
Table 9.2: Result of interaction process of different actor characteristics

\begin{tabular}{|c|c|c|c|}
\hline & Implementing actor & Target actor & Linking actor \\
\hline Motivations & $\begin{array}{ll}\text { - } & \text { Positive: To } \\
\text { provide an } \\
\text { alternative energy } \\
\text { service for } \\
\text { indigent } \\
\text { households } \\
\text { - } \quad \text { Positive: Staff } \\
\text { very enthusiastic } \\
\text { to deliver services } \\
\text { for poor } \\
\text { households - own } \\
\text { motivation } \\
\text { Positive: Support } \\
\text { from district } \\
\text { municipality for } \\
\text { indigent register }\end{array}$ & 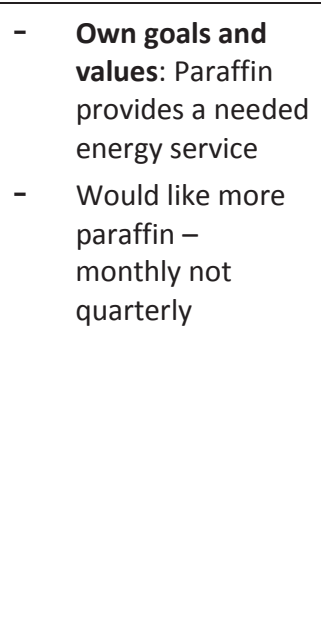 & 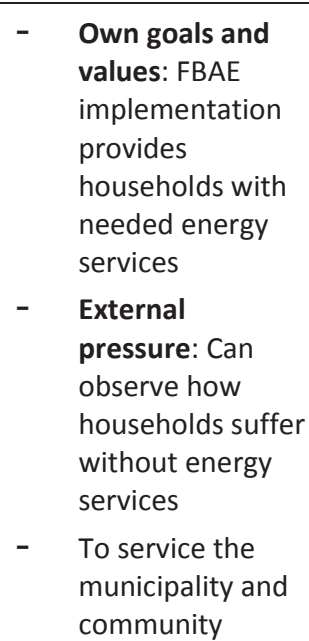 \\
\hline $\begin{array}{l}\text { Cognitions } \\
\text { (Information } \\
\text { and } \\
\text { knowledge) }\end{array}$ & $\begin{array}{ll}\text { - } & \text { Have information } \\
\text { on FBAE policy } \\
\text { implementation } \\
\text { - } \quad \begin{array}{l}\text { Constantly } \\
\text { updating indigent } \\
\text { register }\end{array} \\
\text { - } \quad \text { Sharing } \\
\text { information with } \\
\text { households } \\
\text { - } \quad \text { Informed that } \\
\text { FBAE } \\
\text { implementation } \\
\text { helps households } \\
\text { They know the } \\
\text { costs of } \\
\text { implementing } \\
\text { FBAE policy }\end{array}$ & $\begin{array}{ll}\text { - } & \begin{array}{l}\text { Don't know why } \\
\text { they are receiving } \\
\text { paraffin }\end{array} \\
\text { - } & \text { Paraffin received } \\
\text { helps them } \\
\text { - } \quad \text { They don't know } \\
\text { what the } \\
\text { municipality plans } \\
\text { are for them } \\
\text { Their households } \\
\text { are difficult to } \\
\text { reach and deliver } \\
\text { services to }\end{array}$ & $\begin{array}{ll}\text { - } & \text { Limited access to } \\
\text { information on } \\
\text { FBAE and other } \\
\text { services } \\
\text { - } \text { Knowledge of } \\
\text { households in the } \\
\text { village, hence } \\
\text { helpful for } \\
\text { indigent register }\end{array}$ \\
\hline $\begin{array}{l}\text { Power and } \\
\text { resources }\end{array}$ & 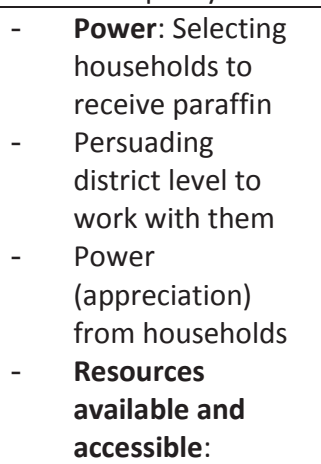 & $\begin{array}{ll}\text { - } & \text { Power: No } \\
\text { decision-making } \\
\text { power about } \\
\text { energy services } \\
\text { - } & \text { Accept decisions } \\
\text { made on their } \\
\text { behalf by the } \\
\text { municipality } \\
\text { Resources } \\
\text { available and } \\
\text { accessible: No } \\
\text { access to }\end{array}$ & $\begin{array}{ll}\text { - } & \text { Power: Limited } \\
\text { power to bring all } \\
\text { the services } \\
\text { needed by people } \\
\text { - } \quad \text { Some power to } \\
\text { get community } \\
\text { involved in village } \\
\text { projects } \\
\text { Resources } \\
\text { available and } \\
\text { accessible: } \\
\text { Limited access to }\end{array}$ \\
\hline
\end{tabular}




\begin{tabular}{|c|c|c|c|}
\hline & Implementing actor & Target actor & Linking actor \\
\hline & $\begin{array}{ll} & \text { Hardworking staff } \\
\text { - } & \text { Undertrained } \\
\text { staff } \\
\text { - } \quad \text { Need reliable } \\
\text { vehicles } \\
\text { - } \quad \text { Not enough } \\
\text { funding } \\
\text { - } \quad \text { Staff availability } \\
\text { not guaranteed at } \\
\text { all times }\end{array}$ & $\begin{array}{l}\text { resources - they } \\
\text { depend on } \\
\text { implementing and } \\
\text { linking actors for } \\
\text { energy services }\end{array}$ & $\begin{array}{l}\text { resources } \\
\text { (implementing } \\
\text { actor) }\end{array}$ \\
\hline
\end{tabular}

On the other hand, the target actor is also motivated for the FBAE policy to be implemented. For this actor, the implementation of this policy means that they receive energy services such as paraffin. Even though the amount of paraffin they receive is not enough to cater for all their household energy uses, it is significant enough to relieve the households of the energy costs burden from time to time.

The linking actor's is motivated to deliver energy services to the indigent households through the implementation of the FBAE policy. The main reasons for this actor's motivations is that although it responds to the needs of the implementing and the target actors - delivery of FBAE services also fulfills its role as a link between the other two actors.

A focus on cognitions shows that all three actors have some differences and similarities. The implementing actor has some information from the national and provincial government departments on how to implement the FBAE policy. This actor also shares this information with the linking actor and sometimes with the target actor. Due to its dedicated staff complement that focuses on the delivery of Free Basic Services, this implementing actor easily gathers household information that it uses for updating the indigent register.

The target actor is not very well informed about the implementation of the FBAE policy and to some extent lacks valuable knowledge that could be used to secure FBAE services for all households. For instance, this actor is 
not well informed of the municipal plans of service delivery and therefore cannot negotiate or make decisions on how they want these services delivered to them. This actor also depends on what it observes within its surroundings to get an indication of what to expect from the implementing actor regarding service delivery. The linking actor's main strength is its access of household information. This makes it easy for this actor to have links with both the implementing and the target actors. It is however difficult for this actor to use this information in order to achieve its goals (motivations) without the buy-in of the implementing actor. For the linking actor to ensure that the FBAE policy is implemented, it needs the assistance and commitment of the implementing actor and the need of such services by the target actor.

On power and resources these three actors have differences and some similarities. The implementing actor can be considered as having power because it is the one that delivers the services as per policy requirements. This actor makes household selection decisions on who will receive paraffin as part of FBAE service delivery. The linking actor also has some power as the municipality (implementing actor) depends on it for the information on households to compile the indigent register. The resources available to the implementing and linking actors are not a guarantee that successful implementation of the FBAE policy will occur. On the other hand, the target actor does not have much power and resources to meet its FBAE policy implementation goals as it depends on the implementing and linking actors for the delivery of energy services. This actor's resources are limited and close to none and in this Mhlontlo case, the target actor finds itself in a position where it accepts service delivery decisions made by the implementing actor.

\subsubsection{Summary of mutual relations of actor characteristics}

In Table 9.3, a summary comparing how the characteristics of different actors influence each other is provided. Similar to all the case chapters, this is a summary resulting from analysing the mutual relations arising from the interaction processes in Figures 9.3, 9.4 and 9.5. 
Although all three actors have a common motivation of aspiring to the successful implementation of the Free Basic Alternative Energy (FBAE) policy, their 'focus of attention' slightly differs due to various reasons. The implementing actor is focused on wanting to achieve the implementation of FBAE by providing alternative energy services to indigent households. This is possible for this actor to do because it has access to household information which it constant updates for the indigent register. On the other hand, the target actor's focus is also on FBAE implementation but this actor depends on the other actors for this to happen. Therefore, the target actor's attention in focused on the implementing actor (the municipality) to deliver alternative energy services as part of FBAE policy implementation. The linking actor also depends on the municipality to ensure the delivery of alternative energy services to the indigent households. This is because the linking actor, although it has access to household information and to some degree is influential in the delivery of alternative energy service, it does not have the necessary resources to provide it with capacity to implement the FBAE policy as it wishes.

Actors 'perceive opportunities and threats' differently depending on their circumstances and context. The implementing and the linking actors perceived availability of reliable information as an opportunity that would make it possible to implement the FBAE policy and deliver alternative energy services to indigent households. For the target actor, their perception of opportunities and threats is closely linked to their cognitions, especially on their observations of reality and frames of reference. The target actor's perceives loyalty to the local political leadership which is in charge of the local municipality as an act that guarantees them service delivery such as alternative energy services through the implementation of the FBAE policy. The other side of this interpretation is that lack of support of the local political leadership brings a threat of non-delivery of services. 
Table 9.3: Result of mutual relations of actor characteristics in the implementation process

\begin{tabular}{|c|c|c|c|c|}
\hline $\begin{array}{l}\text { Actor } \\
\text { characteristics }\end{array}$ & $\begin{array}{l}\text { Result of } \\
\text { mutual } \\
\text { influence }\end{array}$ & $\begin{array}{l}\text { Implementing } \\
\text { actor }\end{array}$ & Target actor & Linking actor \\
\hline \multirow{2}{*}{ 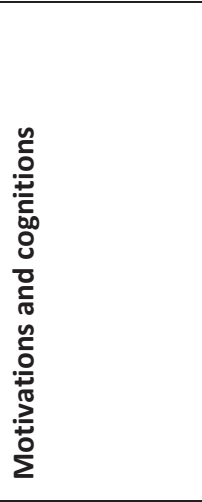 } & $\begin{array}{l}\text { Focusing } \\
\text { attention }\end{array}$ & $\begin{array}{l}\text { Considerable } \\
\text { levels of } \\
\text { attention to } \\
\text { FBAE because of } \\
\text { available } \\
\text { information }\end{array}$ & $\begin{array}{l}\text { Looking up to the } \\
\text { municipality to } \\
\text { provide energy } \\
\text { services }\end{array}$ & $\begin{array}{l}\text { Focus } \\
\text { dependent on } \\
\text { municipality } \\
\text { action regarding } \\
\text { FBAE } \\
\text { implementation }\end{array}$ \\
\hline & $\begin{array}{l}\text { Perception of } \\
\text { opportunities } \\
\text { and threats }\end{array}$ & $\begin{array}{l}\text { With adequate } \\
\text { and reliable } \\
\text { information } \\
\text { FBAE } \\
\text { implementation } \\
\text { is possible }\end{array}$ & $\begin{array}{l}\text { Loyalty } \\
\text { guarantees } \\
\text { paraffin service } \\
\text { (FBAE } \\
\text { implementation) } \\
\text { but still lack } \\
\text { other services }\end{array}$ & $\begin{array}{l}\text { Information is } \\
\text { important for } \\
\text { FBAE policy } \\
\text { implementation }\end{array}$ \\
\hline \multirow{2}{*}{ 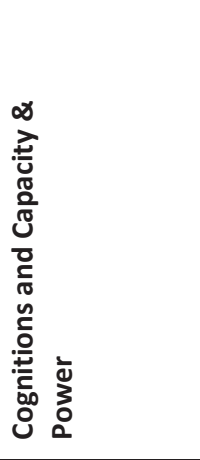 } & $\begin{array}{l}\text { Strategic } \\
\text { value }\end{array}$ & $\begin{array}{l}\text { Information } \\
\text { provides them } \\
\text { with plans to } \\
\text { strategize on } \\
\text { FBAE delivery }\end{array}$ & $\begin{array}{l}\text { Strategy is to } \\
\text { accept what is } \\
\text { given without } \\
\text { challenging (and } \\
\text { questioning) the } \\
\text { municipality }\end{array}$ & $\begin{array}{l}\text { Access to } \\
\text { information but } \\
\text { difficult to fully } \\
\text { implement FBAE }\end{array}$ \\
\hline & $\begin{array}{l}\text { Data search } \\
\text { and } \\
\text { processing } \\
\text { capacity }\end{array}$ & $\begin{array}{l}\text { Constant } \\
\text { household data } \\
\text { collection and } \\
\text { processing }\end{array}$ & $\begin{array}{l}\text { Very low } \\
\text { information } \\
\text { gathering } \\
\text { capacity - rely } \\
\text { implementing } \\
\text { and linking actor }\end{array}$ & $\begin{array}{l}\text { Good data } \\
\text { gathering } \\
\text { capacity for } \\
\text { indigent register }\end{array}$ \\
\hline \multirow{2}{*}{ 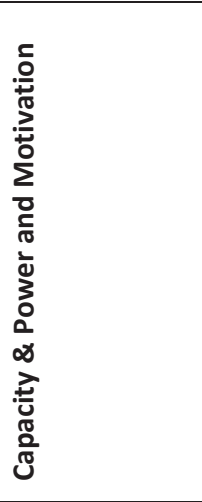 } & $\begin{array}{l}\text { Relevance of } \\
\text { resources for } \\
\text { intended } \\
\text { action }\end{array}$ & $\begin{array}{l}\text { More resources } \\
\text { would help } \\
\text { provide better } \\
\text { FBAE services }\end{array}$ & $\begin{array}{l}\text { Access to } \\
\text { relevant } \\
\text { resources would } \\
\text { assist in monthly } \\
\text { paraffin } \\
\text { distribution }\end{array}$ & $\begin{array}{l}\text { Cannot provide } \\
\text { all services } \\
\text { needed by } \\
\text { households } \\
\text { because of } \\
\text { limited power } \\
\text { and resources }\end{array}$ \\
\hline & $\begin{array}{l}\text { Availability of } \\
\text { resources for } \\
\text { intended } \\
\text { action }\end{array}$ & $\begin{array}{l}\text { Limited but well } \\
\text { used resources }\end{array}$ & $\begin{array}{l}\text { Limited access to } \\
\text { resources - only } \\
\text { when made } \\
\text { available by } \\
\text { implementing } \\
\text { actor }\end{array}$ & $\begin{array}{l}\text { Limited access } \\
\text { to resources } \\
\text { makes it difficult } \\
\text { to fully satisfy } \\
\text { all households } \\
\text { needs }\end{array}$ \\
\hline
\end{tabular}


The 'strategic value' of information for any interaction process is that it provides the actors with knowledge. In this case, the strategic value of information for the implementing and linking actors is that it provides them an opportunity to plan the delivery of alternative energy services for indigent households. The implementing actor uses this information through the indigent register and is able plan ahead and decide on the number of households to provide paraffin to at a time. This way, the implementing actor is also able to plan ahead on the availability of its resources that will enable it to deliver FBAE services. For the target actor, the strategy of accepting what is given by the municipality may be seen as a top-down approach to implementation. It is however a strategy that this actor uses to receive services from the implementing actor. By being dependent on the implementing actor for service delivery and being loyal to the political leadership, this actor places itself strategically in a position that sees it being provided for instead of being independent.

The implementing and linking actors have good 'data search and processing capacity'. Here the data is the household information collected for the compilation of indigent registers. The implementing actor rely on the linking actor for the raw household data which they process to select households that qualify as indigents. The processing of data is also linked to the available resources and the actor motivations. The number of households selected by the implementing actor for service delivery depends on the amount of funds that the municipality has available to spend on paraffin and paying of the service provider. The target actor relies on the linking actor to deliver its information to the implementing actor in order for it to receive the FBAE services. The target actor provides its information to the linking actor with the hope that this enable it to have access to paraffin as part of the FBAE policy implementation process.

For the implementing actor, 'resources are relevant' for the delivery of FBAE services to indigent households. This implementing actor is the only municipality in this study that has made an effort to employ staff dedicated only to the delivery of Free Basic Services which include FBAE policy implementation. Staff availability is a relevant resource as well as funds that 
enable the municipality to hire services of a service provider to deliver paraffin to indigent households. For the target actor resources are also relevant for realising the goal of receiving FBAE services. The target actor relies on the linking and the implementing actors as resources that make it possible to receive alternative energy services.

The 'availability of resources for intended action' is important for all actors. For the implementing actor, there are some resources available such as funds for a limited number of households to receive paraffin as part of FBAE policy implementation. Other resources include staff members that are committed and responsible for the delivery of Free Basic Services as well as the ability to outsource some of the service delivery to contractors. Some resources do not satisfy the need to meet the goals of the actor. The Mhlontlo municipality does not have sufficient vehicles to access their areas of service due to the high maintenance caused by driving on gravel roads. The linking actor highly depends on the implementing actor's resources in order to achieve implement the FBAE policy. This actor's resource is the knowledge of the households, hence the ability to collect information that is useful for the indigent register. However, this knowledge is not very useful if the implementing actor does not use it in a way that benefits the target actor through the delivery of FBAE services.

This section has summarised the results of the interaction process between the actors and their actor characteristics. It shows how the interaction process influences the result of the FBAE policy implementation and how each actor uniquely contributes to this process.

\subsection{Conclusions}

Out of the five cases analysed in this thesis, Mhlontlo stands out as one with reasonable implementation success. In this case, the municipality's mission to implement the FBAE policy is made clear by its dedication of staff and resources. Mhlontlo is the only municipality that has staff members with the sole responsibility of providing Free Basic Services (including FBAE) 
unlike the other municipalities that form the case studies in this thesis where this task is added on to existing (and often many) responsibilities.

The analysis of this case has revealed that the implementing actor has a weak interaction relationship with the linking and target actors. Among other things that lead to this weak relationship is that the implementing actor withholds vital information necessary for implementation from the other actors and does not give these actors an opportunity to make decisions regarding the implementation of the FBAE policy. Despite this weak relationship, this implementing actor still manages to implement this policy with reasonable success in terms of delivery of alternative energy services. The exclusion of the linking and target actors from decisionmaking processes has nevertheless led to their dissatisfaction about how decisions are made on their behalf.

The Mhlontlo case also provides an opportunity to assess the factors that (may) lead to better implementation success. Some of these factors include:

- The municipality ensuring that there is enough capacity (staff members) responsible for service delivery as part of implementation. This reflects its strong motivation to implement the FBAE policy,

- Proper allocation of resources such as funds, vehicles, office space and necessary equipment to enable ease of delivery of services,

- Constantly updating household information to ensure credibility of the indigent register and working together with the district municipality to avoid duplicating efforts,

- Not letting insufficient funding interfere with service delivery plans by improvising where possible.

In this way there developed a productive reinforcement of positive motivation, cognitions and resources, something that has been lacking in other cases. The situation could probably even improve further when the interaction with the linking actor and the targets would improve. However the case also shows that when the implementing actor is determined a reasonable degree of implementation success can already be achieved 
without a strong contribution of the linking actor aspect of the FBAE implementation scheme. 


\section{Chapter 10: Comparative analysis of the five cases and conclusions}

\subsection{Introduction}

This comparative study is based on the analysis of the Free Basic Alternative Energy (FBAE) policy implementation in five local municipalities under the OR Tambo District in the Eastern Cape province of South Africa. This comparison focuses on the similarities and differences that these municipalities have in delivering FBAE services. This chapter starts with the access and use of energy services to give the background of the type of services delivered to all the study areas. Highlighting access and use of energy services also assists in showing the need for alternative energy services in these areas. The comparative analysis then focuses on the actor characteristics following the theoretical framework by Bressers (2004) referred to as the Contextual Interaction Theory (CIT). In working with this theory to compare the five cases, the analysis reveals the importance of what CIT classifies as actor characteristics in the FBAE policy implementation process and how these characteristics influence each other, how they influence the actors and how they influence the outcome of the policy implementation process. This comparison also assists in revealing and highlighting key issues that need to be considered when implementing the FBAE policy.

After this introductory section the chapter starts with an overview of energy access in the five municipalities. In a sense this is the ultimate dependent variable of the policy, since the improvement of energy access is the main goal of the policy scheme. However, many other factors as well as the historical background of South Africa influence these access to energy form many households. For that reason also the assessments of the overall implementation success as concluded in each of the case chapters is added as an intermediate policy output. While each situation has very different 
characteristics it is a bit daring to give an overall assessment of the implementation success. With the argumentation given in the concluding sections of the case chapters a few words are chosen to label the degree of implementation success in each case, enabling a ranking of them on an ordinal scale.

Section 10.3 in this chapter starts with an overview of actors characteristics that have influenced FBAE policy implementation. Although the picture that evolves from this overview is by no means straightforwardly positive, neutral or negative but is rather mixed, there is a clear correlation between the combination of positive or negative scores on each of the characteristics and the ordinal rank of the municipalities involved. After this analysis the section continues with delving deeper into the qualitative stories behind all of these scores, thereby also creating a summary of the case chapters.

In section 10.4 the interaction between the various actor characteristics is addressed along with the interactions between the three groups of actors involved in each case. Together they produce a brief summary of the implementation process in these cases. A similar picture arises as with the comparison of implementation success with the overview of individual actor's characteristics: the strength of the ties among the actors is correlated with the level of implementation success. However, it should be kept in mind that some relations might be of greater importance than others to produce the degree of success or failure.

This chapter and this thesis closes with a section on conclusions and outlook in which the research questions are answered, followed by a reflection on the theoretical approach used in this thesis and recommendations for research and practice. 


\subsection{Comparing energy access and implementation success in the municipalities}

Provisions for the implementation of FBAE policy is dependent on budget allocations which are used to determine the number of beneficiaries under each local municipality. These beneficiaries are known as indigent households which are placed on a register because of their low-income status. This classification entitles them to benefit from government subsidies, some of which are administered by the local municipalities.

The 2011 census data from the Statistics South Africa (2011) shows the energy sources used by households across the local municipalities allowing for a comparison of energy use patterns between these areas. For each service such as lighting, cooking and space-heating, there are some notable differences and similarities between these local municipalities. As mentioned earlier in the case study chapters, the energy carrier used for lighting can be used as an indicative measure of an area's level of electrification. Another reason that lighting is used as a proxy indicator is that, as an application, lighting using grid electricity is considerably cheaper than for other household energy services such as cooking and spaceheating. Previous studies of South African household energy use have indicated that even if households cannot afford to use all of their electrical appliances all the time, they continue using lights because this costs less (Thom et. al. 2001; Prasad \& Ranninger 2003). Lighting using electricity provides higher quality illumination, as well as being safer and healthier, than using candles and paraffin.

\subsubsection{Energy for lighting}

As can be observed in Figure 10.1, three of the local municipalities in this study have more than $70 \%$ of their households with grid electricity. The data also indicate the scale of electrification backlog for each municipality and show that in the least electrified area (Ingquza Hill), 37\% of households do not have a grid connection. The most electrified area (King Sabata Dalindyebo - KSD) has a smaller backlog of $27 \%$ of households without grid electricity (StatsSA 2011). However there is no guarantee that these 
households will get grid electricity in the near future as they are located in the remoter rural areas, which makes the electrification costs higher. In fact, in most of the country's rural areas, the households that remain unelectrified are located in remote rural areas (Peters 2012). The Department of Energy has stated that it gets more expensive to extend the grid to remote rural areas due to the high costs of installing the network lines in these areas (Barnard 2012).

To illustrate the level of electrification over the years, since 2001, using census data collected by Statistics South Africa in 2001, 2007 ${ }^{93}$ and 2011 it is easy to observe that in earlier years the rate of electrification was much faster and many households were provided with this energy source. Prior to 1994, the South African rural areas and many locations occupied by Black people were not provided with basic services such as electricity by the apartheid government. In cases where electricity was provided, the rate of installation was very slow and the levels of electrification were very low.

\footnotetext{
${ }^{93}$ The 2007 Community Survey was not a full census but a 'stratified multistage probability survey that reached out to 284000 households' to provide information at the level of municipalities and give a summary of living conditions in South Africa. (Stats SA 2007).
} 


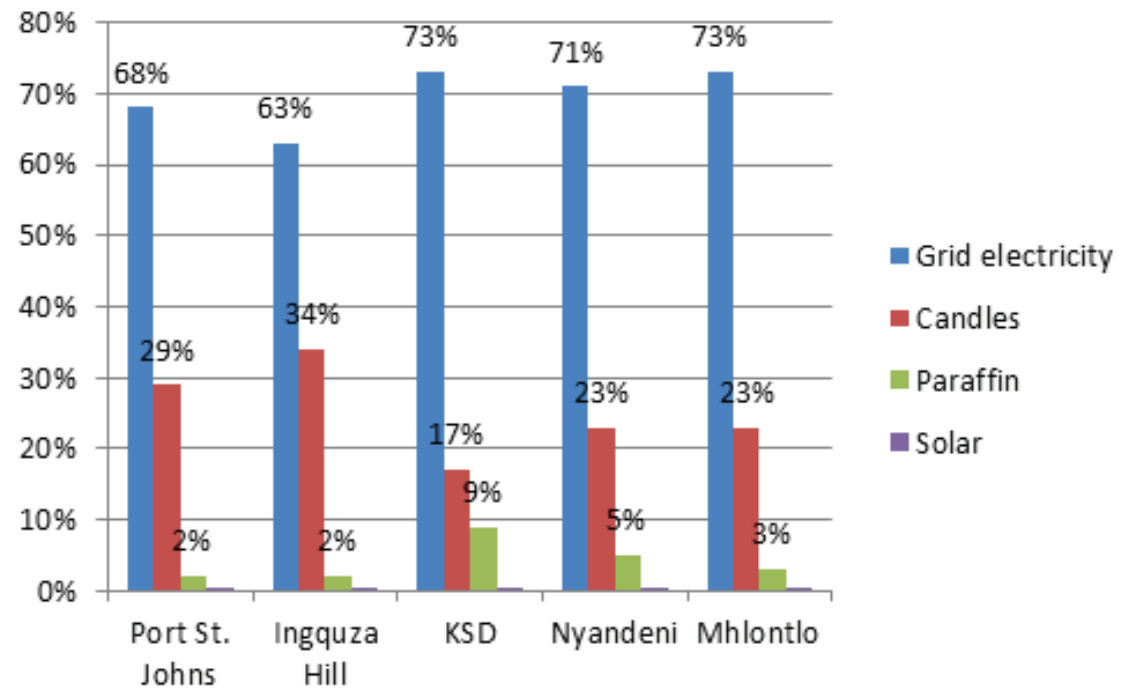

Figure 10.1: Percentage of households using different energy sources for lighting

After 1994 with the new democratic government in place, electrification of households was a priority and implementation was target based. It was also easier for Eskom to provide electricity to a high number of households, especially in the urban areas such as townships, because of their close proximity to the grid, which has the lowest costs of electrification. During the political transition period, the provision of basic services was a way that the government used to bring equality to the citizens of the country. Electrification, as a service that can be seen by people, served a purpose of proving to people that the government delivered the services it had promised. 


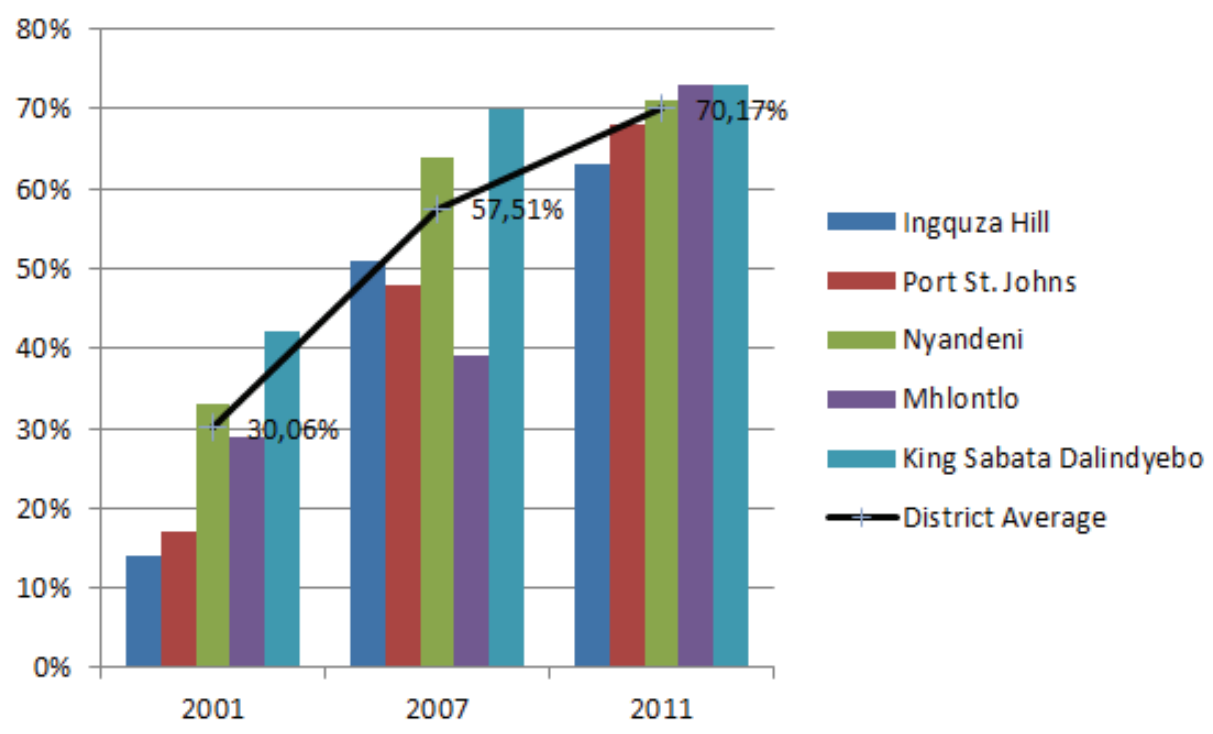

Figure 10.2: Grid electricity use for lighting over time to indicate level of electrification in the OR Tambo district

Figure 10.2 illustrates the percentages of households using electricity for lighting in all five local municipalities under the OR Tambo district. This figure also shows how low the electrification levels were in 2001 and how they peaked in the subsequent years as indicated by the district average. Only $30 \%$ of the households had grid electricity in the OR Tambo district in 2001 , by 2007 there were $57.5 \%$ households with electricity and this number rose to $70 \%$ in 2011 (StatsSA 2001; 2007; 2011).

\subsubsection{Energy for cooking}

Figure 10.3 shows the percentages of households using different fuels for cooking in the study areas. King Sabata Dalindyebo (KSD) local municipality has the highest percentage of households (57\%) using electricity for cooking. This can be attributed to the fact that this municipality has the highest number of grid-electrified households as it is the only municipal 
town with urban features and offers some opportunities for income generating activities for people from the surrounding rural areas and towns.

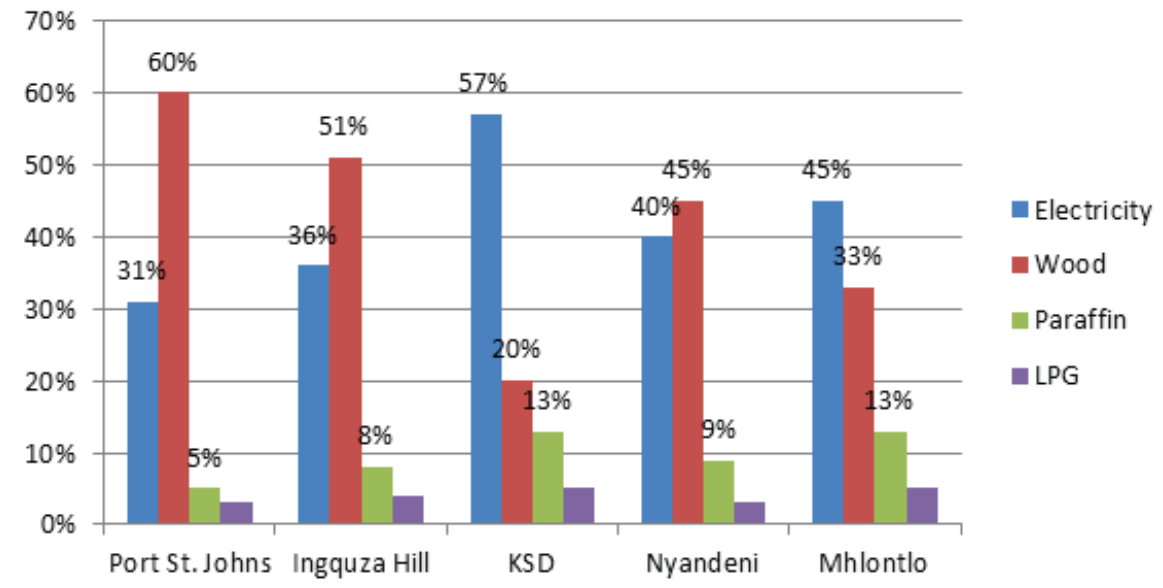

Figure 10.3: Percentage of households using different energy sources for cooking

On the other hand, the Port St. Johns local municipality has the highest percentage of households (60\%) using wood for cooking. As stated in the case chapter dedicated to this municipality, Port St. Johns is surrounded by areas with natural vegetation, therefore areas where wood can be collected are easily accessible. Although wood is easily accessible for most households in this area, the dangers of using this source of energy remain high. Indoor air pollution is a well-documented problem and has been classed among the four most critical environmental problems in the developing countries (Cecelski 2003). It is also well known that women as users of this energy source when cooking, are the ones most affected from the smoke. When collecting wood, the wood bundles carried on the head pose a danger on women and girl-children's bodies as it affects the development of the spine and neck muscles (World Energy Outlook, 2006; Potgieter et al. 2006; Matinga 2010; Clancy et al. 2011) 
Paraffin is a commercial fuel that most low-income households in the urban and rural areas rely on mainly for cooking, space-heating in colder areas and lighting. It is also a fuel that three of the five local municipalities in this study have opted to distribute as part of the Free Basic Alternative Energy (FBAE) implementation process. Figure 10.3 shows that both Mhlontlo and King Sabata Dalindyebo municipalities have only $13 \%$ of households using paraffin for cooking as their main fuel. Paraffin is one of the most expensive fuels in South Africa as its price is dependent on the oil prices. Often, with the rise in oil price, paraffin also goes up just like petrol and other petroleum products. Due to a realization that many low-income households rely on paraffin, the South African government has zero-rated paraffin where Value Added Tax (VAT) is not added to the final price of this fuel (Cnossen 2003). In the rural areas similar to the municipalities on this study, paraffin access is not always easy because of the long distances to the paraffin distributers. This fuel is also often more expensive in the rural areas than it is in the urban areas because of transport costs when travelling to purchase paraffin and because it is often sold more expensively in remote rural areas. The high price mark-up that retailers put on the final price of this fuel (Truran 2010) also makes it more expensive for households especially located in remote rural areas.

There are very few households that use Liquefied Petroleum Gas (LPG) in the rural areas under the municipalities in the OR Tambo district. This can be attributed to the costs of this fuel, the difficulty in transporting it as well as the high costs of appliances. 


\subsubsection{Energy for space-heating}

South African winter temperatures are moderate but do get low especially in the mornings and nights. Many houses do not have insulation to keep the homes warm in winter and there are no provisions made for central heating. For this reason, many households in the country use a variety of energy sources (depending on access, availability and affordability) for space-heating during the winter months. Figure 10.4 shows the percentage of households using different energy sources for space-heating. Again, similar to the cooking percentages, Port St. Johns figures (69\%) in wood use are much higher than the rest of the other local municipalities. In fact, only King Sabata Dalindyebo municipality has household percentages of less than $50 \%$ (29\%) using wood for space-heating but their use of paraffin for this end-use is much higher (38\%) than the other municipalities. As stated above, King Sabata Dalindyebo municipality is the 'economic hub' of this district and as expected it has more grid electrified households and has more households relying on commercial fuels and modern energy sources than the rest of the municipalities under the same district.

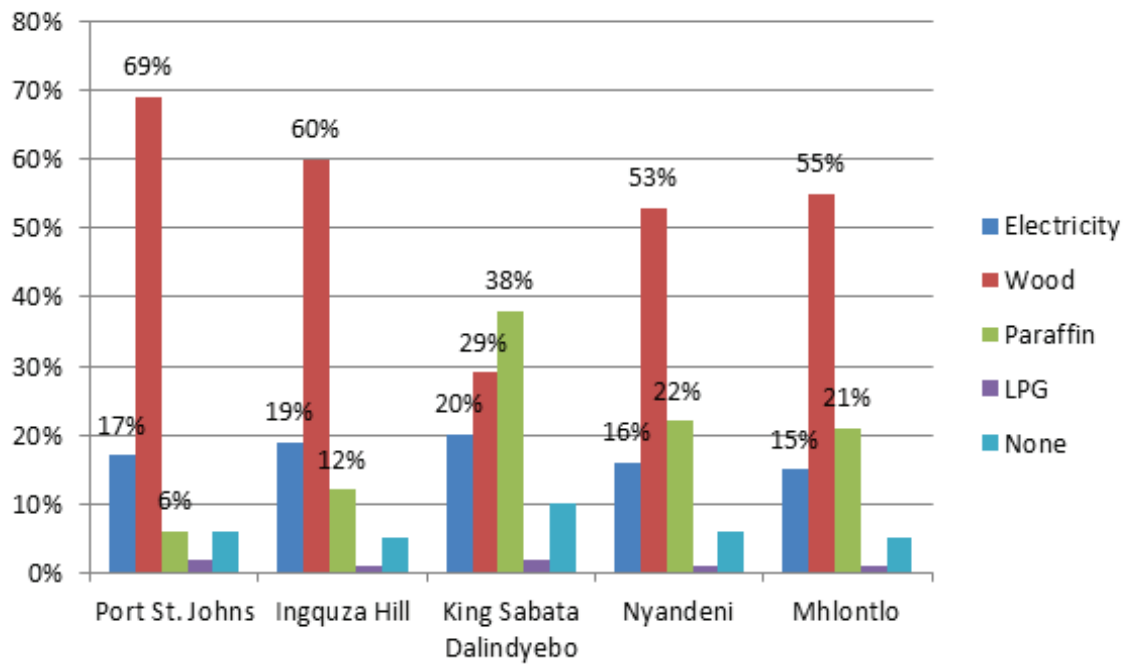

Figure 10.4: Percentage of households using different energy sources for space-heating 
The energy use analysis above has provided an introduction to the comparison of the municipalities under the OR Tambo district. The importance of energy use analysis in this study is that it provides the basis for understanding the need for the implementation of the Free Basic Alternative Energy (FBAE) policy in these rural areas. Moreover, understanding energy use patterns provides a context that assists in understanding the energy costs, access and affordability issues that the households under these municipalities are faced with whilst they wait for better alternatives to the energy sources they are using now.

The following sections of this chapter focus on the implementation of the FBAE policy by the municipalities under this district. The comparative analysis of the municipalities' implementation processes are analysed using the Contextual Interaction Theory (Bressers 2007) where actor characteristics through their dynamic interaction are said to influence the policy implementation process.

\subsubsection{Degree of implementation success}

Each of the case study chapters had a conclusion in which the degree of implementation success was categorized qualitatively. These - and of course the argumentation given for these characterizations provide the basis for an ordinal rank of relative implementation success in the five municipalities. The factors and analysis based on Contextual Interaction Theory should be able to explain these differences or at least to make these differences understandable.

For summary purposes when placed in a tabular form to compare their implementation success and to rank on the ordinal scale - Table 10.1 shows that Mhlontlo has a much better implementation success than the rest of the local municipalities, while also among those there is a variety of degrees, especially when also the potential for improvements is taken into account. 
These qualitative descriptors act as an aggregate form of our dependent variable in the comparative analysis.

Table 10.1: Implementation success per municipality

\begin{tabular}{|l|l|c|}
\hline Study area & Implementation success & $\begin{array}{l}\text { Scale 1-5 (1 = Failed implementation; } \\
\text { 5 = Reasonable implementation } \\
\text { success) }\end{array}$ \\
\hline Port St. Johns & Failed and given up & 1 \\
\hline $\begin{array}{l}\text { King Sabata } \\
\text { Dalindyebo }\end{array}$ & Very low & 2 \\
\hline Ingquza Hill & $\begin{array}{l}\text { Low but keep seeking } \\
\text { opportunity }\end{array}$ & 3 \\
\hline Nyandeni & $\begin{array}{l}\text { Mediocre, lacking } \\
\text { internal support }\end{array}$ & 4 \\
\hline Mhlontlo & Reasonable & 5 \\
\hline
\end{tabular}

\subsection{Comparing how actor characteristics influence the process of Free Basic Alternative Energy policy implementation across the municipalities}

When comparing the actor characteristics such as motivations, cognitions, resources and power across all the actors in this study in the five research areas, there are significant and notable similarities and differences. This part of the chapter goes beyond the focus on the obvious reasons that lead to lack of successful FBAE policy implementation in these five local municipalities. Some of the reasons that may seem obvious from observations and information collected during interviews with all actors include the following:

(i) lack of motivation by the actors (and negative motivation);

(ii) lack of information about households qualifying for FBAE services;

(iii) lack of resources such as funds, vehicles and equipment to enable implementation;

(iv) lack (and shortage) of skilled staff; and 
(v) political influence.

This research, through the analysis of collected data and the use of the Contextual Interaction Theory (CIT) uncovers the underlying issues behind the state of FBAE policy implementation in the chosen municipalities. Using $\mathrm{CIT}$ to compare the key actor characteristics for each actor or actor group in each municipal area allows for the opportunity to identify similarities and differences amongst the actors and how these characteristics influence the way the FBAE policy is implemented.

Motivations, cognitions and capacity and power are the main characteristics analysed to find out about the policy implementation process concerning FBAE in these five local municipalities. Using these characteristics as analysis variables allows the study to focus on the interaction of these actor characteristics with each other for each actor. This also allows for these characteristic to be compared across actors. This way, the study will not only show how each actor characteristic influences the policy implementation process, but will also show whether these characteristics produce similar or different reactions in FBAE policy implementation across the actors.

Table 10.2 will be used to analyse the influence of actor characteristics on FBAE policy implementation. The data in this table is further broken down into smaller sections throughout this section for easy and clearer analysis of all actor characteristics across all municipalities under the OR Tambo district in this study. Analysing the actor characteristics in this way gives the study a chance to illustrate how the interactions of these characteristics influence each other and how this in turn influences the implementation of the FBAE policy. This process will also assist in extracting, in more detail, the real in-depth issues surrounding FBAE policy implementation in these municipal areas.

An analysis of these issues will possibly lead to a recommendation of solutions and processes that may facilitate much better delivery of alternative energy services to indigent households through the FBAE policy implementation process. 


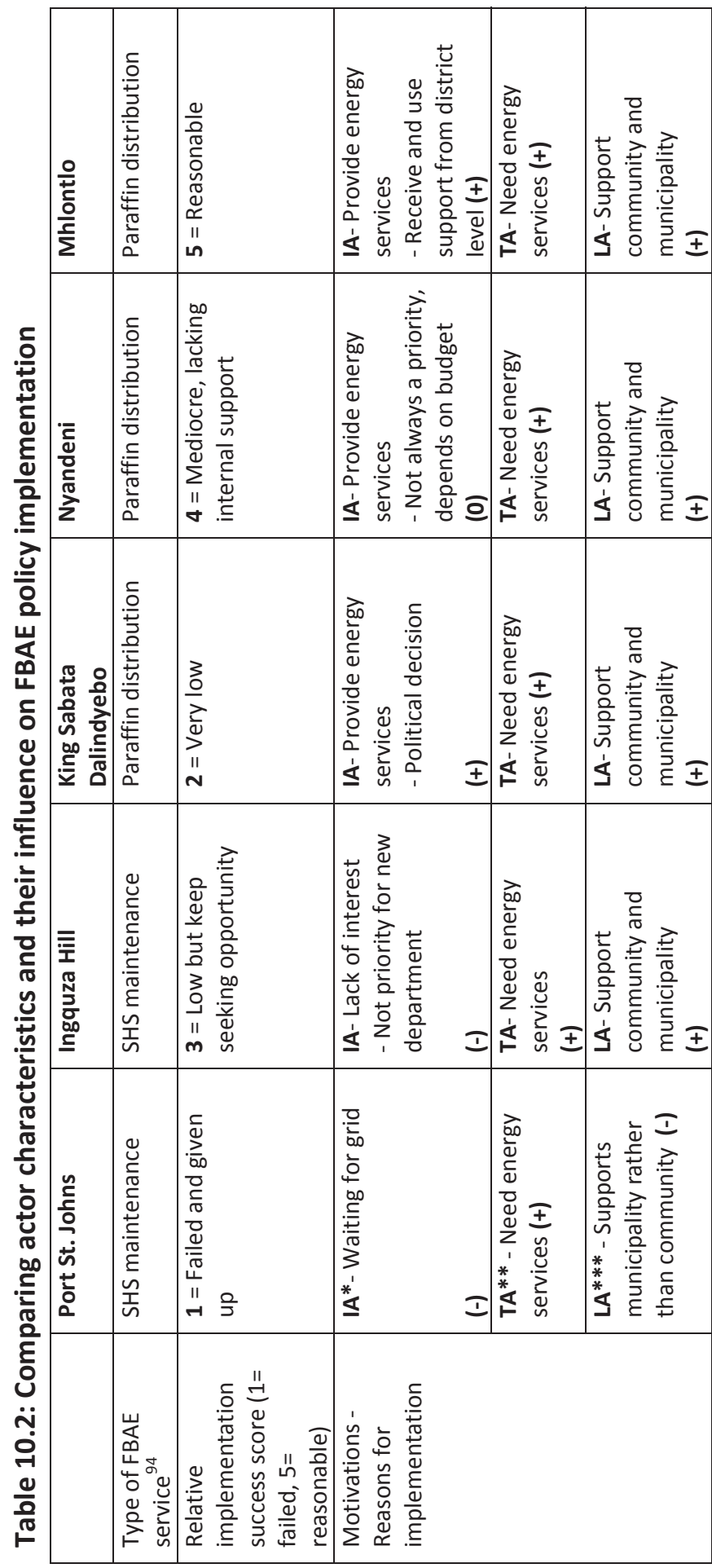

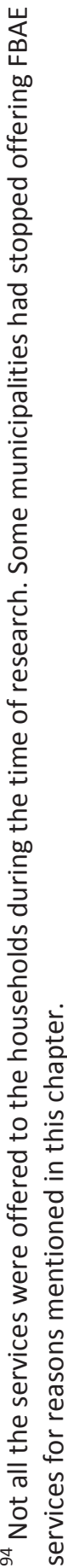




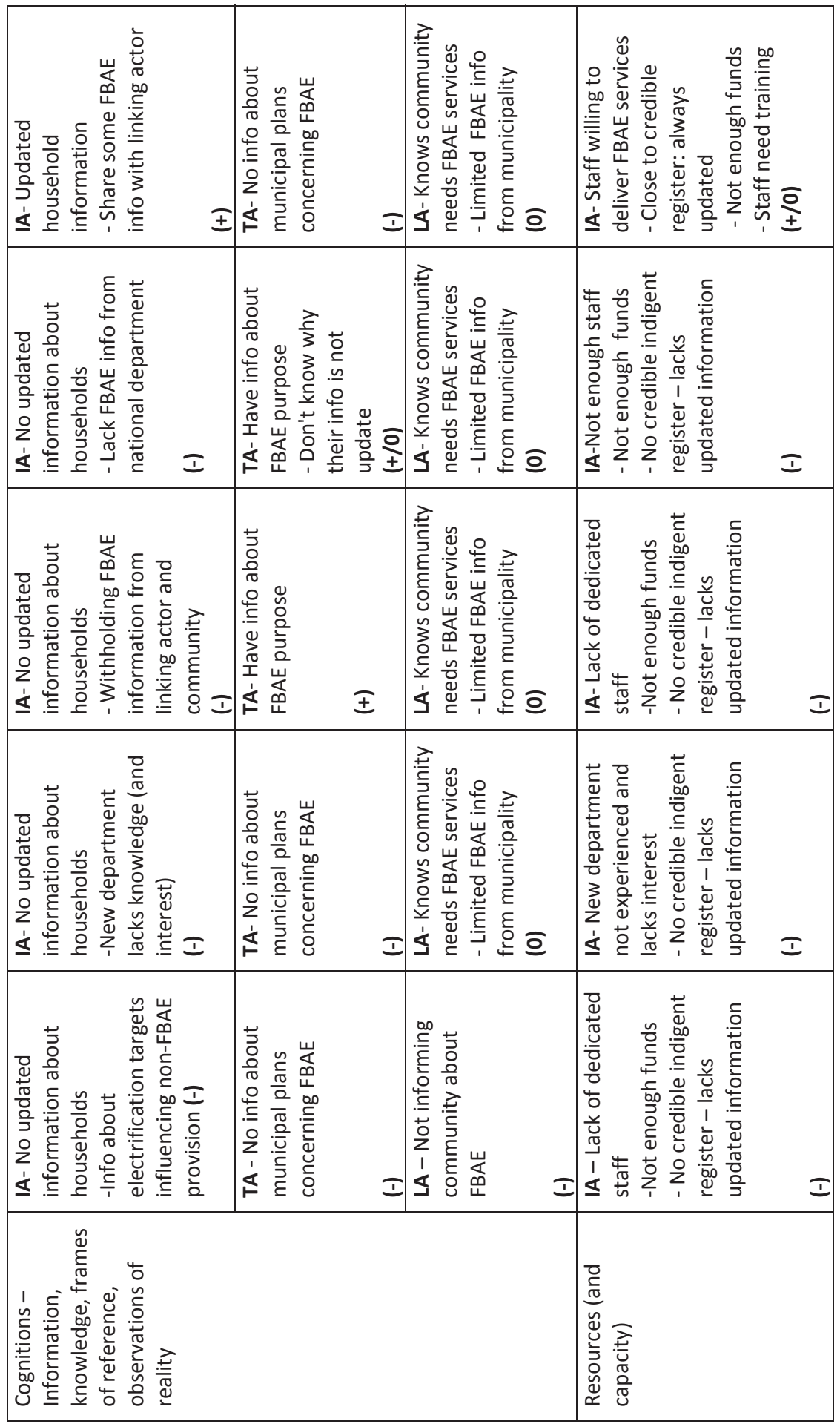




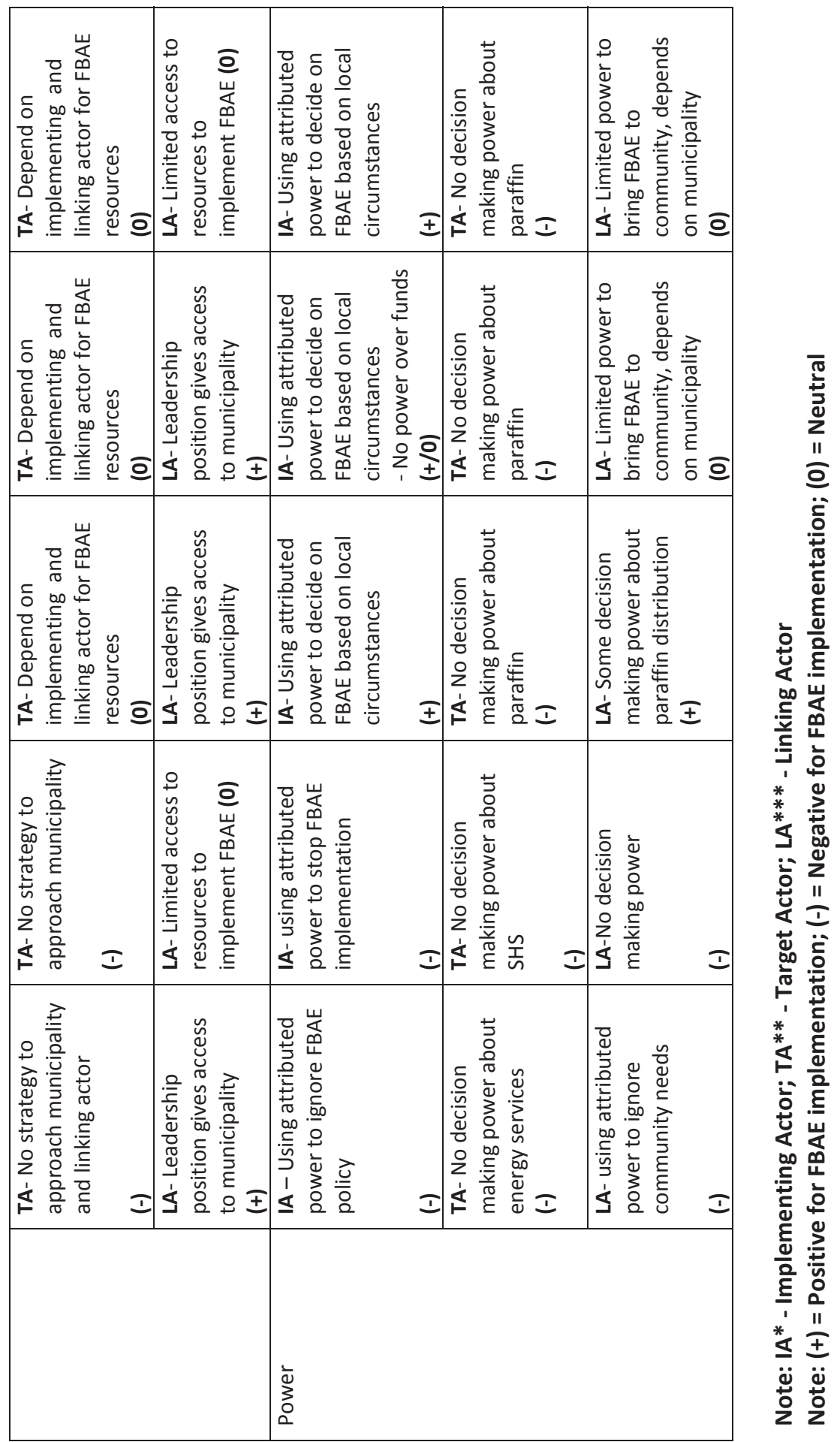


While it might seem tempting to do so, just adding and subtracting the scores in this table to compare them with the ordinal ranks is not possible. The implicit assumption of equal weight is not justified to allow a use for that purpose. Neither does it seem wise to concentrate on one or two factors that show the highest correlation with the ordinal ranks in this sample of five municipalities. The scores merely serve the purpose to create some overview of actor characteristics to give an idea of their influence on the FBAE policy implementation process. Nevertheless it is quite obvious that the higher the degree of success (or lower the degree of failure) the more positives sign at various crucial actor characteristics are identified in the case studies.

In order to emphasize the "richer" or more complete stories behind these factors and ranks the next subsections will dive somewhat deeper again in each of them.

\subsubsection{Analysing the actors motivations}

Motivation to undertake an activity such as policy implementation can either be positive or negative and can yield either favourable or unfavourable results. Motivation as an actor characteristic can be driven by personal goals, external pressure and self-effectiveness assessment (Bressers 2004; Bressers 2007; De Boer and Bressers, 2010). The actor's personal goals can be influenced by a number of factors that an actor comes across during the implementation process. The actor can be motivated or demotivated depending on the conditions such as the type of policy to be implemented, availability of resources such as funds and capacity. External pressure can motivate actors towards compliance and non-compliance in policy implementation, depending on where the pressure comes from. Actors are also motivated by self-effectiveness assessment of the work they are doing. If actors are not positively motivated by the results of their self-assessment this impacts negatively on the policy instruments they engage with, affecting the policy implementation process. The analysis below shows that that in an interaction process such as FBAE policy implementation, actor motivations 
have an impact and an influence on the other actor characteristics namely cognitions and capacity and power.

\section{The implementing actors' motivations}

When comparing the implementing actor's motivations in implementing the Free Basic Alternative Energy (FBAE) policy, there are some similarities and differences. Starting with the similarities, in three of the municipalities (King Sabata Dalindyebo, Nyandeni and Mhlontlo) motivations were driven by them (the implementing actors) truly wanting to provide energy services to the indigent low-income rural households in their areas (Table 10.2).

Being motivated to provide energy services as a municipality can be driven by three possible factors namely - own goals, external motivation and selfeffectiveness assessment - as indicated in the CIT basic model that shows the dynamic interaction between key actor-characteristics (Bressers 2007). The King Sabata Dalindyebo municipality implemented the FBAE policy in order to provide energy services to its low-income indigent households without access to grid electricity - this can be classified as an own goal. On the other hand, the timing of the delivery of energy services for the first time as part of FBAE implementation indicates that external pressure had an influence on the implementation and delivery of alternative energy services. This municipality is the last to initiate the delivery of FBAE services out of the five municipalities. The first time the delivery of such services took place was a day prior to the local government elections in 2011. In this case, the municipality was strategic as well as motivated by external pressure, namely the country and area-specific politics as well as the municipal (local government) elections. The strategy would encourage the people to vote for and retain the political party leading the municipality as they would be presented with physical evidence that this party delivers the much needed energy services and may do more after the local elections.

The Nyandeni implementing actor was also motivated to provide energy services to its indigent low-income rural households without grid electricity. For this municipality, the motivation was driven by their own goals, external pressure and self-effectiveness assessment. This municipality's own goals of 
providing energy services were based on their motivation to fulfil the goals within their Integrated Development Plans ${ }^{95}$ (IDP). In this planning document, providing alternative energy services as part of FBAE implementation is stated as a goal to be achieved by the municipality within a certain time frame. This municipality is also motivated by external pressure to deliver energy services through the implementation of FBAE. For this implementing actor, external pressure comes from within its area and from outside. External pressure from within its area is from the households that expect the energy services from the municipality as they do not have grid electricity and are living in poverty. On the other hand, the external pressure from outside is from provincial and national government departments. These government departments expect this local municipality to reach certain targets in providing FBAE services whilst lack of sufficient funds to meet these targets makes it difficult for this implementing actor to sufficiently provide alternative energy services. The last influence on motivation of this municipality is their self-effectiveness assessment where the Community Services department sometimes does not go ahead with the full implementation of the FBAE policy. This is due to being discouraged and fear of not being able to achieve their implementation goals due to other factors that discourage them in making it possible to provide alternative energy services.

Mhlontlo municipality as an implementing actor is motivated to provide energy services and this is driven by own goals. Based on the interviews with respondents representing the municipality as an implementing actor, there is a real commitment to deliver energy services as well as other services to households classified as indigent. Where FBAE policy implementation is concerned, this municipality has employed staff dedicated to ensuring that indigent households receive FBAE services. In fact, out of the five municipalities studied, this was the only one with more than one person responsible and dedicated to the implementation of the

\footnotetext{
${ }^{95}$ IDPs are five-year plans that each municipality in South Africa is required to develop according to the Municipal Systems Act of 2000 (Section 35) and they are a method to plan future developments for their areas (Education and Training Unit 2011).
} 
FBAE policy within the municipality. For this municipality, external pressure comes from knowing the energy needs of the indigent households and constantly thriving to satisfy these through the delivery of services. Such an experienced pressure is of course not separate from own goal motivation. Another source of external pressure is from the provincial department which this municipality has to report to regarding the number of households it provides with FBAE services and the amount of money spent from the allocated budget. Reporting to the provincial department is required of all municipalities that deliver Free Basic Energy services but not all municipalities diligently follow this requirement due to the different circumstances they work under ${ }^{96}$.

The motivations of the Port St. Johns municipality as an implementing actor led to halting the delivery of alternative energy services to indigent households as this actor claimed that it was waiting for grid electricity installations planned to take place in 2014. As Owens (2008) states, the Contextual Interaction Theory (CIT) "presupposes that policy implementation includes the accomplishment of implementation, the avoidance of implementation and efforts to alter the substance of a given policy implementation" (2008: 51). By making a claim that they are waiting for grid electricity, the Port St. Johns implementing actor avoids the implementation of the FBAE policy and justifies this by saying that there are not enough funds to provide FBAE services to carry out the implementation. While avoiding the implementation of the FBAE policy, this actor also fails to acknowledge the fact that the Department of Energy has shifted the universal electrification target from the year 2014 to 2025. According to the Department of Energy, alternative energy services (instead of grid electricity) will play a more significant role in the future of electrification in South Africa to cover the backlog of up to 3.4 million households (Peters 2013).

\footnotetext{
${ }^{96}$ Information on how municipalities report to the provincial department was given by the provincial Department of Local and Traditional Affairs during interviews held on 04 July 2011 and 04 June 2012 in Bisho, Eastern Cape province.
} 
This actor is not motivated to implement the FBAE policy in the way that is expected by the provincial and national departments where it is supposed to maintain Solar Home Systems (SHS) previously installed by national government as part of a rural electrification programme. The reason for this may be that this actor was not involved with the planning and execution of this programme but is expected to be fully involved with the implementation of the FBAE policy. On looking at the self-effectiveness part of motivation, by avoiding the task of FBAE policy implementation, this actor may be displaying what Bandura (1986) terms as "choice behaviour". He states that "people tend to avoid the tasks and situations they believe exceed their capabilities" (1986: 393). This is also linked to Lipsky's (1980) concept of Street Level Bureaucrats (SLBs)where implementing actors such as the Port St. Johns local municipality take on the role of SLBs and have to make important decisions on issues such as service delivery. According to Lipsky, "they are professionals that exercise discretion and make decisions about the type of services people receive and who receive these services" (1980: 507). Indeed, the Port St. Johns implementing actor has made a decision not to provide FBAE services even though they have indigent households that qualify and are in need of this service, therefore avoiding FBAE policy implementation in favour of waiting for grid electricity.

The Ingquza Hill municipality's motivation on implementing the FBAE policy has led it to assess and evaluate the effectiveness of the alternative energy services it delivers to its indigent households. This implementing actor halted the Solar Home Systems maintenance programme in order to assess whether this programme was viable for the municipality. The concerns about the programme included the costs of maintaining old systems, whether the municipality should replace the SHSs with new Renewable Energy Technologies more suitable for its rural areas or whether to stop the programme and wait for grid electricity installations. During the time of this study's field research, a decision on the best option was not yet made, instead, other developments occurred such as the shifting of FBAE service delivery responsibilities from one department to another. 
This municipality is also influenced by external pressure that mainly comes from the provincial and national government departments. These departments have recommended that this municipality shifts the responsibility of FBAE policy implementation from one department to another. Instead of improving the level of motivation, this has created a lack of interest in the FBAE programme within the municipality staff as the new department has no knowledge nor the expertise to carry forward the FBAE implementation programme. On the other hand, the department that used to be in charge of implementing this policy and providing FBAE services has been 'cut-off' and not consulted to impart its knowledge and experience regarding the implementation of the FBAE policy. This also illustrates how the implementing actor lacks control on decisions regarding the implementation of the FBAE policy. Even though the municipal actor was in the process of making a decision on the best way forward in providing alternative energy services, the provincial government department's decision is final and to an extent, does not consider the implementing actor's concerns.

\section{The target actors' motivations}

When comparing the motivations for target actors in the five local municipalities chosen for this research study, as expected, the results show that the target actors have different motivational backgrounds based on several contextual influences even though at the surface their motivation is equal, that is: supportive to the implementation of the FBAE policy. 
Table 10.3: Needing energy services as motivation target actors

\begin{tabular}{|c|c|}
\hline Municipal Area & A need for energy services as a motivation \\
\hline $\begin{array}{l}\text { Port St. Johns - } \\
\text { Noqhekwana } \\
\text { village and } \\
\text { Mthumbane } \\
\text { township }\end{array}$ & $\begin{array}{l}\text { Noghekwana village: No energy services from the municipality at all. } \\
\text { There are no known plans for grid extension for the future and the } \\
\text { community does not have access to alternative energy services from } \\
\text { the municipality. Households rely on wood, paraffin which in most } \\
\text { cases they cannot afford and candles. } \\
\text { Mthumbane township: Even though most of the township has grid } \\
\text { electricity connections and the local municipality states that it will } \\
\text { provide all households with grid - unelectrified households are in need } \\
\text { of modern alternative energy services as they have to rely on wood, } \\
\text { paraffin and candles. }\end{array}$ \\
\hline Ingquza Hill & $\begin{array}{l}\text { Chitwayo village: Households have Solar Home Systems that were } \\
\text { installed as part of the government rural areas electrification } \\
\text { programme. The municipality has stopped the SHSs maintenance } \\
\text { programme and the households have to rely on wood, paraffin and } \\
\text { candles to meet their energy needs as they do not own the SHSs and } \\
\text { therefore cannot maintain them themselves. There are no modern } \\
\text { alternative energy services being provided by the local municipality. }\end{array}$ \\
\hline $\begin{array}{l}\text { King Sabata } \\
\text { Dalindyebo }\end{array}$ & $\begin{array}{l}\text { KwaMpuku informal settlement: Household receive } 20 \text { litres of } \\
\text { paraffin every three months (each quarter of the year) and welcome } \\
\text { this energy service provided as part of the FBAE policy implementation } \\
\text { process. Households said the received paraffin allows them to use } \\
\text { money for other household needs. Besides this paraffin energy } \\
\text { service, households do not receive any other energy services from the } \\
\text { local municipality. }\end{array}$ \\
\hline Nyandeni & $\begin{array}{l}\text { Municipal Wards } 11 \text { and } 20 \text { : Target actors at these wards were } \\
\text { households that receive } 20 \text { litres of paraffin every three months (each } \\
\text { quarter of the year) from the local municipality. The reasons for } \\
\text { needing energy services to be delivered as part of FBAE policy } \\
\text { implementation are that the households are not receiving any other } \\
\text { energy services from the local municipality as it expected and the } \\
\text { paraffin received is needed to meet their energy household needs. }\end{array}$ \\
\hline Mhlontlo & $\begin{array}{l}\text { Gqwesa village: Target actors in this village receive } 20 \text { litres of paraffin } \\
\text { every three months from the municipality as part of FBAE services } \\
\text { delivered through FBAE policy implementation. The village is remote } \\
\text { and rural and energy services such as grid electricity are not available } \\
\text { for the households. The paraffin received by households is used for to } \\
\text { meet some household energy needs. }\end{array}$ \\
\hline
\end{tabular}


One of the main reasons for the target actors' needs for the FBAE energy services or the FBAE policy to be implemented in a way that benefits them, is that they need modern energy services for their homes (and communities). However, the target actors have different reasons behind each energy service. To get the views of the target actors regarding their energy needs and FBAE policy implementation, discussions with the community representatives were held in Port St. Johns' Noqhekwana village and a meeting with the community leader was held in Mthumbane township. At Ingquza Hill, some informal interviews were conducted with households that have Solar Home Systems (SHSs). In King Sabata Dalindyebo, informal interviews were conducted with some households receiving paraffin as part of FBAE service delivery. Table 10.3 highlights what is expressed by target actors as their needs concerning the delivery of FBAE services. This shows that even though these target actors have similar motivations, there are some differences in their needs for FBAE services. This also emphasizes that the target actors are not a homogenous group and FBAE service delivery should be specific to each actor's needs.

\section{The linking actors motivations}

Just like the implementing and target actors, linking actors' motivations also influence the implementation process of FBAE policy in each municipal study area. In four municipal areas the linking actors' had the same motivations concerning the implementation of the FBAE policy. These linking actors' motivations were to support the community and the municipality in implementing FBAE and providing alternative energy services. The only linking actor with a different motivation was from the Port St. Johns area.

Based on Table 10.4 I will discuss the similar motivations of four of the linking actors and explain what 'supporting the community and the municipality' means as motivation for these actors and how this influences FBAE policy implementation in each area. 
Table 10.4: Supporting the community and municipality as motivation for linking actors

\begin{tabular}{|c|c|}
\hline Municipal Area & Supporting the community and the municipality as a motivation \\
\hline Port St. Johns & $\begin{array}{l}\text { The linking actor in this area was in support of the municipality's } \\
\text { decision not to deliver FBAE services due to the belief that all the } \\
\text { households will be receiving grid electricity. }\end{array}$ \\
\hline Ingquza Hill & $\begin{array}{l}\text { The linking actor in this area was supportive and encouraging of the } \\
\text { municipality to reinstate the SHSs installation programme as part of } \\
\text { FBAE policy implementation. This would provide households with } \\
\text { needed energy services and provide the linking actor with work from } \\
\text { the municipality as a SHSs maintainer. This way, the linking actor would } \\
\text { be providing support for both the community and the municipality as } \\
\text { well as personally benefiting from the services. }\end{array}$ \\
\hline $\begin{array}{l}\text { King Sabata } \\
\text { Dalindyebo }\end{array}$ & $\begin{array}{l}\text { The linking actor in this area was in support of the community to } \\
\text { receive paraffin as part of FBAE service delivery as there were no other } \\
\text { energy services provided by the municipality. The linking actor also } \\
\text { supported the municipality by constantly providing it with household } \\
\text { information to update the indigent register - which would enable the } \\
\text { municipality to easily identify households and provide services such as } \\
\text { FBAE. }\end{array}$ \\
\hline Nyandeni & $\begin{array}{l}\text { The linking actor in this area was in support of the community to } \\
\text { receive paraffin as part of FBAE service delivery as there were no other } \\
\text { energy services provided by the municipality. The linking actor also } \\
\text { supported the municipality by constantly providing it with household } \\
\text { information for the indigent register - which would enable the } \\
\text { municipality to easily identify and provide services such as FBAE. }\end{array}$ \\
\hline Mhlontlo & $\begin{array}{l}\text { The linking actor in this area was in support of the community to } \\
\text { receive paraffin as part of FBAE service delivery as there were no other } \\
\text { energy services provided by the municipality. The linking actor also } \\
\text { supported the municipality by constantly providing it with household } \\
\text { information for the indigent register - which would enable the } \\
\text { municipality to easily identify and provide services such as FBAE. }\end{array}$ \\
\hline
\end{tabular}

Although the motivations are similar, it is also clear that each linking actor has their own underlying reasons for this motivation. The reasons also depend on the relationships that the linking actors have with the target and implementing actors, their position in the area and their influence over the delivery and demand of services.

In Port St. Johns, the only study area where the linking actors support only the municipality and neglects the community, the linking actors' motivation influences FBAE policy implementation in a way that favours the local municipality. In both areas under this municipality, namely Noqhekwana 
village and Mthumbane township, the linking actors were not advocating for the communities' needs for alternative energy services. Instead, in Noqhekwana village, the linking actor ignored the community's pleas for delivery of household energy services in the area. While in Mthumbane township, the linking actor did not see it as necessary to provide alternative energy services for a small number of households whilst most of the households in the township had grid electricity connections. Further analysis of these linking actors' motivations show that they were in support of the municipality's decisions, to wait for grid electricity instead of providing unelectrified households with alternative energy services as required by the FBAE policy.

\subsubsection{Analysing the actors cognitions}

For the purposes of this study, cognitions refer to the information that the actors have access to and how they use it for the purposes of implementing the FBAE policy. Information refers to the information that municipalities have access to that assists them to compile indigent household registers and the process of collecting this information. Information also refers to the access of FBAE information that all actors have access to and how this is used towards the implementation of the FBAE policy. Cognitions also refer to the prior and present knowledge which is based on the information that the actors have about each other and about the interaction process. According to the Contextual Interaction Theory, cognitions are based on observations and interpretations of information that is held to be true by actors as well as the elements of knowledge that they use as frames of reference (Bressers 2007).

\section{The implementing actors' cognitions}

Information is important in the implementation of the FBAE policy, especially for the implementing actor. The information that the implementing actor holds to be true, has access to and the way this information is treated (and used) - influences the policy implementation process of FBAE. As with the analysis of actor motivations above, in this section some of the actors' cognitions will be analysed to extract the 
reasons behind the similarities and differences given where cognitions are concerned and how these influence the FBAE policy implementation process.

Out of the five municipalities in the study, four (Port St. Johns, Ingquza Hill, King Sabata Dalindyebo and Nyandeni) had no updated information about the indigent households they were supposed to deliver alternative energy services (through FBAE implementation) to. Collection and updating of this information is critical for all municipalities as it informs them of the number of indigent households in their areas as well as enables them to deliver basic government funded services to these households.

Table 10.5 shows the reasons behind the implementing actors' lack of updated information and how this impacts on the implementation of the FBAE policy and service delivery. As can be seen, lack of updated information is caused by a number of reasons such as lack of staff capacity within the municipality to update the data, lack of interest by staff to update the data and deliver FBAE services and confusion that may have been caused by transfer of responsibilities from one department to another. 
Table 10.5: Household information update as a cognition influencing implementing actors' FBAE policy implementation

\begin{tabular}{|l|l|}
\hline Municipal Area & Household information update \\
\hline Port St. Johns & $\begin{array}{l}\text { Lack of updated household information is due to the municipality not } \\
\text { collecting households' information and not updating its old database, } \\
\text { therefore making it difficult to have a credible indigent register. Even } \\
\text { with a newly set-up indigent committee, there are concerns of lack of } \\
\text { capacity within the committee to collect and update the information } \\
\text { for the indigent register. }\end{array}$ \\
\hline Ingquza Hill & $\begin{array}{l}\text { Lack of updated household information is due change in the FBAE } \\
\text { policy implementation responsibilities from one department to the } \\
\text { other. There was no proper hand-over of responsibilities and the new } \\
\text { department shows lack of interest in the provision of FBAE services. }\end{array}$ \\
\hline Daling Sabata & $\begin{array}{l}\text { In this municipality there was only one person responsible for the } \\
\text { implementation of the FBAE policy and to ensure the provision of } \\
\text { alternative energy services to indigent households in this area. The } \\
\text { municipality relied on an outdated indigent register that was compiled } \\
\text { by the district municipality in 2007. According to the municipality, this } \\
\text { register was not only outdated but did not reflect the actual number of } \\
\text { indigent households therefore making it difficult to budget for activities } \\
\text { such as the delivery of FBAE services and often underestimating the } \\
\text { costs. }\end{array}$ \\
\hline Myandeni & $\begin{array}{l}\text { The lack of a credible indigent register was due to the municipality not } \\
\text { having capacity to update household information on its database. Even } \\
\text { though household information was collected by the linking actors } \\
\text { (community representatives under this municipality), it was not } \\
\text { updated due to a shortage of staff to conduct this task and lack of } \\
\text { sufficient funds to employ people to do this. This municipality blamed } \\
\text { the national Department of Energy for not having sufficient } \\
\text { information about what was happening on the ground, hence } \\
\text { allocation insufficient funds for the FBAE policy implementation } \\
\text { activities. }\end{array}$ \\
\hline $\begin{array}{l}\text { Constant collection and updating of household information on the } \\
\text { indigent household register ensures better knowledge of household's } \\
\text { energy needs and better delivery of FBAE services. }\end{array}$ \\
\hline Mhlontlo
\end{tabular}


In the case of Mhlontlo, the implementing actor had indigent household information which was used for the indigent register and subsequently, as a guide that informed the municipality of the households that needed FBAE services in the areas without grid electricity. This implementing actor's ability to update its indigent households information and have a close-tocredible indigent register can be attributed to some factors. Such factors include the availability of staff to work on FBAE service delivery, support within the municipality for the implementation of FBAE policy and working together with the district municipality in collecting household information.

The implementing actors also have different ways that they use and interpret the information and knowledge to influence the process of FBAE policy implementation. Spillane (2000) states that "cognitive theory suggest that people use their prior knowledge and experiences to construct new understandings" (2000: 146). This way the implementer does not only process the information received from the policy but other information and knowledge from previous experiences and situations. The municipalities studied as cases in this thesis give evidence of the depth of influence their own cognitions have on Free Basic Alternative Energy (FBAE) policy implementation and how this in turn influences the other actor characteristics such as motivations and resources. As Spillane (2000) explains, policy is a stimulus which leads implementers to make decisions on whether to implement, ignore, sabotage or change their existing behaviour. Whatever action is chosen by the actor, is still part of the implementation process (Bressers 2007).

When analysing how the Port St. Johns implementing actor used information and knowledge at its disposal, such as information on how the FBAE policy can be implemented, as well as the information on grid electrification targets. This municipality chose to ignore the FBAE policy implementation directive to provide alternative energy services and opted to 'wait' for grid electricity. This implementing actor has used information to its advantage by drawing reasons for not providing alternative energy services. Some of the reasons include insufficient funding to implement the policy through providing services such as SHSs maintenance, lack of 
knowledge of the number of households that need this service, availability of knowledge that grid electricity will be available by the year 2014 - even though the national Department of Energy has postponed this target to 2025 (Peters 2013).

The King Sabata Dalindyebo and Mhlontlo implementing actors exhibit differences on the sharing of information. As mentioned above, information is an important part of the actor's cognitions as it influences the decisions made on the process of policy implementation. The differences between these municipalities are: King Sabata Dalindyebo municipality withholds FBAE policy implementation information from the linking and target actors, whilst the Mhlontlo implementing actor shares this information with these actors. These differences naturally influence the results of how the FBAE policy is implemented. In the research area under the King Sabata Dalindyebo municipality withholding information resulted in both the target and linking actors not knowing what the municipal plans were regarding the provision of alternative energy services through FBAE. This had a ripple effect as it affected the linking actor who was constantly questioned by the community about the alternative energy services such as the paraffin provided by the local municipality. As this was an impoverished community, households were always keen in knowing when the paraffin will be delivered as it brought relief to their household budgets - even though they received this fuel once in three months. Withholding information works to the advantage of the implementing actor as this actor can avoid external pressure by not revealing its plans which relieves the municipalities of some service delivery responsibilities. One can even say this strategy helps the implementing actor not to set ambitious targets where FBAE policy implementation is concerned, therefore not setting itself up for failure. As expected with the use of the Contextual Interaction Theory (CIT) - actor characteristics influence each other and the policy implementation process (Bressers 2007: 7) and this example shows that.

The Mhlontlo implementing actor on the other hand shared FBAE policy implementation information with the linking and target actors. As mentioned above where actor motivations are analysed, Mhlontlo FBAE 
policy implementation process is driven by the municipality's own goals to deliver alternative energy services to indigent households. The constant sharing of information with linking and target actors not only keeps the other actors informed but it also ensures that the municipality as the implementing actor keeps to its own goals. This is also a strategy that the municipality uses for constantly updating the other actors of its progress regarding FBAE policy implementation - this way it keeps track of its own progress. In this case, as Spillane (2000) states, the policy is used as a stimulus to come up with different ways of implementation that the implementer is most comfortable with. The result of sharing FBAE information with other actors not only benefits this implementing actor in achieving its own goals, but has positive impacts where the target and linking actors know that they can rely on their municipality to keep them informed of its plans and to a certain extent, deliver on its promises.

An implementing actor that experienced lack of information on FBAE policy implementation is the Nyandeni municipality. This implementing actor said it lacked important information from the national Department of Energy about the process of implementing the FBAE policy. To some extent, this affected implementing actors' policy implementation process negatively as it could not rely on this department for information and guidance, especially concerning funding of FBAE service delivery activities. For this implementing actor it was important to have information from the national Department of Energy as applying its own knowledge and experience of policy implementation on delivering FBAE services proved to be inadequate. Despite this lack of information and compared to some of the municipalities in this study, Nyandeni's effort to provide alternative energy services made a positive contribution to the indigent households.

\section{The target actors' cognitions}

The target actors are important in the process of Free Basic Alternative Energy (FBAE) policy implementation as they are the main reason the policy was developed. It is therefore important to analyse how these actors use the information and knowledge that is available to them in the process of 
FBAE implementation and to find out how their cognitions influence the implementation process. Similar to the other actors, the target actors' actions and attitudes have an influence on the other actors and therefore on the whole process of FBAE policy implementation in the municipal cases in this study.

In order to construct an understanding of new (and old) concepts and ideas such as the FBAE policy, knowledge and past experiences are needed to construct a new understanding (Spillane, 2000). When comparing the target actors' cognitions, the analysis shows that two of the actors have access to information regarding FBAE policy implementation. Availability of information provides knowledge for the actor to make decisions about the implementation process of the policy. Although the implementing actor withholds information from the King Sabata Dalindyebo target actor, the linking actor provides this target actor with some information (even though inadequate) regarding the FBAE service. Having information about the purpose of FBAE policy implementation provides these actors with an opportunity to know why they are receiving FBAE services. These target actors have an understanding that the FBAE services are provided to them because of their indigent status and the fact that they do not have access to grid electricity. The target actor receives this information from the linking actor - who receives it from the paraffin service providers.

On the other hand, target actors from three areas reported that they had no information about municipality plans concerning FBAE policy implementation. Similar to the analysis above, it is expected that these target actors, although having similar responses concerning a common issue, their reasons may be different which will reflect their own unique experiences. Table 10.6 illustrates how the Port St. Johns, Ingquza Hill and Mhlontlo target actors define and make sense of the lack of information about municipality plans concerning FBAE policy implementation. It also shows how the Nyandeni and King Sataba Dalindyebo target actors access some of the information from the linking actors. 


\section{Table 10.6: Access to information about municipal FBAE plans as an influencing cognition on target actors}

\begin{tabular}{|c|c|}
\hline Municipal Area & Access to information about municipal plans \\
\hline Port St. Johns & $\begin{array}{l}\text { Noghekwana village: The community has not received any information } \\
\text { regarding the implementation of FBAE in their area. The linking and } \\
\text { implementing actors do not communicate any energy provision plans } \\
\text { for the area with this community. The community has experienced } \\
\text { having a community leader (Ward Councillor) that has never responded } \\
\text { to their concerns. This has led the community to give up on asking for } \\
\text { information from the implementing and linking actors as they state } \\
\text { that they will not be able to get any response from these actors. } \\
\text { Mthumbane township: The community is not informed about the FBAE } \\
\text { policy and its implementation as the implementing and linking actors } \\
\text { believe that informing the target actor about this service is not } \\
\text { necessary will be useless. The implementing actor has no intentions to } \\
\text { provide FBAE services to the unelectrified households and insists that } \\
\text { grid electricity will be provided by } 2014 \text { to all households. }\end{array}$ \\
\hline Ingquza Hill & $\begin{array}{l}\text { At Chitwayo village, the study area under this municipality, the target } \\
\text { actor did not have information about municipal plans because the } \\
\text { implementing actor did not share this information. The community had } \\
\text { no idea why the FBAE services of SHSs maintenance had stopped nor } \\
\text { did they know when they would resume. They did not know where to } \\
\text { ask for information regarding the SHSs they had in their homes and } \\
\text { were not told whether these systems would be repaired, removed or } \\
\text { replaced and if they would be receiving grid electricity. }\end{array}$ \\
\hline $\begin{array}{l}\text { King Sabata } \\
\text { Dalindyebo }\end{array}$ & $\begin{array}{l}\text { The implementing actor withholds information from the target actor } \\
\text { but there is some access to information from the linking actor which } \\
\text { assists in providing knowledge about FBAE services. }\end{array}$ \\
\hline Nyandeni & $\begin{array}{l}\text { Some information from the linking actor assists in providing knowledge } \\
\text { about FBAE services. }\end{array}$ \\
\hline Mhlontlo & $\begin{array}{l}\text { Even though the implementing actor mentioned that it shares } \\
\text { information with the target and linking actors, the community } \\
\text { representatives at Gqwesa village said they did not have enough } \\
\text { information about FBAE services. They did not know how long they } \\
\text { would be receiving paraffin as part of FBAE services for and whether } \\
\text { they would be expected to pay for this fuel by the municipality. They } \\
\text { also did not have information on other energy services such as when } \\
\text { they would be receiving grid electricity. }\end{array}$ \\
\hline
\end{tabular}


In the case of Port St. Johns, the lack of information and being left out of decision-making processes about FBAE policy implementation has caused the target actor to give up on having their voice heard and not to insist on the provision of services by the municipality. In analysing the target actor's cognitions, it is clear that that this actor has based its decisions on previous experiences it has had with the implementing and linking actors in the past. Due to "not being listened to" ${ }^{97}$ and "not receiving clear responses about energy services in the area" ${ }^{\prime 9}$, the target actor in the Noqhekwana village has opted to stop asking questions and wait for the municipality and the Ward Councillor to make their own decisions about energy service provision in the area.

When target actors avail their household information to the linking and implementing actors in order to be added to the indigent register, they expect that they will receive the services aimed at improving indigent households' living conditions. This is how they interpret the action of information collection by the municipality and this raises their hopes about receiving FBAE services. The case of Nyandeni illustrates this point clearly where the target actor has given their household information for the purposes of being added to the indigent register, but they do not receive services because their household information is not updated on the indigent register. As explained in the Nyandeni case chapter (see Chapter 8), even though household information is collected by the linking actor and submitted to the implementing actor - it is usually not used to update the indigent register. One of the main reasons given by the implementing actor for not updating the information is that it has no staff capacity to carry out this task. On the other hand, the target actors see and interpret this as the fault of the linking actor which they accuse of not passing their information on to the municipality, therefore denying them access to FBAE services.

There were similarities between the King Sabata Dalindyebo and Mhlontlo municipality with regards to the usefulness of the FBAE services received by

\footnotetext{
${ }^{97}$ Information extracted from interviews held with community representatives of Noqhekwana Village on 20 April 2012 in Port St. Johns.

${ }^{98}$ Ibid
} 
the households. Knowing their own household conditions, especially that they cannot afford to pay for energy services, households receiving paraffin from these municipalities said through experience, they knew that the FBAE services received were helpful for them. Even though these households received the 20 litres of paraffin only four times a year, this was still helpful to them as it freed the household budget for other household needs ${ }^{99}$. With acknowledging the usefulness of the FBAE services received and making this information known to the implementing and linking actors, the target actor emphasizes the need for such energy services for indigent households. This also influences the implementing actor to a certain extent to continue delivering these FBAE services to the households and encourages the linking actors in these areas to continue advocating for such services to be delivered.

\section{The linking actors' cognitions}

Linking actors are an important part of the Free Basic Alternative Energy (FBAE) implementation process. They make both implementing and target actors accessible to each other as they provide the much needed link that is often overlooked and not nurtured. Without this link, the implementing actor lacks knowledge of the target actor's needs regarding service provision. In ideal situations, this link also provides the target actors with an opportunity to express their needs to the implementing actors.

In analysing the linking actor's cognitions such as the information and knowledge they possess and use in influencing the FBAE policy implementation process, certain issues emerge for each study area. These issues emphasize the differences in the manner in which linking actors in each area respond to the FBAE policy implementation process based on their knowledge of the communities and municipalities as well as previous experiences on implementing other policies and strategies in their areas. One of the most important roles of the linking actor is to know the needs of

\footnotetext{
${ }^{99}$ This is based on interviews conducted with households, community leaders and municipality representatives.
} 
the communities so that they can inform the municipalities and offer guidance on how best to cater for such needs. Table 10.7 shows how linking actors' knowledge of community needs for FBAE services influences the policy implementation process and how it impacts on the other actors' actions in the same process. The knowledge and understanding of community needs is demonstrated by giving a background on each linking actors' interaction with the target and implementing actors. In this way, the linking actors' cognitions influence the way households and municipalities respond to the need for alternative energy services in these areas.

Due to various reasons, some emanating from the actor's motivations and resources, it is not always a guarantee that the information given by the linking actor to the implementing actor on the needs of FBAE services will encourage the municipality to provide such services. However, this information provides the municipality with knowledge of the needs of communities they are supposed to be providing services to.

The information also gives the municipality a chance to assess its abilities and resources to provide services as well as incorporate these needs to its plans such as the Integrated Develop Plans (IDPs). It is also not a guarantee that the linking actor will always pass the information it receives from the target actor to the linking actor. This action is determined by the linking actor's interests and motivations as well as the relationship it has with the other actors.

Linking actors' cognitions can also influence the policy implementation process to favour the implementing actor more than the target actor as this has been revealed in the analysis of the Port St. Johns case. The linking actor used the information given by the implementing actor to avoid the implementation of the FBAE policy therefore denying the indigent households the opportunity to access alternative energy services. In the Noqhekwana village, the linking actor was not informing the community about FBAE services whilst in Mthumbane township, the linking actor supported the non-provision of alternative energy services because the municipality claimed that grid electricity would be provided in the near future. 
Table 10.7: Knowledge of community needs for FBAE service as the linking actors' influencing cognition

\begin{tabular}{|c|c|}
\hline Municipal Area & Linking actors' knowledge of community needs for FBAE services \\
\hline Port St. Johns & $\begin{array}{l}\text { Even though the linking actors know that the communities need } \\
\text { alternative energy services, they do not pass this information to the } \\
\text { implementing actor as they know that the municipality plans to wait } \\
\text { and provide grid electricity. The households' current energy needs are } \\
\text { therefore ignored by the linking actor and this adds to the } \\
\text { implementing actor's avoidance of FBAE policy implementation. }\end{array}$ \\
\hline Ingquza Hill & $\begin{array}{l}\text { Information on the community needs was received from the target } \\
\text { actors through community meetings and individual consultations with } \\
\text { the chief and the headman. The linking actor also lived in the same } \\
\text { area as the community that was in need of the SHS maintenance } \\
\text { services and had seen how this services assisted the households as part } \\
\text { of FBAE service provision. The linking actor passed this information to } \\
\text { the municipality with the hope that services would be provided for the } \\
\text { community. }\end{array}$ \\
\hline $\begin{array}{l}\text { King Sabata } \\
\text { Dalindyebo }\end{array}$ & $\begin{array}{l}\text { Information received from the target actors through community } \\
\text { meetings and making observations. The linking actor also lived in the } \\
\text { same community and knew most of the households' living conditions } \\
\text { as she was the one collecting household information for an update on } \\
\text { the indigent register. The linking actor knew that the community } \\
\text { needed and appreciated receiving the } 20 \text { litres of paraffin given as part } \\
\text { of FBAE service provision by the municipality. The linking actor also } \\
\text { gave feedback to the municipality on how and what the households } \\
\text { used the fuel for as well as their wishes to receive the fuel on a more } \\
\text { regular basis instead of once in three months. }\end{array}$ \\
\hline Nyandeni & $\begin{array}{l}\text { The linking actors in this area were informed by the households as well } \\
\text { as the traditional leaders. Linking actors knew that the communities } \\
\text { they served and lived in were impoverished and needed assistance } \\
\text { with accessing alternative energy services - since grid electrification } \\
\text { plans for this area were not known. This information together with the } \\
\text { lists of households to be added to the indigent register, was passed on } \\
\text { to the municipality. }\end{array}$ \\
\hline Mhlontlo & $\begin{array}{l}\text { The linking actor knows the community needs as explained and as } \\
\text { witnessed in the everyday lives of the people in the villages. In the } \\
\text { unelectrified villages, communities are in need of alternative energy } \\
\text { services and always ask the linking actors about the municipality's } \\
\text { plans on providing these services. The linking actor passes this } \\
\text { information to the implementing actor whilst pleading for the provision } \\
\text { of alternative energy services on behalf of the indigent households in } \\
\text { these communities. }\end{array}$ \\
\hline
\end{tabular}


Table 10.8: How information from municipality influences linking actors' cognitions in FBAE implementation

\begin{tabular}{|c|c|}
\hline Municipal Area & Linking actors' information from municipality \\
\hline Port St. Johns & $\begin{array}{l}\text { This linking actor was informed by the municipality that it is best to } \\
\text { wait for grid electricity connections instead of providing indigent } \\
\text { households with FBAE services. This has led to the linking actor's lack of } \\
\text { information dissemination to the target actor about the FBAE policy } \\
\text { and how the indigent households can benefit from the implementation } \\
\text { of this policy. }\end{array}$ \\
\hline Ingquza Hill & $\begin{array}{l}\text { The linking actor is not given full information on the municipality's } \\
\text { plans of providing FBAE services to the households. This results in the } \\
\text { linking actor not having information to pass on to the target actor and } \\
\text { straining the relationship this actor has with the community. }\end{array}$ \\
\hline $\begin{array}{l}\text { King Sabata } \\
\text { Dalindyebo }\end{array}$ & $\begin{array}{l}\text { Due to limited information provided by the municipality to this linking } \\
\text { actor, it made it difficult to plan ahead and prepare the community for } \\
\text { paraffin delivery. The linking actor was not always informed about } \\
\text { when paraffin would be distributed to the area, therefore could not } \\
\text { ensure that all the household representatives would be present to } \\
\text { accept the paraffin. Missing an opportunity to receive paraffin meant a } \\
\text { three month wait for the next paraffin distribution phase and possible } \\
\text { use of tight household budgets to buy paraffin. }\end{array}$ \\
\hline Nyandeni & $\begin{array}{l}\text { The linking actor did not receive enough information regarding FBAE } \\
\text { policy implementation and could not respond to questions asked by } \\
\text { the community. In this area, lack of information was based on the } \\
\text { outdated indigent register. However, the indigent households } \\
\text { questioned the situation as they had previously provided their } \\
\text { information to register for FBAE services. This caused tensions between } \\
\text { the linking and target actors as the community concluded that the } \\
\text { linking actors were not passing their household information to the } \\
\text { municipality. }\end{array}$ \\
\hline Mhlontlo & $\begin{array}{l}\text { There was not enough information available to the linking actor } \\
\text { regarding FBAE services. The municipality delayed informing the linking } \\
\text { actor about the paraffin delivery dates and times. The linking actor did } \\
\text { not understand how households were selected to be provided with } \\
\text { paraffin. This was because not all households that registered as } \\
\text { indigents were on the paraffin distribution list at all times due to the } \\
\text { 'rotation system' used by the municipality where some households } \\
\text { were skipped in order to provide everyone an equal chance to access } \\
\text { the paraffin services. }\end{array}$ \\
\hline
\end{tabular}


The linking actors' implementation of the FBAE policy is also influenced by the amount of information they receive from the implementing actor. The linking actors reported that they are not receiving enough FBAE information from the municipality and this affected the way they interacted with both the implementing and target actors. Table 10.8 illustrates how information affects and impacts on all the actors and how this results in different types of FBAE implementation processes in each study area.

Not having sufficient information about FBAE policy implementation influences the linking actors to respond in different ways to the policy and the situations presented by it. In some municipal areas the linking actors are in support of the target actors' ambitions to receive alternative energy services since they live in unelectrified areas - (see linking actors' motivations on Section 3.1.3). It is therefore natural that tensions and uncertainties arise when the linking actor does not have (enough) information to provide to the target actor about a service that is on the municipal plans. This is especially because the target actors expect the linking actors to have knowledge of the municipality's energy services plans since they are in their positions to bridge the information gap between the implementing and target actors. Some linking actors use the insufficient information as an excuse not to be accountable to the target actors' energy service's needs.

\subsubsection{Analysing the actors resources}

Resources are important for all actors to ensure proper implementation of the Free Basic Alternative energy (FBAE) policy. It is also obvious that without proper resources, not a lot can be done to accomplish the goals of policy implementation. It is therefore important to explain in-depth the type of resources that are needed for the implementation of a policy such as the FBAE, the importance of these resources and how these resources influence the actors' policy implementation processes.

According to Bressers (2004) and De Boer and Bressers (2011), resources are important to provide a capacity to act and are relevant as a source of 
power. Some examples of resources may vary from money, physical goods, skilled people, time, trust and political support. All actors, in one way or another, need resources for the successful implementation of a policy and may also depend on each other's resources for this purpose.

\section{The implementing actors' resources}

The implementing actors in the cases used for this study are all local municipalities tasked by the national government to provide FBAE services to indigent households. As explained in the previous chapters, each municipality can choose from the prescribed list on the policy document the type of alternative energy service to deliver as part of FBAE policy implementation (Department of Minerals and Energy, 2007). This service is partly subsidized by the national government and the municipalities are expected to contribute the shortfall of the funds needed to provide all indigent households with alternative energy services. For urban based municipalities it is easier to raise funds through revenue collection to subsidize some basic services for indigent households but, what is often neglected is that "not all municipalities have the same capacity to raise revenues as levels of poverty vary considerably and are particularly high in rural municipalities" (Kanyane, 2011). This is true for all the municipalities chosen as cases on this study as they are in the rural areas in a district located in one of the poorest provinces in the country due to high levels of income disparity where the majority of the population is poor and wealth is in the hands of a few (Makiwane and Chimere-Dan, 2012).

Four out of the five municipalities reported that they do not have sufficient funds to implement the FBAE policy in a satisfactory way. Some of the reasons may include municipalities not being able to provide the alternative energy services to everyone on the indigent register because of the cost of the energy service or that they are not able to fund the payment of personnel that would be responsible for providing FBAE services. 
In Table 10.9, it is explained how for each implementing actor, the lack of sufficient funds impacts on the implementation of the FBAE policy and how in turn this impacts on the other actors.

In Port St. Johns, even though the municipality was convinced that all the households will be provided with grid electricity by 2014, the Department of Energy had shifted the electrification targets to 2025 (11 years later). Furthermore, there is no guarantee that these will be grid installations as the government is investing in Renewable Energy Technologies for a more sustainable energy supply (Peters, 2013). Although it is not the most prominent The claimed lack of sufficient funding as a resource for this municipality influences the process of FBAE policy implementation in that this implementing actor has reason to avoid the service provision.

The King Sabata Dalindyebo municipality, due to its lack of staff capacity to work on FBAE implementation, has relied on the district municipality's figures of indigent households. These numbers are based on the data collected by the district municipality to estimate the number of indigent households in the entire district. Some local municipalities prefer not to rely on this data as they have concluded that it does not represent the true numbers of indigent households in each municipality but is based on rough estimates ${ }^{100}$. Use of this 'incorrect' data to apply for funding from provincial and national government to implement basic services such as FBAE leads to municipalities receiving insufficient funds that fail to cover all the expenses associated with service delivery by rural municipalities. The trickle-down effect of lack of sufficient funding as a resource is that it prevents the implementing actor from accomplishing its goals of providing alternative energy services for indigent households and even can restrict its motivation due to low self-effectiveness assessment.

\footnotetext{
100 Information obtained through interviews with various municipal representatives under the OR Tambo District. The information was also confirmed by the Nyandeni linking actor who said the data was not collected from all households.
} 


\section{Table 10.9: How insufficient funds and other resources influence the implementing actors' FBAE implementation process}

\begin{tabular}{|c|c|}
\hline Municipal Area & Implementing actors' lack of sufficient funds and other resources \\
\hline Port St. Johns & $\begin{array}{l}\text { Apart from lacking motivation to provide FBAE services because of the } \\
\text { claimed grid electricity connections planned for the near future, this } \\
\text { municipality stopped the provision of SHS maintenance to indigent } \\
\text { households. It also claimed that there were not enough funds to pay } \\
\text { the service provider even though money is provided by the national } \\
\text { and provincial government departments. }\end{array}$ \\
\hline Ingquza Hill & $\begin{array}{l}\text { Lack of a clear consultative process by the provincial government } \\
\text { department to this municipality has led lack of motivation. As a result } \\
\text { no time and staff training is invested on the delivery of FBAE services. }\end{array}$ \\
\hline $\begin{array}{l}\text { King Sabata } \\
\text { Dalindyebo }\end{array}$ & $\begin{array}{l}\text { This implementing actor blames the OR Tambo District for its lack of } \\
\text { sufficient funding for FBAE services. For funding purposes, this } \\
\text { municipality submitted the number of indigent households to the } \\
\text { national government as recorded by the district municipality. These } \\
\text { indigent household figures are much lower than what is on the ground } \\
\text { and this implementing actor finds itself without enough funding to } \\
\text { provide all indigent households with alternative energy services } \\
\text { through FBAE. }\end{array}$ \\
\hline Nyandeni & $\begin{array}{l}\text { This implementing actor, although still providing alternative energy } \\
\text { services for its indigent households, says that it is impossible to provide } \\
\text { this service for all households in need. This is blamed on the national } \\
\text { departments that give insufficient funds "without knowing the reality } \\
\text { faced by the rural municipalities"101. This implementing actor says it is } \\
\text { costly to provide this service to all indigent households because of the } \\
\text { other factors that have to be considered such as lack of proper road } \\
\text { infrastructure that makes it difficult and more expensive to reach } \\
\text { households in remote rural areas. }\end{array}$ \\
\hline Mhlontlo & $\begin{array}{l}\text { Compared to the other municipalities, this implementing actors' } \\
\text { strategy of FBAE policy implementation is more focused. It is the only } \\
\text { municipality in this study with a specific Free Basic Services office } \\
\text { where the FBAE services are organised. Although this municipality also } \\
\text { lacks sufficient funding for FBAE implementation, it is more active in } \\
\text { delivery of alternative energy services than the other municipalities. } \\
\text { The lack of sufficient funding stops this implementing actor from } \\
\text { providing more alternative energy services to its indigent households. }\end{array}$ \\
\hline
\end{tabular}

${ }^{101}$ Information extracted from face-to-face interview with the Nyandeni municipality representative on 08 May 2012 at Nyandeni. 
In Nyandeni the implementing actor's lack of sufficient funding leads to the municipality's inability to provide alternative energy services to its indigent households. The lack of sufficient funds as a resource has forced this municipality to find alternative ways to implement FBAE services. Similar to the street level bureaucrats (Lipsky 1980: 507), these municipalities "have to exercise discretion" and decide how to allocate the funds to FBAE services and other priorities and responsibilities within the municipality. The Nyandeni, King Sabata Dalindyebo and Mhlontlo municipalities have decided to provide 20 litres of paraffin as an FBAE service once in three months to indigent households. This strategy assists the municipality to ease the load of paraffin delivery on a monthly basis as this would be more expensive and quantities of paraffin per household would be much less. The consequences of lack of funding have forced these municipalities to be flexible in their implementation process in order to achieve their goals of providing alternative energy services to their indigent households.

Mhlontlo municipality's lack of sufficient funding for FBAE services prevents it to a small degree from providing paraffin to all the indigent households that need this service. Regardless of this insufficient funds, this municipality has employed staff entirely dedicated to Free Basic Services which include the provision of FBAE services. This department ensures that the indigent register is updated and credible, a strategy that guarantees access to funding from national government. Lack of sufficient funding as a resource has influenced this implementing actors' strategy to fund some of the FBAE policy implementation activities from its own funds.

Sufficient and dedicated staff is an important resource for implementing actors in the FBAE policy implementation process. Three of the five municipalities reported that they experienced a lack of sufficient and dedicated staff to implement the FBAE policy and provide alternative energy services to unelectrified indigent households. The Port St. Johns, King Sabata Dalindyebo and Nyandeni municipalities said they did not have enough staff members to work on FBAE policy implementation issues. This affected the implementing actors in different ways. As a resource, staff is important for provision of FBAE services because of the responsibilities 
involved in the delivery of alternative energy services, especially in the remote rural areas. The main challenge that these implementing actors faced was that the staff members they had were not only expected to be responsible for FBAE policy implementation, but had to be responsible for other tasks within the municipality. In fact, FBAE policy implementation was not their primary responsibility but an additional duty added to their existing responsibilities. This leads to implementing actors making decisions and choices on which responsibilities to work on and which to ignore or not pay much attention to. This re-emphasizes Lipsky's point on how civil servants (implementing actors) have to use their own discretion (Lipsky1980). Lack of staff as a resources impacts negatively on the delivery of services and on the households that are supposed to benefit from such services.

Ingquza Hill provides this study with an example that illustrates that even with a department dedicated to providing FBAE services, such as the Community Services department in this municipality, if the staff is not dedicated to the implementation process, nothing happens. This implementing actor previously delivered FBAE services through the Electrification Management department but had to transfer this responsibility to the Community Services department as per requirements of the provincial government. According to the municipality staff, the transfer process was not consultative and did not consider that the department where the duties were being transferred to did not have experience in delivering FBAE services. This has led to this department's lack of interest and motivation in the delivery of FBAE services to its indigent households. The implementing actor feels disempowered as it is not in a position to make concrete decisions on FBAE service provision due to constant intervention from the provincial government and the indecisiveness of the national government about the SHS programme in this area. The lack of experience as resources for the Ingquza Hill implementing actor has a negative impact on households as they are denied FBAE services such as SHS maintenance or provision of other Renewable Energy Technologies. 


\section{The target actors' resources}

In South Africa, depending on the geographical location and the type of area, it is common to find communities protesting for service delivery if they feel that their municipalities are not providing them with the best basic services. Due to the South African history where the majority of citizens did not have access to basic services prior to the rule of the democratically elected government in 1994, the provision of services such as water, sanitation and to an extent electricity - is viewed as a basic right. In urban areas especially where households pay rates to the municipality, communities feel that they have a right to question and demand the services they are paying for. In urban low-income areas, although there is a higher rate of non-payment for services, communities still feel that they are entitled to basic services such as water, electricity and sanitation and from time to time, protest against the municipality that is not providing them with these services. This is also linked to the Constitution Act of 1996 that protects the rights of citizens and specifies their right to an environment that is protected to benefit the current and future generations ${ }^{102}$. In protesting for provision of (modern) energy services, the citizens are often justified as they have the right to a clean environment where pollution and ecological degradation should be prevented.

In the rural areas such as the ones being researched in this study, service delivery protests are rare mainly because households do not pay for municipal services since most of them are considered to be indigent. It is also difficult for the municipality to collect revenue if it does not provide any services worthy of payment. For instance, households in the rural areas do not have purified running water and most of them still rely on rivers and dams. Sanitation services are also very basic as the municipality only supplies households with pit latrine toilets that do not flush due to inadequate water supplies. There are less work opportunities in the rural areas and people's circumstances often change for the worst as they experience poverty more than those in urban areas.

${ }^{102}$ Constitution - chapter 2, section 24 (b) 
While varying access to resources creates often mutual dependencies with effects on the balance of power among actors, in these cases targets lack most resources and are thus dependent and rather powerless. When analysing the target actors' resources in this study, it is clear that in all five municipal areas, the target actors do not possess resources that could assist them in receiving or improving their access to FBAE services.

The Port St. Johns and Ingquza Hill target actors had no strategy to approach the municipality where FBAE services were concerned. A strategic approach by the target actor when interacting with the implementing actor is useful in ensuring that the services needed are delivered or an explanation is provided for the lack of such services. In Port St. Johns, the target actor could not approach the implementing actor because of the past (negative) experiences and the relationship with the linking actor. In the Noqhekwana village, the target actor was never informed by the implementing and linking actors about the plans for energy services in the area. Even though the target actor inquired, there was no response to the community needs and information about the FBAE policy and its implementation was always withheld. After years of lack of energy services this community had decided not to take action against the implementing and linking actors and to remain without these services until a decision is made by the municipality to provide energy services. In Mthumbane township the target actor was also not informed about the FBAE policy and the alternative energy services that unelectrified indigent households qualified for, instead they were informed that they would be receiving grid electricity in the near future.

A strategy to approach the municipality about their energy needs would have been a beneficial resource for the target actors in Port St. Johns. An example of such a strategy would have been a demand for meetings with the implementing and linking actors to discuss the need for energy services in these areas. Due to lack of this resource (the strategy), the implementing actor continues to deny the indigent households of alternative energy services by not implementing the FBAE policy. 
In Ingquza Hill the lack of strategy to approach the municipality for alternative energy services has led to the indigent households' lack of FBAE services. The lack of resource to approach the implementing actor by the community has led the households to tolerate the presence of malfunctioning and out-of-use SHSs due to lack of maintenance services that were part of FBAE services once provided by the municipality. Although the community communicates their concerns with the linking actor, this does not guarantee that alternative energy services will be delivered by the municipality even though the linking actor passes the information on to the implementing actor.

In King Sabata Dalindyebo, Nyandeni and Mhlontlo the target actors depend on the implementing and linking actors for FBAE resources and like the target actors in Port St. Johns and Ingquza Hill, they lack the strategy to access alternative energy services according to their needs. Table 10.10 illustrates how each target actor depends on the implementing and linking actors for FBAE services.

The King Sabata Dalindyebo target actor is dependent on the implementing and linking actors because of the type of living conditions it is under. As mentioned in the King Sabata Dalindyebo case chapter, the KwaMpuku informal settlement is not provided with adequate basic services by the local municipality because it is built illegally on land not owned by the residence of this settlement. The municipality therefore is not allowed to provide services such as electricity nor to make promises to provide other types of service that requires permanent infrastructure to these households. This community relies on the implementing actor not to evict them from this land and to provide them with services such as FBAE in order to access alternative energy services since they have no access to grid electricity. For this community, the linking actor is a resource that makes it possible for the municipality to provide paraffin as part of the FBAE service. The linking actor records the names of households and ensures that all of them are registered as indigent households by the municipality. 


\section{Table 10.10: How target actors depend on implementing and linking}

actors for FBAE resources

\begin{tabular}{|c|c|}
\hline Municipal Area & Target actors depending on implementing and linking actors \\
\hline Port St. Johns & $\begin{array}{l}\text { The target actor relies on the linking actor to pass information to the } \\
\text { implementing actor about the energy needs of the households in the } \\
\text { townships and villages. The linking actors in this case were not } \\
\text { supportive of the target actor which has led to the target actor } \\
\text { remaining despondent about receiving alternative energy services from } \\
\text { the municipality. }\end{array}$ \\
\hline Ingquza Hill & $\begin{array}{l}\text { The target actor has no strategy to ensure that their energy services } \\
\text { needs are communicated to the implementing actor by the linking } \\
\text { actor. The target actor also has no knowledge of who to contact } \\
\text { regarding the malfunctioning solar systems as neither the } \\
\text { implementing and the linking actors have taken responsibility for these } \\
\text { systems or for providing alternative energy services. }\end{array}$ \\
\hline $\begin{array}{l}\text { King Sabata } \\
\text { Dalindyebo }\end{array}$ & $\begin{array}{l}\text { This target actor depends on the municipality for services such as } \\
\text { water, sanitation and most importantly land. The KwaMpuku informal } \\
\text { settlement does not have access to services because of being } \\
\text { established on land not earmarked for municipal services. The } \\
\text { implementing actor makes its own decisions whether to provide or } \\
\text { deny FBAE services to these households. This target actor also depends } \\
\text { on the linking actor because this is the only source of information } \\
\text { regarding FBAE services for this community. The linking actor also } \\
\text { advocates for this target actor to be provided with alternative energy } \\
\text { services due to the energy poverty of these households. }\end{array}$ \\
\hline Nyandeni & $\begin{array}{l}\text { The target actor relies on both the implementing and linking actors } \\
\text { because there is no access to grid electricity. The implementing and } \\
\text { linking actors collaborate to bring alternative energy services to these } \\
\text { households. Similar to the other target actors, this one also does not } \\
\text { have the strategy to bring adequate alternative energy services for all } \\
\text { unelectrified indigent households. }\end{array}$ \\
\hline Mhlontlo & $\begin{array}{l}\text { At Gqwesa village, the target actor relied on the implementing and } \\
\text { linking actors because the community did not have a strategy to access } \\
\text { alternative energy services. Being located in remote rural villages } \\
\text { where municipal representatives hardly ever visit, it was difficult for } \\
\text { this target actor to express their needs to the implementing actor even } \\
\text { with the linking actor's assistance. }\end{array}$ \\
\hline
\end{tabular}


In Nyandeni, the target actor relies on the linking actor to provide its household information to the implementing actor in order to be able to access alternative energy services. This reliance emphasizes the lack of strategy for these households to access alternative energy services on their own rather than depending on the implementing and linking actors. Relying on both these actors does not always guarantee that all the indigent households receive paraffin on distribution days as the indigent register is not often updated. The households continue to depend on these two actors because they know that this is the only way they will receive FBAE services.

The target actor in Mhlontlo relies on the implementing actor for bringing services to the villages. Being situated in a remote rural village such as Gqwesa makes it difficult for this target actor to make a choice on the type of alternative energy services the municipality provides. The reliance on implementing and linking actors has an influence in the way the FBAE policy is implemented. The implementing actor is often left to make its own decisions on the type of energy service to be provided as part of FBAE without consulting the households about their preferences. This decision is often based on the implementing actors' abilities and goals to provide a certain energy service. The linking actors are relied upon to ensure that household information reaches the municipality in order to be added on the indigent register.

\section{The linking actors' resources}

The linking actor is a resource for both the implementing and target actors but, in order to be effective, this actor needs access to its own resources. Access to resources for linking actors depends on how this actor interacts with the implementing and target actors. In cases where the linking actor has a good relationship with the implementing actor, it gains access to municipal resources and information. Similarly, if the linking actor has a good relationship with the target actor, it will have access to this actor's information and use this to benefit the target actors' needs, in this case provision of FBAE services. 
Table 10.11 shows that three out of the five municipal areas, the linking actors' main resource was their community leadership position which gave them access to the municipality. The leadership position in these cases guaranteed their access to municipal information such as the plans that the municipality has regarding a number of issues including energy service provision.

\section{Table 10.11: How linking actors' resources influence FBAE policy} implementation

\begin{tabular}{|l|l|}
\hline Municipal Area & Linking actors resources \\
\hline Port St. Johns & $\begin{array}{l}\text { Noghekwana village: this linking actor used their leadership position to } \\
\text { work closely with the implementing actor in avoiding FBAE } \\
\text { implementation and therefore not providing alternative energy } \\
\text { services. } \\
\text { Mthumbane township: This linking actor provided information to the } \\
\text { target actor from the implementing actor and the other way around as } \\
\text { a resource - they were still more beneficial as a resource for the } \\
\text { implementing actor than for the target actor. }\end{array}$ \\
\hline Ingquza Hill & $\begin{array}{l}\text { The linking actors have access to the municipality but are not fully } \\
\text { provided with the municipal plans regarding FBAE policy } \\
\text { implementation. The target actor cannot therefore fully rely on this } \\
\text { linking actor to provide information regarding FBAE services. }\end{array}$ \\
\hline King Sabata & $\begin{array}{l}\text { This linking actor had access to the local municipality as a ward } \\
\text { committee member. Most importantly this linking actor was a resource } \\
\text { that the indigent households in KwaMpuku could rely on if they needed } \\
\text { information about FBAE (and other) services. }\end{array}$ \\
\hline Nyandeni & $\begin{array}{l}\text { Access to the municipality as Ward Councillors gave these linking actors } \\
\text { access to the municipality. The leadership position in the community } \\
\text { made them reliable sources of information for the municipality as well. }\end{array}$ \\
\hline Mhlontlo & $\begin{array}{l}\text { The linking actors have access to the municipality but are not fully } \\
\text { provided with the municipal plans regarding FBAE policy } \\
\text { implementation. }\end{array}$ \\
\hline
\end{tabular}

In the case of Port St. Johns, the Noqhekwana village linking actor was not favoured by the community because of how he used his leadership position to prevent the indigent households access to alternative energy services that would have been delivered through the implementation of the FBAE policy.

Leadership as this actors' main resource has influenced FBAE policy implementation in this area by ensuring that the implementing actor's 
motivations of waiting for grid electricity remain unchanged. In Mthumbane township, the implementing actor's leadership position provided him with a resourceful position where he could obtain information about energy services from the municipality and share with the community. However, this linking actor's actions supported attaining the goals of the implementing actor rather than those of the target actor. This actor influenced the FBAE implementation process by not advocating for the delivery of FBAE services to unelectrified indigent households in this village and agreed with the implementing actor that it would be best to for these households to wait for grid electricity.

The leadership position as a resource provided the King Sabata Salindyebo linking actor an advantage to have access to the municipality. This situation allowed this linking actor to have privileged access to some information regarding the FBAE policy and the municipality's plans for implementing it. This linking actors' goal is to be supportive of both the implementing and target actors. By knowing what the municipality's plans are, it can provide support for the implementing actor as well as advocating for the alternative energy services for indigent households in the KwaMpuku settlement.

In Nyandeni, the linking actor had access to the municipality and its plans on FBAE policy implementation. This actor also used its leadership position as a resource to obtain information from indigent households on their alternative energy needs. The linking actor in Nyandeni used its leadership position to influence the FBAE policy implementation process by assisting the municipality with access to household information in order to compile the indigent register. This position also made it easy for the households to trust this linking actor with their personal details as they knew that they would benefit from the delivery of alternative energy services to their areas.

The Ingquza Hill and Mhlontlo linking actors have limited access to resources to implement the FBAE policy. These linking actors rely on the municipality to provide them with information about the provision of alternative energy services. In Ingquza Hill, the linking actor had limited knowledge about the implementing actors' plans in respect of the 
maintenance of SHSs for indigent households. The implementing actor had stopped the maintenance services but could not provide confirmation on whether this service would continue or not. As the linking actor is relied upon by the target actor - the relationship between the two actors become strained if the linking actor cannot provide information on services that are needed by the target actor. In Chitwayo village, the linking actor could not provide the households with information on whether the municipality will continue to provide maintenance services for households with SHSs. In this case, the linking actors' limited access to the municipality's plans as a 'lacking resource' has influenced the FBAE policy implementation process as it has left the indigent households without important information.

Limited access to resources for the Mhlontlo linking actor means that this actor cannot provide full support to both the implementing and target actors in the FBAE policy implementation process. Similar to the Ingquza Hill implementing actor, this actor does not have full access to the implementing actor and therefore is not always knowledgeable of the FBAE services plans. As a link with the implementing actor and as an information provider for the target actors, due to limited access to resources such as the municipality, this linking actor cannot fully engage in fulfilling its goals of providing support to the target and implementing actors where FBAE policy implementation is concerned.

\subsubsection{Analysing the power attributed to the actors}

The use of the concept of power as an actor characteristic in this thesis is concerned with attribution of power by others as described in the Contextual Interaction Theory (Bressers, 2004). Each actors' power depends in the first instance on how the other actors view them depending on their position in society, the community or the policy implementation process. When not clearly falsified, such attributed power can remain in-tact for a long time. When challenged, attributed power needs to be shown to be backed-up by relevant access to resources. Some examples of obvious power attribution aspects include communities viewing municipalities as having the power to implement policies, or communities having the power 
to decide the types of energy services they want from municipalities, or linking actors having the power to convince the municipality to provide certain types of energy services for communities. The attributed power also shapes the actor's behaviour and response to the policy implementation process. Below is the analysis of power as an actor characteristic that influences Free Basic Alternative Energy (FBAE) policy implementation for all three actors in this study.

Table 10.12: How implementing actors influence the FBAE policy process through their power

\begin{tabular}{|l|l|}
\hline Municipal Area & Implementing actors' power to decide of FBAE services \\
\hline Port St. Johns & $\begin{array}{l}\text { This implementing actor uses its decision-making powers to ignore the } \\
\text { directive to provide alternative energy services as part of FBAE policy } \\
\text { implementation. This actor's decision is based on the belief that grid } \\
\text { electricity will be available for all households under its municipality, } \\
\text { therefore no need for alternative energy services. }\end{array}$ \\
\hline Ingquza Hill & $\begin{array}{l}\text { This implementing actor decided to halt FBAE services in order to } \\
\text { review whether the municipality could afford the solar maintenance } \\
\text { services it was providing. Halting the services was also in retaliation to } \\
\text { the provincial government's decision to shift FBAE services from one } \\
\text { department to another within this municipality. }\end{array}$ \\
\hline King Sabata & $\begin{array}{l}\text { The power to decide on the implementation process is attributed to } \\
\text { this actor by the target and linking actors. They await direction from } \\
\text { the implementing actor based on the decisions it has made. In } \\
\text { KwaMpuku, the linking actors knows that the implementing actor } \\
\text { makes decisions on the type of alternative energy services delivered } \\
\text { and the time of delivery. }\end{array}$ \\
\hline Nyandeni & $\begin{array}{l}\text { This implementing actor has the power to select the households that } \\
\text { qualify for FBAE services based on the resources available. }\end{array}$ \\
\hline Mhlontlo & $\begin{array}{l}\text { The implementing actor has power on how FBAE services are delivered } \\
\text { to indigent households - also based on its local circumstances. This } \\
\text { actor makes decisions best suited for its local conditions such as the } \\
\text { household needs and what it can realistically deliver. }\end{array}$ \\
\hline
\end{tabular}

\section{Power attributed to the implementing actors}

Power to decide on the Free Basic Alternative Energy (FBAE) policy implementation process is one of the actor characteristics displayed the implementing actors in this study. The King Sabata Dalindyebo, Nyandeni and Mhlontlo implementing actors influence the policy implementation process through their power to decide the type of alternative energy 
services to deliver to unelectrified indigent households. The Ingquza Hill and the Port St. Johns implementing actors influence the FBAE policy process through their power to decide to stop the delivery of solar maintenance services for various reasons. In Table 10.12 illustrates how these implementing actors use this power to implement the FBAE policy.

In King Sabata Dalindyebo, the power attributed to the implementing actor by the target and linking actors makes it easy for this implementing actor to decide on how best to implement the FBAE policy. Given the circumstances that this implementing actor has to work under, for example: lack of staff, insufficient funds and lack of updated household information - having power to decide how to implement this policy is helpful. Although this implementing actor's decision is influenced by other factors such as pressure from the provincial and national government departments as well as the local politics, having power to decide on the FBAE implementation process helps with realistically dealing with the circumstances it faces.

In Nyandeni, the power attributed to the implementing actor by the target and linking actors allows this actor to make decision on the delivery of alternative services as it sees fit. Similar to the King Sabata Dalindyebo implementing actor, this actor is faced with various circumstances influence the decisions it makes when implementing the FBAE policy. For the Nyandeni implementing actor, having the power to decide on which households are to receive the FBAE services and the frequency of delivery (for example: 20 litres once in three months) assists this municipality is spreading its limited funds.

In Mhlontlo, the implementing actor also had the power to decide on the type of service to offer indigent households as part of FBAE services. Similar to the other two municipalities, this implementing actor also exercised power of selection when deciding the number of households that could receive paraffin. This is due to limited funding which prevents implementing 
actors to deliver these alternative energy services to all households on their indigent registers. This implementing actor also used it power to access support from the district municipality for purposes of registering indigent households in order to ensure more efficient delivery of FBAE services to these households. As this municipality had a department dedicated to FBAE services and could display their achievements in FBAE service delivery, this gave the implementing actor power to convince the district municipality to offer it assistance to further its work.

For all the three implementing actors analysed above, it is clear that their power influences the FBAE implementation process. These actors have used this power attributed to them to make decisions that best suit their circumstances and conditions such as being rural-based municipalities with insufficient funds and having more households on the indigent register than they can sufficiently provide alternative energy services to.

Power attributed by others can also have negative consequences for the actors involved. In Port St. Johns and Ingquza Hill, the implementing actors were seen to be in the powerful position by the target and linking actors. This was due to the obvious fact that the municipality is in charge of decision-making for the town and all its areas where service delivery is concerned. Therefore, the implementing actor was seen to have power to make all the decisions for the benefit of all the inhabitants of the municipality. In the Noqhekwana village, the community saw the implementing actor as a powerful actor and the negative effects of this is that this actor could not even be approached and questioned about the decisions it had taken concerning the provision of energy services for this village. This target actor saw the implementing actor as exercising its power by not responding to the communities' energy needs and avoiding the implementation of the FBAE policy.

In Ingquza Hill, the implementing actor was also regarded as having the power to decide on the delivery of energy services. When this implementing actor decided to halt the SHS maintenance services for unelectrified indigent households, it did not consult with the community nor with the linking actor. Although the decision was taken by this 
implementing actor to review its alternative energy distribution strategy, this was not well communicated with the target and linking actors and made it difficult for these actors to ask questions as they did not know who to approach. The households did now know whether the SHS maintenance services would be revived by the implementing actor or they would be receiving grid electricity. The implementing actors' silence and decisionmaking also put the linking actor in an awkward position where they did not know the implementing actors' plans and therefore could not respond to the target actor's questions about alternative energy service delivery in their areas.

\section{Power attributed to the target actors}

When comparing the target actors' attributed power, one can deduce that it is possible for this actor to be thought of having power to decide the type of alternative energy services to be delivered through the implementation of the FBAE policy. In the analysed cases concerned with the five municipalities, the target actors' voices are muted when it comes to the implementation of this policy. First, although the FBAE policy document considers the households - the final decision on the energy service to be received by these households lies with the municipality and is based on what the implementing actor sees as viable to implement. The households are therefore given the particular energy source without much consultation on whether this is their preferred fuel or technology and whether such an energy service meets their needs. Due to their circumstances such as poverty, these households also perceive themselves as powerless to make such energy decisions and influence the municipality and therefore often leave this responsibility to the implementing actor. In cases where they have views about the energy services, the households in the areas studied for this thesis approach the linking actor whom they trust will speak and act on their behalf where the municipality is concerned. These target actors' lack of decision-making power influences the FBAE policy implementation process and the behaviour of the implementing and linking actors. 
When analysing the cause of the lack of power experienced by these target actors, the following conclusions can be drawn for each target actor based on the information extracted from the interviews conducted for this study in all the five municipal areas under the OR Tambo district.

1. Port St. Johns: The target actor had no decision-making power about FBAE policy implementation as this decision was left to the implementing actor and supported by the linking actor in both Noqhekwana village and Mthumbane township. The target actors' voice was not heard nor considered and at the end this actor took a decision to remain silent and wait for the implementing actor to make its decisions regarding provision of energy services. This actors' power was also taken away by being denied access to information about the FBAE policy. By withholding FBAE policy information, the implementing actor ensured that it could avoid the implementation of this policy as well as expectations from the target actor for this policy to be implemented.

2. Ingquza Hill: The target actor did not have any power to decide on the type of alternative energy service it could access through the FBAE policy implementation process. When the households in Chitwayo village applied for the SHSs as part of the national renewable electrification programme in the early 2000s, they had agreed to pay the monthly service fees under the conditions that they would not attempt to maintain the system themselves. When the programme was handed over to the local municipality by the national government department it created uncertainties for the households and the municipality. The municipality was expected to take over the maintenance of these systems and subsidize more than $90 \%$ of the payment for the maintenance services whilst collecting less than $10 \%$ in fees from the households. The municipality did not have the capacity nor enough funds to do this and eventually decided to stop providing this maintenance service whilst the households were left without an alternative to other energy services. At the end, no power was attributed to the household by the implementing and linking actors to make the decision about the alternative energy services they were receiving. In this case, even the government energy department did not 
attribute any decision-making power to the households when it handed the programme to the local municipality.

3. King Sabata Dalindyebo: The target actor could not make decisions on the type of alternative energy services it preferred from the municipality as part of the FBAE policy implementation process. The indigent households in KwaMpuku informal settlement were provided with paraffin as part of FBAE services but could not request an alternative. This target actor's location does not give it the right to demand services as the municipality considers these households as occupying land illegally. Having no right and access to own land has made this target actor voiceless and without guarantee that they will receive services they request from the implementing actor. The municipality does not attribute any decision-making power nor even influence to this target actor regarding service delivery.

4. Nyandeni: This target actor had no decision-making power about the type of alternative energy service it received from the implementing actor. The municipality decided the type of energy service based on its budget and capacity and the target actor accepted this decision because of the energy poverty experienced by indigent households and the need to meet household energy needs. Similar to the other target actors, this one also accepts decisions made by the implementing actor.

5. Mhlontlo: This target actor is similar to the other target actors as it also accepted decisions made by the implementing actor on the type of energy service delivered as part of FBAE services. The Gqwesa village community, an impoverished remote rural village has no access to municipal services and most of the households here are indigent and depend on the government for social services. There is no attribution of power by the municipality to this community to make its decisions on the energy services they receive.

The points mentioned above illustrate that target actors do not have much power attributed to them where the implementation of the FBAE policy is concerned. Their lack of power influences the policy implementation as decisions are left to the implementing actors and some to the linking actors. 


\section{Power attributed to the linking actors}

As mentioned above, linking actors have an important role to play between the implementing and target actors. They bridge the gap between the two actors through communicating each actors needs and plans to the other actor. Both the implementing and target actors expect this actor to satisfy their needs and provide assistance to them in order to achieve their goals. In the process of Free Basic Alternative Energy (FBAE) policy implementation, the linking actor has a role to ensure that alternative energy services are delivered to the target actors and that the implementing actors fulfil their mandate to deliver these services.

Table 10.13: Influence of power on the FBAE policy implementation process

\begin{tabular}{|l|l|}
\hline Municipal Area & Influence of power on the implementation process \\
\hline Port St. Johns & $\begin{array}{l}\text { Power attributed by the implementing actor to support its service } \\
\text { delivery decisions. Power attributed by the target actor makes it easy } \\
\text { to ignore community needs. }\end{array}$ \\
\hline Ingquza Hill & $\begin{array}{l}\text { Power attributed by the target actor in trusting that the linking actor } \\
\text { communicates their needs to the implementing actor. Not much power } \\
\text { is attributed to this actor by the implementing actor, hence no power } \\
\text { to make decisions regarding the delivery of energy services such as } \\
\text { FBAE. }\end{array}$ \\
\hline Daling Sabata & $\begin{array}{l}\text { Power attributed by the target actor in trusting that the linking actor } \\
\text { communicates their needs to the implementing actor. Not much power } \\
\text { is attributed to this actor by the implementing actor, but still retains } \\
\text { some decision-making power about paraffin distribution. }\end{array}$ \\
\hline Nyandeni & $\begin{array}{l}\text { Power attributed by the target actor in trusting that the linking actor } \\
\text { communicates their needs to the implementing actor. Power attributed } \\
\text { by the implementing actor to collect household information that is } \\
\text { important in the delivery of FBAE services. }\end{array}$ \\
\hline Mhlontlo & $\begin{array}{l}\text { Attributed power by the target actor to assist the households in } \\
\text { accessing services from the municipality. Power attributed by the } \\
\text { implementing actor to collect household information that is important } \\
\text { in the delivery of FBAE services. }\end{array}$ \\
\hline
\end{tabular}

When looking at power as a linking actor's characteristic that influences the implementation of the FBAE policy, it is important to analyse the type of power. Power is attributed to the linking actors by the other actors and in 
turn, this influences the way the linking actor contributes to the implementation of the FBAE policy.

The linking actors representing the five study areas had different power experiences in the way they used power that was attributed to them and in the way their power affected the other actors and influenced the FBAE policy implementation process. Table 10.13 presents a list of observations related to the linking actors' attributed power. It is followed by an in-depth explanation of each observation relating it to the influence of this attributed power to the policy implementation process.

In Port St. Johns' Noqhekwana village, the linking actor was said to have ignored the community's needs for alternative energy services. Even though the linking actor was elected through the local elections by the community to represent them in the municipality, this position is associated with decision-making power. The community itself saw this linking actor as having power to directly communicate and be part of the municipal structure whilst holding a high position within the community. Ignoring the community needs for alternative energy services meant that this linking actor supported the implementing actor's decision to avoid the implementation of the FBAE policy by not providing FBAE services such as maintenance of SHSs for unelectrified indigent households. In this case, the linking actor has influenced the FBAE implementation process by exhibiting support for the municipality and ignoring the community. Also within Port St. Johns, the Mthumbane township linking actor ignored community needs for alternative energy services by promoting the municipality's belief that grid electricity will be provided to all households in the near future. Even though the Mthumbane township unelectrified indigent households were not vocal about their needs for alternative energy services, the linking actor knew that this service would be useful in the absence of grid electricity. In order to support the municipality on avoiding the implementation of the FBAE policy, this linking actor had to turn a blind eye to the community's needs for alternative energy services.

The Ingquza Hill linking actor, although a Chief and highly respected in the community because of this leadership position, did not have much power 
with persuading the municipality to deliver alternative energy services to the community as part of the FBAE policy implementation strategy. This linking actor was still relied on by the community as the indigent households with solar systems in this area still hoped for maintenance services from the municipality. Since the municipality did not communicate its intentions and plans with the community regarding the delivery of alternative energy services, the linking actor became the only source of information for the target actor. The linking actor's lack of decision-making power highlights the power dynamics in this case and shows that the implementing actor holds more power in deciding about alternative energy services for the communities of this area. This is also an observation that can be made by the indigent households that are expecting the linking actor to use their power to advocate for their access to alternative energy service.

The King Sabata Dalindyebo linking actor is also in an elected position which the community has given to her. By electing this linking actor, the community has attributed some power to her and placed her in a position where she can be the link between the implementing and the target actors. This implementing actors' goals were to support both the implementing and linking actors in making it possible for indigent households to access alternative energy services as part of the FBAE policy process. By attributing power to this linking actor, the target actor has allowed her to negotiate on their behalf in instances where indigent households face threats of not being provided with paraffin because they are not listed on the indigent register. This linking actor uses this power to make the paraffin distributer understand that these households need the fuel because of the poverty they are experiencing and to make the distributer aware that it is the municipality's fault and lack of capacity that these households are not on the register - and not the fault of the households.

The Nyandeni and Mhlontlo linking actors had limited power to bring FBAE services to the community and depended on the municipality for this service. In this case, decision-making about the alternative energy sources to be delivered to indigent households mainly rested on the hands of the 
implementing actors. The limited power of these implementing actors is concerned with the access to household information which they collect for the municipality's indigent register. Their knowledge and access to the communities gives them some power to access household information that is used in order to provide alternative energy services for households.

\subsection{Results of actor characteristics' interaction process}

In comparing the FBAE policy interaction process across all actors using the Contextual Interaction Theory's (CIT) illustration of the dynamic interaction between the key actor characteristics (Bressers 2007), it is possible to see how these actor characteristics influence each other. For purposes of this analysis I have summarised the results of the actor characteristics interaction processes for all actors with the aim of showing their similarities and differences in the FBAE policy implementation process. Table 10.14 shows how motivations, cognitions and capacity and power overlap to produce the 'results of mutual influence' as termed in CIT. Analysing the actor's focus of attention shows that implementing actors levels of attention on FBAE implementation are low. This means although this actor may have motivations to implement the policy successfully through the delivery of FBAE services, situations such as lack of information and resources may discourage the actor's focus on this policy. The target actors' attention is on the municipalities to provide FBAE services. This is understandable as these are indigent households that depend on government for their basic needs and can hardly afford to pay for energy services. Linking actors also depend on the implementing actors to deliver FBAE services as they cannot do this themselves due to lack of necessary resources, power and information.

Actors' perceptions of opportunities and threats are also analysed as outcomes of motivations and cognitions. For all actors in this study, lack of information came up as a threat to delivery of and access to FBAE services. As discussed above, information in these municipal cases refers mainly to household's information that is gathered for the purposes of compiling indigent registers. Without a credible indigent register, it is difficult for a 
municipality to have access to adequate funds to implement the FBAE policy. Information for the target actors refers to the information that is supposed to be made accessible to them by the implementing and linking actors about the FBAE policy and the municipality's plans to deliver alternative energy services through this policy. The linking actor's lack of information refers to the information they are not receiving from the implementing actors about the plans for the FBAE service delivery. This places these actors in a difficult position as they cannot give reasons to the target actors as to why the FBAE services are not delivered.

The combination of cognitions and capacity and power as actor characteristics give rise to an assessment of the implementation strategy that actors may have and the value of this strategy in the whole policy implementation process. The analysis of all implementing actors in the study shows that these actors have a limited strategy to implement the FBAE policy due to lack of information. Lack of information deprives the implementing actor of the knowledge it requires about the number of indigent households it needs to provide alternative energy services to. This makes it impossible to raise sufficient funding for delivery of these services. Without information, target actors also lack strategy to access FBAE services from municipalities. Relevant information about the FBAE policy would give target actors an insight of what they could expect, demand or negotiate for from the implementing and linking actors. Lack of decisionmaking power has made it impossible for the linking actors to ensure delivery of FBAE services according to target actors' needs. Although linking actors have access to some of the implementing actors' information and FBAE delivery plans - they do not have the power and resources to provide these services to the indigent households. 
Table 10.14: Results of actor characteristics interaction process

\begin{tabular}{|c|c|c|c|c|}
\hline $\begin{array}{l}\text { Actor } \\
\text { charact } \\
\text { eristics }\end{array}$ & $\begin{array}{l}\text { Result of } \\
\text { mutual } \\
\text { influence } \\
\end{array}$ & Implementing actor & Target actor & Linking actor \\
\hline \multirow{2}{*}{ 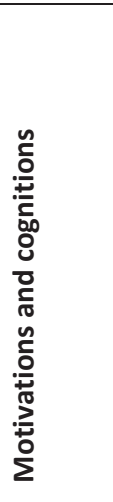 } & $\begin{array}{l}\text { Focusing } \\
\text { attention }\end{array}$ & $\begin{array}{l}\text { - Four out of five } \\
\text { municipalities } \\
\text { displayed low levels } \\
\text { of focus on FBAE } \\
\text { implementation }\end{array}$ & $\begin{array}{l}\text { - Due to lack of } \\
\text { information, the } \\
\text { focus of attention } \\
\text { on municipality to } \\
\text { provide FBAE } \\
\text { services }\end{array}$ & $\begin{array}{l}\text { - Mainly focused on } \\
\text { municipality to } \\
\text { provide FBAE and } \\
\text { other services }\end{array}$ \\
\hline & $\begin{array}{l}\text { Perceptio } \\
n \text { of } \\
\text { opportuni } \\
\text { ties and } \\
\text { threats }\end{array}$ & $\begin{array}{l}\text { - Opportunity to } \\
\text { successfully } \\
\text { implement FBAE } \\
\text { policy if there is } \\
\text { sufficient } \\
\text { information and } \\
\text { motivation }\end{array}$ & $\begin{array}{l}\text { - Lack of information } \\
\text { a threat to accessing } \\
\text { FBAE services }\end{array}$ & $\begin{array}{l}\text { - Lack of information } \\
\text { a threat to delivery } \\
\text { of FBAE services. } \\
\text { - FBAE may bring } \\
\text { relief to indigent } \\
\text { household }\end{array}$ \\
\hline \multirow{2}{*}{ 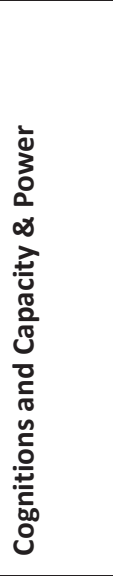 } & $\begin{array}{l}\text { Strategic } \\
\text { value }\end{array}$ & $\begin{array}{l}\text { - Information } \\
\text { availability such as } \\
\text { household data and } \\
\text { FBAE policy info is } \\
\text { important for } \\
\text { developing an } \\
\text { implementation } \\
\text { strategy }\end{array}$ & $\begin{array}{l}\text { - No strategy in } \\
\text { accessing better } \\
\text { FBAE services or } \\
\text { ensuring that } \\
\text { municipality } \\
\text { (always) delivers } \\
\text { these services }\end{array}$ & $\begin{array}{l}\text { - No strategy due to } \\
\text { lack of decision- } \\
\text { making power and } \\
\text { resources, even } \\
\text { though there is } \\
\text { access to } \\
\text { information. }\end{array}$ \\
\hline & $\begin{array}{l}\text { Data } \\
\text { search } \\
\text { and } \\
\text { processin } \\
\text { g capacity }\end{array}$ & $\begin{array}{l}\text { - Four out of five } \\
\text { municipalities had } \\
\text { low data search and } \\
\text { processing capacity }\end{array}$ & $\begin{array}{l}\text { - Overall, very low } \\
\text { data search and } \\
\text { processing capacity, } \\
\text { hence lack of } \\
\text { information } \\
\text { regarding FBAE } \\
\text { services }\end{array}$ & $\begin{array}{l}\text { - Data search } \\
\text { capacity but low } \\
\text { processing capacity } \\
\text { as this depends on } \\
\text { the municipality }\end{array}$ \\
\hline \multirow{2}{*}{ 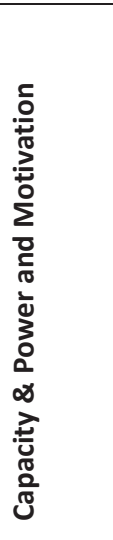 } & $\begin{array}{l}\text { Relevance } \\
\text { of } \\
\text { resources } \\
\text { for } \\
\text { intended } \\
\text { action }\end{array}$ & $\begin{array}{l}\text { - Skilled staff, funds } \\
\text { and information are } \\
\text { relevant resources } \\
\text { for FBAE delivery }\end{array}$ & $\begin{array}{l}\text { - Resources such as } \\
\text { knowledge, } \\
\text { supportive linking } \\
\text { and implementing } \\
\text { actors are relevant } \\
\text { for access to FBAE } \\
\text { services }\end{array}$ & $\begin{array}{l}\text { Need for adequate } \\
\text { resources such as } \\
\text { decision-making } \\
\text { power to deliver } \\
\text { FBAE services }\end{array}$ \\
\hline & $\begin{array}{l}\text { Availabilit } \\
y \text { of } \\
\text { resources } \\
\text { for } \\
\text { intended } \\
\text { action }\end{array}$ & $\begin{array}{l}\text { - Limited access to } \\
\text { resources. } \\
\text { Sometimes, access } \\
\text { to resources does } \\
\text { not guarantee } \\
\text { successful } \\
\text { implementation }\end{array}$ & $\begin{array}{l}\text { - Lack of resources } \\
\text { makes it difficult to } \\
\text { achieve goals }\end{array}$ & $\begin{array}{l}\text { Overall limited } \\
\text { access to resources } \\
\text { that make it } \\
\text { possible to provide } \\
\text { FBAE services to } \\
\text { indigent households }\end{array}$ \\
\hline
\end{tabular}


Data search and processing capacity as a result of analysing the overlap between cognitions and capacity and power actor characteristics reveals the importance of information use in the implementation of the FBAE policy. As mentioned above where the indigent register is concerned, the implementing actor's low data search and processing capacities have led this actor across the majority of the studied cases to not having credible indigent registers. This is linked with the lack of skills, capacity and funding where municipalities have difficulties in compiling the indigent register. The target actor had no data search and processing capacity but had information (data) that was relevant and important for the implementing and linking actors in the compilation of indigent registers. The linking actor had data search capacity as it was tasked by the implementing actor to collect household information. This activity was made possible by the fact that linking actors lived with the target actors and therefore had easy access to information that is relevant and important for compiling indigent registers. Due to lack of resources, the linking actor did not have strong data processing capacity to enable the delivery of FBAE services. Instead, this actors' data processing capacity was limited to the data it collected but not data it handed over to the implementing actor.

Table 10.14 shows that one of the resulting influences from this process is analysing the relevance of resources for the intended action. In these cases, the intended action is the implementation of the FBAE policy. For the implementing actors, the resources that are relevant for the implementation of this policy are skilled staff, funds and information. For the target actor, the relevant resources for accessing FBAE services is information and 'own-voice'. This actors' lack of access to information has deprived it of relevant resources which has made it difficult for this actor to express its needs to the implementing actor - and to some extent, to the linking actor. For the linking actor, decision-making power is a relevant resource that it needs to be able to provide access to FBAE services for the target actor. Both the implementing and linking actors in all the studied areas had limited access to resources. For the implementing actor, access to resources was highly dependent on others such as the national and provincial government departments - but this was also influenced by this 
actor's access to information and its motivations to implement the policy. The linking actor's limited access to resources was due to its dependence on the implementing actor for FBAE policy implementation. Although this actor had access to household information that it provided to the implementing actor - it could not guarantee that this information would be used to benefit the indigent households by providing them with alternative energy services through FBAE. The target actor had no access to resources and in all areas of comparison, relied on both the implementing and linking actors for the delivery of FBAE services.

\section{Comparing the relations among actors and the implementation success}

The interaction is not confined to the actor characteristics only, the actors themselves do interact too. These interactions are influenced by the separate actor characteristics and the interactions among them. In order to round up the study, it is important to summarise again the success level of FBAE policy implementation in each area and to compare this with the actor interaction patterns. The case study chapters and the comparative analysis have provided an analysis of how the implementation process took place and the reasons for this process but they do not explicitly state whether the policy was implemented successfully or not.

Keeping in line with the previous sections, it is important to look at how the relationships between actors have influenced the implementation process and eventually how this leads to the implementation success or failure in each case. Using the three-actor model (see Figure 3.5 in Chapter 3 and Figure 10.5), I summarise the actor relationship by picking some of the key issues that lead to strengths and weaknesses of the actor relationships and how these contribute to the whole FBAE policy implementation process in these areas. A strong actor-relationship may be characterised by actors working together for the common goal, sharing information and taking care of each other's needs. A weak actor-relationship may be characterised by lack of common interests and goals with regards to the implementation process, withholding information from each other and not considering each 
other's needs. Where the actor-relationship is neither weak nor strong, I define it as one-sided. This is where one actor seems stronger and has more authority than the other actor.

The three-actor model is a contribution of this study to the diversification of the Contextual Interaction Theory which has always illustrated the actor interaction process in a two-actor model (see Figure 3.1 in Chapter 3). In the series of figures (see Figure 10.5), the use of solid and dashed lines with arrows illustrates the strength and weakness of the relationships between the actors, and in turn how this influences the implementation of the policy.

For the Port St. Johns case, the model shows that the relationship between the implementing and the linking actors is strong while the relationship between the implementing and the target actor is weak. The relationship between the linking and the target actor is also weak. This summary is based on the information analysed in the previous chapters. The number of strong and weak relationships between actors in each case can indicate the level of success of the implementation process. In Port St. Johns for instance, the weak relationships between the key actors have led to unfavourable implementation conditions and this has led to a failed implementation process where the key actors have given up on making it successful.

The analysis of the actor-relationships for the Ingquza Hill case reveals a weak relationship between the implement and the target actors, a onesided relationship between the linking and the implementing actor as well as between the linking and the target actors. Lack of communication and information exchange about the FBAE services has led to the weak relationship between the implementing and the target actor. The relationship between the linking and the implementing actor is one-sided because the implementing actor does not involve the linking actor in making decisions about the provision of alternative energy services as part of the FBAE policy implementation process. The relationship between the linking and target actors is one-sided because although the linking actor has information about the households' energy needs, the target actor cannot 
rely on the linking actor for assistance because this actor is not accessible to the target actor. The overall Ingquza Hill case analysis and this actorrelationship analysis leads to the conclusion that this case's implementation success is low but the municipality keeps seeking opportunity to implement the policy better.

In King Sabata Dalindyebo the relationship between the linking and implementing actors can be summarised as weak as well as the relationship between the implementing and the target actors. This is due to lack of information exchange about plans regarding the implementation of the FBAE policy and the fact that the target actor is voiceless in issues concerning the planning of service delivery. On the other hand the relationship between the target actor and the linking actor is strong where the target actor depends on the linking actor for energy service delivery information and to play a mediator role between the target actor and the implementing actor. Taking all of this into consideration and the analysis given in Chapter 7 about the King Sabata Dalindyebo case, one can conclude that this case's implementation success is very low.

The Nyandeni actor-relationship case analysis shows a strong relationship between the linking and the implementing actors. The strength of the relationship is due to the support that is given by the linking actor to the implementing actor in its efforts to deliver alternative energy services. The implementing actor strengthens the relationship by sharing some implementation information with the linking actor. The relationship between the implementing and the target actor is weak as well as the relationship between the linking and the target actor. Similar to the other cases analysed in this study, the target often does not have access to implementation plans by the implementing actor. The case analysis in Chapter 8 has revealed that the Nyandeni implementing actor, although trying to deliver services as successfully as possible, there is a lack of internal support for its efforts which results in mediocre FBAE policy implementation success. 


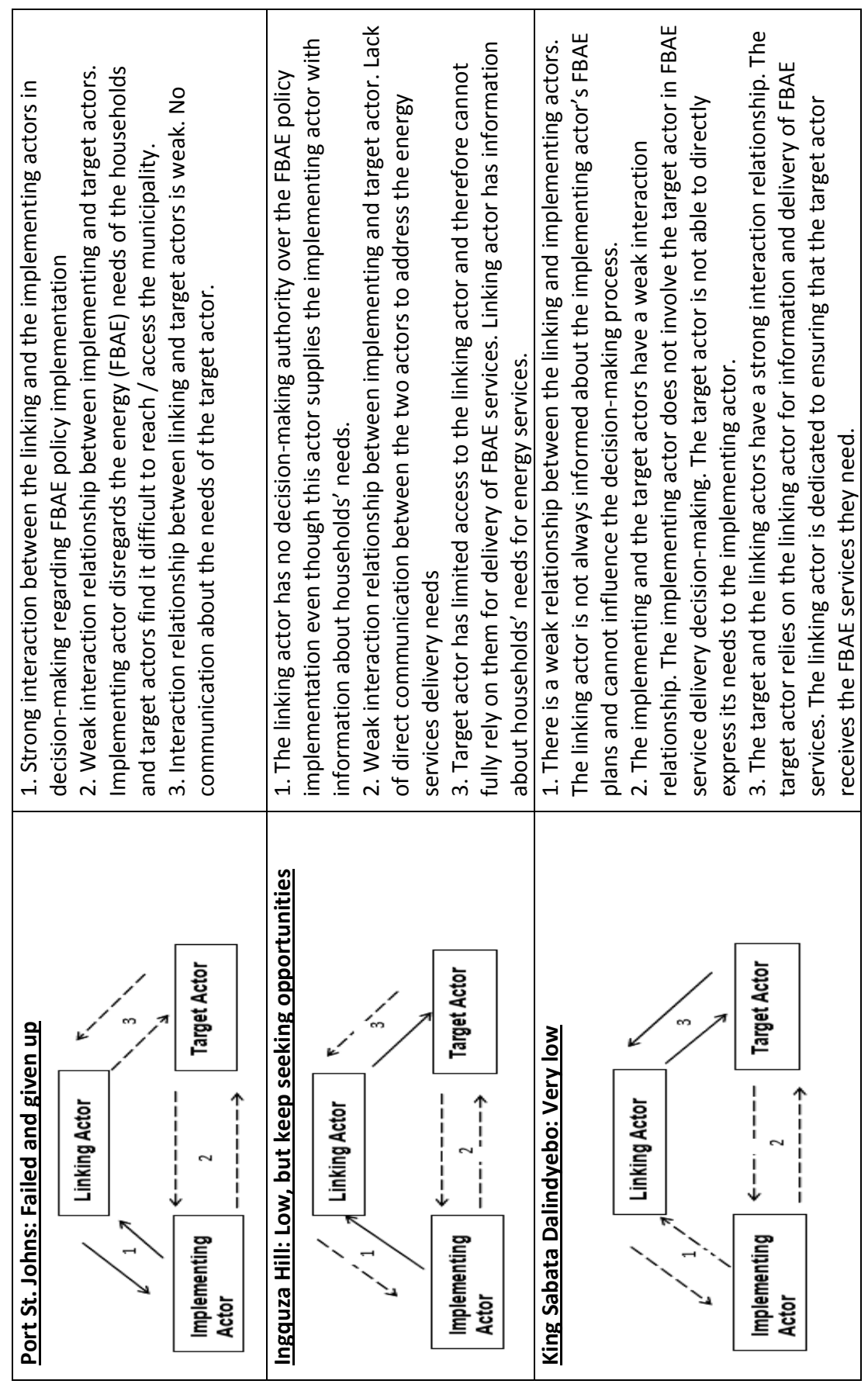




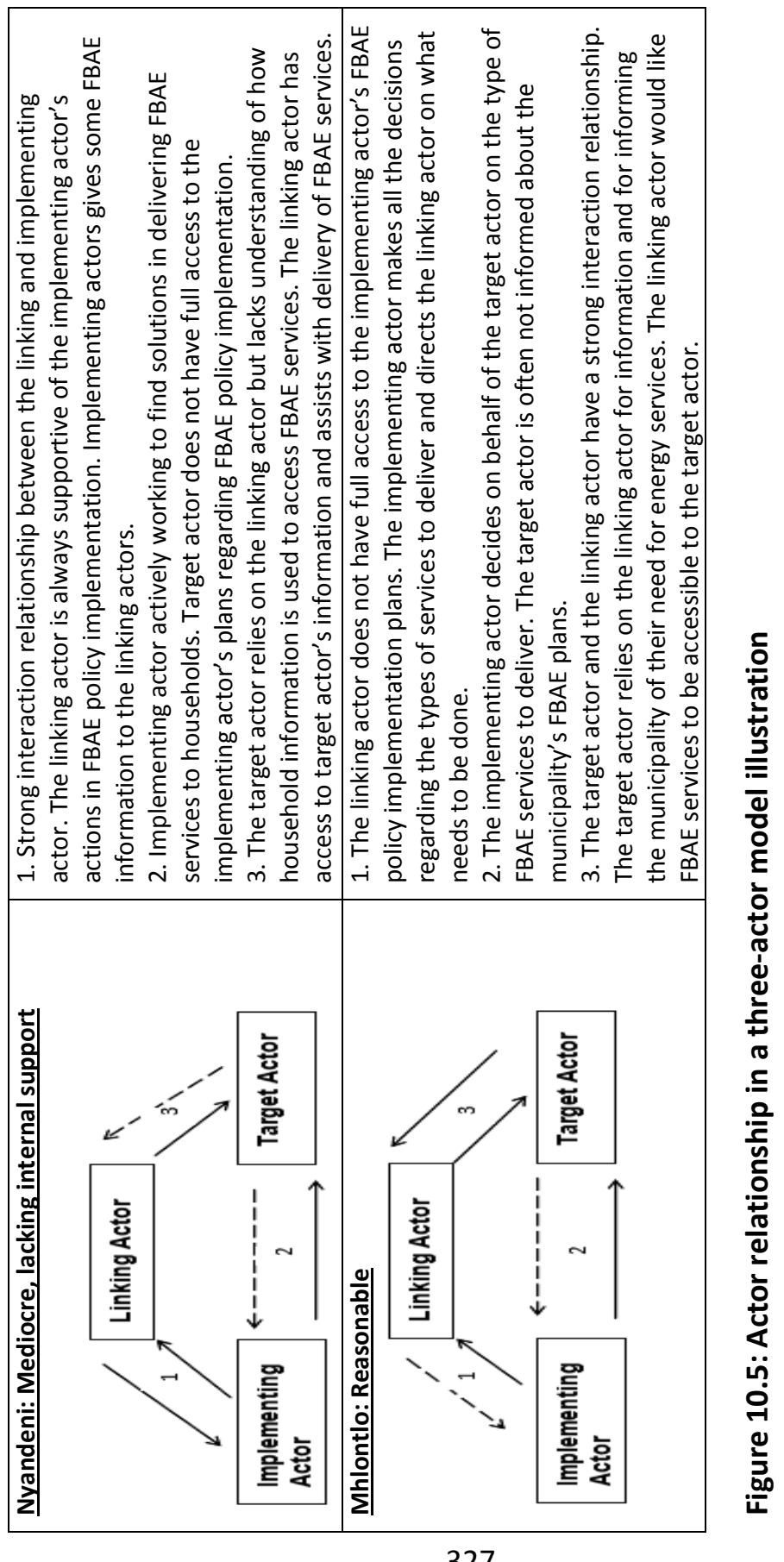


In Mhlontlo the actor-relationship between the linking and the implementing actor is one-sided. This is the same for the relationship between the implementing and target actor. On the other hand, the relationship between the linking and the target actor is strong. The linking actor does not have full access to the implementing actors' plans and the implementing actor makes service provision decisions without (fully) involving the linking and the target actors. Mhlontlo's case analysis in Chapter 9 shows that this actor's implementation success is reasonable despite the weak relationship between the implementing and the linking actors.

Table 10.15: Implementation success per municipality

\begin{tabular}{|l|l|c|c|}
\hline Study area & $\begin{array}{l}\text { Implementation } \\
\text { success }\end{array}$ & $\begin{array}{l}\text { Relative score 1-5 (1 = } \\
\text { Failed; } \\
\text { 5 = Reasonable }\end{array}$ & Interaction rating \\
\hline Port St. Johns & Failed and given up & 1 & +-- \\
\hline $\begin{array}{l}\text { King Sabata } \\
\text { Dalindyebo }\end{array}$ & Very low & 2 & $0-0$ \\
\hline Ingquza Hill & $\begin{array}{l}\text { Low but keep } \\
\text { seeking opportunity }\end{array}$ & 3 & +-- \\
\hline Nyandeni & $\begin{array}{l}\text { Mediocre, lacking } \\
\text { internal support }\end{array}$ & 4 & $00+$ \\
\hline Mhlontlo & Reasonable & 5 & \\
\hline
\end{tabular}

The interaction rating is represented by going anti-clockwise through the actor relation, where + is a mutual strong relation, 0 a one sided relation and - a weak strong relation.

While the correlation in Table 10.15 is not very high, one should consider that the implicit assumption of equal importance when making such an overview is probably not right. For instance the arrows reaching the target group are strong in the two best cases, restricted to those from the linking actors in the next two cases and absent in the worst case. This analysis of relationships between actors can thus be considered as a useful addition and extension to the comparison of implementation scores with actor characteristics, but not as a potential replacement thereof. 


\subsection{Conclusions and outlook}

With this section we are arriving at the end of this thesis. We set out with a few simple questions that should lead us to a better understanding of the problems with implementing a policy that is potentially of major importance to many poor people in South Africa. But we also wanted to move beyond the standard explanation of both insiders and external observers that lack of resources is the obvious and paramount cause for implementation failure in a developing country setting. Is it really true that just pouring in more resources would easily solve all implementation problems? Would that be true in a wealthy country's setting? Diversity of motivations and cognitions play an important role there. Why would these be less important in a developing nation's setting? With reference to South African policy implementation failure, Khosa (2003) concludes that "reasons for failure to implement policies vary from capacity constraints to logistical issues and research shows that many policies were overambitious and therefore unrealistic, given the resources available to transform the legacy of inequality and social marginalisation" (Khosa, 2003: 47).

In this section we will revisit our research questions and reflect upon the theoretical approach used in this thesis. Furthermore we will present some possible outlooks for research and practice.

\subsubsection{Answering the research questions}

\section{The primary research question is:}

- How do actors influence the Free Basic Alternative Energy (FBAE) policy implementation process in the local municipal areas under the $O R$ Tambo District?

With this question I wanted to find out how the actors (as individuals, groups, organisations and institutions) influence the FBAE policy implementation process. For this I used the Contextual Interaction Theory which emphasizes the specific actor characteristics of motivations, 
cognitions and capacity and power. The use of such few variables to analyse policy implementation may be seen as parsimonious, however it is advantageous as it allows the analysis to focus on the key areas that are most relevant in an interaction process. Moreover it allows the inclusion of numerous second order factors that work through their influence on the actor characteristics. These factors stem from various layers of context around the actors that are involved in the implementation process.

In order to answer this question, it is important to confirm that the FBAE policy implementation process proves to be indeed a multi-actor interaction process and not just a government action. The manner in which the actors influence this process is complex and different in each case due to the specific circumstances experienced by each actor during the implementation process.

In these cases, actors influence the implementation process in a number of ways. Their characteristics of motivation, cognitions, resources and power play an important role in the FBAE policy implementation process. The actor motivations in the five cases were important as these were the drivers that put actors into action in the implementation process. For instance, if the implementing actor was positively motivated to provide alternative energy services as part of the FBAE policy implementation process, they would make this their goal and incorporate it onto their Integrated Development Plans (IDP) ${ }^{103}$. By doing this, the implementing actor enables the implementation process in terms of ensuring that the necessary resources (capacity) are available.

If actors are not positively motivated to implement the FBAE policy, they will not make it part of their goals that they wish to achieve successfully. For instance, a linking actor that has no interest in the delivery of alternative energy services to indigent households (for whatever reason)

\footnotetext{
103 IDPs are five-year plans that each municipality in South Africa is required to develop according to the Municipal Systems Act of 2000 (Section 35) and they are a method to plan future developments for their areas (Education and Training Unit 2011).
} 
will not inform the target actor about the FBAE services that they are entitled to benefit from.

There are various ways that implementing actors in these cases influence the FBAE policy implementation process. Allocation of staff, allocation of funds, allocation of resources such as vehicles, appointing and paying for the service provider to deliver alternative energy services, keeping other actors informed about FBAE policy implementation plans, knowing other actor's needs concerning the provision of alternative energy services, monitoring of the implementation process and keeping a credible indigent register.

The comparative analysis in this chapter revealed that actor characteristics being more positive and actor relations being more tight and reciprocal indeed seem to explain the varying degree of implementation success, even though for a full understanding the qualitative stories of the implementation process should be taken in their completeness.

\section{The secondary question is:}

- How do contextual factors influence the implementation of the FBAE policy?

This question seeks to find out the contextual factors that influence the process of FBAE policy implementation in the municipalities under the OR Tambo District Municipality. The Contextual Interaction Theory identifies layers of context that in turn influence the actors' characteristics that ultimately drive the process. This question has received "secondary" 104 attention in this study, as it investigates factors-behind-the-factors. Nevertheless some observations can be given here.

\footnotetext{
${ }^{104}$ Secondary attention does not indicate that this question is less important but that the main focus of the study was on the primary research question. The secondary question is important to give the specific and the structural context of the study.
} 
The contextual factors of focus in this thesis include the influence of the geographic location under specific context, multi-level governance under the structural context and the political context which is mostly influenced by the country's history.

Starting with the geographical location of the areas in this study, it is important to show how this influences the policy interaction process. These five areas are located in the OR Tambo district, a district located in one of the impoverished provinces in South Africa. The OR Tambo district is highly rural with an unemployment rate of $44 \%$. Even though most of the areas in this district have access to grid electricity connections, those in the remote rural areas are still unelectrified and may not be until the year 2025. The geographical location has influenced the policy implementation process in the following ways:

(a) The actors, specifically the implementing actors, have to take into consideration the type of roads and gravel terrain which makes it difficult to reach and deliver services to remote rural households,

(b) Information about the implementation of the FBAE policy is not easily available to households living in the remote rural areas. This is worsened by implementing and/or linking actors that are not keen in successfully implementing the policy and therefore tend to withhold information from the target actor.

(c) Municipalities in the rural areas have competing priorities where provision of services is concerned and the implementation of FBAE is not often high on the list of priorities.

(d) Rural areas in South Africa suffer from skills drain due to many people leaving and seeking (better) employment opportunities in the urban areas. In some of the municipalities in this study there was a clear lack of staff members (part of resources) and this negatively influenced the FBAE policy implementation process. 
Multi-level governance also has an influence in the FBAE implementation process. Chapter 4 of this thesis analyses the different levels of government and their contribution to the way this policy is implemented. As a policy formulated in the national level of government and implemented by the local government department with the assistance of the provincial government - the process is clearly complex. Starting from the bottom, the local government (municipalities) are expected to implement this policy as it is added to their tasks and responsibilities. The fact that some of the municipalities do not have the needed capacity to meet this task is often not taken into consideration. Even with the provision of funds for the implementation of this policy, the fact that these funds are not ring-fenced makes it difficult to ensure that they are spent solely of the FBAE services as they can be used for other service provision priorities within the municipality.

In South Africa until recently, the delivery of energy services was not part of the rural-based local municipalities. The introduction of the FBAE policy in 2007 was one of the catalysts that pushed these municipalities to start adding the task of energy service provision to their list of responsibilities. With these new responsibilities, the municipalities had to have staff members with the skills to provide such services. It is common to find local municipalities without the dedicated department responsible for the delivery of FBAE services and is some instances where such a department exists, it is often overwhelmed with other responsibilities. However, this was not the case in Mhlontlo where the implementation success was reasonable. Mhlontlo provided for a full staff compliment to ensure that the municipality meets its goals of providing alternative energy services to its indigent households.

Moving up to the provincial level of government the findings in this study show that the provincial department played a role of monitoring the municipality's implementation progress. The provincial department also provided the local municipalities with information needed on how to implement the FBAE policy and how to ensure a credible indigent register. This department's influence was positive for some municipalities as they 
were encouraged to implement the FBAE policy with the knowledge that help was available from the provincial department. However, some of the local municipalities were not positively influenced by the provincial department role and did not subject themselves to being monitored by this department nor be provided with relevant information on the implementation of the FBAE policy. In the cases studied here, the local municipality that did not participate in the activities set by the provincial government was not successful in implementing the FBAE policy. On the other hand, the municipality that allowed itself to be monitored by the provincial government had reasonable success in implementing the FBAE policy. Obviously, the direction of causality might be two-sided here.

The national government department influences the FBAE policy by virtue of being the policy maker. At the national level, decision-making about policy implementation mainly entails funding allocation and deciding who is best (government sphere) to implement such a policy and to decide on how this policy should be implemented. The national level has been accused of making decisions without consulting with the local level to find out if they are capable of the responsibilities given and if the funding and other resources provided are enough to make it possible for the local level to implement the policy.

The political influence stems from the country's history and the need to provide services to households and parts of society that were denied these services in the past as discussed in Chapter 2. The political influence also brings some uncertainty in the planning and implementation process. Uncertainty was voiced out by the Mhlontlo municipality (Chapter 9) when they were not sure if they will have access to the Ward Committee members (linking actors) after the local elections as political structures may change due to the elections results. The linking actors were useful to collect data for the indigent register. The King Sabata Dalindyebo case also presents an example of political influence in the implementation process. The municipality which has a dominance of African National Congress 
(ANC) ${ }^{105}$ representatives in its Council, decided to deliver FBAE services for the first time a day before the local elections in 2011.

This study has attempted to address the 'policy gap' within the South African context based on the implementation of the Free Basic Alternative Energy policy. This gap has been addressed in two ways:

1. The study has provided an in-depth analysis of the factors that contribute to unsuccessful policy implementation by using a theoretical framework to address the issues that are often neglected in the policy studies. This thesis has shown that policy implementation failure cannot and should not be attribute only to the lack of funds or the presence of corruption as it is often thought in developing countries. By analysis the actor characteristics in an in-depth way, this study has shown that other factors contribute to the policy implementation failure - and these should be acknowledged by all the actors in the policy arena. Actor motivations, cognitions, capacity and power play an important role in the policy implementation process.

2. The study addresses the policy gap where implementation research is concerned. This has been done by scientifically studying a policy implementation issue in a developing country setting, using the Contextual Interaction Theory for the first time in South Africa and adapting this theoretical framework to address the unique South African conditions and 'what transpires in the implementation process between policy expectations and perceived policy results' (Brynard, 2007). In so doing it has made a significant contribution to South African scholarship by contributing to the under-researched field of the implementation of the FBAE policy.

\footnotetext{
105 The ANC is the political party leading the government of the Republic of South African since the establishment of the country's democracy in 1994.
} 


\subsubsection{Reflections on the theoretical framework used}

\section{(i) Using the dynamic interaction model and not the more static flowchart model:}

The Contextual interaction Theory can be applied in a number of ways using its diverse applications and methods. One of the ways of applying $\mathrm{CIT}$ is the use of the flowchart model ${ }^{106}$ (Bressers, 2004) which emphasizes that implementation can be differentiated as to whether there is any implementation at all and whether the implementation is adequate to satisfy the policy aims. The strong point of the flowchart model is that it provides an explanatory (and predictive) hypothesis. The main reason why this thesis does not use the flowchart model is that this study did not just seek to find out whether implementation would be likely to take place or whether there would be of implementation. Instead, this thesis is analysing an on-going policy implementation process and it seeks to find out how the actors and their characteristics through their interaction influence this process. The degree of implementation success in the cases studies in this thesis was a given, and the relative straightforwardness of the flowchart model seemed to be insufficient to provide the detailed explanation that we sought.

This thesis therefore uses the dynamic interaction framework ${ }^{107}$. Even though the dynamic interaction model pays attention to the interaction between the key-actor characteristics, never before has this feature been really used in empirical research to enable and create a more holistic view of the implementation situation.

As Bressers (2009) clarifies, "the actor characteristics are much more elaborated here, not visualised as linked to specific actors and for presentation reasons placed outside of the process box. This enables also to

\footnotetext{
${ }^{106}$ See Figure 3.2 in Chapter 3.

${ }^{107}$ See Figure 3.4 in Chapter 3 and see how the dynamic interaction framework is applied in the study cases - Chapters 5,6,7,8, and 9.
} 
show the mutual influences between these factors and the process itself" (Bressers 2009: 132).

To use this model in this study was extremely beneficial in analysing the influence the actors and their characteristics have on the FBAE policy implementation process. First this model allows this thesis to focus attention on each individual case where the actors are scrutinised by analysing their characteristics (motivations, cognitions, resources and power) to see how these influence the implementation and how in turn they influence each other. The model also allows this thesis to make a comparison of all the cases in this study to draw the results and to view the similarities and differences which further explain the influence of the actor characteristic's on the implementation process. Paying attention to the way the three groups of actor characteristics influence each other makes the model much more dynamic and potentially helpful to understand the development of the interaction process over time.

Another model of the Contextual Interaction Theory which is used in this thesis but given "secondary" attention to answer the secondary research question is the layers of contextual factors model. With this model I analyse factors within the specific context and within the structural context. Within the specific context I analyse how the geographic location of the municipalities that make up the cases in this study influence the FBAE policy implementation process. Multi-level governance and the political context are analysed under the structural context to find out their influence in the interaction process. The usefulness of using this model was that it addresses issues that are otherwise difficult to give specific attention to in the dynamic interaction model. As the dynamic interaction model concentrates on the actors and their characteristics, the contextual factors model gives an opportunity to analyse the external issues that also affect the implementation process. These external issues impact on the actor characteristics, like the degree to which the actors are motivated, or to which extent they have access to adequate resources. 
The CIT's process model ${ }^{108}$ (Bressers, 2004) depicts a two-actor interaction process to illustrate the interaction process of actors and their characteristics. For purposes of use in this thesis, this model was modified in order to suit the conditions of this study. Below is some reflection on adding a third actor to the study by modifying the process model.

\section{(ii) Adding a third actor to the scheme:}

During the data collection and analysis process for this thesis, it became obvious that using the two-actor interaction process model to illustrate the interaction process in this study's cases would not be feasible. With each case analysis it became clear that there were three key actors involved in the FBAE implementation process at any given time and it would be impossible to confine them into a two-actor model. As mentioned in Chapter 3 (Section 3.4.3) it therefore became clear that ignoring the third actor's contribution to the policy implementation process could leave out important contributions that illustrate how these actors' characteristics influence the implementation process. While third actors in implementing processes can take many forms, like mediators, or judges, in this study they are seen to have a linking role. The third actor in this study is referred to as the linking actor as they are an in-between among the target and the implementing actors. In most of the cases, the implementing actor (local municipality) relied on the linking actor to convey their intentions to households, especially those regarding service delivery. They also used the linking actor to collect household information that would enable the municipality to compile an indigent households' register to make it easier to delivery basic services to low-income households. Likewise, the target actor (households) relied on the linking actor to convey their messages regarding the services they required from the local municipality. The linking actor shares some characteristics of both the implementing and target actors and therefore it is difficult to ignore their role in the FBAE policy implementation process.

${ }^{108}$ See Figure 3.1 in Chapter 3. 
It is also important to note that as obviously important as the role of the linking actor proved to be in the interaction process, this varied from case to case. The analysis of the five cases show that even though the linking actor is an important part of the process and a link for both the implementing and the target actor, this actor does not hold the power to decide on the implementation of the FBAE policy. In some cases, the linking actor has facilitated the delivery of alternative energy services to indigent households by ensuring that the implementing actor has the households' relevant information but the final decision on whether to deliver these services lies with the implementing actor. In some other cases the linking actors had trouble finding their role and in one case just regarded as part of the (unmotivated) municipality. The case of Mhlontlo illustrates that even while the linking actor is not always included in making decisions about the delivery of FBAE services, this does not need to negatively affect the ability of the implementing actor to deliver FBAE services to indigent households. In this case, the linking actor facilitates activities such as collecting indigent households' data and keeping the target actor informed about the FBAE policy, which leads to the provision of services by the implementing actor.

In all, the linking actor's role is useful but it is important to note that the usefulness varies from case to case due to circumstances and the context influencing the policy implementation process.

\section{(iii) Splitting the Resources variable into a Capacity part and a Power part:}

Resources as an actor characteristic are important (for an actor) to provide capacity to act and as an ultimate source of power (Bressers, 2009). Thus in CIT it is indicated halfway that actually the resources variable has two ways to manifest itself in the process. In this study, the resources variable has been split into two parts - one that focuses on capacity and one that focuses on power as intended by the Contextual Interaction Theory's dynamic interaction model. Capacity and power in the CIT framework refers to the capacity that is provided by the resources to enable the actors to carry out the implementation process. 
For this study, focusing on the capacity part of resources ensured that the analysis did not concentrate on monetary resources only - as this is often blamed for policy implementation failure. Capacity therefore brings together a variety of issues and factors that are often neglected in policy studies but are important as they influence policy implementation process. In the cases analysed for this study examples of capacity include the actor's capacity to collect and process data, capacity within the municipalities to fulfil their service delivery responsibilities and capacity in terms of skills and experience related to the implementation of the FBAE policy. This was useful to show that funds are not the only resources needed in the FBAE policy implementation process and that a variety of resources is important to enable relevant capacity.

"Power is largely a result of attribution to an actor by others" (Bressers 2009) - but, as Bressers (ibid) observes, if this attribution of power is not backed by real resources it is far from stable. The analysis of power and how it is attributed by the actors to each other showed that power as a resource is important in influencing the FBAE policy implementation process. In the cases analysed here, the actors with more resources had more power attributed to them by the other actors and therefore could make implementation decisions without being dependent on the actors in that part of the process.

(iv) Usability of the framework to do research in a very poor setting (did it "deliver" in providing a broader understanding of the reasons for implementation success or failure?)

Since its development, the Contextual Interaction Theory has been used mainly in studies analysing policy in the environmental context and focusing on sustainable development in Western countries. Applying the Contextual Interaction Theory to analyse the implementation of policy that seeks to provide basic services aimed at alleviating the effects of energy poverty is a new domain of application. This study is the first to apply CIT in the South African policy implementation context. The aim of using this theoretical 
framework in a very poor setting was to provide a broader understanding of the FBAE policy implementation process. Using CIT provided an opportunity to analyse the implementation process beyond focusing on the resources only as the reason for policy implementation failure. This theoretical framework allows the analysis to take advantage of other variables within the CIT framework, that although a few and seemingly (over) parsimonious, do provide an opportunity to explore other contributory factors (such as those that impact on actor's motivations and cognitions) in an in-depth approach.

As mentioned in Chapter 3 (Section 3.4.2), when applying the Contextual Interaction Theory to the cases analysed in this thesis the unique issues that shape the South African society had to be kept in mind as these influence the policy implementation process and are part of the actors' motivations, cognitions and capacity / power. By using the layers of contextual factors model, these South African issues that give the implementation process a context can be analysed and their influence on the implementation process can be scrutinized. The geographical setting and the political influence on the implementation process are important in the South African context because policy making and implementation is closely linked to the country's political transition from an apartheid to a democratic state.

The use of $\mathrm{CIT}$ in a poor country setting has therefore delivered in providing the ability to analyse the FBAE policy implementation process in more depth.

\subsubsection{Some outlooks for research and practice}

As Goggin et al. (1990) observe, policy implementation is a complex and dynamic process. It is also not homogenous as has been illustrated in this thesis that one cannot apply the same principles for all municipalities even though they fall under the same administrative district in the same geographical area. For example, each municipality develops its own Integrated Development Plans where unique goals and plans to achieve these goals are documented. The achievement of such goals depends on a 
variety of issues for each municipality including but not limited to: the willingness to deliver particular services, the need for certain services in an area, the availability of resources to meet these goals, the relationship with other stakeholders. It is therefore important to realise that even though the municipalities have the responsibility to deliver services based on a policy, their implementation processes will vary linked to their individual and specific contexts.

The policy system feature of using "linking actors" is appealing but practice shows that it sometimes works well and sometimes not so good. The linking actor concept should not be discarded just because it does not work well is some cases - but the linking actor's presence should always be acknowledged (whether they are active or not) because they are part of the target actor and also part of the implementing actor. In the Mhlontlo case where the success of the implementation process clearly did not depend on the linking actor, this actor still had a role to play, such as collecting data for the indigent register up-to-date.

The analysis of the cases in this study showed that the FBAE policy implementation process is not only dependent on resources such as funding but there is a need staff training, information, monitoring among other factors that influence the implementation process.

Monitoring and supervision of the implementation process is also important and may influence implementation success as policy implementers may take the policy seriously if they knew that they are closely monitored. Recognizing that implementation is predominantly a local interaction process and that the influence of top-down pressures is always limited, does not preclude that some degree and form of overview remains important.

Information from the upper levels of government needs to be clear enough for the implementers to set realistic goals where policy implementation is concerned. Lack of clear information leads to lack of motivation based on an understanding of reality (for example "the grid is coming soon") that is not always correct. It might be important for the higher authorities to 
actively inform the people about the degree of truth behind such claims by local implementers.

\subsubsection{Policy recommendations}

Since this study's main focus was the implementation process of the Free Basic Alternative Energy policy and it has found serious weaknesses, it is appropriate to offer policy recommendations based on the experience gained from this research. The recommendations will focus on the national, provincial and local levels of government.

\section{National-level recommendation:}

1. Policy makers should take into consideration the complexities that accompany policy implementation processes. Through the analysis of the five cases, this study has shown that the implementation process is actordriven and that the actor's goals (motivations) are an important component of the process. The goals of a policy should therefore reflect or at least align with the goals of the implementers in order for the policy to be attractive to the potential implementers.

2. Policy makers need an effective assessment and evaluation system to ensure that the policies they formulate are implemented according to plan. This would ensure that policy makers follow-up on the policies and do not leave all responsibility for implementation to the local municipalities. The assessment and evaluation system would also assist in finding out what needs to be improved at the policy formulation level and at the implementation level to facilitate successful policy implementation. This should not take the form of a top-down hierarchical approach, but should take an approach of mutual learning between policy makers and policy implementers. 
3. It is recommended that from time to time the national-level of government keeps in contact with the provincial and local levels of government to keep up to date about the FBAE implementation progress.

4. Municipalities are not homogenous and they do not serve homogenous communities and households. Where the implementation of the FBAE policy is not successful, it is important for the national-level of government to find out the reasons behind the failure. Some suggestions about how this level of government can stay informed include:

- keeping in contact with the local and provincial levels of government to find out the progress of implementation,

- visiting the beneficiaries to assess whether they receive and benefit from the FBAE services or not,

- realising that provision of FBAE services by a municipality does not always mean that the policy is implemented successfully, other issues may need to be considered for successful implementation.

\section{Provincial-level recommendation:}

1. This study has revealed the important role played by the provincial level of government in the implementation of the FBAE policy. The provincial level provides essential information regarding the FBAE implementation processes, assists with providing information about the indigent policy and about developing a credible indigent register as well as providing a platform (in the form of energy forums) for implementing actors to voice their concerns regarding the implementation process. In order to be more effective in their delivery of services to the local municipalities, it is recommended that the provincial level be provided with skills and capacity support by the national government. There was lack of capacity in terms of shortage of experienced staff within the provincial-level department and this unfairly forced the burden of policy implementation support onto a few skilled individuals. 
2. As one of their responsibilities is to monitor the FBAE service delivery process undertaken by the municipalities, the provincial department does this through 'checking' the indigent registers submitted to them by municipalities. Tightening the assessment and monitoring measures would assist in ensuring that the municipalities are providing FBAE services to the rightful beneficiaries. This can only be possible if the provincial level has enough people on the ground to work hand-in-hand with the municipalities in compiling and verifying the indigent registers.

\section{Local-level recommendation:}

1. As the level of government mandated to implement the FBAE policy by delivering alternative energy services, the local municipalities are faced with an important responsibility. The analysis of cases in this thesis showed that local municipalities have a number of complex issues to consider throughout the implementation process. As the main implementing actors, the local municipalities often have to make critical decisions regarding the implementation of FBAE. It is therefore recommended that the national and provincial levels of government recognise and acknowledge that the local level needs support and capacity in order to be able to make service delivery decisions.

2. The multi-actor interaction is more visible at the local level where the implementing, target and linking actors interact in the FBAE implementation process. Each actor and their characteristics influence the policy implementation process and its results. At this level it is recommended to clarify the role of each actor (if any) in the interaction process. Formalising the role of the linking actor in the FBAE policy implementation process may produce positive results in ensuring that this actor provides services to the implementing and target actors.

3. The local level should use the avenues of communication provided by the provincial level to express their views about the policy implementation process. In some of the cases, the implementing actor expressed the view 
that the national level does not follow-up with municipalities to find out if they are able to cope with the FBAE implementation responsibilities.

This thesis has documented the Free Basic Alternative Energy policy implementation process in the municipalities that fall under the OR Tambo district municipality jurisdiction. The analysis has proven that indeed, policy implementation is dynamic and complex and it is influenced by the actors and their characteristics. During the periods of data collection for this study I came across a number of hardworking individuals that dedicated their energy to the implementation of this policy regardless of the complexities presented by the process. I conclude this thesis with the hope that the insights provided by this study will provide some solutions to these individuals and their institutions and will contribute to the improvement of the implementation process and consequently alleviate energy poverty for the $15.3 \%$ of the South African households that are without grid electricity. 


\section{References}

Bandura, A. 1986. Social Foundations of Thought and Action: A Social Cognitive Theory. Englewood Cliffs, N.J.: Prentice Hall.

Barrett, S.M. 2004. Implementation Studies: Time for Revival? Personal Reflections on 20 Years of Implementation Studies. Public Administration. 82,doi: 10.1111/j.0033---3298.2004.00393.x, pp. 249-262.

Barnard, W. 2012. Integrated National Electrification Programme (INEP):

Overall Performance - end of July 2012. Department of Energy, SALGA and Eskom Briefing in the Parliament of the Republic of South Africa, 14 February 2012.

Bandura, A. 1986. "Social Foundations of Thought and Action: A Social Cognitive Theory”. Englewood Cliffs, N.J.: Prentice Hall.

Bhorat, H., Oosthuizen, M. and van der Westhuizen, C. 2012. "Estimating a Poverty Line: An Application to Free Basic Municipal Services in South Africa". Development South Africa, 29: 1, 77-96, DOI. Routledge.

Bressers, H. 2004. "Implementing Sustainable Development: How to know what works, where, when and how", in Lafferty, WM (ed). Governance for Sustainable Development: The Challenge of Adopting Form to Function. Cheltenham, 2004, pp 284-318.

Bressers, H. 2007. "Contextual Interaction Theory and the issue of boundary definition: Governance and the motivation, cognitions and resources of actors". Report for the European Union Integrated Systems and the Boundary Problem project. Enschede, The Netherlands.

Bressers, H. 2009. "From Public Administration to Policy Networks: Contextual Interaction Analysis", in Stéphane Narath and Frédéric Varone (Eds). Rediscovering Public Law and Public Administration in Comparative Policy Analysis: A Tribute to Peter Knoepfel, Lausanne: Presses polytechniques, pp. 123-142. 
Bressers, H. and Huzen, T.P. 1984. 'Een politicologische benadering van bestuursinstrumenten (A political science approach to governance instruments). Enschede, The Netherlands: CBO.

Bressers, H. and Klok, P.J. 1988. 'Fundamentals for a Theory of Policy Instruments'. International Journal of Social Economics, 15 (3/4), 22-41.

Bressers, H. and Ringeling, A. 1995. Policy Implementation. In: Walter Kickert and Frans van Vught (Eds). Public Policy and Administration Sciences in The Netherlands. London: Prentice Hall / Harvester Wheatsheaf pp. 125146

Briggs, X. 2003. Working the Middle: the Roles and Challenges of Intermediaries. The Art and Science of Community Problem Solving Project at Harvard MIT.

http://web.mit.edu/cpsproject/images/art_sci_tool_intermedaries_web_0 63.pdf [accessed 30 May 2014]

Brinkerhoff, D. W. and Crosby, B. L. 2002. "Managing Policy Reform:

Concepts and Tolls for Decision-makers in Developing and Transitioning Countries". Kumarian Press, Inc. Bloomfield.

Brynard, P.A. 2005. "Policy Implementation: Lessons for Service Delivery". Journal of Public Administration, Vol. 40 No. 4(1), 649-664. December 2005. South African Association of Public Administration and Management (SASPAM), Pretoria.

Brynard, P.A. 2006. "The Nature of the Policy Problem". Journal of Public Administration, Vol. 41 No. 2.2, 357-373. August 2006. South African Association of Public Administration and Management (SASPAM), Pretoria.

Brynard, P.A. 2007. "The Policy Gap in South Africa". Journal of Public Administration, Vol. 42 No. 3, 357-365. August 2007. South African Association of Public Administration and Management (SASPAM), Pretoria.

Brynard, P.A. 2009. "Mapping the Factors that Influence Policy Implementation". Journal of Public Administration, Vol. 44 No. 3 (1), 557577. August 2009. South African Association of Public Administration and Management (SASPAM), Pretoria. 
Brynard, P.A. 2010. "Policy Implementation and Cognitive Skills: the Difficulty of Understanding Implementation". Journal of Public Administration, Vol. 45 No. 1.1, 190-201. June 2010. South African Association of Public Administration and Management (SASPAM), Pretoria.

Cecelski, E. 2003. "Enabling Equitable Access to Rural Electrification: Current Thinking on Energy, Poverty and Gender". In Energy, Poverty and Gender (2003) 27.

Clancy, J.S., Winther, T., Matinga, M.N. and Oparaocha, S. 2011. Gender Equity in Access to and Benefits from Modern Energy and Improved Energy Technologies. World Development Report Background Paper. Leausden: ETC Nederland BV.

Clancy, J.S. 2011. Energy Affordability and Household Energy Security. Discussion Note 9 Electronic Forum on Energy Security in Asia and the Pacific, UNESCAP. Bangkok: Institution.

Cnossen, S. 2003. The Incidence of Consumption in Member Countries of the South Africa

Development Community. Paper prepared for the Southern African Conference on Excise

Taxation, Centurion Lake Hotel, Gauteng, South Africa, 11-13 June 2003.

Constitution of the Republic of South Africa Act No. 108 of 1996.

Cowan, B. and Mohlakoana, N. 2004. "Barriers to Modern Energy Services in Low-income Urban Communities: Khayelitsha Energy Survey 2004. Energy Research Centre, University of Cape Town.

Davis, M. (1998). 'Rural Household Energy Consumption: The effects of access to electricity - evidence from South Africa'. Energy Policy (26): 207217.

De Boer, C. 2012. 'Contextual Water Management: A Study of Governance and Implementation Processes in Local Stream Restoration Projects'. PhD dissertation. University of Twente. 
De Boer, C. and Bressers, H. 2011. "Analyzing the Renaturalization of the Dutch Regge River: Complex and Dynamic Implementation Processes". University of Twente, The Netherlands.

Department of Minerals and Energy (DME), 1998. "White Paper on Energy Policy for Republic of South Africa”. DME, Pretoria.

Department of Minerals and Energy (DME), 2003. "Electricity Basic Services Support Tariff (Free Basic Electricity) Policy for the Republic of South Africa". DME, Pretoria.

Department of Minerals and Energy (DME), 2007. "Free Basic Alternative Energy Policy: Household Energy Support Programme”. DME, Pretoria.

Department of Provincial and Provincial and Local Government (DPLG), 2005. 'Framework for a Municipal Indigent Policy: Executive Summary'. DPLG (now known as CoGTA), Pretoria.

Eastern Cape Socio-Economic Consultative Council. 2012. "Eastern Cape Development Indicators 2012".

http://www.ecsecc.org/files/library/documents/EasternCape withDMs.pdf - Accessed 22 July 2014.

Education and Training Unit (ETU). 2011. http://www.etu.org.za/ - site accessed on 01 February 2011

Elmore, R. 1979. "Backward Mapping: Implementation Research and Policy Decisions" Political Science Quarterly 94:601-616.

Energy Research Centre. 2002. "Options for Basic Electricity Support Tariff: Analysis, issues and recommendations". 28 February 2002 - University of Cape Town.

Energy Research Centre (ERC). 2003. "Options for a Basic Electricity Support Tariff: Supplementary Report”. February 2003 - University of Cape Town. 
Energy Research Centre. 2004. 'Solar Electrification by the Concession Approach in the Rural Eastern Cape: Phase 2 Monitoring Survey'. University of Cape Town.

Evers, J.G. 2011. Werk in Uitvoering: De Toepassing van Interactieve Uitvoering in de Praktijk. University of Twente, The Netherlands.

GNESD Energy Access Knowledge Base. 2012. South African Electrification Programme. [online] Available at:

http://energyaccess.gnesd.org/index.php?option=com content\&view=artic le\&id=141:south-african-electrification-

programme\&catid=3:projects\&Itemid=24 [Accessed 24 October 2013]

Goggin, M. L., Bowman, A. O'M., Lester, J. P. and O'Toole, L.J. (1990). 'Implementation Theory and Practice: Towards a Third Generation'. Upper Saddle River, New Jersey: Scott Foresman.

Hill, M. and Hupe, P. 2002. Implementing Public Policy. London: Sage.

Hull, C.J. and Hjern, B. 1987. Helping Small Firms Grow: An Implementation Perspective. London, Croom Helm.

International Energy Agency (IEA). World Energy Outlook. 2010. "Comparative Study on Rural Electrification Policies: Keys to Successful Policies". Paris, France.

International Energy Agency (IEA). World Energy Outlook. 2010. “Energy Poverty: How to Make Modern Energy Access Universal”. Paris, France.

Javakhishvili, N. and Jiblaze, G. 2013. Contextual Interaction of Actors to Implement Anti-domestic Violence Policy. Unpublished Paper presented at the $3^{\text {rd }}$ European Conference on politics and Gender (ECPG), Universitat Pompeu Fabra, Barcelona: 21-23 March 2013.

Kanyane, H. 2011. "The Perplexing Problem of Salvaging Rural Municipalities". HSRC Review, Vol. 9, No. 4 - December 2011. HSRC Press, Cape Town. 
Khosa, M. 2003. Towards Effective Delivery: Synthesis report on the on the project entitled 'Closing the Gap between Policy and Implementation in South Africa'. Centre for Policy Studies, Johannesburg.

King Sabata Dalindyebo Local Municipality (KSDLM). 2010. 'Indigent Policy for 2010-2011 Financial Year. Approved by Council on 29 June 2010'. Kotzebue, J. R. 2012. 'Spatial Misfits in Multilevel Governance Impacts on the Small Island State of Malta'. PhD dissertation. University of Twente.

Kotzebue, J. R., Bressers, H. and Yousif, C. 2010. Spatial Misfits in a Multilevel Renewable Energy Policy Implementation Process on the Small Island State of Malta. Energy Policy, 38 (10), 5967-5976.

Lipsky, M. 1980. "Street-level bureaucracy: Dilemmas of the Individual in Public Services". New York: Russell Sage Foundation.

Makiwane, M. and Chimere-Dan, D. 2012. "The people matter: Poverty, Population Dynamics and Policy”. HSRC Review, Vol. 10, No. 2 - June 2012. HSRC Press, Cape Town.

Marquard, A. 2006. "The Origins and Development of South African Energy Policy". Thesis presented for the degree of Doctor of Philosophy in the Faculty of Engineering and the Built Environment. University of Cape Town.

Marquard, A., Bekker, B., Eberhard, A. and Gaunt, T. 2007. South Africa's Electrification Programme: An Overview and Assessment. Working Paper. Graduate School of Business, University of Cape Town.

Matinga, M. 2010. "We Grew Up with it: An Ethnographic Study of the Experiences, Perceptions and Responses to the Health Impacts of Energy Acquisition and Use in Rural South Africa". University of Twente, The Netherlands.

Matsika, R., Erasmus, B.F.N. and Twine, W.C. 2013. Double Jeopardy: The Dichotomy of Fuelwood Use in Rural South Africa. Energy Policy, 52 (2013), 716-725. 
Mazmanian, D. A. And Sabatier, P.A. 1981. 'Effective Policy

Implementation'. Lexington, Massachusetts: Lexington Books.

Mazmanian, D. A. And Sabatier, P.A. 1983. 'Implementation and Public Policy'. Glenview, Illinois: Scott, Foresman.

Modi, V., McDade, S., Lallement, D. and Saghir, J. 2006. Energy and the Millennium Development Goals. New York: Energy Sector Managament Assistance Programme, United Nations Development Programme.

Mohlakoana,N. 2003. "Needs-based Impact Assessment of Non-grid Rural Electrification: A Case of Eastern Cape". Thesis submitted for the degree of Masters in Energy Studies in the Faculty of Engineering and the Built Environment. University of Cape Town.

Noah, A. 2012. Eskom's Electrification Programme. Presented at the National Electrification Indaba, 15-16 March 2012. Durban, South Africa.

O’Toole, L. J. 1986. Policy recommendations for multi-actor implementation: An assessment of the field. Journal of Public Policy, 6(2), 181-210.

O'Toole, L.J. 2000. Research on policy implementation: Assessment and prospects, Journal of Public Administration and Theory, Vol. 10, April 2000, pp. 263-288.

O'Toole, L.J. 2004. The theory-practice issue in policy implementation research, in: Public Administration Review, Vol. 62, No. 6, pp. 491-503.

O.R. Tambo District Municipality. 2011. "Integrated Development Plan 2011 - 2012 Review”. OR Tambo District municipality, Eastern Cape, South Africa.

Owens, K.A. 2008. 'Understanding How Actors Influence Policy Implementation: A comparative study of wetland restorations in New Jersey, Oregon, The Netherlands and Finland'. PhD dissertation. University of Twente. 
Özerol, G. 2013. 'Aligning the Multiplicities in Natural Resource Governance: A Study on the Governance of Water and Land Resources in Irrigated Agriculture". PhD dissertation. University of Twente.

Peters, D. 2012. Address by the Minister of Energy at the Energy Month Launch. 6 March 2012

Peters, D. 2013. Remarks by the Minister of Energy on Response to the UN Secretary General's Call for Sustainable Energy for All (SE4ALL). Speech presented in New York, USA on 22 April 2013.

Potgieter, C., Pillay, R. and Rama, S. 2006. 'Women, Development and Transport in Rural Eastern Cape, South Africa'. HSRC Research Monograph: Gender and Development Unit. Cape Town, South Africa.

Prasad, G. 2007. "Electricity from Solar Home Systems in South Africa". Report prepared for Create Acceptance - Cultural Influences on Renewable Energy Acceptance and Tools for the development of communication strategies to promote ACCEPTANCE among key actor groups. Energy Research Centre, University of Cape Town.

Prasad, G. and Ranninger, H. 2003. The Social Impact of the Basic Electricity Support Tariff (BEST). Paper delivered at the Domestic Use of Energy conference 2003.

Pressman, J.L. and Wildavsky, A.B. 1973. "Implementation: How Great Expectations are Dashed in Oakland; or, Why It's Amazing that Federal Programs Work at All, This Being a Saga of the Economic Development Administration as Told by Two Sympathetic Observers Who Seek to Build Morals on a Foundation of Ruined Hopes". Berkeley: University of California Press.

Pritchett, Lant, Michael Woolcock, and Matt Andrews (2010), Capability Traps? The Mechanisms of Persistent Implementation Failure, Working Paper 234, Center for Global Development, Washington DC, USA. 
Sabatier, P. 1986. Top-down and Bottom-up approaches to implementation research: A critical analysis and suggested synthesis. Journal of Public Policy, 6(1), 21-48

Sabatier, P. 2005. "From policy implementation to policy change: a personal odyssey". In A. Gornitzka et al. (eds.), Reform and Change in Higher Education, 17-34.

Saetren, H. 2005. "Facts and Myths about Research on Public Policy Implementation: Out-of-Fashion, Allegedly Dead, but Still Very Much Alive and Relevant," in Policy Studies Journal33, 4 (November 2005): 559-582

SALGA. 2012. Update on the implementation of the national indigent policy vis-à-vis electricity basic services and support tariff. Overview of the effectiveness of the national indigent policy Sufficiency of 50KWh. Presentation made to the Parliamentary Portfolio Committee on Energy. 22 March 2012.

Shea, J. 2011. Taking Non-profit intermediaries Seriously: A Middle-Range Theory for Implementation Research. Public Administration Review, January - February 2011. Wiley-Blackwell.

Spratt, K. 2008. Assessment of the Contextual Interaction Theory to Identify HIV Policy Implementation Barriers in Asia. : AIDS 2008 - XVII International AIDS Conference: Abstract no. TUPE0923. http://www.iasociety.org/Abstracts/A200717593.aspx accessed on 05 September 2013.

Spillane, J.P. 2000. Cognition and Policy Implementation: District Policymakers and the Reform of Mathematics Education. Cognition and Instruction Journal, Vol. 18, No. 2 (2000) 141-179. Taylor and Francis Group. Statistics South Africa (StatsSA), 2007. "Community Survey 2007: Municipal Data on Household Services". Report No. 03-01-22 (2007). STATS SA, Pretoria. 
Statistics South Africa. 2011. Cooking, heating and lighting excel data received through email from the Stats SA Head office on 14 January 2013. Pretoria, South Africa.

Statistics South Africa. 2011. Census 2011: Municipal Fact Sheet. Extracted from "The South Africa I know, the home I understand". Pretoria, South Africa.

Szanton, P. 2003. Towards More Effective Use of Intermediaries. New York: Foundation Centre.

http://foundationcenter.org/gainknowledge/research/pdf/practicematters 01 paper.pdf [Accessed 30 May 2014].

Tewari, D. D. and Shah, T. 2003. "An assessment of South African prepaid electricity experiment, lessons learned and their policy implications for developing countries". Energy Policy 31 (9). Pages 911-927.

The Presidency and the Department of Provincial and Local Government. 2005. "Provincial Growth and Development Strategy Guidelines". Pretoria, South Africa.

Thom, C. 2000. Use of grid electricity by rural households in South Africa. Energy for Sustainable Development. Volume IV, No. 4 - December 2000.

Thom, C., Mohlakoana, N., Dekenah, M. and Heunis, S. 2001. Case studies on the impact of electrification in rural areas. Eskom report RES/RR/00/11953. Version March 2001 (Qualitative research). Rosherville: Eskom Resources and Strategic Division.

Truran, G. 2008. Household Energy Poverty and Paraffin Consumption in South Africa. Boiling Point issue 56 - 2008, pp. 2-6. Household Energy Network

Truran, G. 2010. Poverty and Migration: A Case for an Evidence Based, People-Centred Household Energy Policy. Paper delivered at the Domestic Use of Energy conference, Cape Town March 2010. 
UNFCCC 2012. Programme of Activities Design Document - Energy Efficient Cook Stoves in South Africa. CDM Executive Board.

http://www.energy.gov.za/files/esources/kyoto/2012/POA DD 13 04[1].p df - Accessed on 30 August 2014.

Van Meter, D. and Van Horn, C.E. 1975. "The Policy Implementation

Process: A Conceptual Framework". In Administration and Society, 6 (4), pp. 445-488.

Vinke-de Kruijf, J. 2013. 'Transferring Water Management Knowledge: How Actors, Interaction and Context Influence the Effectiveness of Dutch-funded Projects in Romania'. PhD dissertation. University of Twente.

Walker, L. and Gilson, L. 2004. 'We are Bitter but We are Satisfied: Nurses as Street Level Bureaucrats in South Africa'. Social Science and Medicine, 59 (2004) 1251-1261. Elsevier.

White Paper on Reconstruction and Development. 1994. Government gazette. 353 (16085). 15 November. Notice number 1954 of 1994. Cape Town: Government Printer.

Winter, S.C. 2003. "Implementation Perspectives: status and Reconsideration," in B. Guy peters and Jon Pierre, (eds.), The Sage Handbook of Public Administration (London: Sage 2003). Pages 212-223.

Wlokas, H.L. 2011. "A review of the Solar Home System concession programme in South Africa". Energy Research Centre, University of Cape Town.

World Energy Outlook (WEO), 2006. "Energy for Cooking in Developing Countries: Focus on Key Topics". International Energy Agency (2006) 424. http://www.worldenergyoutlook.org/docs/weo2006/cooking.pdf>.

World Health Organisation (WHO), 2006. "Development of WHO Guidelines for Indoor Air Quality". Report on a Working Group Meeting - Bonn, Germany. 23-24 October 2006.

Yin, R. K. 2009. "Case Study Research: Designs and Methods". London: Sage. 


\title{
Annex 1: Port St. Johns Noqhekwana village focus group with community representatives
}

\author{
Venue: Noqhekwana Church building at 10am \\ Date: 20 April 2012 \\ Attended by the ward committee leader and five other residents of \\ Noqhekwana village
}

Noqhekwana was chosen because it is a community without grid electricity. Residents depend on wood, paraffin, LPG and petrol generators for energy sources in their homes. I made an appointment with the ward committee leader after his details were given to me by a Ward Councillor.

The ward committee leader asked other community members and leaders to attend the meeting as he also wanted them to listen to what I had to say and contribute to the conversation. Everyone came to the meeting on time and were enthusiastic about the research and had a lot to contribute. The issues discussed are as follows:

- The people present at the meeting, including the ward committee leader did not know about FBAE. I had to explain to them and give an example of 'free electricity' that is received by residents with electricity connections.

- They have never had a discussion with the local Councillor about FBAE... although their village qualifies for this subsidy, the municipality does not provide this service to them.

- The village leaders don't know why they don't have grid electricity yet they are not sure when the municipality will give them electricity but they think that this may happen over the next 2 years, at least by 2014 . This confirms the municipality's plans as they also plan to have all the households provided with electricity by the year 2014. 
- There were conflicts between the community leadership, residents and the former Ward Councillor - Apparently he was a Cllr for 10 years and "has not done much for the community" - the leadership says they got frustrated when they asked him about the electrification status of the village as he did not give them appropriate responses and told them that he did not know the plans of the municipality.

- The community leaders said that the village is in desperate need of electricity as they have projects that depend on electrical power... these projects are:

Jam making;

Agriculture cooperative;

Basket making; and

Sewing

- The local school is also in need of electricity and the community leaders said it would be best even if the school is provided with Solar power. Eskom had come to the school previously but said they would not be able to do much as there were no power lines where they could extract electricity from for the school. This was discouraging for the school and the residents. The leadership says that this is not fair as the children are 'left behind' - they do not have exposure of working with computers and other lessons that could benefit them. This makes it difficult for the children to compete with their peers from other schools as they do not have the same level of exposure to technology and this impairs their learning abilities.

- Out of all the basic services provided by the municipality, the residents have only receive pit-latrines as part of sanitation basic services.

- Residents buy paraffin from the local shops (within the village) but they complain that it is too expensive here. They would rather buy it in town where it costs R13 to R14 per litre and R40 for a 5 litre bottle. They use paraffin for cooking and lighting when they have enough available, otherwise they use candles and wood. "Wood is the only thing we know and it is most affordable for us although we have to carry the heavy loads on our heads" said one of the residents. 
- The ward committee leader said that the electrification process is taking very long and it is going too slowly. All they know is that it is budgeted to be installed by the year 2014 - but they don't know when exactly they will receive it in their households.

- Some households have generators that use petrol but "these don't last long and the after a few uses they break down. It is expensive to repair them and it is also expensive to buy petrol all the time. For some reason, the generators are not repairable."

- A 'few months ago', the village received a visit from someone that called themselves a solar systems contractor. $\mathrm{S} / \mathrm{he}$ said the residents of Noqhekwana can have SHSs if they present 100 names of people that want SHS. They would later pay R300 for each system after wiring (installation) has taken place. The leaders said they have collected the names of households that want SHSs for themselves but they have not submitted them to the SHS contractor.

- When asked whether households in Noqhekwana are on the indigent list, the community leaders were not sure what I was talking about. I explained what the indigent list is and how households qualify to be on this list. They said that 'people from the municipality have come to the village to collect names of households that have homes in need of structural maintenance. These households were placed on the temporary structures list. The ward committee leader said that they are still waiting for these temporary structures to be built but nothing has come from the municipality'.

- The leadership showed dissatisfaction with many things that were happening or not being done by the municipality. One of the main issues is that of tourism. "Many white people and Indians come to this area to fish and because it is very beautiful. From a long time ago we were promised that a camping site area will be built in this village to accommodate the fisherman that visit the area all the time. We don't know why, but every year the money is returned to government because it is never used. There are many employment opportunities that could be created by having a camping site in this area. This year we heard that the budget for this camping project has gone up to R6 
million but we have heard nothing from the municipality on when this project will start".

- 'There seems to be a 'block' of programs here in Noqhekwana. None of the projects that are planned take shape and become successful. The municipality has a lot of problems and money is getting 'lost' all the time and it is unaccounted for. An example is that of the boats that used to help people cross the Umzimvubu river from the Noqhekwana village. These boats helped school children in the mornings and afternoons and were safe. They stopped operating because they said the municipality was not paying for the services they delivered. The municipality ended up owing the Coast Guard R55 million. The previous municipal management structure lacked disciple and management skills and left the municipality in debt and many services not delivered to people as it was promised".

- "Lack of electricity in the village means that the children are not exposed to new technologies. They cannot even compete with other children from other areas as they have no knowledge of anything happening around the world currently, especially the education that they could be getting from television. There is lack of knowledge in the village and people don't know what is happening around South Africa and in the world. They do not listen or watch the news because it is too expensive to charge batteries for the radio or the car radio for television. People cannot afford to buy batteries to operate their televisions and radio because there is no money and most people are not employed".

- The people in the village are trying to start work opportunities for themselves and have initiated some projects but all this effort is in vain because these projects depend on electrical power to run. The projects are 'jam making', 'basket weaving', 'sewing' and an 'agricultural cooperative'.

- The local school also has no electricity, the children do not have any equipment to help them learn and prepare them for the future. The pre-school which is currently located at the local church also has no equipment, toys, blankets and energy services. 
- "The village has great potential in starting a fishing project because most people fish on daily basis. They catch big fish, crayfish, mussels and oysters and they have permits to do this. The problem is that the village has no electricity and this makes it difficult for people to store their catch. If they cannot sell what they have caught, they are forced to give it away or sell at the lowest price. We are living a difficult life here, we are forced to eat everything because food gets spoilt easily if we keep it. If we slaughter a cow for a ceremony, we have to eat everything on that same day... even if you are full, you have to force the food down and leave nothing for tomorrow, else, it will go bad (there was anger on the ward committee leader's face as he was saying these words). It is also expensive for households because they have to shop more frequently than necessary... this is costly in transportation and buying smaller portions instead of bulk".

- Another problem mentioned was that of low bridges... this is a problem during rainy season as children are unable to cross the rivers to get to school and people are stuck in the village as they are trapped by high water. 


\section{Annex 2: Port St. Johns local municipality alternative energy service provider}

The former service provider that was contracted by the local municipality of Port St. Johns to maintain solar home systems ${ }^{109}$. She is no longer providing SHS maintenance for the Port St. Johns local municipality (and the other municipalities) under the OR Tambo District due to a number of issues, mainly having to do with non-payment for her services. This service provider is well experienced in solar home system maintenance as she was employed by the previous company that was contracted by government on solar home systems installations.

As a service provider in the area of Port St. Johns, she was provided with capital by Department of Energy in 2006 to start her business as a SHS maintainer in the areas previously provided with solar home systems through the government programme. She signed a service contract with the Department of Energy which introduced her to the local municipality, which she also signed a service contract with. He company serviced for local municipalities by providing solar home system maintenance services. The contact specified her responsibilities as follows:

- To conduct routine maintenance on SHSs at least every six months to ensure that the batteries are in working condition;

- To be on call for households that had maintenance issues with their systems;

- To clean the solar panels for the households.

Under the Port St. Johns local municipality, the service provider had a contract to maintain SHSs for 49 to 57 households from 2006 to October 2008. When the contract expired, she continued working under a verbal agreement with the local municipality and expected to be paid as per agreement. The service provider said the payments from the municipality stopped even though she submitted invoices and proof that solar systems were maintained. In September 2009 she decided to stop providing services

${ }^{109}$ Face-to-face interview with former solar home systems service provider on 24 June 2011. 
for the Port St. Johns municipality which impacted negatively on her business. According to the service provider, there was an internal change in management within the local municipality and she suspected that this may have brought the change and the halting of her services. She was told that the local municipality needed to verify the number of households that the service provider was maintaining systems for before they could be reappointed for further services. According to the service provider, even after the verification was carried out by a member of staff from the local municipality to ensure that all the systems claimed for were in existence, the service provider was still not paid for work done. She was told by the municipality that the internal report was not compiled by the staff member that conducted the verification process and therefore could not be submitted to the relevant authorities, hence the non-payment for her services.

\section{Difficulties faced by the Solar Home Systems service provider}

The service provider said that she recognised the compilation of indigent lists as the most challenging for the municipalities she provided services to. As discussed above, these lists are important in collecting information determining which could be used to identify indigent households that could benefit from Free Basic Services from the local municipalities. She said, she observed that even with the assistance of the district municipality in collecting information, the local municipalities still had difficulties in compiling complete and credible indigent lists.

Another problem that she faced whilst working as a maintenance provider was that of solar panels that were giving constant problems because of age. She mentioned that the solar home systems that people had in the villages where she carried out her maintenance duties, were old and needed to be replaced. When she made the municipalities aware of this, she was told that it would be too costly for them to replace these solar home systems. The service provider said it became an attractive option to stop providing services to the local municipalities as she was running out of funds. She said, as most of the systems needed replacing, especially the batteries, this 
would have been an expensive exercise, especially because the municipalities were not prepared to pay. 


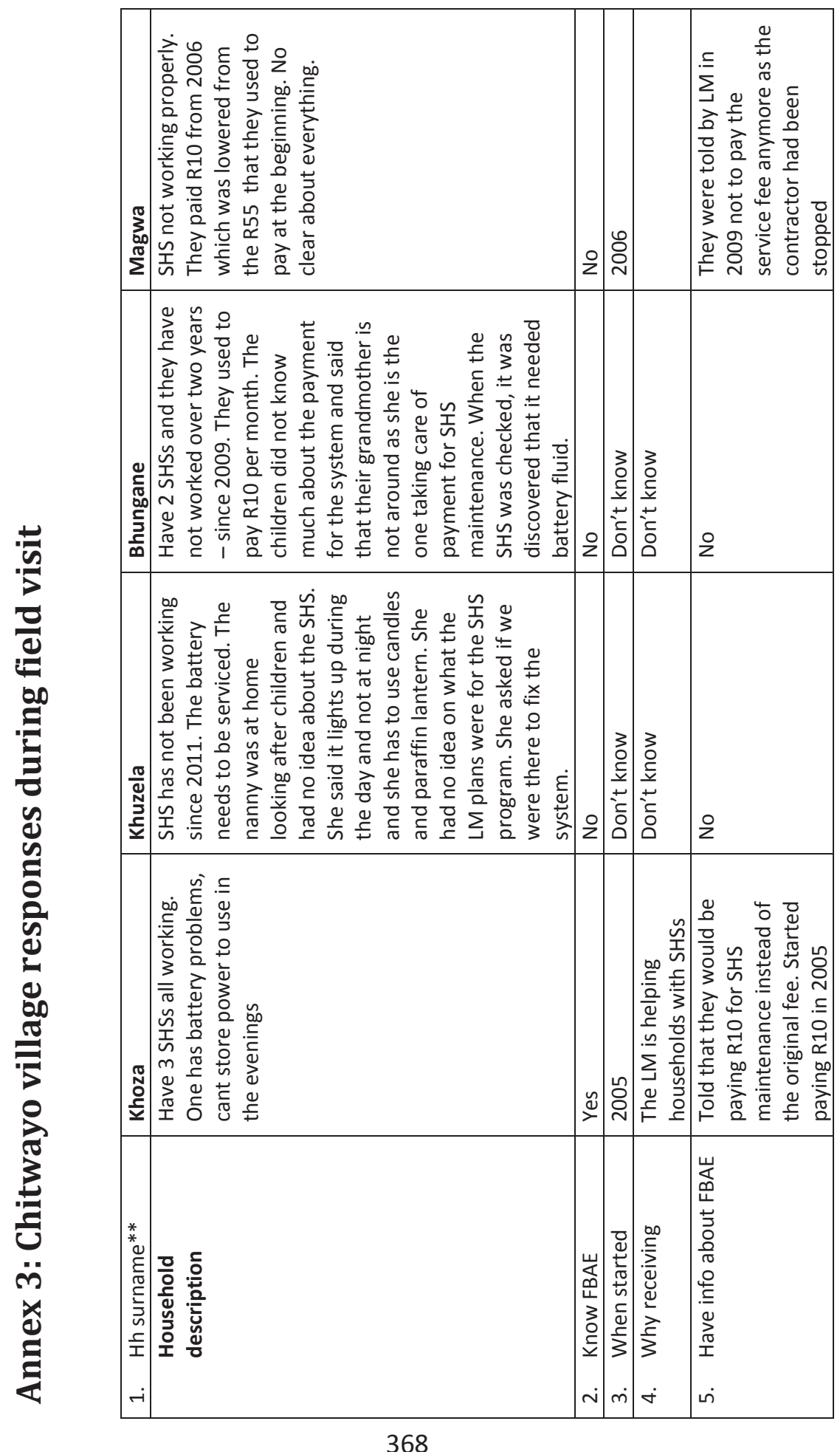




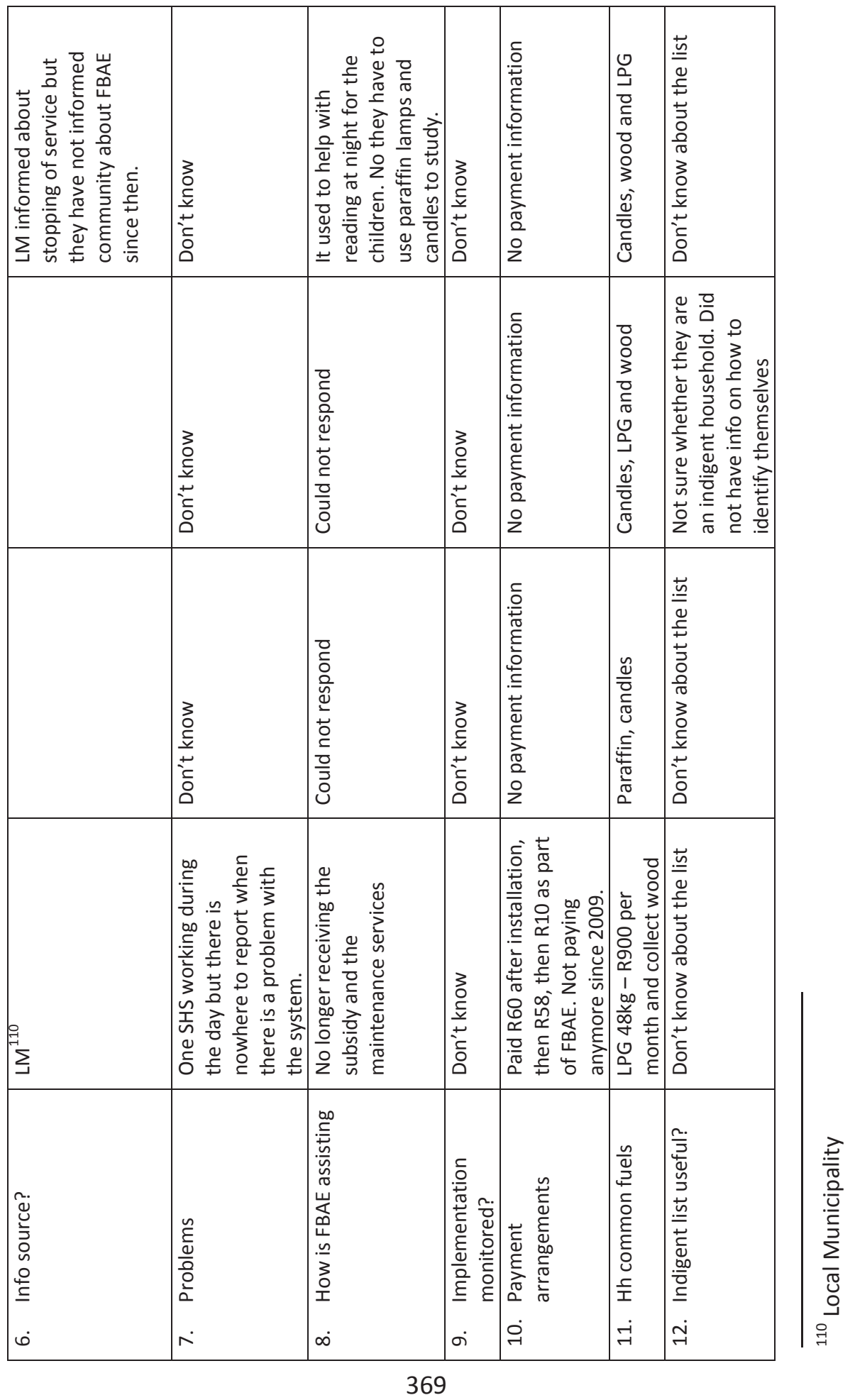




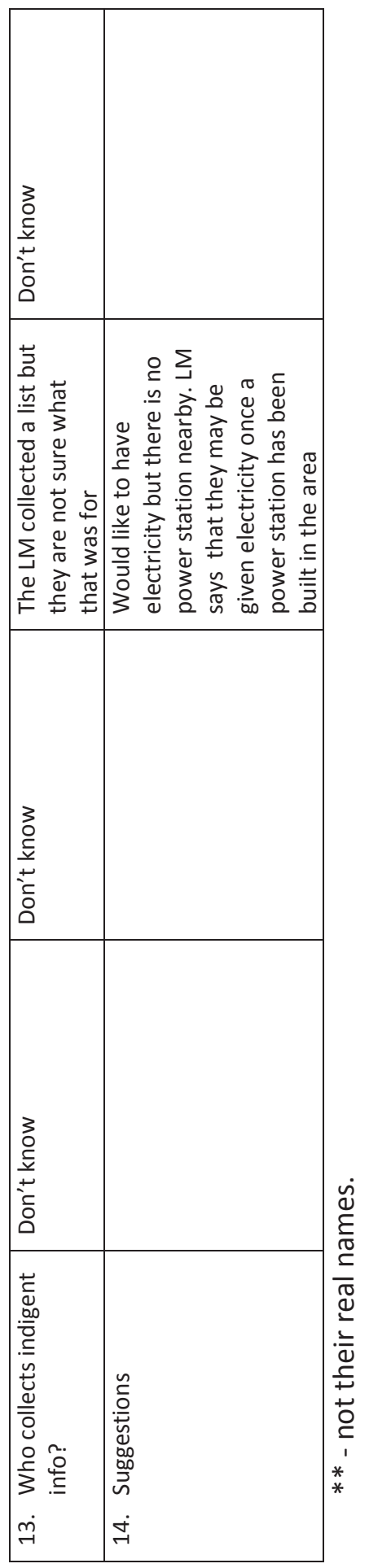




\section{Annex 4: Integrated Development Plan presentation by OR Tambo District Municipality}

Location: Ingquza Hill local municipality, Holly Cross community hall.

Date: 03 May 2012

The OR Tambo IDP document was presented by Cllr. Sociko from the District Municipality on behalf of the Mayor. The ORT DM was on a roadshow for a few weeks where Cllrs. from the district and local municipalities were calling meetings where people from different wards under an area would meet at the community halls where they would listen to the presentations and comment on the document. People were expected to give their comments on the state of issues in their areas and let the Cllrs. Know what they were not happy with when it comes to service delivery.

Cllr. Sociko presented the IDP as follows:

- Explaining what the IDP is and how it fits in the governance picture. He explained how the DM prioritizes its budget or the funds that they have available for service delivery and explained that the IDP informs the budget.

- He told the audience that it is required by law for each municipality to have an IDP document,

- He explained that all projects that are under the municipality, are supposed to be on the IDP document,

- The Cllr. explained that the IDP ensures that everything planned by the municipality goes according to plan,

- He said that the people had the right to hold the ORT DM and their municipality responsible for what is documented on the IDP document,

- The IDP is a way that the municipality works towards bridging the urban and rural divide by ensuring that rural areas benefits from services that are available in the urban areas. 
- $\quad$ The Cllr. explained that plans from different villages make up Ward Plans which in turn when combined, are formulated into IDP documents at local municipality level then to the District Municipality levels.

- The IDP documents formulated need to convince investors that the area is worth investing money on. It is a document that shows opportunities for potential investors from within the area and outside.

- The IDP document links the past and the present budget reviews to show what has been done in the past with the funds allocated and what is to be done whilst stating the amount of funds needed for this.

- The 'Situational Analysis' (page 6-7) of the IDP document shows the five local municipalities under the OR Tambo District and demographic information such as population statistics, gender composition, education \& educational facilities, employment statistics and income levels.

- For each IDP there are Key Performance Areas that are used to judge and monitor progress of how the LMs are working and whether they are meeting the goals as stated on the IDP documents.

\section{Comments and Questions from the audience:}

1. "There is no water in most wards under the IHLM. What does the ORT DM plan to do about this? We have been given water tanks but they are empty and the LM is not filling them for us."

ORTDM: "The DM has bought water tanks and brought them to the local municipalities and it is the responsibility of that LM to ensure that they provide water for that ward or area. Each municipality has also been supplied with a water trunk that they are supposed to use to fill the tanks. The complaint should therefore be directed at the local municipality because we have played our role".

2. "In the previous IDP meetings we raised issues such as fencing of our ponds and we were promised that this would happen but it has not 
been done. We have to share water with cows and other livestock and it is more difficult in winter when we don't have enough water. People end up being sick from sharing water with animals".

ORTDM: "The issue of fencing the water places is still under discussion and unfortunately, no decision has been taken yet. It is also the responsibility of a $L M$ to ensure that its areas have sufficient drinking water".

3. "There is a need of public toilets in the town area as what we are forced to be exposed to is embarrassing. Old men and women have to relieve themselves in the open when they visit town".

ORTDM: "I agree, the situation in town is embarrassing. Everyone relieves themselves in the open and children lose respect for adults when they see them in that position. There are plans to construct sanitation facilities in the town area and we hope that this will be done".

4. "There is a great need for banking services in the rural areas, especially during social grant pay-out days when people end up spending up to R70 on transport - money which they could be using to feed their families".

ORTDM: "We have to understand that banking is a private business and it is not provided by government. If a bank is going to have its facilities in the area, this needs to be worth it for the bank and the area has to have businesses. Unfortunately, we cannot guarantee that the banks will come and open branches in the rural areas".

5. "How many times will the budget be presented before action is taken? We have been attending these meetings every year and we are told the same thing, but we never see any action. What is the point"?

ORTDM: "We have been providing services and there are visible things that have been done based on the previous budget presentations". 
6. "I am unhappy about the lack of basic services in this area, there has not been any improvement at all".

ORTDM: "The DM is trying hard to provide services to all areas but our mandate as the DM is to deliver water services and sanitation, which we are doing. Other basic services are responsibility of the local municipalities".

7. A man complained about nepotism and awarding of tenders and contracts in the area. He said tenders were given to people that have no interest in the development of an area and the DM is not following up on that, which means 'you are not following up on the money you are spending and are giving an impression that it is ok to waste this money'. The man complained about the recent installation of VIP toilets in his area. He said, although the toilets look beautiful from the outside, the service provider did not do a good job. Instead, his own toilet filled up quicker than the one he had been using previously and had built himself. The new toilet was useless for him and his family.

ORTDM: "We are not aware of this problem in your area but we will follow up on the toilets that were installed to check for quality". 


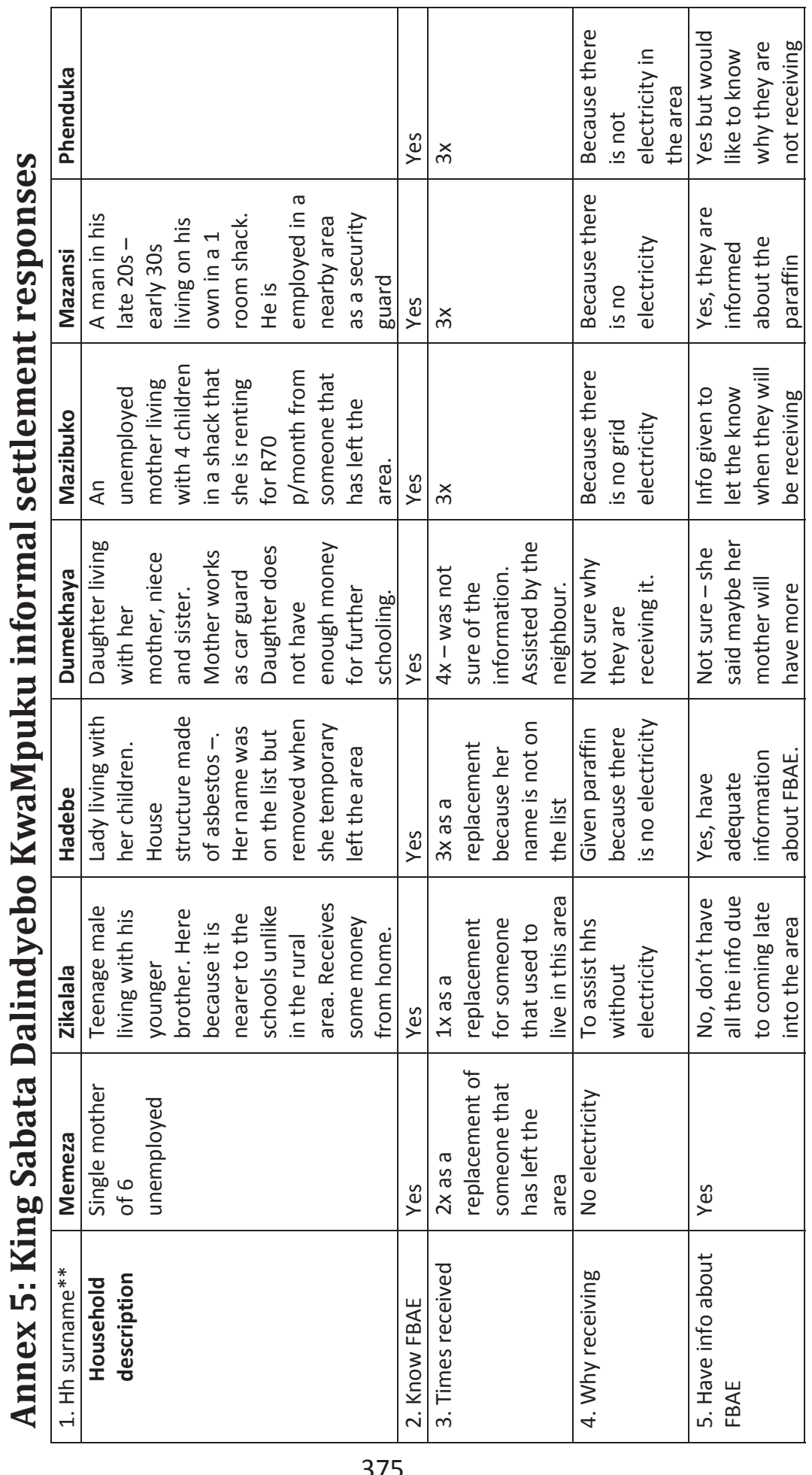




\begin{tabular}{|c|c|c|c|}
\hline 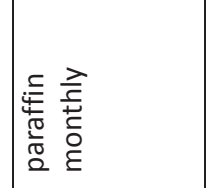 & $\sum_{3}$ & 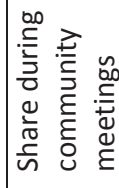 & 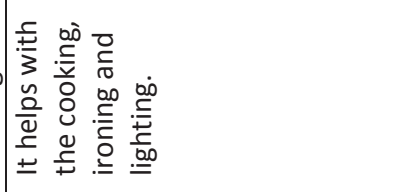 \\
\hline 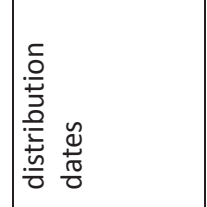 & $\sum_{3}$ & 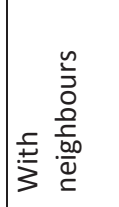 & 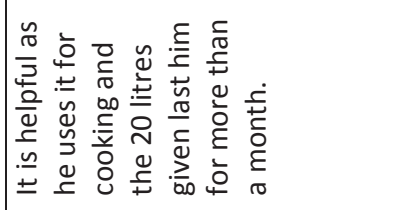 \\
\hline 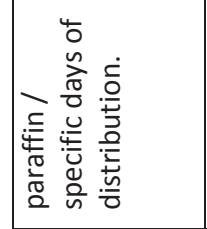 & $\sum_{3}$ & 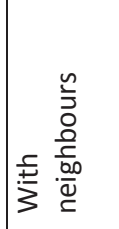 & 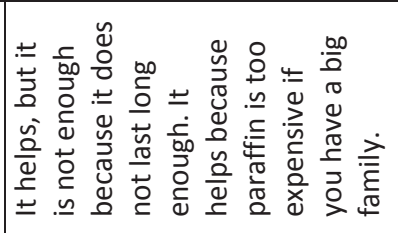 \\
\hline 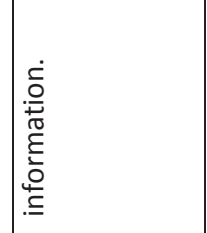 & & & 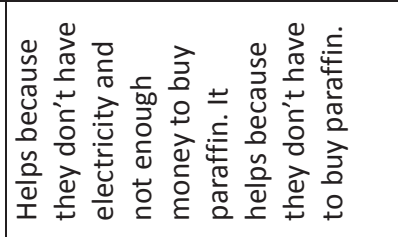 \\
\hline 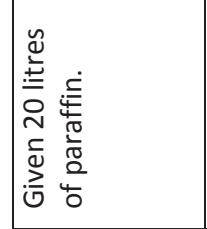 & $\sum_{\substack{\infty \\
\infty}}^{\infty}$ & 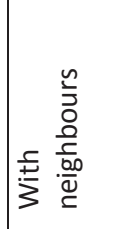 & 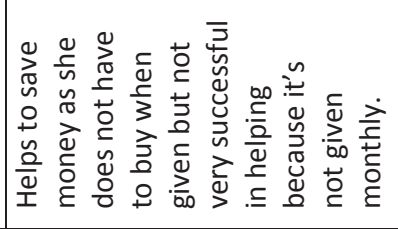 \\
\hline \multirow[t]{3}{*}{ 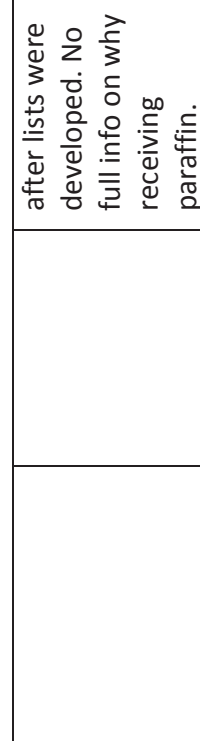 } & 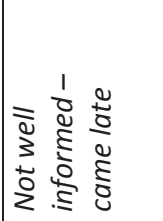 & $\frac{\pi}{2}$ & 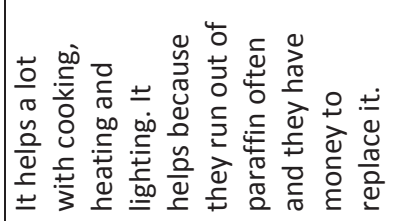 \\
\hline & 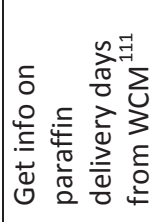 & 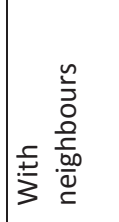 & 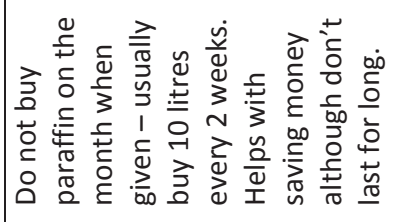 \\
\hline & 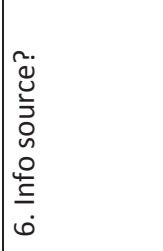 & 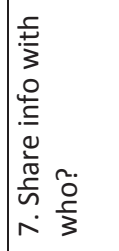 & 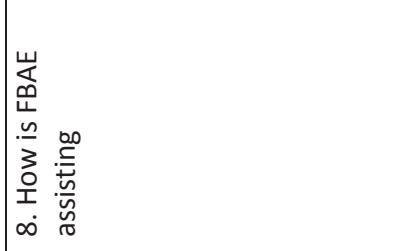 \\
\hline
\end{tabular}




\begin{tabular}{|c|c|c|}
\hline 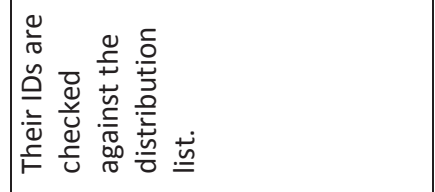 & 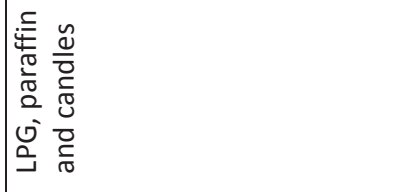 & \\
\hline 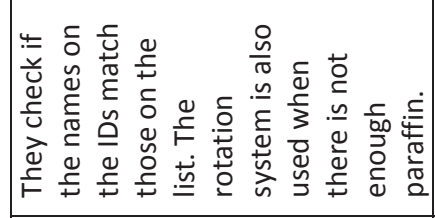 & 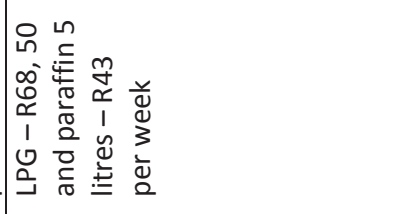 & 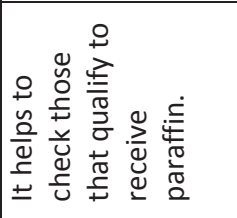 \\
\hline 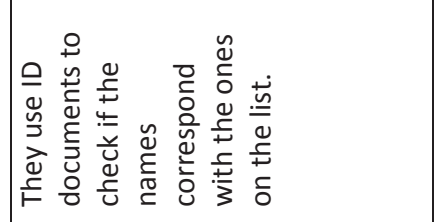 & 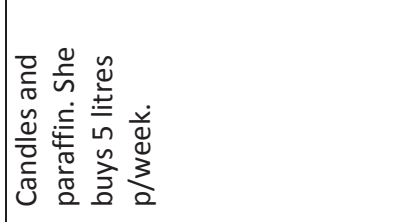 & 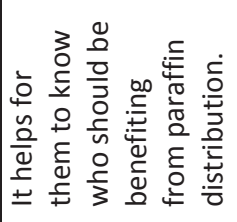 \\
\hline 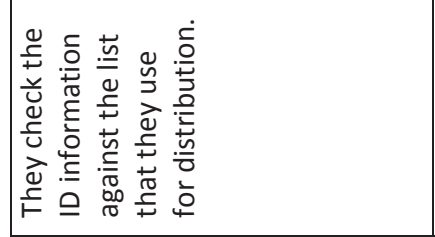 & 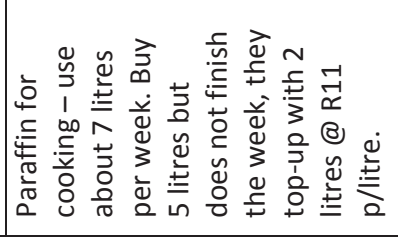 & \\
\hline 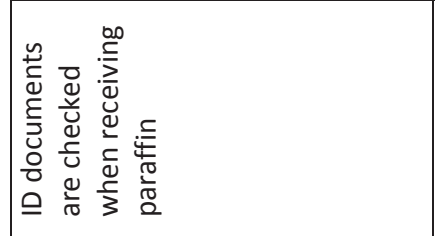 & 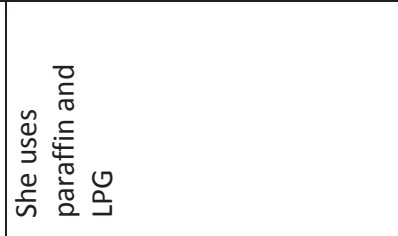 & 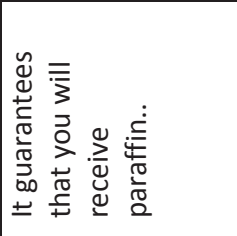 \\
\hline 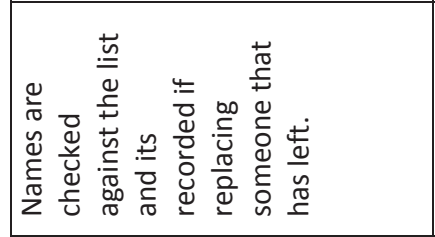 & 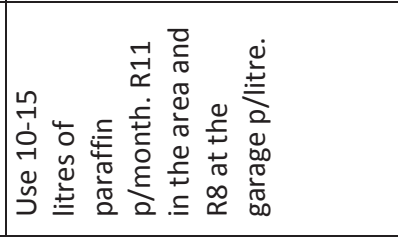 & 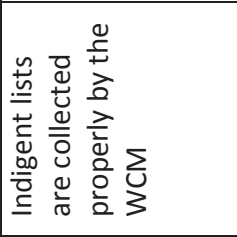 \\
\hline 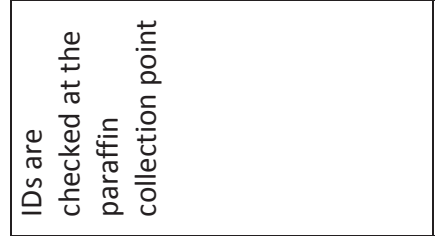 & 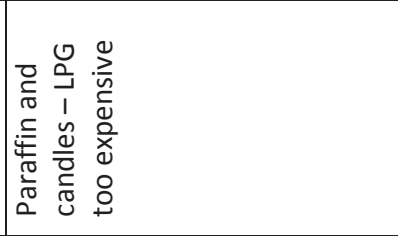 & 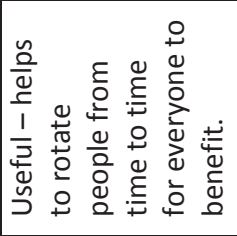 \\
\hline 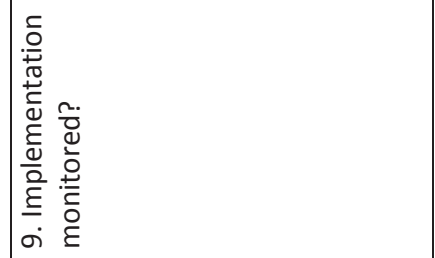 & 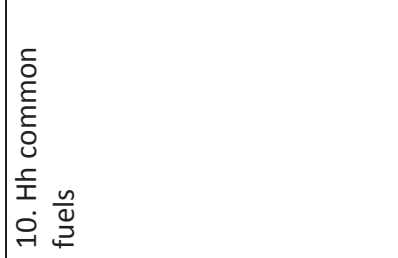 & 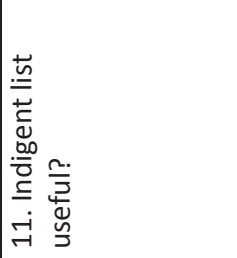 \\
\hline
\end{tabular}




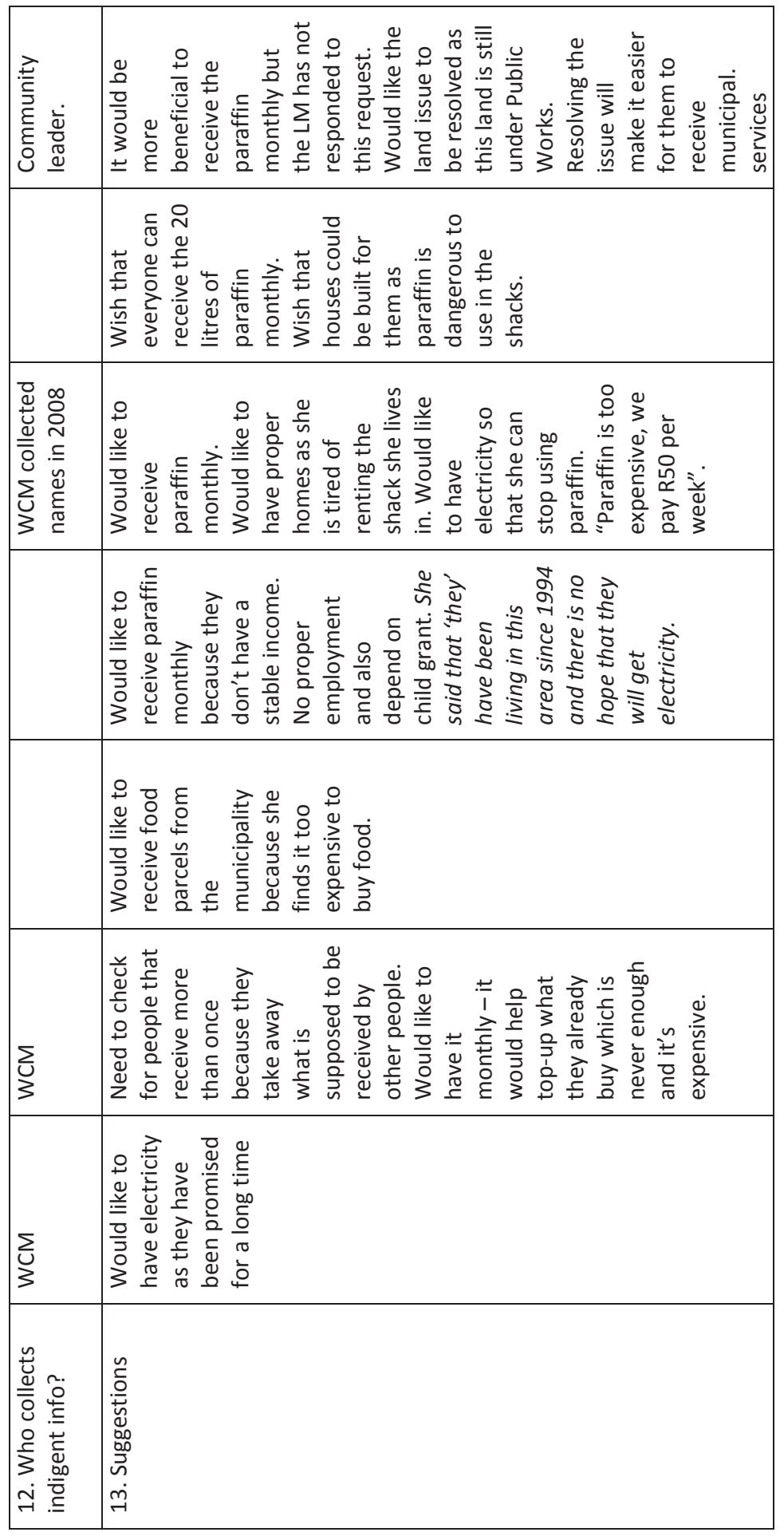

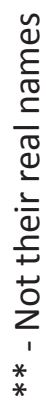




\section{Annex 6: Observations made during household interviews at KwaMpuku settlement}

During the interviews with households, it was clear that people knew what I was asking them about when I mentioned Free Basic Services and used the paraffin they were receiving as an example. All the households said that they knew that they were receiving paraffin because they did not have electricity in their homes and this was a way that the municipality (government) was helping them. During the interviews I made some observations where I saw that households had very minimum resources in their homes. Their homes were mostly built with a combination of wood and corrugated iron. The floors were compressed mud and some covered with a carpet or a vinyl sheet. The shacks were not more than $18 \mathrm{~m}^{2}$ and out of the households I visited, only one person stayed by himself. The rest of the homes were occupied by more than one person - they were occupied by families. The family situations were different and the only two things in common. The first one was that they lived in Kwampuku and the second was that they were experiencing poverty. The people I spoke with had different stories of how they lived, survived and how the paraffin they received from the municipality was assisting them. Families ranged from two person households to homes where a mother lived with her four grown children in a shack. Out of all the people I spoke with, only one was employed. The others depended on social grants and sold fruit and vegetables on the side of the Mthatha roads. One of the households I spoke with had a young lady that had finished her secondary school and because she was unable to secure a bursary, she could not attend university due to lack of funding. She said she lives with her mother, her younger sister and her niece (her older sister's daughter). Her mother is not officially employed but makes a living as a car guard at the local shopping centre. Typically at the Mthatha Plaza shopping centre, women work as car guards. They indicate open parking spaces to vehicles arriving at the shopping centre. Once parked, they ask the driver if they can look after the car whilst s/he does some shopping inside the mall. By agreeing, the car driver indicates his or her willingness to pay for the guarding services provided by the car 
guard. The payment does not depend on the amount of time that the vehicle is left at the parking area but on whatever amount the driver can 'afford' to pay the car guard. The amount paid to the car guard ranges from two to five rands (twenty to fifty euro cents). Some drivers give more, some less and some nothing at all. It all depends on the car driver. The shopping centre is very busy and it would be safe to estimate that the women car guards assist at least 20 cars on average on a normal week day. The number of cars may be more depending on how busy the shopping centre is, especially on weekends. On a personal note, a few days before I interviewed the young lady that informed me that her mother is her car guard, I had my reservations about paying the women that offered to look after the car I was driving. One day I drove to the shopping centre for some food stuff and I sat in the parked car for a few minutes before getting into the shops. I sat there to observe what these women car guards were really doing, and I concluded that it did not make sense to pay these women as they did not really do any work regarding the guarding of cars. As cars approach the parking area, the women would be sitting there and they would start indicating to the driver where they can park. A parking space that you as a driver of a vehicle would have been able to spot without any assistance. If the car guard feels that you are having difficulty with parking your vehicle, she stands up from her chair and with her hands, waves to you the direction you should swerve to in order to get your car in the parking space. When you come back to your car, she will stand from her chair to assist you with reversing out of the parking area by which time she moves closer to your window with an extended arm indicating that you should give her some money. The shopping centre parking area does not pose any visible threat of theft or harm to the vehicles. I also thought to myself that if there was a real crime problem in the shopping centre vicinity, the shopping centre management would have professional guards as it happens in most shopping centres in South Africa. Until that young lady told me that her mother works as a car guard, I had not considered that these women car guards are making ends meet by guarding these cars. The money they were receiving for the work they were doing was feeding their families beyond what I could begin to imagine and understand. Their sitting on chairs was a sign of laziness to me, and I did not consider that they may be tired from 
hours of sitting in the sun, cold, rain and all weather elements without any cover because they needed to make a living for their families.

A few other households that I had a chance to engage with during the interviews gave me their stories without any hesitation. In fact, they were curious about where I came from and what I would do with the information. They spoke to me and expressed their gratitude for the paraffin they were receiving from the municipality and expressed that if it would be possible, I should let the municipality know that they would like to receive more of this fuel. 


\section{Annex 7: Transcription of live recording of the Gqwesa village meeting and observations}

Upon arrival at Gqwesa village, the district municipality representative accompanying the local municipality Free Basic Services coordinators addressed the villagers in attendance ${ }^{112}$. His responsibility was to explain how and why the people in the village were receiving free basic services.

"We would like to assure you that government services do not come only before voting time, as you can see, we are here to deliver a service to you and this has nothing to do with upcoming elections. The government is giving money to people that are supposed to be receiving subsidies. This money is not supposed to be given to people that are employed or can manage to find work. Pensions and grants should be directed to the elderly and not to people that are working or have the ability to work. There are conditions that we have to follow, such as the number of children that women are allowed to get the support grant for. This number should not exceed three children at a time. The government says that if someone is working or has a partner that also works, if their income is R2045,00 or less, they qualify for the state grant and subsidies (including Free Basic Alternative Energy). If the couple is old (pension age), they can even get grants for their children and grand-children, they still do qualify for indigent services because of their age and their conditions of living are taken into consideration as the places they live, such as this village, are poor.

\footnotetext{
${ }^{112}$ The visit to Gqwesa village took place on 14 May 2012 and I was invited to observe how municipal representatives inform communities on free basic services and collect information to update their indigent register.
} 


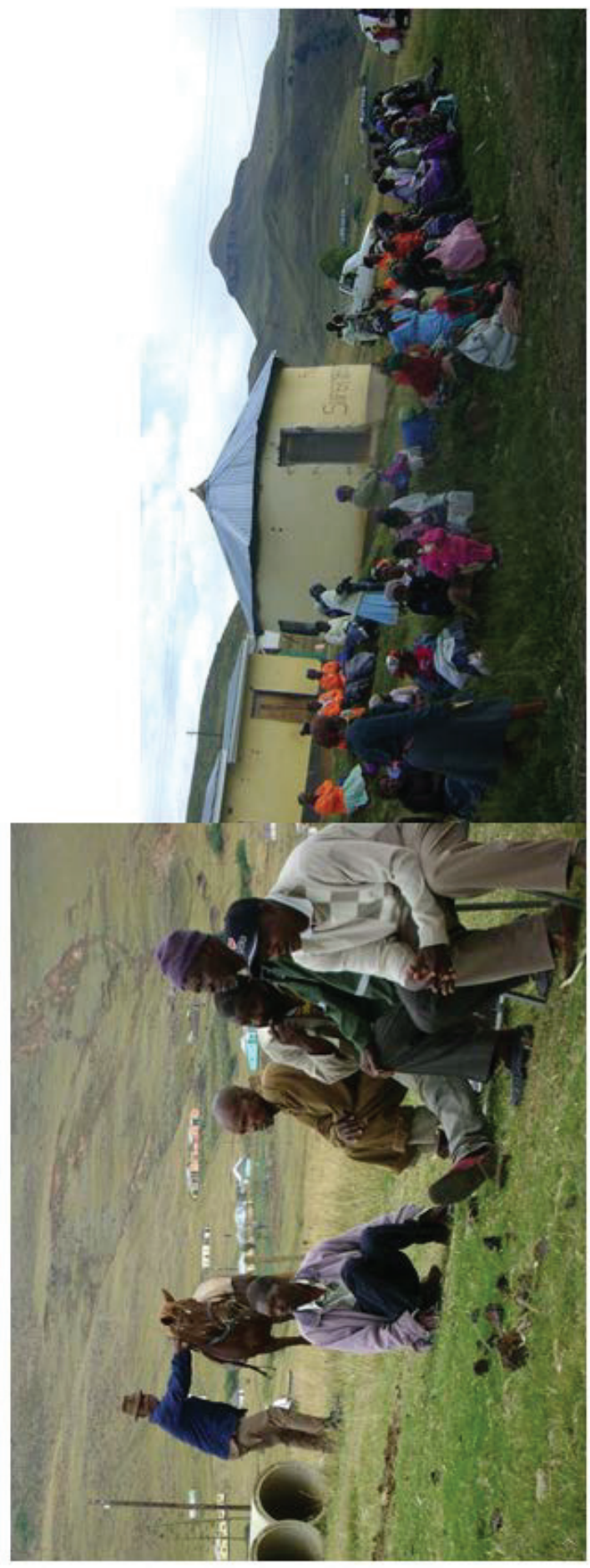

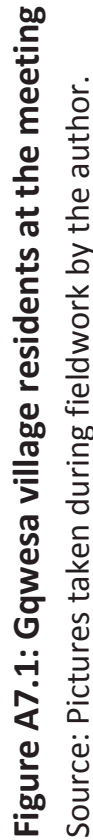


The difference is that if an elderly person, has children that are working and have stable employment, they should not be benefitting from all government programs as their children should (and would) be assisting them to pay for and access their everyday needs. It is like the issue of paraffin distribution - we prefer that we first give the people in extremely difficult and poor conditions such as the elderly people, afterwards the others may follow.

We are here today to verify the information we have on people that qualify for basic services and are on our lists which we are going to read out to you now. If your name is already on the list and your details are correct, you can go home because it means that we have captured your details and you qualify for subsidized services. If your name is not read out, we will register you immediately. We want to make sure that we put people that qualify on the list so that we don't have incorrect people benefitting. If there are women with husbands working in urban areas, you will not be able to qualify for all the benefits such as food parcels but you will be able to get things such as paraffin (FBAE).

Now we will take some questions from you if you need some clarification on what has been said

\section{Questions:}

1. Do people looking after orphans and getting child welfare grants qualify for government subsidized services?

Answer: This question should be responded to by the Ward Councillor... she will check the ages of the orphaned children you are looking after and let you know which ones qualify.

2. My husband gets a disability grant from time to time but it is not enough for us, can I qualify for other state grants and subsidies? 
Answer: Yes, you should be able to qualify for other state grants if you are not receiving any other income. Even those that have temporary work should still benefit from the government grants because their work is not permanent.

3. What about if I am looking after disabled children?

Answer: You are supposed to benefit from the government grants.

\section{Verification of names on the indigent register}

My colleague is going to read the names of the people on the list. Please assist us if you know who is being referred to. Please help us register the people that you live with currently, not those living away from home.

During the registration of your households on the indigent lists, please note that the household head should always be the "Father" or the eldest male member of the household, if they are not present, then the household head should be the eldest female member of the household.

People's names were called out to verify them from the list. People were called by their first names and year of birth e.g. Florence born in ' 56 , Nothulani born in '66, etc.

\section{Observations:}

As the municipality representative was calling out people's names from her laptop computer, I observed the following: Although the process was good, it was confusing to some people. At some instances, the municipality representative was too quick to move to the next name on the list and because of the crowd of people and the fact that the meeting was held outdoors, it was difficult for some people to hear their names being called out. Another unfortunate thing is that only 'first names' were called out and their year of birth. People were not sure whether if it was them that were being called and were confused by the process. They said they do not 
address each other by their first names, especially those on their identification documents as they are in English. In the village they address each other by their traditional isiXhosa names, which are usually not on their official documents. Moreover, married women are always addressed by their husbands' surnames as a sign of respect to their marital status and the use of their first names in everyday village conversation is extremely uncommon. As a result of this, the municipality representative was asked to go back to re-read the names a number of times and some in instances that she could not hear the request, people passed on information they were not sure of about the names that were called out.

After the verification of names, all those that had not been called out but were present at the gathering, were asked to go to one of the huts where the local and district municipality representatives would record their details and add their names on to the indigent register. 


\section{Summary}

With the aim of contributing to the goal of universal access to modern energy services for all in the context of South Africa, this study examines how successful the implementation of the Free Basic Alternative Energy (FBAE) policy has been in respect of energy services in the rural areas of OR Tambo district in the Eastern Cape. Many rural municipalities have not been able to successfully implement the FBAE policy, where successful implementation refers to a situation where the implementation of the FBAE policy leads to satisfactory delivery of alternative energy services to unelectrified indigent households in each local municipality. This means many low-income households in the remote rural areas have to depend on low quality energy sources such as wood that they collect, candles and paraffin. Port St. Johns, Ingquza Hill, King Sabata Dalindyebo, Nyandeni and Mhlontlo are the five local municipalities under the jurisdiction of the OR Tambo district and in this study they are used as cases to show the complexities involved in the process of implementing the FBAE policy. The areas within these municipalities are rural and not all of them have access to grid electricity, hence the need to provide alternative energy services. One of the ways to do this is by implementing the Free Basic Alternative Energy (FBAE) policy.

This study provides an in-depth analysis of the implementation of the FBAE policy in the rural areas and with the use of the Contextual Interaction Theory (CIT) (Bressers 2004, 2009) the study focuses on how actors and their characteristics influence the FBAE policy implementation process. The use of the CIT framework makes it possible to seek understanding of how the actors' motivations, cognitions, capacity and power influence the implementation process and in turn, how they influence each other. In addition, the study is interested in the complex relationships between the actors and how these relationships are influenced by the implementation process and by the actor characteristics. 
Chapter 1 of the thesis provides the background of the study, the study objectives and the research questions. The research questions were developed with the aim to find out how the actors (individuals, groups, organisations and institutions) within these municipal areas and in the other levels of government (provincial and national) influence the FBAE policy implementation process. The methodology section focuses on how 1 selected the OR Tambo district and its municipal areas as suitable for the analysis of the FBAE policy implementation process. A combination of qualitative research methods was used as a result of a variety of circumstances presented by the field. Most of the data was gathered with the use of in-depth interviews and these were mostly with municipal, provincial and national government officials. Other forms of data gathering used in this study include meetings with the community representatives which took the form of focus-group discussions, brief unstructured household interviews and observations.

Chapter 2 provides an introduction of the Free Basic Alternative Energy (FBAE) policy and the South African energy context. This chapter starts off with a brief synopsis of policy changes and their impacts which sets the scene for the rest of the chapter as it refers to South Africa's transition from an apartheid state to a democratic state and how this impacted on policy formulation and implementation. The analysis of the South African energy policy development in this chapter starts with the year 1994, the year that marks the country's independence, to the current period where I focus on the implementation of the FBAE policy. Here, the reader is provided with the background to the development of the White Paper on Energy Policy for the Republic of South Africa of 1998 and how its implementation where household energy provision is concerned, resulted to the development of other policies which include the Free Basic Alternative Energy policy. The chapter gives reasons behind government's decisions to provide free basic services to low-income households in the rural and the urban areas. 
Chapter 3 focuses on the Contextual Interaction Theory (CIT) as a theoretical framework used in this study. Here, a brief historical background of implementation research and its influence to the current implementation theories is given. The focus of the chapter narrows to concentrate on CIT by giving a brief history of this theoretical framework and how it has developed over the years through use in different projects, academia and implementation settings. I then focus on how I have adopted the $\mathrm{CIT}$ to fit into a developing country study context and how this leads to the re-definition of some of this theory's concepts. Adapting this theory to the developing country's context also led to the need to develop and introduce a three-actor model to the CIT framework in order to for the theory to suit the setting of my study.

Chapter 4 presents an overview of how different levels of government are involved in the implementation of the FBAE policy. I provide a background of the main roles of the key government spheres as well as the other stakeholders that are involved in the FBAE policy implementation process. The importance of this chapter is that is it highlights the different stages that the FBAE policy implementation process goes through and how the actors in each phase influence this process. At the end, the chapter highlights the important responsibility that is placed on the local municipalities as they are expected to deliver energy sources in order to provide energy services to unelectrified indigent households through the implementation of the FBAE policy. Even though in the past the local municipalities were not responsible for providing energy services, the FBAE policy forces this sphere of government to integrate energy services into their daily plans and activities.

Chapters 5, 6, 7, 8 and 9 focus on Port St. Johns, Ingquza Hill, King Sabata Dalindyebo, Nyandeni and Mhlontlo municipal areas respectively as cases researched for this study to analyse the implementation of the FBAE policy by rural municipalities. In these chapters the Contextual Interaction Theory 
is extensively used to analyse the dynamic interaction between the key actor-characteristics that drive the social interaction process. These chapters are structured in a similar way to provide information on the similar issues that arise in the analyses of these cases. In each of these chapters, the areas are described to provide evidence that even though they are within the same district and are located in rural areas, their FBAE policy implementation approach is not the same due to a number of factors. In these chapters I also give a brief background of the importance of the indigent register for each municipal area and how this directly influences the FBAE policy implementation process. As the source of information, the indigent register is also important in the analysis of the case studies through CIT as it forms part of the actor's cognitions.

Chapter 10 is divided into two parts. The first part provides a comparative analysis of the five cases mentioned above and the second part provides the study conclusions. In this chapter I start with the an overview of energy access in the five municipalities researched for this study. Energy access analysis provides the reader with an understanding of the households' energy needs in these municipal areas and in turn highlights the need for alternative energy services that could be provided by implementing the FBAE energy policy. As with the previous chapters, in this chapter I continue to use the Contextual Interaction Theory to compare the similarities and differences in the interaction processes and FBAE policy implementation experiences in each case. Comparing the cases provides an understanding of why each municipal area implement the FBAE policy the way they do and how actors and their characteristics influence the implementation process. The first part of this chapter concludes with the rating of the five cases based on the results of the actor-interaction analysis as they implement the FBAE policy. This analysis of relationships between actors can thus be considered as a useful addition and an extension to the comparison of implementation scores with actor characteristics, but not as a potential replacement thereof. This rating superficially measures results of each case, the implementation success levels of the five cases are compared and rated to create a form of overview summary of the case chapters using a few words that capture and describe the success levels. Finally, the chapter 
and this thesis concludes with a section on conclusions and outlook in which the research questions are answered, the theoretical approach used in this thesis is reflected upon and some possible outlooks for research and practice are presented. 


\section{Samenvatting}

Dit proefschrift wil eraan bijdragen dat iedereen in Zuid Afrika toegang krijgt tot moderne energiediensten. Daarom onderzoekt dit proefschrift hoe succesvol de implementatie van het "Free Basic Alternative Energy (FBAE)" beleid is geweest. De studie concentreert zich op het leveren van energiediensten op het platteland van de relatief onontwikkelde OR Tambo regio in de Oostkaap provincie. Veel plattelandsgemeentes zijn er niet in geslaagd om dit FBAE-beleid succesvol te implementeren. Onder succesvolle implementatie wordt hier een situatie verstaan, waarin de implementatie van het FBAE-beleid leidt tot een toereikende levering van alternatieve energiediensten aan behoeftige huishoudens in elke lokale gemeente die niet zijn aangesloten op het elektriciteitsnet. Dit betekent, dat veel huishoudens met een laag inkomen in afgelegen gebieden afhankelijk zijn van energiebronnen van lage kwaliteit, zoals verzameld brandhout, kaarsen en paraffine. Port St. Johns, Ingquza Hill, King Sabata Dalindyebo, Nyandeni en Mhlontlo zijn de vijf gemeentes die samen het OR Tambo district vormen en die in dit onderzoek worden gebruikt als casussen om de complexiteit van het implementatieproces van het FBAE-beleid te bestuderen. Deze plattelandsgebieden hebben maar voor een deel toegang tot het elektriciteitsnet. Vandaar de noodzaak om in alternatieve energiediensten te voorzien. Eén van de manieren om dit te bereiken is de implementatie van het "Free Basic Alternative Energy (FBAE)" beleid.

Dit onderzoek levert een diepgaande analyse van de implementatie van het FBAE-beleid in de vijf gemeenten. Met behulp van de Contextuele Interactie Theorie (CIT) (Bressers 2004, 2009) richt dit onderzoek zich op de manier waarop actoren en hun kenmerken het implementatieproces van het FBAEbeleid beïnvloeden. Zo helpt het CIT raamwerk om inzicht te krijgen in de manier waarop motivatie, cognitie, capaciteit en macht van actoren het implementatieproces beïnvloeden en hoe deze kenmerken elkaar beïnvloeden. Bovendien is dit onderzoek geïnteresseerd in de complexe verbanden tussen de actoren en hoe deze verbanden worden beïnvloed door het implementatieproces en de actorkenmerken. 
Hoofdstuk 1 van dit proefschrift geeft de achtergrond van het onderzoek, de onderzoeksdoelen en de onderzoeksvragen weer. De onderzoeksvragen zijn opgesteld met het doel om uit te zoeken hoe de actoren (individuen, groepen, organisaties en instituties) binnen deze gemeentes en bij de andere overheidsniveaus (provinciaal en nationaal) het FBAE implementatieproces beïnvloeden. De sectie over methodologie richt zich onder meer op de redenen waarom het OR Tambo district en zijn gemeentes geschikt zijn voor de analyse van het FBAEbeleidsimplementatieproces. Als gevolg van de omstandigheden in het veld is een combinatie van kwalitatieve onderzoeksmethoden toegepast. De dataverzameling verliep hoofdzakelijk via diepte-interviews met gemeentelijke, provinciale en landelijke ambtenaren. Bovendien is voor de dataverzameling ook gebruik gemaakt van focus-groep discussies met vertegenwoordigers van de lokale bevolking, korte, ongestructureerde interviews met huishoudens en observaties.

Hoofdstuk 2 geeft een overzicht van het Free Basic Alternative Energy (FBAE) beleid en de Zuid-Afrikaanse context. Het hoofdstuk begint met een korte samenvatting van beleidsveranderingen en de effecten van die veranderingen. Dit legt de basis voor het vervolg van het hoofdstuk: hierin wordt de transitie van Zuid-Afrika van een apartheidsstaat naar een democratische staat beschreven en hoe deze transitie de formulering en implementatie van beleid heeft beïnvloed. De analyse van de ontwikkeling van het Zuid-Afrikaanse energiebeleid begint in het jaar 1994, het onafhankelijkheidsjaar, en gaat door tot het heden, waarin de focus ligt op de implementatie van het FBAE-beleid. Daarnaast worden hier de achtergronden van de ontwikkeling van het "White Paper on Energy" voor de Republiek Zuid-Afrika uit 1998 weergegeven en hoe de implementatie van het White Paper, waar het om huishoudelijke energievoorziening ging, heeft geresulteerd in de ontwikkeling van nieuw beleid waaronder het "Free Basic Alternative Energy" beleid. Het hoofdstuk presenteert redenen achter de overheidsbeslissing, om landelijke en stedelijke huishoudens met lage inkomens te voorzien van kosteloze basisvoorzieningen, zoals energie. 
Hoofdstuk 3 richt zich op Contextuele Interactie Theorie (CIT) als het theoretische raamwerk van dit onderzoek. Het hoofdstuk beschrijft de historische achtergrond van implementatieonderzoek en de invloed daarvan op de huidige generatie van implementatie-theorieën. Er volgt een verdieping van $\mathrm{CIT}$ door middel van een korte geschiedenis van dit theoretische raamwerk en zijn ontwikkeling door de jaren heen door zijn toepassing in verscheidene projecten, door verschillende wetenschappers en in diverse uitvoeringsomstandigheden. Vervolgens wordt beschreven hoe CIT voor dit onderzoek aangepast wordt voor de onderzoekscontext van een ontwikkelingsland. Dit leidt tot de herdefinitie van een aantal van de concepten van de CIT. De aanpassing van de theorie aan de context van een ontwikkelingsland heeft ook geleid tot de ontwikkeling van een drieactorenmodel binnen het CIT raamwerk.

Hoofdstuk 4 presenteert een overzicht van de manier waarop verschillende overheidsniveaus betrokken zijn bij de implementatie van het FBAE-beleid. Het hoofdstuk geeft een achtergrond van de belangrijkste rollen van de betrokken overheden en van de andere stakeholders die betrokken zijn bij de FBAE-beleidsimplementatie. Het belang van dit hoofdstuk zit in het feit dat het de verschillende fases uitlegt waaruit een FBAEbeleidsimplementatieproces bestaat en de manier waarop actoren het proces in elke fase kunnen beïnvloeden. Tegen het einde van het hoofdstuk wordt de belangrijke verantwoordelijkheid van lokale gemeentes beschreven. Van gemeentes wordt immers verwacht, dat zij door het FBAEbeleid te implementeren energiediensten kunnen leveren aan behoeftige huishoudens met lage inkomens die niet zijn aangesloten op het elektriciteitsnet. Ook al waren lokale gemeentes eerder niet verantwoordelijk voor de levering van energiediensten, het FBAE-beleid $d$ wingt in principe dit overheidsniveau om energiediensten in hun dagelijkse plannen en activiteiten te integreren. 
De hoofdstukken 5, 6, 7, 8 en 9 richten zich respectievelijk op de gemeentes Port St. Johns, Ingquza Hill, King Sabata Dalindyebo, Nyandeni en Mhlontlo. Dit zijn de casussen waarin de implementatie van FBAE-beleid in landelijke gemeentes wordt onderzocht. In deze hoofdstukken wordt intensief gebruik gemaakt van Contextuele Interactie Theorie om de dynamische interactie te analyseren tussen de belangrijkste actorkenmerken die het sociale interactieproces aandrijven. De hoofdstukken volgen dezelfde structuur om de informatie over aspecten die uit de analyse van de cases volgen beter te kunnen vergelijken. In elk hoofdstuk worden de onderzochte gebieden beschreven om te onderbouwen dat de omstandigheden voor de FBAE-beleidsimplementatie door enkele factoren verschillen, terwijl de gebieden zich in hetzelfde district en landelijk gebied bevinden. Bovendien wordt in deze hoofdstukken ook het belang van het "behoeftigenregister" voor elke respectievelijke gemeente uitgelegd en de directe invloed hiervan op het FBAE-beleidsimplementatieproces. Als bron van informatie over wie recht heeft op de energiediensten is het behoeftigenregister ook van belang in de analyse van de casussen met CIT, omdat het een onderdeel is van de cognities van actoren.

Hoofdstuk 10 bestaat uit twee delen. In het eerste deel worden de vijf casussen vergelijkend geanalyseerd. Het tweede deel presenteert de conclusies van het onderzoek. Het hoofdstuk begint met een overzicht van de mate van toegang tot diverse energiebronnen in de vijf onderzochte gemeentes. Een analyse van energietoegang zorgt voor een begrip van de energiebehoeftes van huishoudens in deze gemeentes. Verder onderstreept de analyse de noodzaak van alternatieve energiebronnen die door de implementatie van het FBAE-beleid zou kunnen worden vervuld. Evenals in voorgaande hoofdstukken wordt in dit hoofdstuk de aangepaste versie van Contextuele Interactie Theorie gebruikt om de gelijkenissen en verschillen in de interactieprocessen en ervaringen van FBAEbeleidsimplementatie te vergelijken. De vergelijking van de casussen verheldert waarom elke gemeente het FBAE-beleid op haar manier implementeert en hoe actoren en hun kenmerken dit implementatieproces 
beïnvloeden. Het eerste deel van dit hoofdstuk eindigt met een beoordeling van de vijf casussen op basis van de resultaten van de actor-interactie analyse tijdens de FBAE-beleidsimplementatie. Deze analyse van relaties tussen actoren kan gezien worden als een zinvolle toevoeging aan de vergelijking van implementatiescores met actorkenmerken, maar niet als een potentiele vervanging hiervan. De mate van implementatiesucces van de vijf casussen wordt vergeleken en beoordeeld om een samenvattend overzicht te verkrijgen van de casus-hoofdstukken. Ten slotte eindigt dit hoofdstuk en daarmee ook het proefschrift met conclusies en een vooruitzicht. Hierin worden de onderzoeksvragen beantwoord en er wordt gereflecteerd op de theoretische aanpak die in dit proefschrift wordt gebruikt. Als laatste worden een aantal mogelijke opties gepresenteerd voor onderzoek en praktijk. 


\section{About the author}

Nthabiseng Mohlakoana (1975) was born in Johannesburg, South Africa. She has 15 years of experience in research focusing on energy use by lowincome urban and rural households as well as gender mainstreaming of energy and climate change projects and programs. In September 2010 she joined the Policy Studies and Environmental Policy (CSTM) at the University of Twente as a PhD candidate where she conducted research focusing on analyzing the implementation process of the Free Basic Alternative Energy policy by local municipalities in the rural areas of the Eastern Cape, South Africa. She is a recipient of the Oppenheimer Memorial Trust international scholarship for her PhD. Some of her activities at CSTM include lecturing in development studies and student project supervision.

Prior to joining CSTM, Nthabiseng held research positions at the University of Cape Town's Energy Research Centre and at the Human Sciences Research Council of South Africa, respectively. Both institutions are highly regarded for conducting scientific research and producing high standard outputs in the fields of energy and social sciences. She has also worked as an independent researcher for three years within a network of energy and development practitioners and with issues of gender and climate change. Between 2006 and 2010 Nthabiseng was the ENERGIA National Focal Point (NFP) in South Africa where she headed the Gender and Energy Network of South Africa (GENSA). During this time she raised funds for the network to work on gender mainstreaming of energy policies and strategies, especially those affecting the low-income areas of South Africa. 
The majority of households without grid electricity in South Africa are located in low-income rural and urban areas. Being located in the remote rural areas makes it expensive to extend the grid and often locks such households into energy poverty where they are forced to use traditional fuels which expose them to unhealthy and difficult living conditions. The Free Basic Alternative Energy (FBAE) policy is aimed at providing alternative energy service to households without grid electricity with the hope of alleviating their energy poverty burden.

This study examines how the FBAE policy is implemented in the rural areas of the Eastern Cape by the five local municipalities under the jurisdiction of the OR Tambo District. Through the use of the Contextual Interaction Theory (CIT) this study analyses how the three-actor groups (implementing actors, target actors and linking actors) and their characteristics (motivations, cognitions, capacity and power) influence the FBAE policy implementation process. Through this analysis, the complexity of policy implementation processes is revealed by highlighting the influence of the dynamic actor-interaction.

By focusing on several actors and the influencing factors, this study moves away from the often accepted assumption that policy implementation processes mainly fail due to lack of resources. The analysis shows that actor motivations in terms of goals, their cognitions in terms of information as well as their capacity and power all play an important role in the success and failure of a policy implementation process.

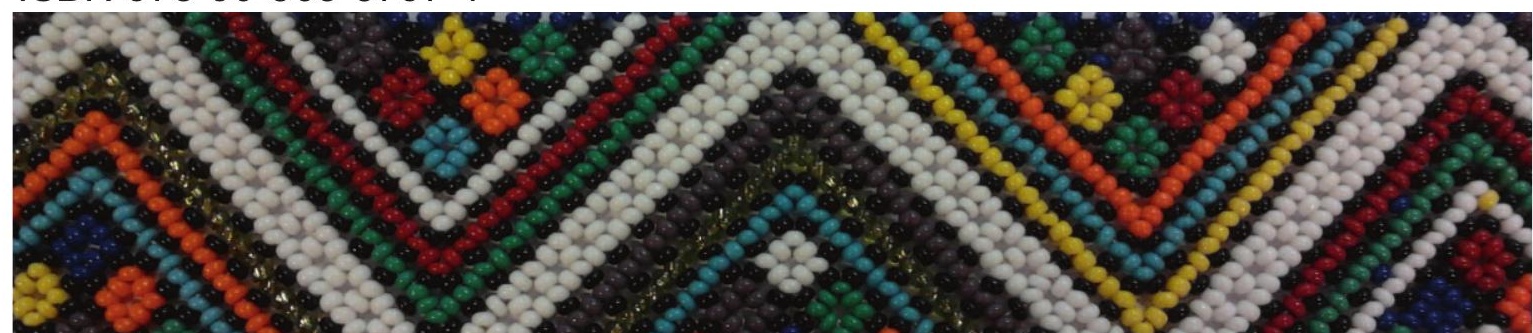

